\title{
ZOOTAXA
}

\section{Serpulidae (Annelida: Polychaeta) from the Suez Canal- From a Lessepsian Migration Perspective (a Monograph)}

\author{
M. NECHAMA BEN-ELIAHU ${ }^{1} \&$ HARRY A. TEN HOVE ${ }^{2}$ \\ ${ }^{\prime}$ The National Natural History Collections of Israel at the Hebrew University of Jerusalem, The Hebrew University of Jerusalem, \\ 91904 Jerusalem, Israel.E-mail: nbenelia@yahoo.com;nbenelia@cc.huji.ac.il \\ ${ }^{2}$ Zoological Museum, Amsterdam (presently the Netherlands Centre for Biodiversity, Naturalis), POB 94766, 1090 GT, Amsterdam, the \\ Netherlands.E-mail: H.A.tenHove@uva.nl
}

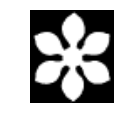

Magnolia Press

Auckland, New Zealand 
M. NECHAMA BEN-ELIAHU \& HARRY A. TEN HOVE

Serpulidae (Annelida: Polychaeta) from the Suez Canal-From a Lessepsian Migration Perspective (a Monograph)

(Zootaxa 2848)

147 pp.; $30 \mathrm{~cm}$.

29 Apr. 2011

ISBN 978-1-86977-685-5 (paperback)

ISBN 978-1-86977-686-2 (Online edition)

FIRST PUBLISHED IN 2011 BY

Magnolia Press

P.O. Box 41-383

Auckland 1346

New Zealand

e-mail: zootaxa@mapress.com

http://www.mapress.com/zootaxa/

(C) 2011 Magnolia Press

All rights reserved.

No part of this publication may be reproduced, stored, transmitted or disseminated, in any form, or by any means, without prior written permission from the publisher, to whom all requests to reproduce copyright material should be directed in writing.

This authorization does not extend to any other kind of copying, by any means, in any form, and for any purpose other than private research use.

ISSN 1175-5326 (Print edition)

ISSN 1175-5334 (Online edition) 


\section{Table of contents}

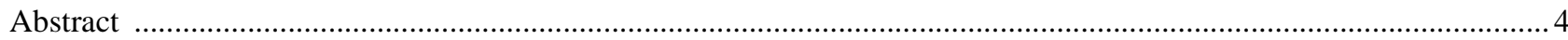

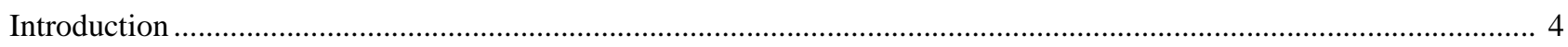

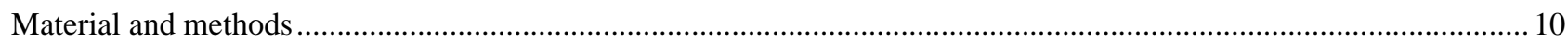

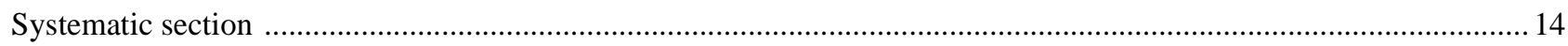

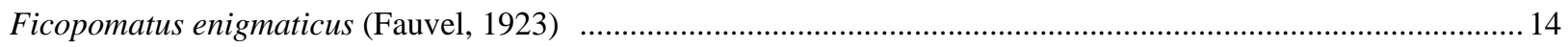

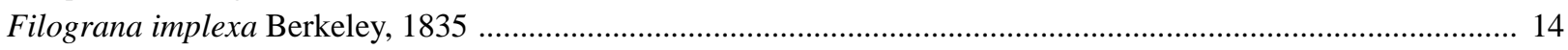

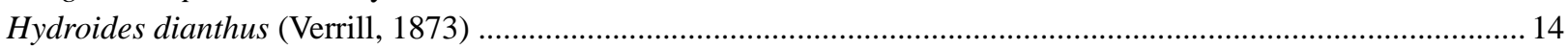

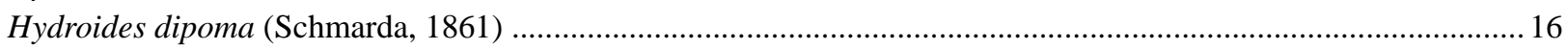

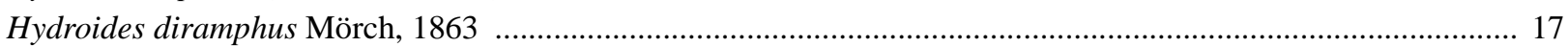

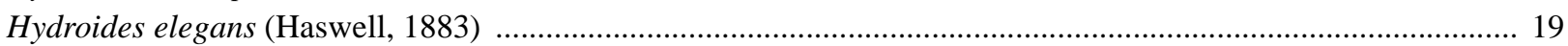

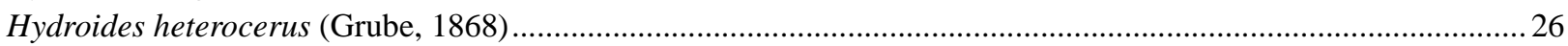

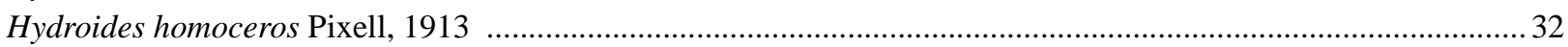

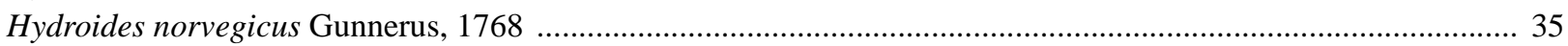

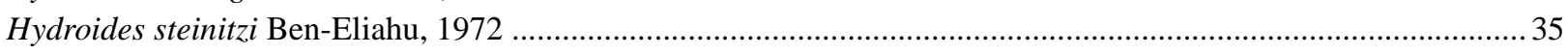

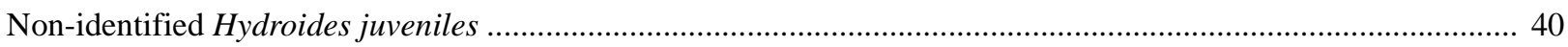

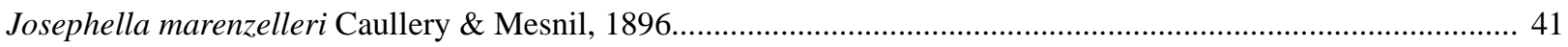

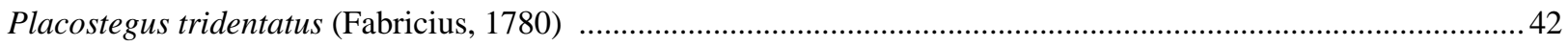

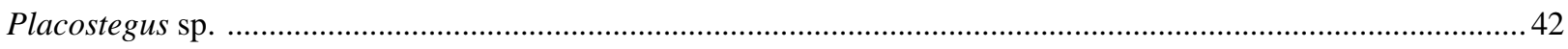

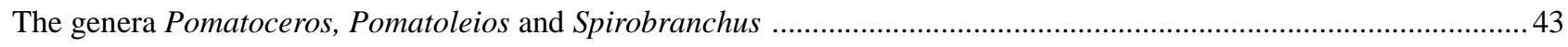

Pomatoceros caeruleus (Schmarda, 1861), variant spelling coeruleus .............................................................43

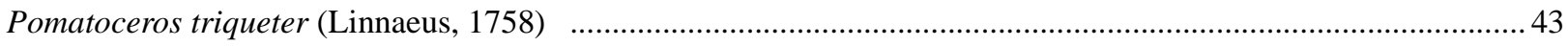

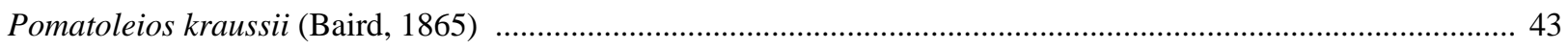

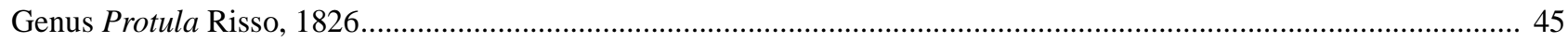

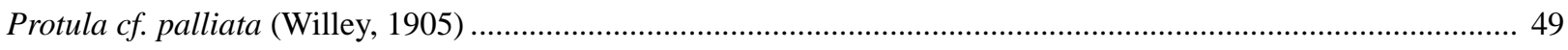

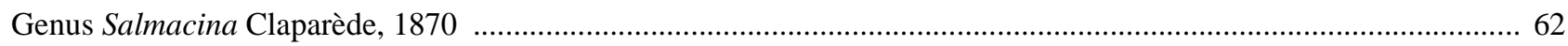

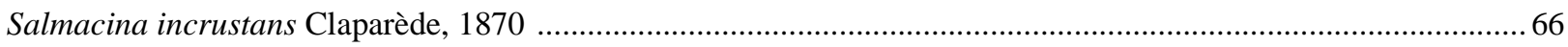

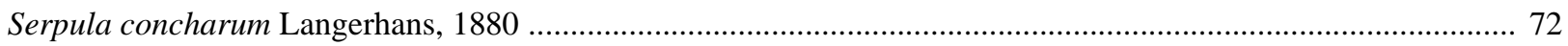

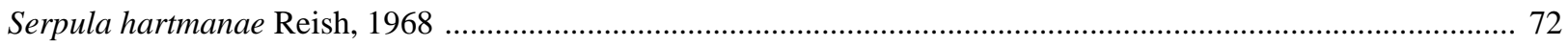

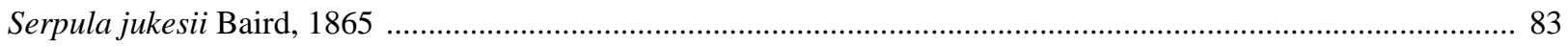

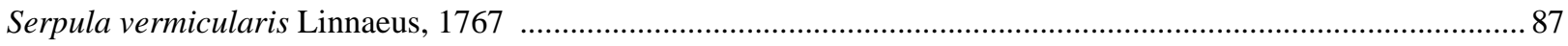

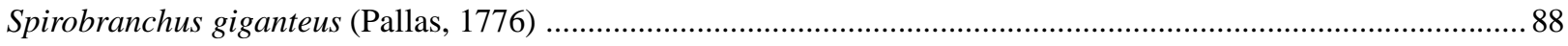

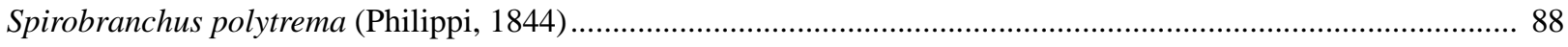

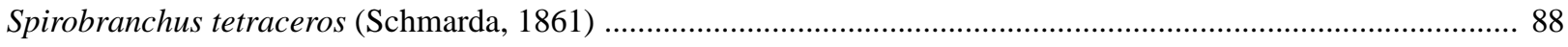

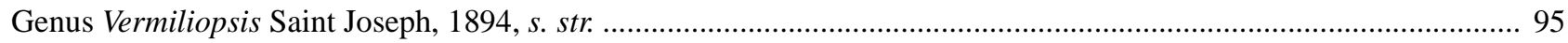

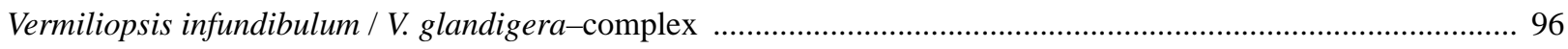

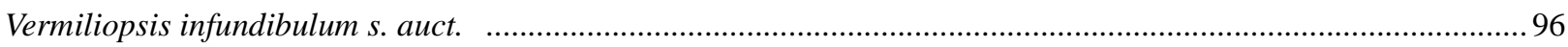

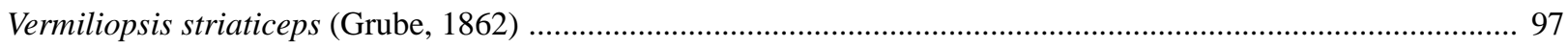

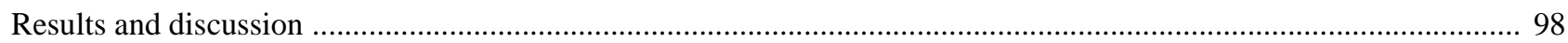

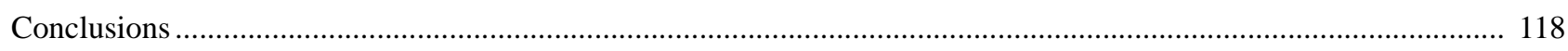

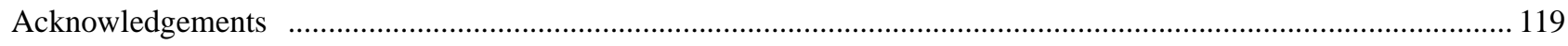

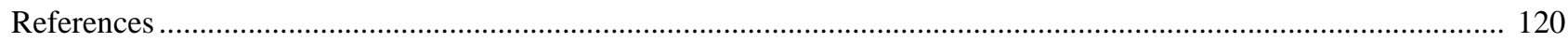

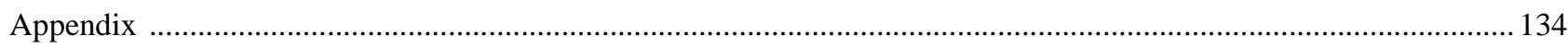




\section{Abstract}

Data on Serpulidae collected in the Suez Canal were assembled and analyzed. Five serpulid taxa are reported from the canal for the first time bringing the number of serpulids to at least 16. The Systematic Section compiles revised literature records, confirmed synonymies of the taxa, redescriptions where necessary, photographic studies of taxa and remarks on the populations studied. The possible Indo-West-Pacific or Mediterranean origins of the taxa in the Suez Canal are considered and their chronological records and distributions tracked within the Red Sea, the Gulfs of Aqaba and Suez, the Suez Canal and the Levant Basin based on the compiled literature and our extensive databases. Two Lessepsian migrants, Hydroides heterocerus and H. homoceros, show evidence of morphological variability along their migration route; the last also provides an example of a founder effect. Problems of identifying Protula and Salmacina taxa are addressed, along with remarks on the "cosmopolitan" designations of some taxa. Various hypotheses concerning Lessepsian migration are discussed, and attributes making Lessepsian migrant serpulid tubeworms successful invasive species are evaluated.

Key words: Suez Canal, Serpulidae, taphonomy, Lessepsian migrants, alien invasive species, "Yellow Fleet”, historical records, biogeography, morphological variability

تم جمع وتحليل البيانات حول الديدان الأنبوبية- السيربيوليدي (Serpulidae) في قناة السويس. ويتم لأول مرة الإبلاغ عن خمسة أصناف من الديدان الأنبويية - السيربيوليدي مما يرفع عددها إلى 16 صنفاً على الأقل. يثـمل القسم المنهجي (Systematic Section)

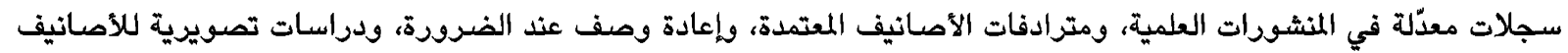

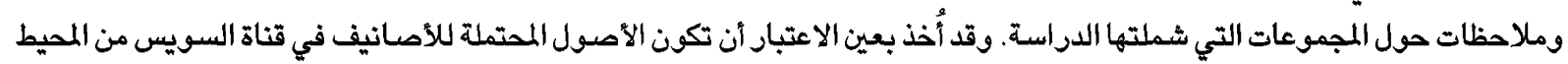

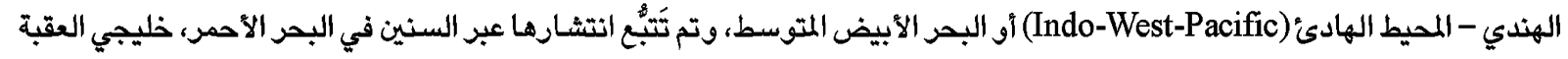

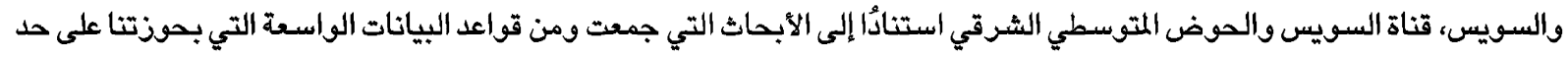

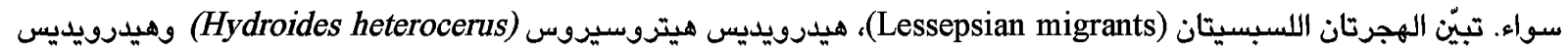

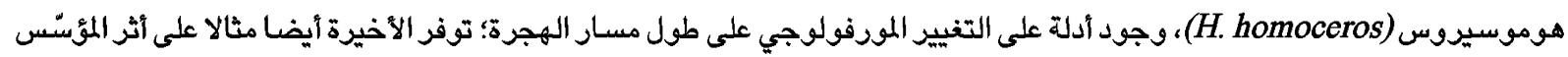

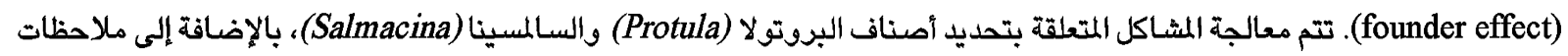

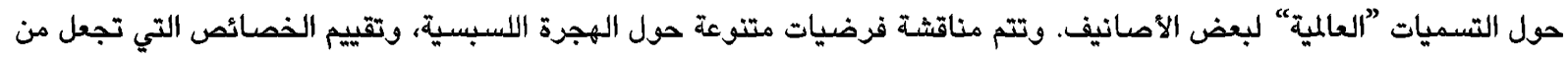

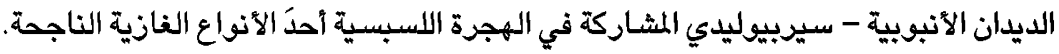

\section{Introduction}

Completed in 1869, the Suez Canal is a man-made marine connection between the Red Sea and the eastern basin of the Mediterranean Sea (Fig. 1). It joins two biogeographical areas inhabited by characteristic and very different biotas, the Red Sea province of the tropical Indo-West-Pacific Region and the subtropical Levant Basin that is part of the warm-temperate Atlantic-Mediterranean Region (Thorson 1971, Briggs 1974, Por 1978). These Regions have been partially separated since the early Miocene (ca. $20 \mathrm{Ma}$ ) and have been completely separated since the Miocene (Serravallian, 13.5 Ma ago) (Harzhauser et al. 2007). Joining these seas opened a pathway for faunal interchange.

The late Dr. Walter Steinitz (1882-1963), a physician and zoologist from Breslau, Germany, was among the first to call for monitoring of the impact of the Suez Canal on the Levant biota in "real" time; he was active in promoting that (e.g., Steinitz 1929) even before immigrating with his family to Palestine in 1933 (BytinskiSalz 1965, Clark \& Aron 1972). This call for monitoring was later taken up by scientists from the Hebrew University of Jerusalem. Some serpulid samples were collected along the Levant coast already in the early 1930s (the university was founded in 1925). In 1967, collaboration between the Smithsonian Institution, Washington, D.C., and the Hebrew University of Jerusalem finally enabled launching the wide-ranging sampling project, "The Biota of the Red Sea and eastern Mediterranean" (1967-1972), to evaluate the extent of reciprocal penetration of migrants into the seas and the impact of these migrants on the indigenous biota. Wm. Aron and Heinz Steinitz, Walter Steinitz's son, and, following the latter's demise in April 1972, F.D. Por, were the co-principal investigators (Por et al. 1972). 
The sampling showed that a significant number of Red Sea taxa had established viable populations in the Levant Basin, and that migration through the Suez Canal is preponderantly unidirectional, with very few species having migrated from the Mediterranean to the Red Sea (Ben-Tuvia 1966, 1973; Por 1978; Achituv \& Safriel 1980; Galil 1986; Galil et al. 1988 / 89; Spanier et al. 1989; Golani 1998a, b, to cite but a few). Por (1978) named the phenomenon of "unidirectional and successful biotic advance" from the Red Sea to the eastern Mediterranean via the Suez Canal "Lessepsian migration". The Red Sea colonizing species were thus "Lessepsian migrants", and the Levant area inhabited by these migrants became the "Lessepsian province" (Por 1990). Allied to the "Biota" sampling, a project to develop a predictive model on migration and colonization success was carried out through analysing pairs of congeners from the Gulf of Aqaba, comparing a successful colonizer (i.e., a Lessepsian migrant) and its most closely-related non-colonizer congener as regards life-history strategies, genetic variability, and niche width. The common factor among the migrant member of these pairs appeared to be $r$-strategy, a high innate capacity for increase of population size of the successful migrant relative to the non-migrant congener (Ayal 1978; Safriel \& Ritte 1980, 1983, 1985, 1986; Ritte \& Pashtan 1982; Ayal \& Safriel 1989; Ben-Eliahu 1989; Golani \& Ben-Tuvia 1989; Golani 1990, 1994, 1998b, 1999; Spanier et al. 1989; Lavee \& Ritte 1994). Other factors were not consistent (Lavie \& Nevo 1986).

As with most other taxa (excepting the Mollusca), pre-Canal baseline data are not available for the Serpulidae of these contiguous regions (Por 1978). A newly discovered "alien invasive" or "exotic" species with Indo-West-Pacific affinities in the Levant Basin is likely to be a Lessepsian migrant (Por 1978). A possible alternative from ancient times might be that the species is a relic of the tropical Paleogene Tethys Sea, which had a connection to the Indian Ocean (Ekman 1953 and Por 1978, 1989b). However, this possibility appears much less plausible in view of present knowledge concerning the salinity crisis in the Messinian Mediterranean (Hsü 1972, Hsü et al. 1978, Por \& Dimentman 1985), even though today it is accepted that many marine species survived the crisis well into the end of the Pliocene, 1.8 million years ago (Por \& Dimentman 2006). Moreover, we would now expect that evolution would have changed ancient serpulids morphologically. For instance, the Azores were repopulated within the past 12,000 years, subsequent to the decimation of the tropical biota by cold Pleistocene temperatures (Briggs 1974: 208). The endemic species, Hydroides azorica Zibrowius, 1972, is presumed to have evolved within that time period. We can also presumably exclude the possibility that marine taxa migrated between the Red Sea and Mediterranean through the ancient Pharaonic canals dating from about the 13th century B.C. (Por 1978: 29; Galil 2006a); the riverine parts of these canals would have blocked the passage of marine species (Galil \& Zenetos 2002), just as the fresh-water lakes forming part of the Panama Canal have largely blocked marine biota from passing between the Atlantic and the Pacific Oceans (Aron \& Smith 1971, Briggs 1967). Indications exist that some serpulids recently succeeded in traversing this barrier (Bastida-Zavala \& ten Hove 2003b: 102).

The hypothesis that a non-indigenous species in the Levant Mediterranean is a Lessepsian migrant is best supported when sequential settlement of Indo-West-Pacific or Red Sea species found in the Levant Basin can be tracked from the "source area" to the colonized Mediterranean area-including records from within the Suez Canal (Steinitz 1968, Por 1978). Por (1978) classified species not indigenous to the Mediterranean that are found only in the Red Sea (or wider Indo-West-Pacific) and in the Levant Basin without intermediate populations within the Suez Canal as "lower-probability" Lessepsian migrants because progressive range expansion into the Levant Basin had not been established for them. An alternative explanation for the presence of an alien population in the Mediterranean lacking records from the Suez Canal is that it was founded by specimens transported by ship, including ships passing through the Suez Canal during their journey (see Zibrowius 1979b, further discussed below). Regretfully, regular monitoring of the Mediterranean biota, necessary to establish that step-wise colonization occurs through expansion of contiguous populations, has been carried out only for large, commercially-fished taxa, e.g., fishes and, to some extent, crustaceans. Moreover, Israeli fishermen tend to report unusual catches to the universities or to the Department of Fisheries (D. Golani, pers. comm.). Monitoring is also carried out for noteworthy pest species such as the alien invasive medusa, Rhopilema nomadica (Galil, 1990, in Galil et al. 1990; Spanier \& Galil 1991; Lotan et al. 1994; Avian et al. 1995). However, small-sized migrants could easily remain undetected (Zibrowius 1991, Zenetos 
et al. 2005). Our knowledge of the Lessepsian migrant serpulid tubeworms, little known, comparatively small-sized creatures that have been sampled only sporadically, is presumably limited to taxa that have already built up sizeable populations (e.g., Ben-Eliahu \& ten Hove 1992; Ben-Eliahu \& Payiatas 1999; Çinar 2006). As the overall intensity of sampling for serpulids has been low, still unrecognized Lessepsian migrant serpulids may be present within the Suez Canal and along the contiguous Mediterranean coastline. Moreover, without population genetics studies, both logistically and financially prohibitive, it is usually not possible to know the history of a particular settlement-whether a newly found non-indigenous taxon is a Lessepsian migrant s. str. or whether it is derived from a ship-translocated invasive population. Unless specifically contraindicated, we will continue to use the more precise term, "Lessepsian migrant" (Por 1978) in preference to the less specific, more inclusive terms, "Erythraean alien," preferred by Çinar 2006; Galil 2006a, b, or "alien invasive species" preferred by Zenetos et al. 2005-recognizing that the term "Lessepsian migrant" refers to a particular instance of both of these terms. The present paper focuses on the Suez Canal fauna with respect to this fascinating migration phenomenon (Por 1978).

Over the last 30 years, observations on Lessepsian migrants have accumulated greatly (a partial list of the citations includes Holthuis \& Gottlieb 1958; Barash \& Danin 1972; Por, 1969, 1989a, b, 1990, 1997; Zibrowius 1983; Ben-Eliahu 1989, 1991a, b; Galil 1989, 1992, 1993, 1997, 2000, 2007; Galil \& Golani 1990; Galil et al. 1990; Spanier \& Galil 1991; Zibrowius 1991; Ben-Eliahu \& ten Hove 1992; Golani \& Ben-Tuvia 1995; Galil \& Lützen 1998; Golani 1998a; Achituv 1999; Ben-Eliahu \& Payiatas 1999; Golani 2000; Çinar et al. 2002; Mienis 2002, 2003, 2004; Zibrowius \& Bitar 2003; Çinar \& Ergen 2005; Selim et al. 2005; Zenetos et al. 2005; Çinar 2006 [Levant coast of Turkey]; Çinar et al. 2006; Kambouroglou \& Nicolaidou 2006 [the Aegean]; Siokou-Frangou et al. 2006; Shirley \& Kark 2006 [Greece]; Bitar et al. 2007 [Lebanon]; Golani et al. 2007 [Sardinia]; Golani et al. 2008; Shakman \& Kinzelbach 2008 [Libya]), Çinar 2009 [Turkey].

Initially, after the canal was opened, the predicted onslaught of migrants was slow in getting underway (Thorson 1971). This was attributed to an osmotic barrier, due to the high salinities then prevailing in the Bitter Lakes-bottom salinities of 68-80\%o-and the presence of a very massive salt layer on the bottom (Thorson 1971), aggravated by "an abrupt drop in salinity to brackish / marine conditions in Lake Timsah to the north" (Steinitz 1968; see Appendix Table 1). By the mid-1950s, bottom salinities had stabilized in the Great Bitter Lake at about 45-46\%o(Ben-Tuvia 1966; Fig. 1; Appendix Table 1) and, by the mid-1960s, the salt layer at the bottom of the Great Bitter Lake had dissipated and the possibilities for marine species to traverse the canal greatly increased (Thorson 1971; Por 1978). Moreover, from the late 1970s, the canal was widened and deepened several times, increasing its flow (Soliman et al. 1988; Galil \& Zenetos 2002). After 1965, the Aswan Dam eliminated the annual flooding of the Nile River into the Mediterranean with its seasonally depressed salinity around the Mediterranean entrance of the Suez Canal (Ghobashy 1984: 41; Fig. 1; Appendix Table 1), and, subsequently, there has been a slight increase in salinity along the Levant coast (Gertman \& Hecht 2002). It also had an impact on the change in current flow, stopping the summer southward flow (Morcos \& Messieh 1973). Other, as yet not thoroughly understood consequences of stopping the Nile flood are changes in the nutrients and plankton in the Levant Basin, and the impact of these changes on the ecosystem (El-Sayed \& van Dijken 1995). A recent rise in the sea temperature appears to have facilitated the establishment of some Lessepsian migrant taxa, and the further dispersal of others to the west (Lotan et al. 1994; Kevrekidis et al. 1998; Çinar et al. 2002; Dulĉić et al. 2004; Galil \& Zenetos 2002; Kambouroglu \& Nicolaidou 2006; Çinar 2006; Koçak 2007). All seven Lessepsian migrant serpulid species reported along the Israeli coast in 1992 by Ben-Eliahu \& ten Hove are ranked as "established migrants" in the recent inventory of alien invasive species in the Mediterranean (Zenetos et al. 2005) and all have been newly reported from the shallow waters of the Turkish Levant coast (Çinar 2006). Interestingly, Çinar's figures (4d, e) provide an indication that the Turkish Hydroides homoceros population originated from ship-transported specimens (not a "classical" Lessepsian migrant sensu Por 1978), whereas the other Levant H. homoceros populations (BenEliahu 1991b) apparently derive from expansion of contiguous populations (see below). Thus, both Lessepsian migrant step-wise populations and alien ship-translocated populations of the same Erythraean or Indo-West-Pacific serpulid species may be present in the Levant Basin at the same time. Indubitably, there is a need for a renewed campaign of sampling to monitor this ongoing, dynamic, colonization phenomenon. 


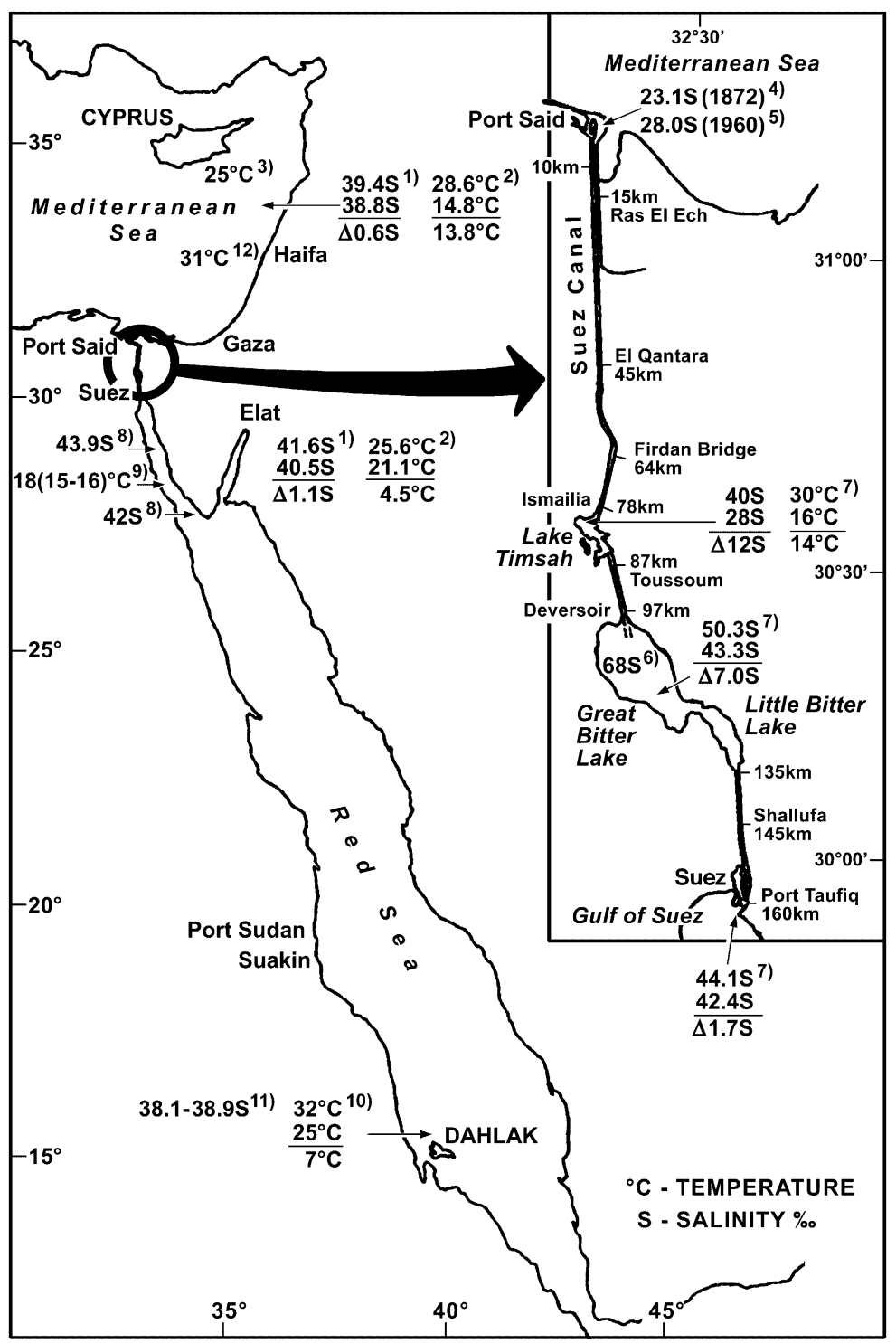

FIGURE 1. Map of Suez Canal showing salinity and temperature relations in the areas joined by the canal compiled from various sources. 1-Ben-Eliahu 1977: 70, Table 21, salinity \%o-seasonality, the extreme range of monthly means of sea surface salinity based on daily 00:08 recordings taken by the Nahariyya hydrographic station, northern Israel, 1968-1972 and the Elat hydrographic station, northern Gulf of Aqaba, 1962-1973, 2-Ben-Eliahu et al. 1988: 263, seasonality of sea surface temperature, Mediterranean coast of Israel and Elat, Gulf of Aqaba in ${ }^{\circ} \mathrm{C}$ (data from hydrographic stations listed above), 3-Por 1978: 118-119, fig. 32, southern Cyprus, summer surface isotherm $25^{\circ} \mathrm{C}$; summer upwelling; $22^{\circ} \mathrm{C}$, 4-Por 1978: 61, depressed salinity in Port Said due to Nile flood, 23.1\%o in autumn, 1872, 5-Ben-Tuvia 1970: 183, depressed surface salinity in Port Said due to Nile flood, autumn peak, IX \& X.1960, 6-Thorson 1971: 842843, initial salinity at Great Bitter Lake, bottom, 8 m: 68-80\%o; surface: 50-52\%o, 7—Ghobashy \& el-Komi 1981a: 169, 171, seasonality of Lake Timsah salinity and temperature between II.1977-I.1979; Ghobashy \& el-Komi 1981b: 180, southern canal, seasonality of salinity and temperature at the Little Bitter Lake (Kabrit) and Suez between II.1977I.1979, 8-Por 1972: 113-114. Gulf of Suez coast of Sinai, Ras el Missala and Ras es Sudr, 15 and $50 \mathrm{kms}$ south of Suez, respectively, X.1970, Ras el Missalla along the shore, 44.25\%o and $25 \mathrm{~m}$ offshore 43.93\%; Ras es Sudr high VIII.1970, 44.25\% ; X.1970, 41.69\%o and I.1971, 42\%o, 9-Oren 1970: 226 reported $18^{\circ} \mathrm{C}$ temperature for the Gulf of Suez; however, Por 1972: 114, 1978: 83 noted even lower winter temperatures, particularly inshore, and found that the temperature decrease from south to north of Gulf of Suez corresponds with the depletion of the tropical fauna (i.e., of corals and associated taxa), from the south to the north of the Gulf, 10-Ben-Tuvia 1966: 255, mean monthly sea surface temperatures at Massawa, Eritrea, 11-Oren 1964: 12, table 3, III.1962, profile of Stn 7, surface to $110 \mathrm{~m}$ (low to high value, respectively) taken in the south Red Sea off Eritrea, off Entedebir and Dahlak Kebir Islands, 12_Brit 2000 (E. Spanier, pers. comm.): High peak temperature (9 m) prevailing off Haifa, northern Israel during August, 2000. 
The history of the sparse sampling of Serpulidae in the Suez Canal is as follows: The first-known sample was collected in 1895 from a barge at Isma'iliya by the "Pola" Expedition (determined E. von Marenzeller [Stagl et al. 1996], Zibrowius 1971; see Fig. 6). In 1905, the Percy Sladen Trust Indian Ocean Expedition carried out limited sampling in Suez under the direction of J. Stanley Gardiner; the material was brought to the Natural History Museum, in London (Pixell 1913). The Cambridge Expedition (1924) undertook the first methodical sampling throughout the Suez Canal (Fox 1926) fifty-five years after its inauguration. Most of the serpulids collected by the Expedition were brought to Cambridge University and listed in Potts' (1928) "Report on the annelids (sedentary polychaetes)". However, additional Cambridge Expedition serpulids, encrusted on mollusc shells, were inadvertently taken to the Mollusc Section of the Natural History Museum in London (see Material and Methods Section below). Another twenty-six years would elapse until, in 1950, C. Beets dredged in the Great Bitter Lake (Beets 1953). Beets' samples of dried molluscs, some with encrusted serpulid tubes containing taphonomic residues, were deposited in the National Museum of Natural History "Naturalis" in Leiden (see Figs 7 and 14). During the years 1967-1973, several Hebrew University sampling trips to the eastern bank of the canal were carried out (Ben-Eliahu 1972a, c, 1991a; Por \& Ferber 1972, Por et al. 1972). As concerns serpulid tube-worms, a uniquely productive sampling expedition was carried out in 1975 by the Norwegian team of H. Brattström and J.P. Taasen: From the onset of the 1967 June ("Six-Day") War until 1975, ship traffic in the Suez Canal was at a standstill. During this 8-year period, 14 ships that had been trapped in the Great Bitter Lake (ships that became known as the "Yellow Fleet" from the colour of the yellow dust covering them [Moritz 1998]), acquired a massive (and well-publicized) biofouling aggregation (Barracca \& Thomas 1975; Figs 2, 3). In January 1975, the Norwegian expedition was carried out to sample this biofouling aggregation before the canal reopened and the ships would disperse. For the serpulids and other sessile taxa, these stationary ships were fortuitous, stable, hard substrates enabling settlement in a venue where natural massive hard substrates are rare. After its release from the Canal, one of the ships, the MS "Münsterland", made its way to Hamburg and from there to a dry dock in Bremerhaven, where the encrustation was resampled, providing a unique opportunity to look for differential resistance of the taxa comprising the aggregation to osmotic and temperature changes encountered on the voyage (J.P. Taasen, pers. comm., 13.III.2001; See Discussion, Section 6). The fouling samples collected by Brattström and Taasen were deposited in the National Natural History Collections in Jerusalem in recognition of the work carried out by Prof. F.D. Por and his colleagues during the "Biota" project.

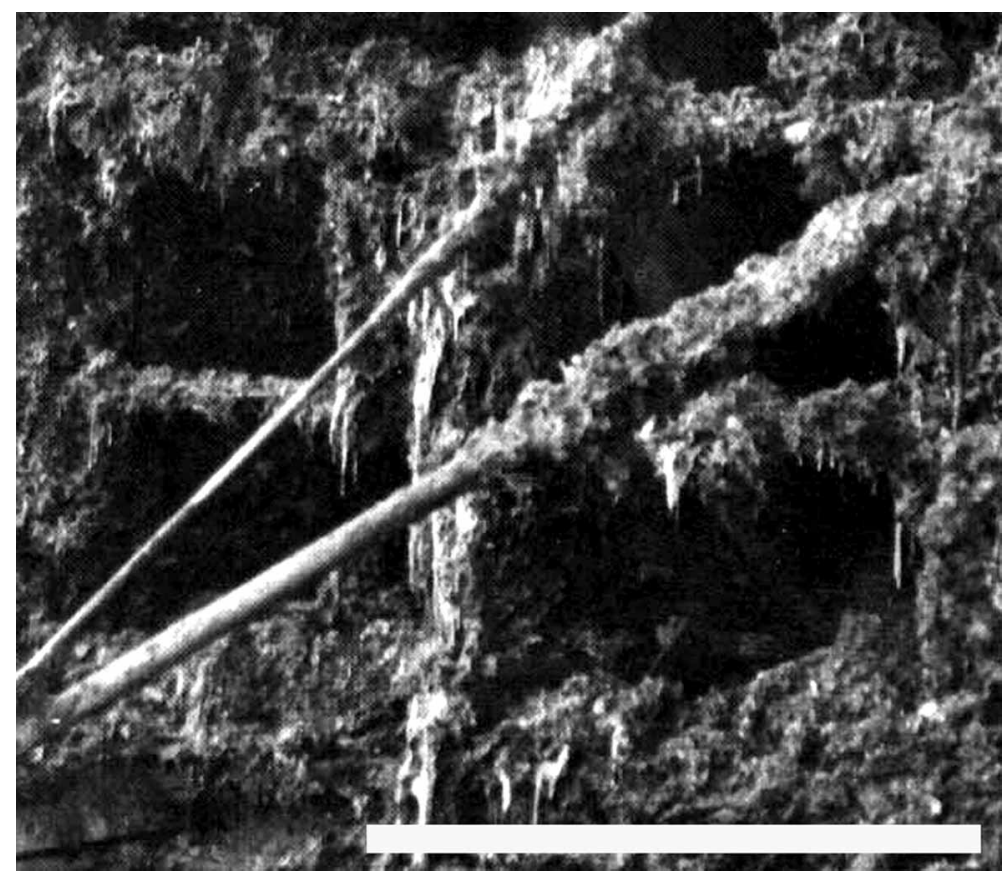

FIGURE 2. Biofouling on a ship that was trapped in the Suez Canal for 8 years when the canal was shut down due to the June 1967 war (adapted from Barracca \& Thomas 1975). Scale: $1 \mathrm{~m}$. 

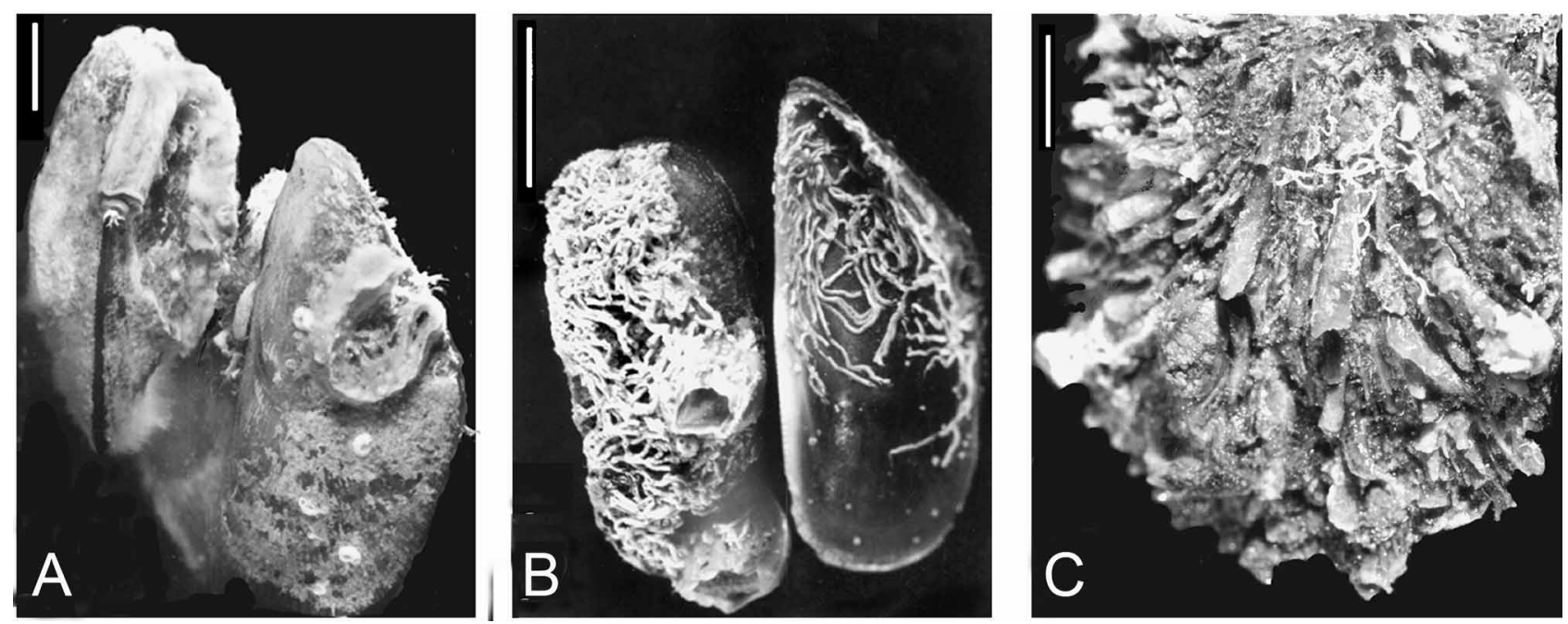

FIGURE 3. Serpulid tubeworms encrusted on bivalve molluscs from the biofouling aggregation on the "Yellow Fleet" ships trapped in the Great Bitter Lake. The aggregation on the ships was sampled in January 1975 by H. Brattström \& J.P. Taasen before the reopening of the Suez Canal to traffic. A-Spirobranchus tetraceros and spirorbids on Brachidontes pharaonis; note Spirobranchus operculum projecting from upper left tube (see Fig. 33 of S. tetraceros), B-Aggregate of Salmacina incrustans and barnacle, Balanus amphitrite, on Brachidontes pharaonis, C-Minute Josephella marenzelleri tubes at base of spines of Spondylus spinosus shell (from subsample Biv 11 [see App. Table 2D]). Scales: 1 $\mathrm{cm}$.

Since the 1960s, Egyptian scientists have published on Suez Canal serpulids, mainly components of biofouling research carried out within the canal and in the Egyptian ports of Alexandria, Port Said, Suez, and Ghardaqa (e.g., Banoub 1961, Saad 1974, Ghobashy \& Selim 1976a,b, Ghobashy 1977, Ghobashy et al. 1980, 1981, Ghobashy \& El-Komi 1981a, b, Ghobashy 1984, Ghobashy \& Hamada 1984, Ghobashy et al. 1986, 1990, El-Komi 1991a, b, 1992a, b, 1996, 1997, 1998, El-Komi \& El-Sherif 1992, El-Komi et al. 1998, Mona 1992, Selim 1996a, b, 1997a, b, Shalla \& Holt 1999, Emara 2002, Emara \& Belal 2004, Ghobashy \& Ghobashy 2005, Selim et al. 2005, Ramadan et al. 2006, Abd-Elnaby 2009, El-Rashidy et al. 2009, Selim 2009 [and see Appendix Table 4]). At a late stage in the preparation of this monograph, two new publications on Suez Canal Polychaeta appeared (Abd-Elnaby 2009, Selim 2009), each listing some nominal serpulid taxa. One of the authors (Dr. Abd-Elnaby) kindly made available an illustration and some data, but the actual specimens could not be sent for examination in Amsterdam. Since polychaetes are a very difficult taxon as evidenced by the many corrected identifications in synonymic lists, regretfully, results on specimens not examined by us can only be speculative and must be dealt with accordingly. Thus, we have interpolated as best we could Abd-Elnaby and Selim's citations in the present manuscript. With the emergence of Scanning Electron Microscopy as a routine tool (and even before the widespread use of molecular genetics expected to revolutionise polychaete biogeography), literature from pre-SEM times must be regarded as subject to revision.

The present research began long ago as an effort to reconstruct the migration process of Lessepsian migrant serpulids into the Levant Mediterranean. We looked for clues to the colonization of the canal by serpulid biota, for patterns relevant to the Lessepsian migration process and attempted to add to the data on the biota by assembling and re-examining sorted and partially sorted sample material from the Suez Canal (see Material and Methods section) and from the adjacent areas. In the Systematic Section, we provide a taxonomically updated account of the compiled serpulid fauna of the canal. Some of the taxa belong to species complexes; their records and geographic citations have included many errors. Thus, only tested synonymies are given, providing their presently known biogeographical documentation. The unique position of having both data on the Serpulidae of the Suez Canal and ample data from nearby Levant areas, enables us, indeed, makes it incumbent upon us, to address for this Family some of the assumptions relating to the Lessepsian migration process (see Discussion). 
The Suez Canal. The Suez Canal (Fig. 1) lies between longitudes $32^{\circ} 20^{\prime}$ and $32^{\circ} 35^{\prime}$ E and between latitudes $29^{\circ} 55^{\prime}$ and $31^{\circ} 15^{\prime} \mathrm{N}$ (Selim 1997b); it is ca. $170 \mathrm{~km}$ long (Por 1978). Initially only $7.9 \mathrm{~m}$ deep, it was later deepened several times. A 1979 edition of the Admiralty Pilot Book (Hydrographic Office) gave its depth as ca. $21 \mathrm{~m}$, and its width at the surface as 160-200 m. In 2000, its depth was $22 \mathrm{~m}$, and its width was $345 \mathrm{~m}$ (AlAhram weekly, no. 497). In 1869, the maximum draft of a ship in the canal could be $6.7 \mathrm{~m}$, but by 2001, a ship with a draft of $18.9 \mathrm{~m}$ could traverse the canal (http://rafimar.com/suez/suez_canal.html [Rafimar, 2009]). There are further plans for widening it to an average of $400 \mathrm{~m}$ and deepening it to $25 \mathrm{~m}$ by 2010 .

The canal has two major water bodies; the Bitter Lakes in the south, surrounded by hypersaline lagoons, comprising ca. $85 \%$ of the water, and Lake Timsah in the north, receiving fresh-water through the Isma'iliya Canal. From the Gulf of Suez, strong tidal currents carrying silt flow into the southernmost part of the canal and into the Bitter Lakes (Ghobashy et al. 1980). The currents within the canal, including the northern section, are predominantly northerly for nine months of the year (the hydrography of the canal is amply discussed in Por 1978); the generating of through-currents by wind forces and other factors was modelled in Agur \& Safriel (1981) and described in situ in Soliman et al. (1988). These currents affect whether Mediterranean or Red Sea water is present north or south of Lake Timsah, and in the section of the canal that joins Lake Timsah with the Bitter Lakes (El Sabh 1968). Although the reduced salinity has caused the Bitter Lakes to lose their density stratification in great measure, Lake Timsah is still a strongly stratified body of water (Ghobashy et al. 1990, Shalla et al. 1995); a detailed study of the biogeology of Lake Timsah is given in Perthuisot et al. (1990). Some data on salinities within the Suez Canal and the contiguous areas are given in Fig. 1, and are compiled chronologically in Appendix Table 1, as the changes in salinity may be cardinal to the progressive settlement of the canal biota.

\section{Sources of the "new" sample material (149 samples detailed in Appendix Table 2A-E)}

A. Cambridge Expedition, 1924 molluscs. The additional ("new") Cambridge Expedition samples of Serpulidae (6.X-29.XII.1924) were obtained by scraping encrusted molluscs from the expedition that had been deposited in the Natural History Museum, London (NBE in 1986), 6 samples (App. Table 2A, see Fox 1926 for details of the sampling).

B. Serpulids scraped from C. Beets' 1950 dried molluscs. The molluscs, dredged between the shore and $11.2 \mathrm{~m}$ depth, are deposited in "Naturalis" in Leiden (31 samples; Map, List of Stations, Beets 1953: 100, 104-106: App. Table 2B). During our visit to the "Naturalis" mollusc section on 29.VII.2003, we used Hoenselaar \& Dekker's (1998) publication on Beets' molluscs to "reassemble" the mollusc samples as the specimens had been sorted and stored in drawers according to taxa. Serpulid tubes on the shells were identified to the extent possible. Shells with tubes that looked as though they might contain taphonomic residues of the tubeworms were brought to the laboratory for further study. The tubes were photographed prior to dislodging and opening them (preferably by breaking through the "attached" surface) to look for possible taphonomic residues; the RMNH collection numbers assigned to the material are given in App. Table 2B. Our findings on tube morphology are summarized in the "Results" section.

C. The Hebrew University-Smithsonian Project, "Biota of the Red Sea and eastern Mediterranean" (1967-1972) and the 1973 Hebrew University expeditions. The Suez Canal sampling carried out during this project consisted of 7 sampling trips, 29 samples (App. Table 2C), that were deposited in the National Natural History Collections at the Hebrew University of Jerusalem. The expeditions sampled along the eastern bank of the Suez Canal by snorkelling, scraping of piers, and turning over stones (Por et al. 1972: 475). Most of the samples are from shallow depth, generally less than $1 \mathrm{~m}$ (for particulars on the expeditions of 20-21.VI.1967, 10.XII.1967, 11.VII.1968, 13-14.I.1969, see Por \& Ferber 1972, Por et al. 1972). An expedition led by U.N. Safriel, 8-9.III.1973, was specifically undertaken to evaluate whether littoral hard substrates that could support step-wise colonization of gastropods might be present along the shore (Safriel et al. 1980), providing an opportunity for NBE to search for serpulids by turning over submerged rocks and debris up to knee-depth, ca. 
$0.5 \mathrm{~m}$ (Ben-Eliahu 1991a). Colouration of fresh specimens was noted. Two expeditions were carried out by Y. Eytam and party: the first, on 8.III.1973, sampled along the shore of the Little Bitter Lake; the second, on 26.XII.1973, sampled in the Great Bitter Lake at $10 \mathrm{~m}$ depth, using a boat and a small grab (Eytam 1974, BenEliahu 1991a). Additionally, some snorkelling was done along the shore. Serpulids were collected on molluscs, stones and debris.

\section{H. Brattström \& J.P. Taasen's Norwegian Academy of Sciences' Expedition 13-20.I.1975 to sam- ple the "Yellow Fleet" ships trapped in the Great Bitter Lake.}

Eighty-one sub-samples of sessile organisms were collected from 6 ships of the "Yellow Fleet" anchored in the central part of the Great Bitter Lake (the "African Glenn", "Essayons", "Killara”, "Marit", "Münsterland" and the "Nordwind"), accessed from the western bank (App. Table 2D). As diving in the lake was not permitted by the Egyptian authorities, the ships were reached by rowboat and the biofouling aggregation removed using a long pole with a scraper and a net (an estimated maximum depth of 3-4 m [J.P. Taasen, pers. comm., 13.III.2001]). Some hydrographic data were also collected (Heimdal et al. 1977). The "Münsterland" left the Great Bitter Lake on May $7^{\text {th }}, 1975$, moved on May $8^{\text {th }}$ into the Mediterranean, and, impeded by the massive biofouling aggregation encrusted on its underwater hull, slowly made its way to Hamburg for unloading, arriving there on May $24^{\text {th }}$. On June $13^{\text {th }}$, it left Hamburg for the Hapag-Lloyd dry-dock in Bremerhaven, arriving on June $14^{\text {th }}$ (D. Albers, P. Müller, and P. Maass, pers. comms). On June $18^{\text {th }}$, at the dry-dock, three additional samples of the biofouling aggregation from the bottom of the ship were taken by J.P. Taasen from about $7 \mathrm{~m}$ depth (See Discussion, Section 6).

E. Some reconstructed samples from Lake Timsah. Specimens forwarded by scientists from the Suez Canal University (and elsewhere) to HAtH for confirmation of identifications (Two samples, see App. Table 2E).

Treatment of the samples. We deal here only with the Serpulidae (the ample spirorbid material in the National Natural History Collections at the Hebrew University remains available for study). The number of serpulids was recorded unless the material formed an aggregate (e.g., Salmacina), then the number given is an estimate with 3 to 15 individuals defined as "few"; 16 to ca. 50 individuals defined as an "aggregate" (enumerated as ca. 30 specs).

Treatment of serpulid data. The subsections in the Systematic Sections, "Suez Canal depth and substrates", do not include determinations from empty tubes. Data from Beets' samples were included in the Systematic Section only when definitive taphonomic residues were found in the tubes (Figs 7 and 14). When attribution to taxa was based on tube morphology alone, these data are dealt with as provisional; they are listed by sample in App. Table 2B. Brattström \& Taasen's samples of the "Yellow Fleet" biofouling conglomerate were all collected within the same week and under the same conditions, thus they were treated as a single pooled sample from 0-4 m depth. App. Table 2D lists for each sub-sample the codes designated by Brattström $\&$ Taasen along with the serpulid taxa present. Where mollusc substrates are cited, *denotes a Lessepsian migrant mollusc; the taxa are compiled in App. Table 3 with identifications reviewed by H.K. Mienis (pers. comm.).

In enumerating the number of serpulid taxa, we counted only taxa collected from locations within the Canal proper (i.e., locations between the grey borders marked in Table 6).

\section{Deposition of Suez Canal material cited in the Systematic Section}

AMNH American Museum of Natural History, New York, USA.

$\mathrm{BM}(\mathrm{NH}) \quad$ The C. Crossland serpulid collections and the molluscs of the Cambridge Expedition are deposited in the Natural History Museum, London (formerly British Museum (Natural History), UK (Appendix Table 2A).

CUZM The Cambridge Expedition Serpulidae (and other polychaete taxa) reported in Potts (1928) are deposited in the Cambridge University Zoological Museum, UK as lot AN.1.1930.

HUJ The Section of Invertebrates of the National Natural History Collections at the Hebrew Uni- 
versity of Jerusalem, Israel houses samples from the Project "Biota of the Red Sea and eastern Mediterranean" as well as Brattström \& Taasen's benthic samples from the "Yellow Fleet" ships; polychaete specimens are coded HUJ-Poly- (Appendix Table 2C, D).

INCNH Israel National Collections of Natural History data are based on the specimens deposited at both HUJ (The Hebrew University of Jerusalem) and at TAU (Tel Aviv University), Israel.

MNHN Musée National d'Histoire Naturelle, Paris, France.

NHMW The "Pola" Expedition material is deposited in the Naturhistorisches Museum, Wien, Austria, formerly the Musei Vindobonensis, section Evertebraten varia.

NMWZ National Museum of Wales, Department of Zoology, Cardiff, Wales.

QM Queensland Museum, Australia.

RMNH C. Beets' collection of molluscs from the Bitter Lake is deposited in the Nationaal Natuurhistorisch Museum Naturalis, Leiden, the Netherlands (formerly the Rijks Museum voor Natuurlijke Historie) along with the serpulid tube residues removed from the molluscs and some taphonomic material of serpulids obtained from the tubes (Appendix Table 2B).

SMF Forschungsinstitut und Naturmuseum Senckenberg, Frankfurt / M., Germany.

TAU Collections of the National Natural History Collections at the Tel Aviv University Zoological Museum; TAU-MO- designates specimens from the mollusc collection, while TAU-NS- is a general code designating other (non-mollusc) taxa, e.g., invertebrates and fishes.

USNM Collection code of the Smithsonian National Museum of Natural History, Washington (formerly United States National Museum, USA.

YPM Yale University Peabody Museum, New Haven, Connecticut, USA.

ZMA V.Pol. Collection code of the Zoological Museum of Amsterdam, the Netherlands, collections that will be moved to the Netherlands Centre for Biodiversity, Naturalis, Leiden, within a few years.

ZMH V., P. Collection codes of the Zoologisches Institut und Zoologisches Museum, Hamburg, Germany. ZMUC Zoological Museum, University of Copenhagen, Denmark.

The figures: Photomicrographs of the worms were taken with a Nikon Coolpix 5000 digital camera fitted with a C-mount microscope adapter and a cable shutter release. For more precise depth focus, the image was projected on a Graetz 14" television screen. The camera was used either with a Wild M5 dissecting microscope fitted with a trinocular camera adaptor (Martin Microscope Company Catalogue, no. 1509.4), or with a Wild M20 trinocular compound microscope with a supplementary zoom and a camera adapter (C-mount). Viewing uncini of the minute taxon Salmacina and those of Protula necessitated examination with a scanning electron microscope. We used the ESEM FEI Quanta 200 at the Hebrew University Medical School and a Jeol JSM 6400 at the Zoologisch Museum, Amsterdam.

Geographical names and order of citation. The names are according to the Encyclopaedia Britannica Atlas On-line 2006. Geographic distributions citing the literature are organized as follows: Atlantic-north to south, Mediterranean west to east and north to south along the Levant Basin coast; Suez Canal; the Gulfs of Suez and Aqaba, Red Sea, western Indian Ocean-north to south and then from west to east to the Pacific. Including the geographic citations does not mean that the present authors agree with the species concepts of the authors cited, however, it provides the reader with a perspective on the approach of the author being cited.

Organization of the Systematic Section. Synonymies dealing with each biogeographical area are grouped separately. If we regard a cited identification as problematic, we placed a question mark in front of the date of publication (see below); if its author queried the determination, the question mark is placed after the date, adjacent to the name of the taxon. Finally, if we know the citation is erroneous, e.g., naming Hydroides norvegicus rather than $H$. elegans, a different taxon, it is referred to as "Hydroides norvegicus not Gunnerus, sensu Author". Due to our interest in the Suez Canal as a conduit for Lessepsian migration as well as being a habitat, the first known sample from the adjacent biogeographic region is indicated.

In the "Material Examined" sections, locations are ordered from north to south, whereas in the "Suez Canal material reported herein" sections the Suez Canal expeditions are listed chronologically and separated by an $m$-dash (-); as follows: Within expeditions, locations are ordered from north to south, and within loca- 
tions, ordered chronologically. To save space, samples in the text are listed only by the sample codes, e.g. SLC, SBE [codes of Suez Canal samples undertaken by the project "Biota of the Red Sea and eastern Mediterranean" (Por et al. 1972); their particulars are detailed in Appendix Table 2C, samples are separated by a semi-colon. The number of regional records is based on samples at the Hebrew University of Jerusalem (HUJ), Tel Aviv University (TAU), and on additional material deposited at the ZMA and SMF. For taxa represented on the Levant Coast or the Red Sea regions adjacent to the Suez Canal, parameters of the depth distribution are given. These include the minimum and maximum depth, and between these depths, the $2^{\text {nd }}-3^{\text {rd }}$ interquartile range is given underlined because the inter-quartile range-the depth range between which $50 \%$ of the samples were collected-may provide a truer reflection of the species' distribution than the extreme limits of the full depth range [for methods and rationale, see Ben-Eliahu \& Fiege (1996)]. Whenever the samples were collected between 2 depths, the depth limits of the sample are given in brackets, e.g., [2-4] m, and in giving the range of depths of samples in the "Material examined" section, the median depth is indicated in underlined bold font. Authors and dates of description of mollusc taxa (substrates) are given in Appendix Table 3.

Treatment of the specimens. Whenever possible, measurements were done using the standardizing method of ten Hove \& Jansen-Jacobs (1984: 144). Width was measured at the widest part of the thorax. Size parameters given as 22(4) / $3 \mathrm{~mm}$ for 50(7) chaetigers refer to total length of $22 \mathrm{~mm}$ (length of the included branchial crown of $4 \mathrm{~mm}$ is given separately) / width, $3 \mathrm{~mm}$ for a worm totalling 50 chaetigers including thoracic chaetigers (specified separately as 7). In attempting to standardize the approach to taxa (e.g., ten Hove \& Jansen-Jacobs 1984, Bastida-Zavala \& ten Hove 2003a), we have become aware not only of new and additional characters of taxonomic importance, but of the need to look for them in a standard way. For example, it is important to look for a selected character always in the same position, e.g., if enumerating ocelli, always selecting the same position for the enumeration, i.e., always on the $1^{\text {st }}$ dorsal radiole; or if detailing structure of the inter-radiolar lappets of Spirobranchus, always selecting lappets between radioles in the same position, e.g., between the $2^{\text {nd }}$ or $3^{\text {rd }}$ radioles; the same is true in specifying the number and position of Apomatus chaetae.

In uncini with a sharply pointed anterior tooth, as in Hydroides, Salmacina and Serpula, the tooth is referred to as a fang (Figs 31D, E and $32 \mathrm{G}, \mathrm{H}$ ); in taxa where the anterior tooth is blunt or gouged, or, as in Protula, elongated and with a blunt tip, the term "peg", is preferred (see ten Hove \& Kupriyanova 2009: 25 and Fig. 20B). Thus, in describing the structure of the uncini, either F or P refers to the anterior tooth. The punctuation used in the formula describing an uncinus is crucial. In the generalised formula, $\mathrm{F}+x / y$, a number following the "+" sign denotes the number of rows of teeth above the fang (whether lateral or frontal view). When the formula reads $\mathrm{F}+5$, i.e., $x=5$, that denotes an uncinus with five "horizontal rows" of teeth above the fang; that formula fully defines a saw-shaped uncinus (Fig. $32 \mathrm{G}, \mathrm{H}$ ), but only defines the lateral view for a rasp-shaped uncinus (e.g., Figs 18 D, L, 23 A, B, 27 A, B, E). For a rasp-shaped uncinus, the $y$ in the generalised formula denotes the maximum number of teeth in the horizontal rows (i.e., the maximum number in all of the rows). Thus, F+7 / 3 denotes a rasp-shaped uncinus with 7 horizontal rows of teeth above the fang, and with 3 teeth as the maximum number of teeth in the horizontal rows without specifying the position of the row. Also, in rasp-shaped uncini, the colon is used to specify the number and position of the teeth in each row beginning with the $(\mathrm{F}+1)$ row proximal to the fang, and up to the apical row. Thus, F:2:2:3:4:5, etc., specifies an uncinus with 2 teeth in the $\mathrm{F}+1$ row proximal to the fang (noted as $\mathrm{F}+1=2$ ), with two teeth in the next row, increasing to 5 teeth posteriorly.

In an effort to find reliable characters to distinguish between populations from different geographic areas, Salmacina uncini were counted from SEM micrographs. In this preliminary study, we compared in a torus, the number of teeth in adjacent uncini, using only the rows proximal to the fang, defined above as the (F+1) rows. For designating adjacent uncini, the punctuation used is a comma. Thus, the F+1 rows in six adjacent uncini, the notation is $3,3, ?, 4,3,5$; in this sequence of uncini, the question mark indicates an uncinus whose teeth were not seen clearly enough to count.

Terminology. For terminology see Bastida-Zavala \& ten Hove (2003a), and ten Hove \& Kupriyanova (2009). 
Chronological settlement of the canal. Table 6 was compiled to show the location of taxa within the Suez Canal taking into account the revised chronology of the records based on our samples. Thus, the chronological codes for the earlier Israeli and Norwegian samples, newly reported here, precede those of the records of Ghobashy and his colleagues from 1980-1990 and of Shalla \& Holt (1999), records that were published earlier but had been sampled at a later date (see footnote to Table 6).

\section{Systematic section}

\section{Ficopomatus enigmaticus (Fauvel, 1923)}

Mercierella enigmatica Fauvel, 1923: 424, fig. 1 [Type locality: France, Canal de Caen]; Fauvel 1927: 360-361, figs 123a-o [France, estuarine].

Ficopomatus enigmaticus: ten Hove \& Weerdenburg 1978: 114-116, figs 2e-i; 3d-e, 1-q; 4a-d, s, aa-bb, nn-vv, zz; 5c; synonymy [Uruguay, Argentina, South Africa, the Netherlands, France, Tunisia, Hawaii, western Australia, New South Wales, California, Texas]; Zenetos et al. 2005: 73 [classified as an "established cryptogenic alien invasive species" in the Mediterranean].

\section{Eastern Mediterranean}

Mercierella enigmatica: Fauvel 1937: 45 [Egypt, Lake Mareotis, first Levant record]; Fauvel 1955a: 11 [first Israeli sample, from the Nur pool, an artificially maintained estuarine pool S.E. of Akko (Acre), legit B. Wahrmann IV.1954, det. P. Fauvel, HUJ-Poly-1582)]; Saad 1974: 53 [Egypt, 6 lakes, 5 from the Lower Delta and one from Upper Egypt]; Ghobashy 1984: 39, 44 [Egypt, Damietta estuary]; Ghobashy \& Hamada 1984: 53-63 [Egypt, Damietta estuary]; El-Komi 1997: 109 [Egypt, Lake Manzalah]; Ghobashy \& Ghobashy 2005: 91 [presence in Damietta estuary citing Hamada (1980) and Abd-Elnaby (2005, for both references see App. Table 4) records from Lake Manzalah and in the area of Abu Qir Bay (eastern Alexandria), all brackish-water areas].

Ficopomatus enigmaticus: Ben-Eliahu \& Dafni 1979: 207 [Israel, Alexander River]; Ben-Eliahu 1991b: 518 [Israel].

Material examined. Locations adjacent to the Suez Canal, Mediterranean side: Israel: 10 samples, HUJ, depth ca. $0.3 \mathrm{~m}$.

Suez Canal material reported herein: 2 samples, 3 specs. Hebrew University-Smithsonian Expedition, Lake Timsah: SBE 7, 2 specs-Little Bitter Lake: SBE 1, 1 spec.

Locations adjacent to the Suez Canal: Landlocked, Egypt: Lake Qârün, legit G.N. El Shabrawy, det. H.A. ten Hove 2000, ZMA V.Pol. 4981, 10 specs.

Locations adjacent to the Suez Canal, Red Sea side: None.

Suez Canal depth and substrates: $0.3 \mathrm{~m}$, shallow; under rocks; encrustation on tin can.

Colouration. Specimens from Lake Timsah with dark brown body; branchia of specimen from Bitter Lake with 6 rows of dark pigment.

Distribution. Worldwide in subtropical to temperate regions, northern and southern hemisphere; brackish. Mediterranean: Israel, Egypt.

Remarks. A new record for the Suez Canal dating from II.1973. A mixo-hyperhaline brackish species (ten Hove \& Weerdenburg 1978, ten Hove \& van den Hurk 1993).

\section{Filograna implexa Berkeley, 1835}

Type locality. England, Weymouth. Not present in the Suez Canal, but see Salmacina.

\section{Hydroides dianthus (Verrill, 1873)}

Serpula dianthus Verrill, 1873: 620-621 [Type locality: U.S.A., New England, Vineyard Sound (see "Material examined", below)].

Hydroides dianthus: Zibrowius 1971: 697-707, figs 1-5 [redescription, synonymy; U.S. eastern Atlantic from New England to Gulf of Mexico; Mediterranean: France, Spain, Tunisia, Italy, Turkey (Aegean); in estuaries and lagoons. In the eastern Atlantic, also on the coast between intertidal to $20 \mathrm{~m}$ or more-a distribution that suggests it is indige- 
nous to that area; Zibrowius 1973a: 683-686 [see above distribution]; Bianchi 1981: 59-62, figs 20a-d [Italy, particularly in ports and coastal lagoons]; Bastida-Zavala \& ten Hove 2003a: 143-146, figs 23-24 [eastern U.S.A., N. Gulf of Mexico and Netherlands Antilles, Curaçao, 0.6-28 m]; Zenetos et al. 2005: 73 [classified it as an "established cryptogenic alien invasive species" in the Mediterranean; as concerns the "cryptogenic" characterization, see remarks below].

Eastern Mediterranean

Hydroides uncinata (Philippi, 1844): Ghobashy 1977: 214-215, table 1 [Alexandria, under rocks; det. S.A. Selim 19734 (?), possible first record from Levant coast—Ghobashy \& Ghobashy (2005: 90) retroactively synonymised this material with $H$. dianthus].

not Hydroides cf. dianthus sensu Ben-Eliahu 1976: 106-107, fig. 1 [Israel, Shavé Ziyyon]; Ben-Eliahu \& Safriel 1982: 387 [same], corrected herein to H. operculatus (Treadwell, 1929), see remarks below.

?not Hydroides dianthus sensu Zibrowius \& Bitar 1981: 159-160 [Lebanon, see remarks below].

Hydroides dianthus: Ergen 1979: 79 [Aegean, Bay of Izmir]; Ghobashy 1984: table 1 [Egypt, Alexandria, Eastern Harbour, based on S.A. Selim (1978, see App. Table 4), 1978 is the first record from Egyptian coast; Selim 1997b: 8790, figs 2a-f [Egypt, Port Said]; El-Komi 1991a: table 3 [Alexandria]; Knight-Jones et al. 1991: 841 [Aegean, near Izmir, Güzelbahca Harbour]; Ben-Eliahu \& Payiatas 1999: 101-119 [Cyprus, Limassol harbour, on ship propeller]; Koçak et al. 1999: 6 [Aegean, Bay of Izmir, 3 m, panels]; Selim 2009: 73 [Egypt, Alexandria; Eastern Harbour, Port Said harbour fouling].

Suez Canal

Hydroides dianthus: Selim 2009: 73, [table 1, Lake Timsah. This appears to be the first record of H. dianthus from within the Suez Canal].

Material examined. More than 16 samples at the AMNH, USNM and YPM, with >150 specimens, e.g., the following six samples:

U. S. A., Connecticut, off New Haven, 11-15 m, syntypes YPM 2698, 2699, 8 specs-Massachusetts, New Bedford, from piles under wharf, legit R. Hall \& A. Elwyn 2.VIII.1909, det. W.G. van Name, redet. H.A. ten Hove; this $H$. dianthus is a "reef" (a solid aggregation of cemented tubes), AMNH 1122 (not counted, but at least 11 specimens).-_New Jersey, Greater Egg Harbour, legit, det. H.E. Webster (1880: 128, 159), transferred by M. Pettibone to H. uncinata, redet. H. Zibrowius 1970 H. dianthus, USNM 381, 1 spec.Florida, Alligator Harbour, Wilson's Beach, Stn 22, Tall Timbers, legit J. Rudloe 25.III.1966, det. H.A. ten Hove 1971 (unpubl.), USNM 51862, 2 specs.

Mediterranean, Naples, Gulf, Zoological Station 1888, separated from Hydroides diramphus, RMNH 392, ZMA V.Pol. 3206, 1 spec.-without further data, det. K.J. Bush (1910: 498) Eupomatus uncinatus, redet. H.A. ten Hove 1985, YPM 2839, 10 dried specs.

Locations adjacent to the Suez Canal, Mediterranean side: Cyprus, Limassol Harbour entrance, CyAI, ca. $0.3 \mathrm{~m}$ depth, scuba, from a ship propeller, legit G. Payiatas \& P. Orfanou 27.X.1997, det. M.N. BenEliahu, HUJ-Poly-80, 2 specs.

Suez Canal proper: No previous records from the Suez Canal.

Locations adjacent to the Suez Canal, Red Sea side: No records

Distribution. Temperate to subtropical coasts of northeast America and western Europe (not north of the English Channel). Atlantic Africa. Mediterranean: Italy, Naples; Cyprus (on ship propeller); Turkey, Aegean; Egypt, Alexandria, eastern harbour, Port Said, Suez Canal (Lake Timsah). Japan, Tokyo Bay.

Remarks. Hydroides dianthus apparently originates from the Atlantic coast of North America and is common in biofouling along the U.S. western Atlantic seaboard (Zibrowius 1971: 704, 1973a: 684). Contrary to the situation in the western Atlantic, there seemed to be no extensive populations in the eastern Atlantic and in the Mediterranean, except those in some Mediterranean lagoons (e.g., Thau lagoon). In the Mediterranean, Hydroides dianthus also occasionally occurs in harbours (H. Zibrowius, pers. comm.). The distribution pattern, conjunct in the western Atlantic and disjunct elsewhere, and the larger reservoir along the U.S. coast, supports the diagnosis of the western Atlantic as the provenance of this species (H. Zibrowius, pers. comm.). Zibrowius (1971) characterized it as tolerating a wide range of salinities and temperatures, between 28-50\%o and 5-30 ${ }^{\circ} \mathrm{C}$. Its first record in the eastern Mediterranean (Aegean, near Izmir) was in 1865 (Zibrowius 1973a). Knight-Jones et al. (1991: 841) reported it from the only station in the Bay of Izmir with eutrophic conditions (turbid waters and rocks covered with Ulva and Mytilus). A first record from Cyprus (X.1997) was 
that of two decaying individuals removed from a propeller of a ship in Limassol Harbour (Ben-Eliahu \& Payiatas 1999), one an operculum without a body; this record does not provide a definitive proof of settlement in Cyprian waters. Hydroides dianthus has not been reported along the Mediterranean coast of Israel (M.N. BenEliahu, unpubl. data); the specimen erroneously published long ago as $H$. cf. dianthus (Ben-Eliahu 1976: 106107, fig. 1, and Ben-Eliahu \& Safriel 1982: 387) is corrected herein to Hydroides operculatus, a Lessepsian migrant (see also Çinar 2006: 229-230, fig. 6). Moreover, Zibrowius \& Bitar's (1981) report of Hydroides dianthus from Lebanon was regarded as questionable (Ben-Eliahu \& ten Hove 1992: 37); the two small Lebanese specimens, when re-examined by one of us (H.A. ten Hove) in 1998 appeared rather to belong to Hydroides cf. brachyacanthus Rioja, 1941, a Lessepsian migrant present on the coasts of Israel and Lebanon as well as the Levant coast of Turkey (Ben-Eliahu \& ten Hove 1992: 43, Zibrowius \& Bitar 2003, Çinar 2006: 225226, fig. 2, respectively).

Selim's (1988) first record of Hydroides dianthus from the southern Levant coast (Eastern Harbour, Alexandria), and a later record from Port Said, not within the canal proper, were documented by a well-illustrated operculum (Selim 1997b fig. 2a). However, Selim's recent record (2009: 78) of Hydroides dianthus from within the canal, ca. $37 \mathrm{~km}$ from its northern mouth, from El Cap, referred to Ben-Eliahu's erroneous record of Hydroides cf. dianthus illustrated with a figure of the H. operculatus operculum (Ben-Eliahu 1976: 106, fig. 1), and the other references cited (Fauvel 1927: 357-358, Bellan 1964: 174-175 and Zibrowius 1968: 109112) referred not to Hydroides dianthus, but rather to H. uncinatus, confused for it (reviewed in Zibrowius 1971). The verticil spines of Hydroides operculatus, a well known Lessepsian migrant, all point inwards (Çinar 2006: 229-230, fig. 6), whereas the spines in H. dianthus all point in the same (ventral) direction (Zibrowius, 1973a: 683). Despite the uncertainty created by Selim's use of these citations and our inability to review a voucher specimen, given Selim's (1997) illustration, we tend to hypothesize that the identification is correct. If that is true, the record is also presumed to be a first record of Hydroides dianthus from within the Suez Canal. This could be indicative of a recent Atlantic-Mediterranean incursion into the canal, a finding with biogeographic significance. However, its disjunctive distribution-it is lacking along the northward Israeli coast but present in the Egyptian ports of Alexandria and Port Said-suggests it could rather be indicative of ship-transport as has been observed in Hydroides elegans and Hydroides diramphus. This is supported by a recent article by Link et al. (2009) that reported its first occurrence in East Asia, Tokyo Bay on artificial hard substrates, presumably due to ship transport, and a subsequent report from Osaka Bay by Otani \& Yamanishi (2010). In the Discussion section below, we have enumerated Hydroides dianthus as a member of the Suez Canal serpulid fauna.

\section{Hydroides dipoma (Schmarda, 1861)}

Not present in the Suez Canal, but in nearby Suez harbour fouling.

Eupomatus dipoma Schmarda, 1861: 29, pl. 61, fig. 177 [Type locality: South Africa, Cape of Good Hope].

Eupomatus spinosus Pixell 1913: 78, pl. 8, fig. 5 [Type locality: Suez].

Hydroides uncinata var. macronyx Ehlers, 1913: 582-583, pl. 46, figs 1-2 [South east Atlantic: South Africa, Simonstown].

Hydroides dipoma: Zibrowius 1973b: 33-35, figs 4 f, g [redescription, synonymy; from Río de Oro, Morocco to Cape of Good Hope, intertidal and subtidal; Suez].

Gulf of Suez

Eupomatus spinosus Pixell, 1913: 78, pl. 8, fig. 5 [Suez, see "Material examined"].

Material examined. Locations adjacent to the Suez Canal, Mediterranean side: None.

Suez Canal proper: No records.

Locations adjacent to the Suez Canal, Red Sea side: Egypt: 2 lots. Gulf of Suez, Suez, C. Crossland, details concerning substrate or habitat not available, det. H.L.M. Pixell Eupomatus spinosus, BM(NH) 1924:6:13:135, 2 specs; syntypes of Eupomatus spinosus Pixell, 1913, donated J.S. Gardiner, BM(NH) 1938:7:25:9-12, 4 specs.

South Africa, legit W. Stephensen 11.VI.1932, det. H. Zibrowius 1972, Hydroides spinosus, BM(NH) 1932.12.23.20, 1 spec.; Cape Peninsula, shore, Stn CP 138, legit, presented and det. J.H. Day H. dipoma, $\mathrm{BM}(\mathrm{NH})$ 1963.1.175, 1 spec. 
Distribution. Atlantic Africa: Río de Oro, Morocco to the Cape of Good Hope; Suez.

Remarks. Pixell (1913: 78) reported Hydroides dipoma (as Eupomatus spinosus) from Suez. Zibrowius (1973b: 36) commented on the species' disjunctive distribution, from the length of the south east Atlantic coast, without additional records from the Mediterranean or from the Indian Ocean or Red Sea; and with a single Indo-West-Pacific location, Suez. We agree with him that it is likely that the record at Suez is due to a ship-borne introduction. We have not enumerated Hydroides dipoma among the species reported from the Canal. However, due to the proximity of Suez to the southern opening of the canal, we would not be surprised if it were to be found in the canal.

\section{Hydroides diramphus Mörch, 1863}

Figs 4, 5A-C

Hydroides (Eucarphus) dirampha Mörch, 1863: 379, pl. 11 fig. 10 [Type locality: Antilles, St. Thomas].

Eupomatus lunulifer Claparède, 1870: 181-182, pl. 31 fig. 3 [Italy, Naples, on ship's hull].

Hydroides lunulifera: Fauvel 1927: 358-359, figs 122 p-s [Spain, Valencia; Italy, Naples; ship fouling]; Day 1967: 807, figs $38.4 \mathrm{j}-\mathrm{k}$ [South Africa, Natal].

Hydroides dirampha: Zibrowius 1971: 706, figs 6-9 [synonymy; Mexico, Vera Cruz; Panama, Colon; Venezuela; Brazil; Bermudas; Grenadines; Antigua; Florida; South Africa; Italy, Naples; Indonesia, Java; Hawaii; New Zealand]; Zibrowius 1979b: 133-134 [France, Toulon Port, biofouling removed from the aircraft carrier "Foch"]; Bianchi 1981: 63-64, figs 21a-e [Italy; Port Said]; Zenetos et al. 2005: 73 [classified as an "established cryptogenic alien invasive species" in the Mediterranean].

Eastern Mediterranean

Hydroides lunulifera: Potts 1928: 701 [Egypt, Port Said (see "Material examined"), 1924 was first record from Levant Basin; Ghobashy 1977: 214-215, table 1 [Alexandria, under rocks; Ghobashy \& Ghobashy 2005: 90 retroactively synonymised this taxon with $H$. dirampha; see below].

Hydroides dirampha: Ben-Eliahu 1972a: 77 [Egypt, Port Said, after Potts (1928)]; Zibrowius \& Bitar 1981: 159-160 [Lebanon, Beirut, Zaitouné, 5 m, 23.IX.1978, from bivalve]; Ghobashy 1984, table 1 [Alexandria, harbour, citing Selim (1978, see App. Table 4)]; Ben-Eliahu 1991b: 518 [Israel]; El-Komi 1991a, b: table 3 [Alexandria, harbour]; Ben-Eliahu \& ten Hove 1992: 40 [Israel, entire coast from north to south, 0-24 m]; El-Komi 1992a, table 4 [Alexandria, harbour]; Ben-Eliahu \& Fiege 1996: 33, 38 [Levant coast]; Selim 1997b: 90-91, figs 3a-f [Port Said, collected in 1988]; Zibrowius \& Bitar 2003: 71 [Lebanon]; Ghobashy \& Ghobashy 2005: 90 [Alexandria, Eastern Harbour; a review article]; Çinar 2006: 226, fig. 3a-c [Levant coast of Turkey, Iskenderun Bay, Yumurtalık Harbour, Mersin Bay, IX.2005, 0.1-3 m, on Pomatoleios kraussii tubes].

\section{Suez Canal}

Hydroides dirampha: Ben-Eliahu 1972a: 77 [misinterpretation of Potts (1928) who had in fact not reported this species from within the Suez Canal but only from Port Said and claimed it had not entered the canal (see below); Ghobashy 1984: 43, 45 [Lake Timsah]; Ghobashy et al. 1986: 319-326, fig. 2 [Lake Timsah]; Ghobashy et al. 1990: 677-685 [Lake Timsah]; Mona 1992: 244-261 [Lake Timsah]; Selim 1997b: 90-91, figs 3a-f [collected in 1988, El-Kab, Lake Timsah, Deversoir; for Lake Timsah citing Shalla (1985) and Mostafa (1992) see App. Table 4 for both references)]; Wehe \& Fiege 2002: 126 [Suez Canal; list of references]; Emara \& Belal 2004: 192-199 [pooled Lake Timsah and Bitter Lakes data]; Ghobashy \& Ghobashy 2005: 90 [syn. H. lunulifera, Suez Canal record from Lake Timsah also citing Barbary (1992, see App. Table 4)]; Selim 2009: 73 [northern part of the canal, in El Cap].

Hydroides lunulifera: Emara \& Belal 2004: 192-199 [synonym of H. dirampha (cited just above); authors kept separate abundance data for these synonyms].

Gulf of Suez

Hydroides dirampha: Selim 1997b: 90-91, figs 3a-f [collected in 1988, Port Taufiq].

Material examined. Locations adjacent to the Suez Canal, Mediterranean side: Israel: 35 samples; one of these is the first sample from Israel, Haifa harbour, legit G. Haas, 22.III.1937, det. M.N. Ben-Eliahu, HUJPoly-867 (previously AN-II-84)—Egypt, Sinai: 4 samples, 0.3-4-15-[57-62] m, HUJ.—Egypt, Port Said, on buoy no. 723, Cambridge Expedition 13.XII.1924, det. F.A. Potts Hydroides lunulifera, redet. H. Zibrowius (1971: 706), confirmed M.N. Ben-Eliahu 1986, CUZM-AN.I.1930, 1 spec.

Suez Canal material reported herein: 13 samples, 100 specs, Cambridge Expedition 6.X-29.XII.1924, 1 "new" BM(NH) sample: Toussoum: 1 spec. (see App. Table 2A, and see just below).—Beets' Great Bitter Lake samples: ca. 6 samples with empty tubes tentatively attributed to Hydroides diramphus (not enumerated, 
see App. Table 2B).-Hebrew University-Smithsonian Expeditions, 1967-1973: 6 samples, 81 specs. Lake Timsah: SBE 7, 30 specs; SBE 8, 44 specs; Great Bitter Lake: SLC 67, 1 spec.; SLC 71, 1 spec.; SLC 3, 2 specs; SLC 117, 3 specs._Great Bitter Lake "Yellow Fleet" Biofouling Samples, January 13-20, 1975: 3 subsamples, 3 specs; Bremerhaven dry dock, 18.VI.1975, 7 m, 1 spec. with operculum still connected to partially decayed body—Lake Timsah, 1984, legit S.H. Shalla, det. H.A. ten Hove, ZMA V.Pol. 5001, 8 specs, tubesEl Tawan Beach, 10 / 19.XI.1988, legit S.B. Shazly, det. H.A. ten Hove, ZMA V.Pol. 3818, 3 specs.

Locations adjacent to the Suez Canal, Red Sea side, reported herein: Cambridge Expedition 6.X29.XII.1924, 1 "new" BM(NH) sample from barge: Presumed Port Taufiq, 1 spec. (see App. Table 2A).

Suez Canal depth and substrates: $0.3-10 \mathrm{~m}$; on algae, e.g., Digenea; on sponge, on molluscs; on a mollusc from a barge; on bivalves, Brachidontes pharaonis, Crenatula picta, Pinctada radiata; on rocks; on artificial substrates: Encrusted tin can submerged in mud, rubber fenders and iron frames; ship fouling.
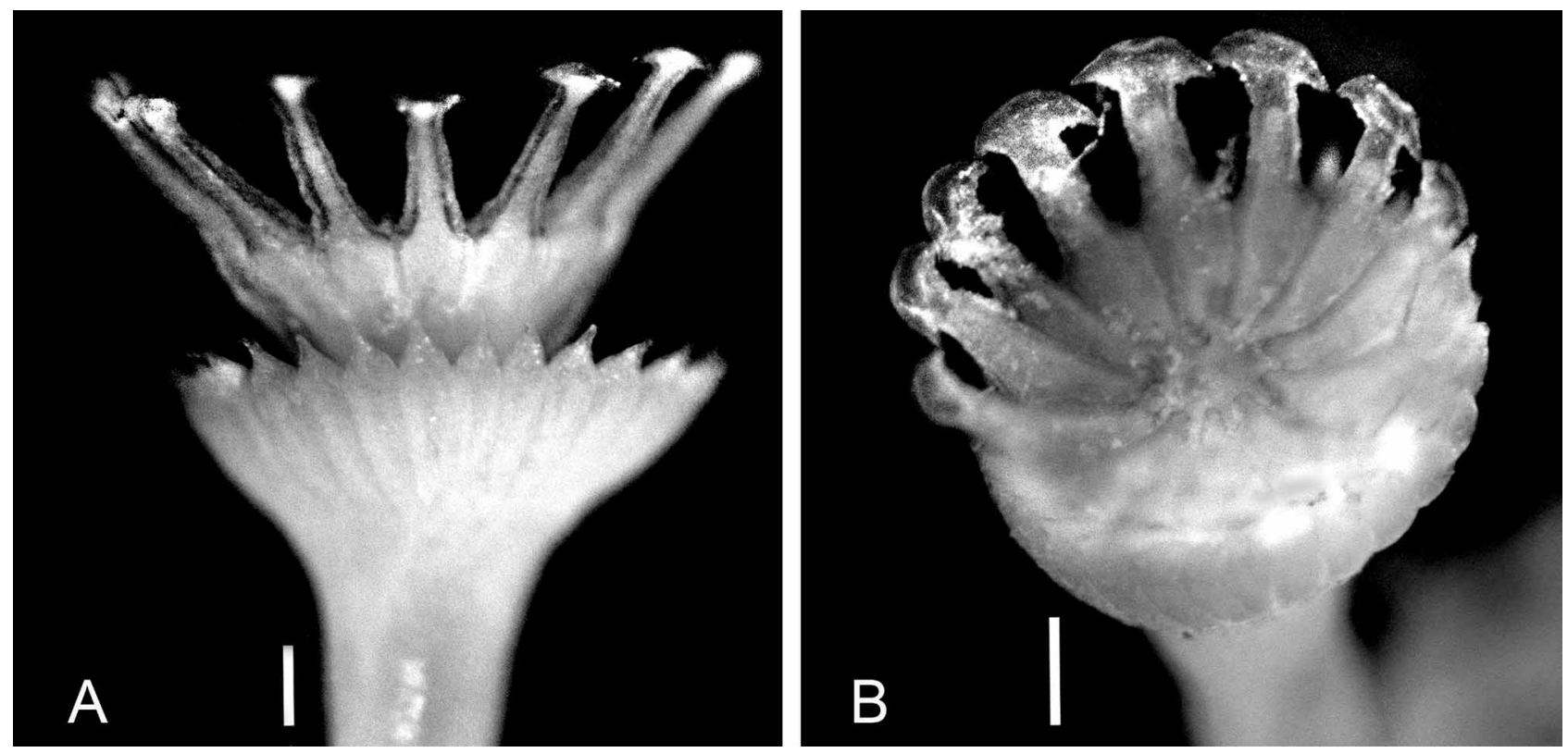

FIGURE 4. Opercula of Hydroides diramphus. A-Operculum of small individual from Lake Timsah (sample SBE 8, App. Table 2C), B-Specimen from the Great Bitter Lake (legit H. Brattström \& J.P. Taasen, 14.I.1975, App. Table 2D). Scales: $100 \mu \mathrm{m}$.

Colouration. Radioles of specimens from Lake Timsah with alternating white and brown banding, widest bands in middle of radiole.

Distribution. Circum(sub) tropical; port fouling species. E. Mediterranean. Turkey, Lebanon, Israel, Egypt.

Remarks. Origin apparently tropical western Atlantic Coast; Zibrowius (1973a) noted a first record of Hydroides diramphus from Naples in 1870 as its synonym, H. lunulifer (Claparède, 1870: 181-182 pl. 31, fig. 3). Its first record from the Levant Basin, from 1924, was from the sample collected by the Cambridge Expedition from a buoy in Port Said (Potts 1928: 701). Potts considered that Hydroides diramphus had not entered the Canal. However, in actuality, two additional samples of Hydroides diramphus had been collected, unknown to Potts, encrusted on the Cambridge Expedition molluses that had been taken to the Natural History Museum in London and deposited in the Mollusc Section of the museum; they were found 62 years later during a visit to the Museum (by NBE) and are referred to above in the "Material examined" section as "new" Cambridge Expedition samples. One was from Toussoum $(\mathrm{km} \mathrm{87)}$ within the canal and the other from "Barge 568", presumably from Port Taufiq. [Potts referred only to "barges" without specifying their number but specifically mentioned only Port Taufiq as a location for them; the precise date of collection is unknown (J. Pickering, pers. comm., see App. Table 2A)]. The first record of $H$. diramphus from within the Suez Canal is herein brought forward to 1924. It is likely that it was present among the dry Great Bitter Lake tubes collected 
later by C. Beets (1950); see Discussion and App. Table 2B, but taphonomic residues, enabling confirmation of our tentative identification of tubes, were not found. In 1973, H. diramphus appeared to be present in larger numbers in Lake Timsah than in the Great Bitter Lake, and there have been consistent records of it there in subsequent Egyptian fouling research (e.g., Ghobashy 1984, Shalla 1985, Ghobashy et al. 1986, Ghobashy et al. 1990 and Mona 1992). Selim (1997b) reported it in the five sites studied along the canal, i.e., in Port Said, El-Kab, Lake Timsah, Deversoir and Port Taufiq. Most of the present specimens had expanded T- or anchorshaped tips of the verticil spines and pointed chitinised tips of the funnel radii (Fig. 4).

Bastida-Zavala \& ten Hove (2003b: 84) described tubes of Hydroides diramphus from California and Hawaii as variable in form "having transversal ridges also with longitudinal ridges"... and sometimes with peristomes. Variability in form is also confirmed for the present material; tubes with three ridges appeared to be rarer than those with two, although the median ridge may be very difficult to see. Fig. 5A-C illustrates some variation in tube ornamentation in Hydroides diramphus. The tube in Fig. 5A is less rugose than the one in Fig. 5B that appears to be covered with a granular layer that could obscure surface sculpturing (i.e., could obscure a low median longitudinal ridge). Several tubes from the Mediterranean coast of Israel had three ridges so low that they could barely be seen with the water surface breaking at the level of the tube surface (these ridges were even lower than the median ridge figured in Fig. 5A).

\section{Hydroides elegans (Haswell, 1883)}

Figs 5D, E, 6, 7

Eupomatus elegans Haswell, 1883: 633, pl. 12 fig. 1 [Type locality: Australia, Port Jackson].

Hydroides elegans: Zibrowius 1971: 721-727, figs 56-64 [synonymy of various older material determined as H. norvegica; distribution: Florida; Senegal; Ghana; Angola; South Africa; France; Italy; Tunisia; Alexandria; Suez Canal, Isma'iliya; Suez; Mozambique; Indonesia, Java; western Australia; New South Wales; Queensland; Hawaii; California]; ten Hove 1974: 46-47, figs 1-3 [Netherlands, U.K., France, Ghana, Tunisia, Malta, Italy, Mozambique, Sri Lanka, Argentina, the Netherlands Antilles]; Zibrowius 1979b: 133-134 [France, Toulon Port, biofouling removed from the aircraft carrier "Foch" that had travelled in the Indo-West-Pacific, going and returning via the Suez Canal]; Bianchi 1981: 56-58, figs 18a-f [Italy]; Ben-Eliahu \& Fiege 1996: 29-30, 33, 38, fig. 10b [Turkey, Cyprus, Israel, Egypt]; Zenetos et al. 2005: 73 [classified as an "established cryptogenic alien invasive species" in the Mediterranean].

\section{Eastern Mediterranean}

Hydroides norvegica not Gunnerus, sensu Potts 1928: 700 [Egypt, Port Said from Buoy no. 723, collected in 1924, first record from the Levant Basin]; Fauvel 1937: 44 (synonymised in Zibrowius 1971: 722) [Egypt, Alexandria, 4-10 m, on Caulerpa]; Tebble 1959: 29 [Israel, off Atlit, Stn 507, 16 m, legit A. Yashouv ( = A. Wirszubski), Teb507, $\mathrm{BM}(\mathrm{NH})$ 1955.10.12.74, 8 specs (7 of them juveniles with primary opercula, material examined by us); ?Banoub 1961: 8, fig. 4 Alexandria, material not examined by us, but in view of remark of Ghobashy \& Ghobashy 2005 below most probably H. elegans]; Laubier 1966: 9, synonymised in Zibrowius 1971: 722 [Lebanon]; Ben-Eliahu 1970: fig. 2a [Israel]; Ghobashy 1977: 214-218, tables 1-3, figs 3-5 [Alexandria (Ghobashy \& Ghobashy 2005: 90 implicitly synonymised this with $H$. elegans by naming $H$. elegans as the principle fouling organism in the harbour since 1976)]; Ghobashy \& Selim 1976a: 287-295, figs 1-5 [Alexandria, eastern harbour (see note above)]; Ghobashy \& Selim 1976b: 303-313 [Alexandria, harbour, (see note just above)]; Goren 1980: 278 [Israel, Ashdod Port, panels, 0.2 m (synonymised in Ben-Eliahu \& Fiege 1996: 7)].

Hydroides elegans: Ben-Eliahu 1976: 107 [Israel, intertidal cryptofauna]; Zibrowius \& Bitar 1981: 159-160 [Lebanon, Beirut, Zaitouné, 5 m, 23.IX.1978, on bivalve]; Ghobashy 1984: 41 [Egypt, Alexandria, harbour]; Ben-Eliahu 1991b: 518 [Cyprus, Israel]; El-Komi 1991a: 6, 7, tables 1-4, fig. 2 [Alexandria]; Ben-Eliahu \& ten Hove 1992: 40 [Israel, entire coast from north to south, 0-24 m]; El-Komi 1992a: 123, 130, 133, tables 2, 4, 5, fig. 3, pls. 1, 2 [Alexandria harbour]; El-Komi \& El-Sherif 1992: 259-260, 263, tables 3, 4, fig. 4 [Alexandria, Eastern Harbour]; BenEliahu \& Fiege 1996: 29-30, 33, 38 [Cyprus, Levant coast of Turkey, Israel, Egypt]; Ergen \& Çinar 1997: 237 [Turkey, Antalya Bay]; Selim 1997b: 91-92, figs 4a-f [Alexandria, Eastern Harbour (citing Selim 1978, see App. Table 4)]; El-Komi 1998: 259, 262, 263 [buoys in Alexandria harbour]; Zibrowius \& Bitar 2003: 71 [Lebanon, Beirut]; 
Ghobashy \& Ghobashy 2005: 90 [Alexandria, Eastern Harbour: Review, refers to Ghobashy \& Selim 1976a, b, Ghobashy 1977, Mona 1978, Selim 1978, 1996, El-Komi 1991, 1992a, b and 1998; the western harbour review quotes Ramadan (1986, see App. Table 4) on settlement]; Çinar 2006: 226, fig. 3 d, e [Levant coast of Turkey, Iskenderun Harbour, Yumurtalık Harbour, Mersin Bay, 0.1-5 m, on rope and tyre, IX.2005]; Ramadan et al. 2006: 26, table 1 [Alexandria, Eastern Harbour; also reviewing Banoub 1961, Megally 1970, Ghobashy 1977, El-Komi 1991a, b, 1992a, 1998]; Abd-Elnaby 2009: 10 [Alexandria]; Selim 2009: 76 [Egyptian waters].

Hydroides sp.: Fishelson \& Haran 1987: 122 [Israel, Mikhmoret; specimens examined in 1999 by Ben-Eliahu all proved to be Hydroides elegans].

Serpula concharum not Langerhans, sensu Fishelson \& Haran 1987: 122 [Israel, Mikhmoret; redet. Ben-Eliahu \& ten Hove in 1999 as Hydroides elegans specimens with primary opercular stages (see "Remarks", below)].

?Serpula vermicularis not Linnaeus, sensu El-Komi 1991a: 7, table 2 [Egypt, Alexandria, fouling study, presumably specimens with primary opercula]; El-Komi 1991b: 290-291, table 1, [Egypt, Alexandria (see preceding remarks)].

Hydriodes [sic] elegans: El-Komi 1991b: 290-291, tables 1, 3 [Egypt, Alexandria].

?Hydroides sp.: El-Komi 1997: 109 [Egypt, Lake Manzalah, with Ficopomatus enigmaticus].

Surpula [sic] sp.: El-Komi 1998: 262-263 [Egypt, Alexandria, buoys in harbour; presumably specimens with primary opercula (see "Remarks", below)].

\section{Suez Canal}

Hydroides elegans: Zibrowius 1971: 721-727, figs 56-64 [synonymy of H. norvegica from "Pola" Expedition 1895, Isma'iliya, first record from the Suez Canal (see "Material examined", below, and Fig. 6) and synonymy of various older specimens determined as H. norvegica; Ben-Eliahu 1972a: 77 [El Qantara, Kabrit, Tis'a]; Ghobashy et al. 1980: 84, 86-91, table 2, figs 4, 5 [major fouling component throughout the canal]; Ghobashy \& El-Komi 1981a: 170-177 [Lake Timsah, 4.5-10 m], 1981b: 180-183 [Toussoum, Deversoir, Kabrit, Geneva, el Shalloufa]; Ghobashy 1984: 39, 45-47 [throughout Suez Canal]; Ghobashy et al. 1986: 319-326, fig. 3 [Lake Timsah], 1990: 677686 [Lake Timsah]; Selim 1997b: 91-92, figs 4a-f [El-Kab, Lake Timsah, Deversoir, ranked "first serpulid" in canal by abundance of individuals]; Wehe \& Fiege 2002: 126 [Suez Canal; list of references)]; Emara \& Belal 2004: 192204 [pooled Lake Timsah and Bitter Lakes]; Ghobashy \& Ghobashy 2005: 90 [a review of the Suez Canal fouling research showed dominance of $H$. elegans on fouling panels throughout the canal-all authors quoted by them are referred to above, with exception of Barbary (1992, see App. Table 4)]; Selim 2009: 73 [northern part of the canal to Toussoum]; Abd-Elnaby 2009: 10 [southern part of the canal].

Hydroides norvegica not Gunnerus, sensu Potts 1928: 700 [collected in 1924, "the most common serpulid throughout the canal"; redet. Zibrowius 1971, see "Material examined", below]; Fauvel 1933a: 76 [R.Ph. Dollfus Expedition, 7.I.1928, Isma'iliya, on boat hull (synonymised Zibrowius 1971)].

?Serpula vermicularis not Linnaeus, sensu Ghobashy et al. 1980: 84; Ghobashy 1984: 45 [Lake Timsah)]; Ghobashy \& Ghobashy 2005: 93 [found in Suez Canal on fouling plates in few numbers, and referring to Ghobashy et al. 1980]; Emara \& Belal 2004: 192-199 [pooled Lake Timsah and Bitter Lakes data]; Selim 2009: 73 [Ras el Esh]; all these records presumably specimens with primary opercular stages of $H$. elegans (or other Hydroides taxa, see Remarks below).

?Serpula concharum not (Langerhans), sensu Selim 2009: 73 [northern part of canal, Ras el Esh]; Abd-Elnaby $2009: 10$ [southern part of the canal], presumably specimens with primary opercula (see "Remarks", below).

?Serpula sp.: Ghobashy et al. 1980: 84, 87, table 2; Ghobashy \& El-Komi 1981a: 172 [Lake Timsah, 4.5-10 m], presumably specimens with primary opercula (see "Remarks", below).

Gulf of Suez and Gulf of Aqaba

Hydroides norwegica [sic] not Gunnerus, sensu Pixell 1913: 74 [Gulf of Suez, Suez, dry dock, bottoms of S.S. "Thira” and S.S. "Slide" that had come from Alexandria, BM(NH) 1924.6.13.148 (synonymised by Zibrowius 1971: 722)].

Hydroides norvegica not Gunnerus, sensu Potts 1928: 700 [Port Taufiq, on barges]; Amoureux et al. 1978: 144-145 [Gulf of Aqaba, Elat, Venezia lagoon, biofouling on floats].

?Serpula concharum not Langerhans, sensu Amoureux et al. 1978: 143 [Gulf of Aqaba, Elat, Venezia lagoon, biofouling on same floats as those referred to just above, presumably specimens with primary opercular stages of $H$. elegans (abundant in the lagoon [1999, M.N. Ben-Eliahu \& H.A. ten Hove, unpubl. data]); also pro parte S. hartmanae (see "Remarks", below)]; El-Komi, et al. 1998: 16-24 [Suez Bay]; Ghobashy \& Ghobashy 2005: 93 [same].

?Serpula vermicularis not Linnaeus, sensu Amoureux et al. 1978: 143 [Gulf of Aqaba, Elat, Venezia lagoon, presumably 
specimens with primary opercular stages of $H$. elegans [part], see above, and "Remarks", below]; El-Komi et al. 1998: 16, 17, 20 [Suez Bay]; Ghobashy \& Ghobashy 2005: 93 [same].

Hydroides elegans: Ghobashy \& El-Komi 1981b: 180-183 [Gulf of Suez, Suez]; Amoureux 1983: 369 [Gulf of Aqaba, sand]; Selim 1997b: 91-92, figs 4a-f [Gulf of Suez, collected in 1988, Port Taufiq]; El-Komi et al. 1998: 11-20 [Suez Bay, collected 1992-1993 on polystyrene fouling panels and buoys]; Abd-Elnaby 2009: 10 [Gulf of Suez].

Hydroides sp.: El-Komi 1996: 7 [Suez Bay, presumably H. elegans].

Red Sea proper-Indo-West-Pacific (excluding citations from Gulf of Suez and Gulf of Aqaba already given above) Hydroides norvegica not Gunnerus, sensu Dew 1959: 24-25, figs a-i [various locations in western Australia, Queensland, New South Wales, Victoria, South Australia, New Zealand, New Britain].

Hydroides elegans: Mohammad 1976: 133 [Persian (Arabian) Gulf, Kuwait]; Vine \& Bailey-Brock 1984: 139-140, fig. 2a [Red Sea, Sudan, Port Sudan, settlement panels at $20 \mathrm{~m}$, coral slabs 30-35 m, undersides of ships (part; probably only ship-fouling material, deep material probably different species)]; Bailey-Brock 1985: 209-210, figs 11a-d ["common fouling species with a cosmopolitan distribution in warm waters of the Atlantic, Pacific and Indian oceans (see Zibrowius 1971)]; Ishaq \& Mustaquim 1996: 170, figs 5a-h [Pakistan, intertidal rocks, boat hull]; Wehe \& Fiege 2002: 126 [Red Sea, Persian (Arabian) Gulf; list of references]; Abd-Elnaby 2009: 10 [Red Sea].

Hydriodes [sic] sp.: El-Komi 1992b: 638 [fouling plates, Egypt, Red Sea, Ghardaqa].

?Serpula concharum not Langerhans, sensu El-Komi 1992b: 638 [fouling plates, Red Sea, Ghardaqa, Egypt]; Ghobashy \& Ghobashy 2005: 93 [citing El-Komi 1992b: 638)]; Abd-Elnaby 2009: 10 [Red Sea]. All presumably specimens with primary opercular stages of $H$. elegans (see Remarks below).

Material examined. Locations adjacent to the Suez Canal, Mediterranean side: Turkey: 4 samples, intertidal-Cyprus: 14 samples, <0.5-[0-8]-[10-18]-26 m-Israel: 106 samples, [intertidal-0.3]-[2-3]-37 m; one of these is the first sample from Israel, Haifa Port, 27.V.1934, leg. G. Haas, det. M.N. Ben-Eliahu, HUJPoly-722-Egypt, Sinai, 11 samples, shallow-[10-15]-46 m.

Suez Canal proper: 13 samples, no. specs not enumerated for each sample, including dry tubes: "Pola" Expedition 1895-1898, Isma' iliya, 17.X.1895 (fide Sturany 1899), on two Potamides conicus gastropods, det. E. von Marenzeller H. norvegicus (fide Stagl et al. 1996), redet. H. Zibrowius 1971 (NHMW, Evert. Varia 2034, alte invert. no. 17199), 2 specs (Fig. 6). -Cambridge Expedition: Ras-el-Esh, Km 14, 20.XII.1924 (Fox 1926: 50); Ferry Post, Isma'iliya, 27-28.II.1924: 3 specs, 1 with long central spine (as in Fig. 6B) and juveniles with only primary operculum (collar chaetae checked); $\mathrm{km} 72$, north of Isma'iliya, 4.XII.1924, Little Bitter Lake, K2, (Kabrit), 17.X.1924, with long central spine; K9, (Kabrit), 25.X.1924, on "Bollard" and on houseboats, various dates, $1 \mathrm{spec}$. with 2 opercula, with central spine well-developed; and 1 sample, Gulf of Suez, Port Taufiq, "Barge 678," 10.X.1924, mass of empty Hydroides tubes, det. F.A. Potts (1928: 700) H. norvegicus, redet. H. Zibrowius (1971: 722) H. elegans, confirmed M.N. Ben-Eliahu 1986; several specs; samples catalogued together as CUZM-AN.1.1930.

Suez Canal material reported herein: $60+? 1$ samples, $565+? 1$ specs (of which 145 were juveniles) plus some additional non-enumerated Lake Timsah juveniles, as well as three of Beets dry samples with 14 determinable taphonomic specs (Appendix Table 2): 4 "new" Cambridge Expedition samples (samples separated from $\mathrm{BM}(\mathrm{NH})$ molluscs [see App. Table 2A]), 3 specs: Lake Timsah-Km 78, Isma'iliya: 1 spec.; T9: 1spec.; Toussoum-Km 87: 1 spec.-Beets' Great Bitter Lake samples, VIII / IX 1950, taphonomic material found in 3 samples, Stns 1, 4 and 21, RMNH 18528-18535, 18538, 18546-18549, 14 specs, plus 24 samples with empty tubes (not enumerated) tentatively attributed to Hydroides elegans (see App. Table 2B, Fig. 7).-Hebrew University-Smithsonian Expeditions, 1967-1973, 27 samples, 493 specs including 131 juveniles (see App. Table 2C): Port Fouad-Km 12: SLC 45, 1 spec.; el Qantara-Km 45: SLC 6, 197 specs (1 juvenile); SLC 20, 5 specs; SLC 31, 9 specs (3 of them juveniles); SLC 32, 1 spec.; SLC 38, 1 spec.; Lake Timsah, Km 78, opposite Isma'iliya: SLC 4, 2 specs (juveniles); SBE 5, 2 specs; SBE 7, 1 spec.; SBE 8, 39 specs; Great Bitter Lake, east of Deversoir-Km 97: SLC 50, 18 specs (3 of them juveniles); SLC 52, 1 spec. (juvenile); SLC 55, 2 specs (juveniles); SLC 60, 6 specs; SLC 61, 6 specs (5 juvenile); SLC 64, 4 specs; SLC 67, 1 spec. (juvenile); SLC 71, 4 specs; SLC 74, 2 specs (1 of them juvenile); SLC 76, 1 spec.; Km 98: SLC 3; 6 specs; 

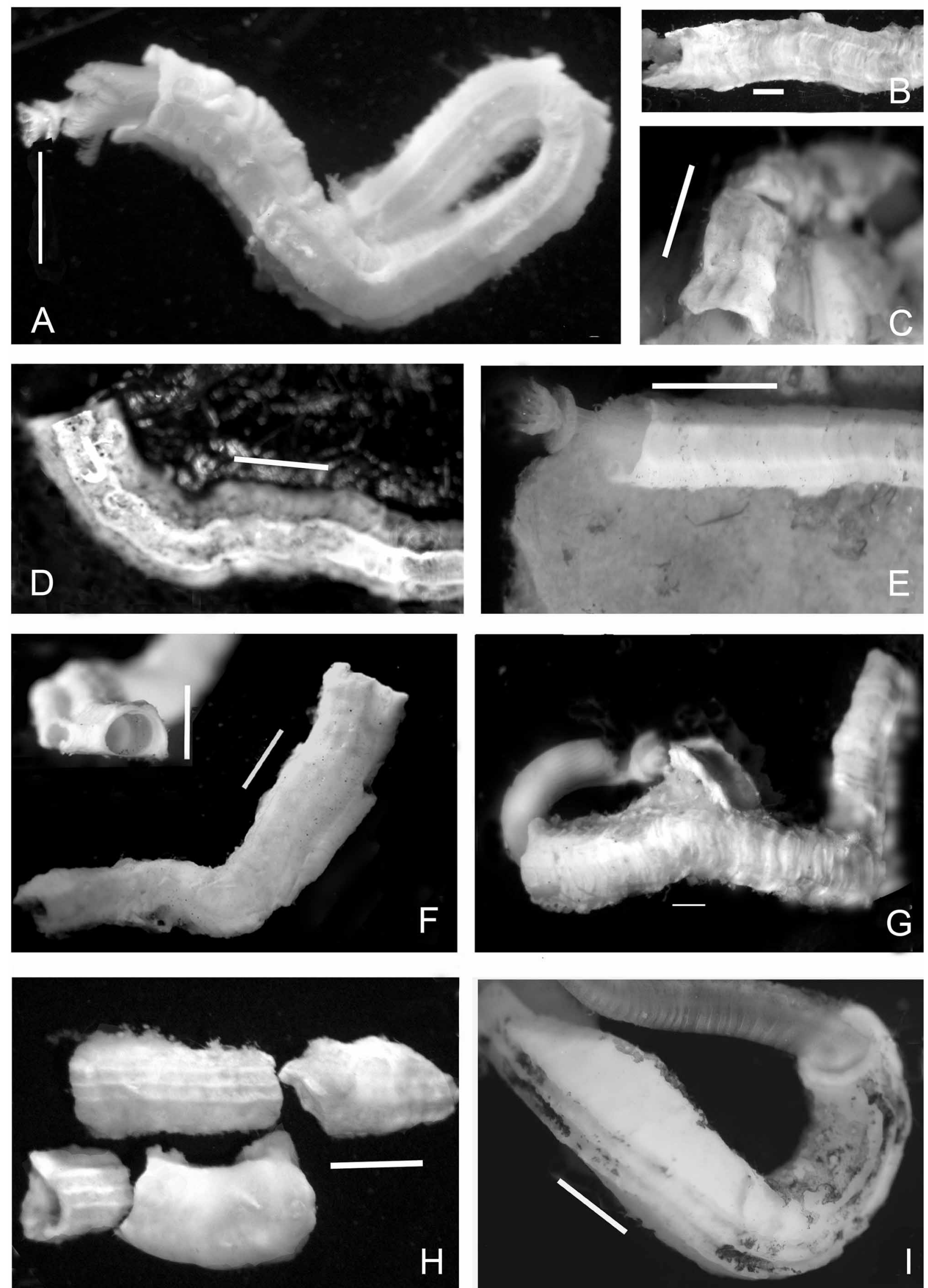
FIGURE 5. Variability in tubes of the genus Hydroides. Hydroides diramphus, A-C: A-Upper surface with higher lateral longitudinal ridges and barely visible median longitudinal ridge (from Mediterranean coast of Israel, Nabi Yunes, legit E. Gilat, sample 1821b, 10.XI.1969, 22 m, on Pinctada radiata; HUJ-Poly-860), B-Tube fragment (anterior, left) with two longitudinal ridges; prominent transversal ridges (Lake Timsah, [SBE 7, App. Table 2C]), C-Three longitudinal ridges seen in anterior of tube; minute, slightly chitinised verticil present at anterior margin of tube (Mediterranean, from fouling panels, Israel Electric Corporation, Haifa; legit A. Glazer, 08.IX.2004, 0.5 m depth, on Cirripedia). Hydroides elegans, D, E: D-Tube with two very prominent longitudinal ridges (Mediterranean, Israel, Jaffa Port ; on shallow rocks; legit S. Hayat, 18.VI.2001), E-Young mature specimen; longitudinal ridges less prominent than in "C", more prominent than in older, abraded tubes as in Fig. 5D, Great Bitter Lake, Km 98, (SLC 117, App. Table 2C). Hydroides heterocerus, F, G: F-Left upper corner inset with apical view of tube; small specimen shows relatively rare tube with 3 longitudinal ridges (Suez Canal, Great Bitter Lake, east of Deversoir (SLC 72, App. Table 2C), G-Typical tube, tube, round, with marked transversal ridges, longitudinal ridges not seen (Great Bitter Lake, legit H. Brattström and J.P. Taasen [sub-sample BIV 9; App. Table 2D]). Hydroides homoceros, H, I: H-Four fragments from a single tube; three of them with three marked longitudinal ridges; one section with a granular surface layer (Great Bitter Lake, legit $\mathrm{H}$. Brattström and J.P. Taasen [sub-sample Tun, App. Table 2D]), I-Tube with three longitudinal ridges, with blotches; from ship fouling that developed in the Great Bitter Lake, sampled when the M/S "Münsterland" reached the Bremerhaven dry dock after it traversed the Mediterranean (18.VI. / 1975, legit J.P. Taasen); note posterior of decayed specimen projecting from fragment of tube. Scales: $1 \mathrm{~mm}$.
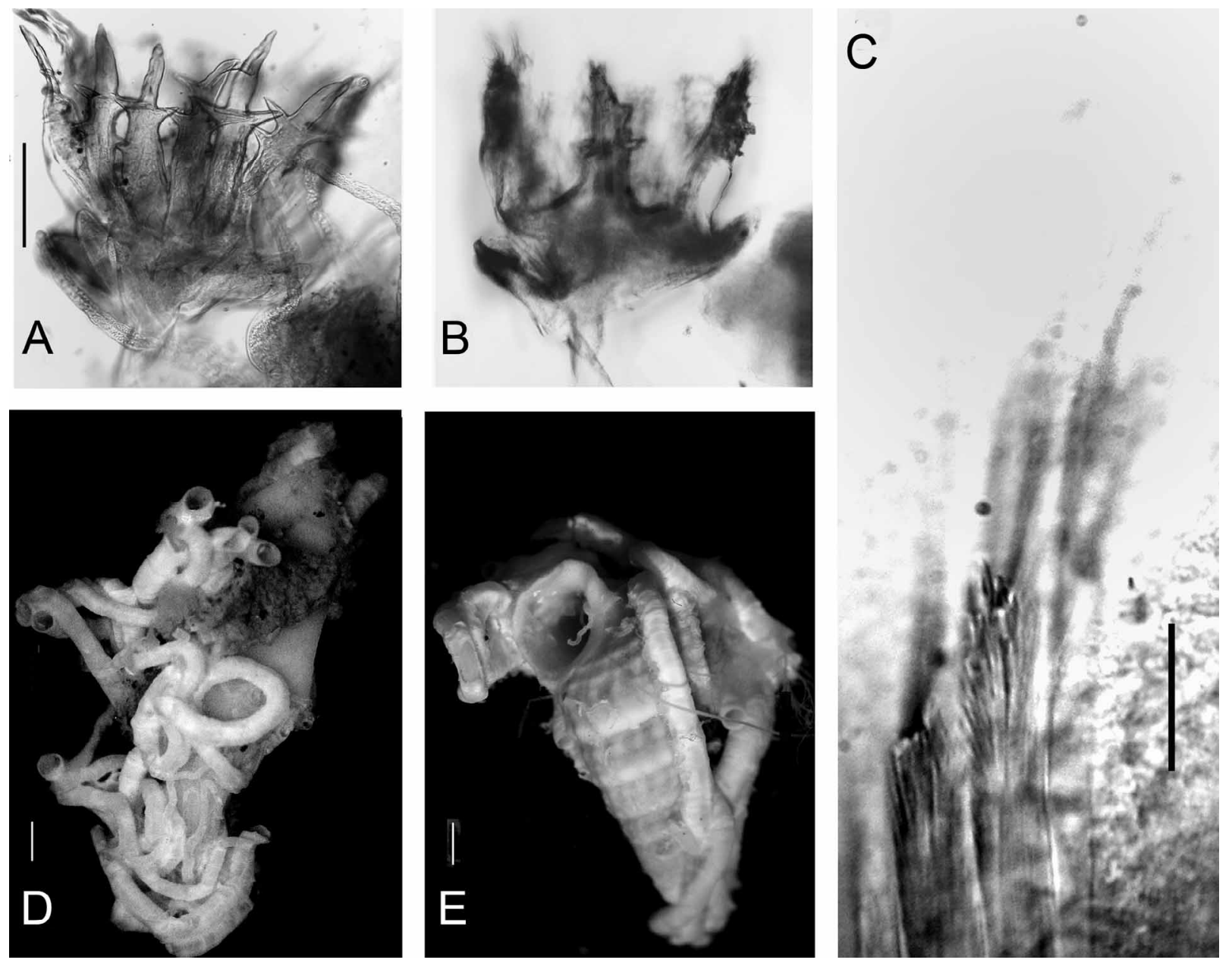

FIGURE 6. The very first serpulid collected from the Suez Canal—Hydroides elegans—from a boat hull, collected by the "Pola" Expedition (Isma'iliya, 17.X.1895, coll. Mus. Vindobonensis, Vienna, Evertebr. Varia, inv. no. 2034 [alte invert. no. 17199]), det. H. Zibrowius. A-Operculum photographed in methylene-blue-glycerine; focus on spines of upper verticil, B-Same, focusing on long tooth arising from the central disk of the verticil, $\mathrm{C}$ - Collar chaetae showing characteristic fine teeth and proximal rasp, D, E-Aggregates of tubes on gastropod, Potamides conicus; note the slightly flattened upper surface of the tube. Scales: A, B-100 $\mu \mathrm{m}, \mathrm{C}-50 \mu \mathrm{m}, \mathrm{D}, \mathrm{E}-1 \mathrm{~mm}$. 
SLC 117, 175 specs (109 juveniles, spot-checked); SLC 123, 2 specs (juveniles); Little Bitter Lake opp. Kabrit-Km 120: SLC 77, 1 spec.; SLC 85, 4 specs (1 juvenile); eastern shore rocky promontory: SBE 1, 1 spec.; Tis'a-Km 149: SLC 2, 1 spec.—Great Bitter Lake "Yellow Fleet" Biofouling Samples, January 13-20, 1975: $24+$ ? 1 subsamples, 33 + ?1 specs (13 of them juveniles, see App. Table 2D).-Lake Timsah, legit S.H. Shalla ca. 1984, det. H.A. ten Hove, ZMA V.Pol. 4997 (juveniles), 5000, 5001, 5002, altogether 17 specs, and juveniles (not enumerated).-El Tawan Beach, legit S.B. Shazly 10 / 19.XI.1988, det. H.A. ten Hove, ZMA V.Pol. 3817, 4 specs (App. Table 2E).

Locations adjacent to the Suez Canal, Red Sea side: Gulf of Suez, Suez, in crevice of stone on shore, legit C. Crossland 1904-1905, det. H. Zibrowius, confirmed H.A. ten Hove, BM(NH) ZB 1972: 22, 1 spec.Cambridge Expedition 6.X-29.XII.1924, 1 "new" BM(NH) sample from barge: Presumed Port Taufiq, 1 spec. (see App. Table 2A). — Gulf of Aqaba: Israel, Elat, 13 samples, 0.5-[6-8]-[40-46]-[81-90] m, HUJ.

Suez Canal Depth and Substrates: 0.2-10 m; on algae: Cystoseira myrica, Digenea, Laurencia, Sargassum; on sponge; on the gastropod, Murex forskoehli; on bivalves: Brachidontes pharaonis, Chama gryphoides, Chicoreus erythraeus, Crenatula picta, Fulvia fragilis, Fusinus verrucosus, Malvufundus normalis, M. regulus, Pinctada radiata, Spondylus spinosus, Pectinidae (not designated); on bryozoans; barnacles; crabs; tunicates; under rocks; on canal walls; on artificial substrates, e.g., on tin can submerged in mud, rubber fenders and iron frames.

Colouration. Lake Timsah field notes describe radioles with 5 red-orange stripes.

Distribution. Worldwide in (sub)tropical to temperate regions; port fouling species. Mediterranean: Israel, Egypt.

Remarks. Hydroides elegans' area of origin is believed to be Australia, its type locality (Zibrowius 1994). It was present in an 1888 harbour-fouling sample from Naples (RMNH 932; ZMA V.Pol. 3205). Its first published Mediterranean record, also from Naples, was by LoBianco (1892: 85) under the synonymous name H. pectinatus (Philippi, 1844). The first Levant Basin reference for Hydroides elegans (as H. norvegica), from 1924, was the specimen collected by the Cambridge Expedition from a buoy in Port Said (Potts 1928). All publications from the Suez Canal report it as the dominant fouling serpulid (see synonymy section, above). Hydroides elegans occurs worldwide in subtropical to temperate regions (northern and southern hemisphere), as opposed to the superficially similar congener, H. norvegicus Gunnerus, 1768 that has a mainly boreal and deeper Mediterranean distribution (see Zibrowius 1971: 717-721, 1973a: 683; ten Hove 1974: 46).

As apparent from the above list of regional synonyms, in recent years, the citations in the fouling literature of this area show increasing awareness that the principle fouling species is Hydroides elegans rather than $H$. norvegicus and many of the erroneous citations of $H$. "norvegicus" have been corrected retroactively. However, the references to Serpula sp. from these same fouling samples / same habitat (or of "S. concharum", or "S. vermicularis, mainly boreal species) suggest that individuals with primary (immature) opercula have been and are probably still being confused for species of the genus Serpula rather than being recognized as immature ontogenetic stages of Hydroides, presumably of H. elegans (see Moran 1984; ten Hove \& Ben-Eliahu 2005 for a review of the relevant ontogenetic history). Fortunately, H. elegans has rather distinctive collar chaetae (Figs 6C, 7C), and by spot-checking the collar chaetae, e.g., in sample SLC 117 and in the biofouling samples, it was possible to confirm that most of the juveniles in the present samples belonged to this species (H. elegans specimens listed as juvenile in App. Table 2A, C-E lack the upper verticil, but the characteristic collar chaetae showed them to belong to this species). The tube of H. elegans is characteristically smooth, without peristomes; flanges or prominent transversal ridges, usually with a narrow flattened area on the dorsal (upper) surface bordered by low smooth, not pronounced longitudinal ridges with a rounded transition to the sides of the tube (see Figs 5E, 6D, E; 7J-K). However, individuals with two prominent longitudinal ridges may also found (e.g., Fig. 5D), with the part of the tube between them appearing to be sunken. This generally confirms the finding of Bastida-Zavala \& ten Hove (2003b: 86). In minute tubes, a barely perceptible median "line" can be distinguished. Many tubes are sufficiently characteristic as to enable confident attribution to this species (e.g., Figs 7J, K; see App. Table 2). 

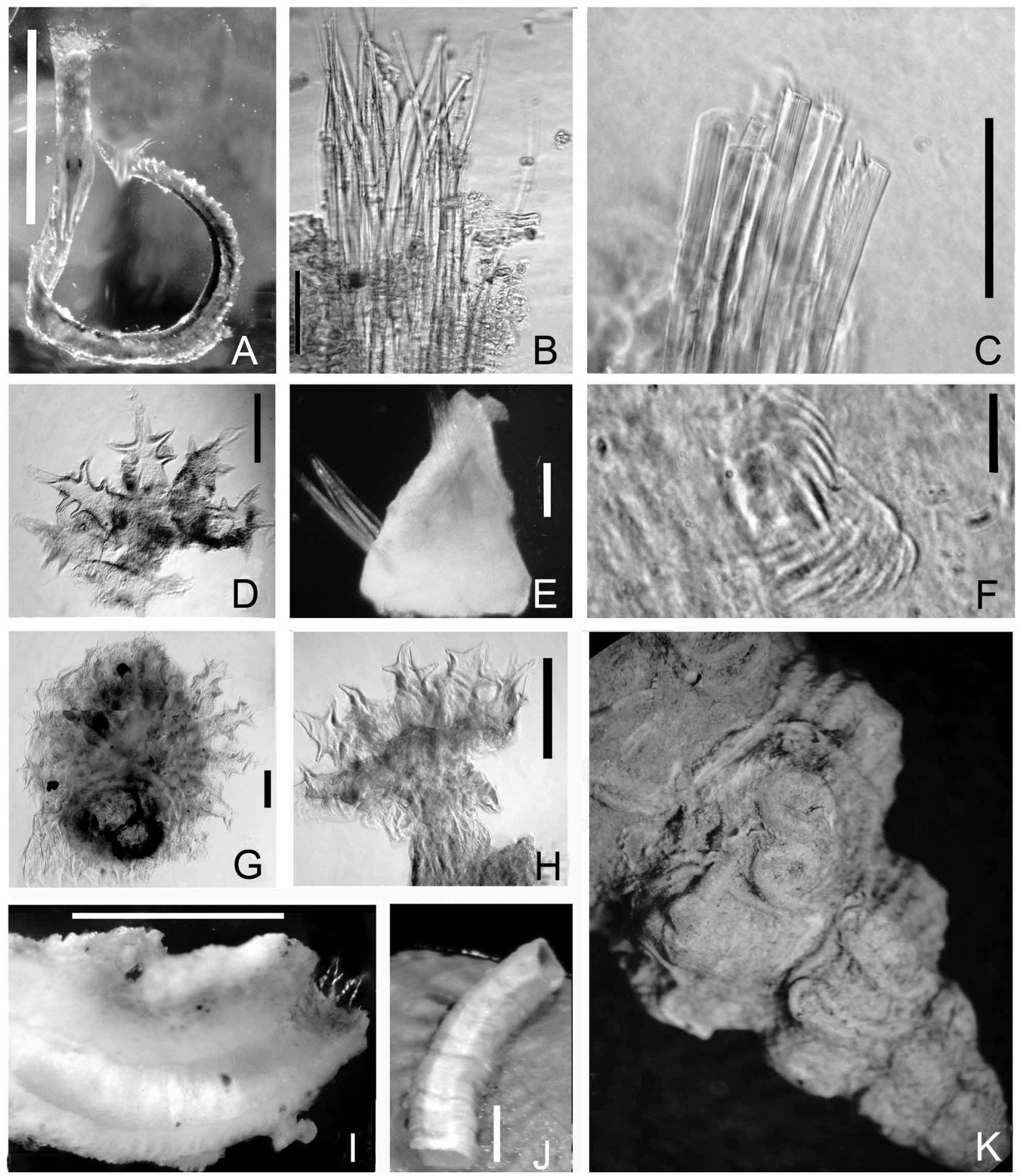

FIGURE 7. Taphonomic residues of Hydroides elegans from mollusc shells collected in the Great Bitter Lake in 1950 by C. Beets. The chitinous residues "survived" more than 50 years in the dried serpulid tubes. A-Body of dried worm, B-Thoracic chaetae, C-Broken but distinctive collar chaetae, D-Residue of verticil, E-Fragment of tube with adhering fascicles of thoracic chaetae (putative identification of species based on tube), F-Thoracic uncini (putative identification to species based on tube), G-Operculum, apical view of verticil, $\mathrm{H}-$ Operculum, $3 / 4$ view. I. Tube with projecting verticil, lower side of tube. J. Hydroides elegans tube fragment on shell of Gafrarium pectinatum, $\mathrm{K}-$ Fusinus polygonoides shell (ca. $11 \mathrm{~cm}$ in length), bearing tubes of $H$. elegans. Scales: A, B, D, E, I, J-1 mm; G, H-100 $\mu \mathrm{m}$; C, F-50 $\mu \mathrm{m}$. Figs A, B, D-F, I, K-from Beets' Stn 4, 0.2-0.8 m, C, G - from Stn 21, 1.5-3 m, H-from Stn 1: 1-2.7 m, J—from Stn 19: 5-5.5 m (for stations, see Beets (1953), Appendix Table 2B). 


\section{Hydroides heterocerus (Grube, 1868)}

Figs 5F, G, 8-10, presumably also Fig. 11

Serpula (Eupomatus) heterocerus Grube, 1868: 639, pl. 7, figs 8a-c [Type locality: Red Sea].

Hydroides heterocera [sic]: Zibrowius 1971: 715, figs 38-39, synonymy and redescription [Beirut; Gulf of Suez; southern Red Sea; Gulf of Aden, Djibouti; Mozambique; Persian (Arabian) Gulf]; Zibrowius 1979b: 133-134 [France, Toulon Port, biofouling removed from the aircraft carrier "Foch"].

Hydroides heterocerus: Zenetos et al. 2005: 73 [classified as an "established alien invasive species" in the Mediterranean].

Eastern Mediterranean

Hydroides heterocerus: Laubier 1966: 17 [Lebanon, first Mediterranean record of this Lessepsian migrant; 25-30 m, 1.IX.1965]; Ben-Eliahu \& ten Hove 1992: 35-53 [Israel, entire coast from north to south, 1-24 m]; Ilan et al. 1994: 45, 51-52 [Israel, 830 m]; Ben-Eliahu \& Fiege 1996: 33-34, 38 [Israel]; Ben-Eliahu \& Payiatas 1999: 101, 117 [Cyprus, Famagusta Harbour (empty tube), legit, det. H. Zibrowius 1998, first sample from Cyprus; Zibrowius \& Bitar 2003: 71 [Lebanon]; Çinar 2006: 227, fig. 4a-c [Levant coast of Turkey, Iskenderun Bay, 1-3 m, $11 \mathrm{~m}$, on rocks, X.2005].

Hydroides heterocera: Zibrowius \& Bitar 1981: 159-160 [Lebanon, Beirut, Zaitouné, 5 m, on bivalve, 23.IX.1978]; BenEliahu 1991b: 518, 520-522 [Lebanon, Israel].

\section{Suez Canal}

Hydroides heteroceros [sic]: Potts 1928: 700 [from El Qantara, Km 46 and Km 152, collected in 1924 (see "Material examined", below]; Ben-Eliahu 1972c: 232, Table 2 [citing Potts 1928, Laubier 1966].

Hydroides heterocerus: Ben-Eliahu 1972a: 77 [citing Potts 1928]; Wehe \& Fiege 2002: 126 [Suez Canal; list of references].

Hydroides heterocera: Selim 1997b: 92-93, fig. 5a-f [from Deversoir; Lake Timsah, collected in 1988, citing Mostafa 1992, see App. Table 4].

Gulf of Suez and Gulf of Aqaba

Hydroides heteroceros [sic]: Pixell 1913: 75, pl. 8 figs 2a-c [Gulf of Suez, wall of Suez quay, collected in 1905; Red Sea, Sudan; Suakin Harbour (see "Material examined", below); Zanzibar]; Fauvel 1933a: 77 [Gulf of Suez, St. 17 bis, $33^{\circ} 23^{\prime} \mathrm{E}, 28^{\circ} 14^{\prime} \mathrm{N}$; and ter, $33^{\circ} 23^{\prime}-33^{\circ} 24^{\prime} \mathrm{E}, 28^{\circ} 12-28^{\circ} 14^{\prime} \mathrm{N}$ ]; Fishelson 1971: 126, table 4 [Gulf of Aqaba, infratidal rocks]; Ghobashy \& Ghobashy 2005: 94, Suez Bay, buoys, misquote of El-Komi et al. 1998.

Hydroides heterocera: El-Komi et al. 1998: 16 [Suez Bay, 1992-1993, buoys].

Red Sea proper-Indo-West-Pacific (excluding citations from Gulf of Suez and Gulf of Aqaba already given above)

Serpula (Eupomatus) heterocerus Grube 1868: 639, pl. 7 figs 8 a-c [Type locality: Red Sea].

Serpula (Hydroides) uncinata not (Philippi), sensu Gravier 1906b: 110 [South Red Sea]; Gravier 1908: 114-115, figs 463-466, pl. 8, figs 286-287, both citations synonymised by Zibrowius 1971: 715 [South Red Sea].

Hydroides heteroceros [sic]: Wesenberg-Lund 1949: 357-358, fig. 46b [Persian (Arabian) Gulf]; Day 1967: 807-808, figs 38.4.1 [Red Sea, Indian Ocean, Madagascar]; Fishelson 1971: 126, table 4 [Red Sea]; Mohammad 1971: 301 [Persian (Arabian) Gulf: Kuwait]; Hartman 1974: 200 [Arabian Sea].

Hydroides heterocerus: Fishelson \& Rullier 1969: 101-102 [S. Red Sea, Musseri Isl. (see "Material examined", below]; Ishaq \& Mustaquim 1996: 168, figs 4a-i [Arabian Sea, Pakistan]; Wehe \& Fiege 2002: 126-127 [Red Sea, Persian (Arabian) Gulf, Gulf of Aden, Arabian Sea; list of references].

Hydroides heterocera: Vine \& Bailey-Brock 1984: 141. 

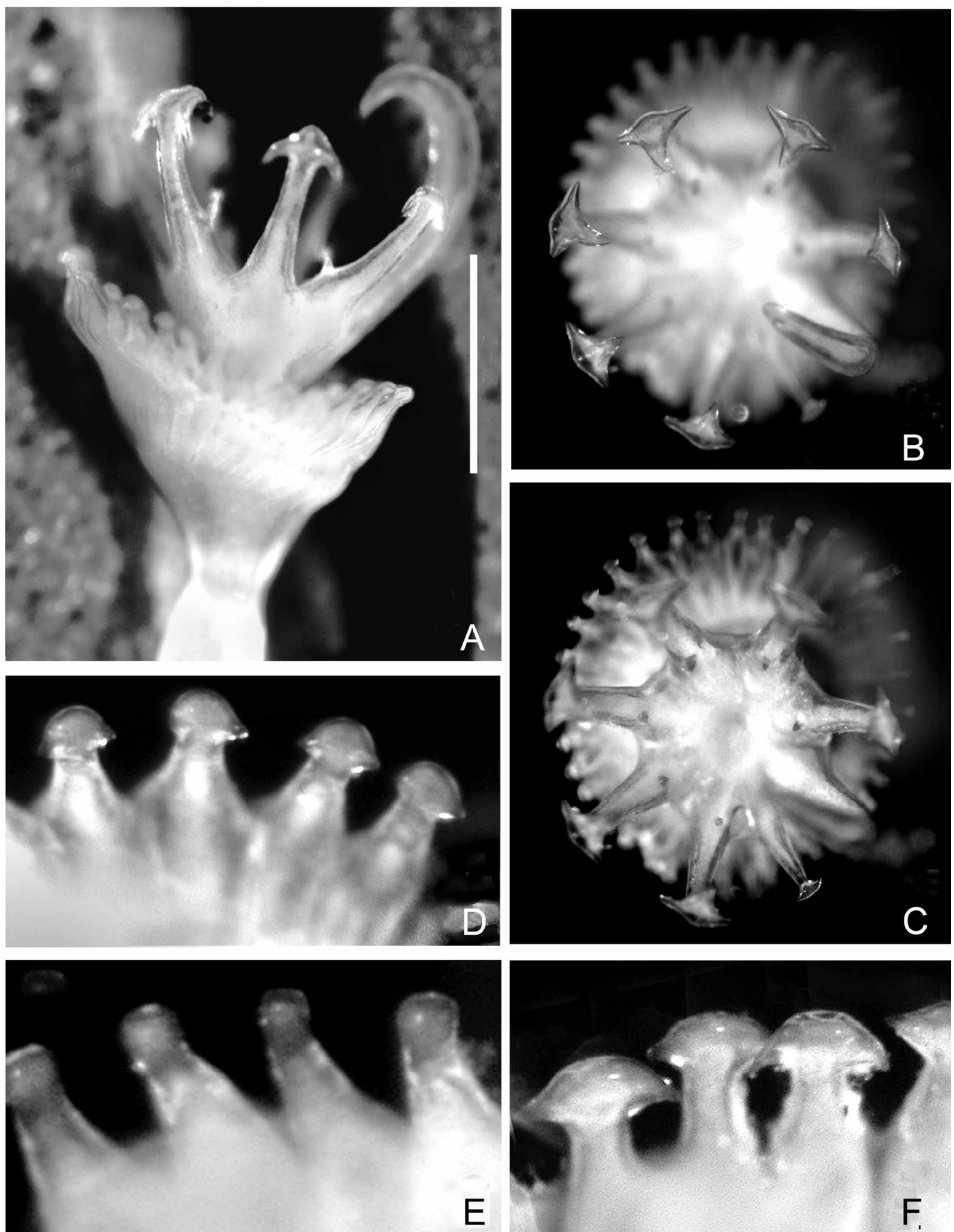

FIGURE 8. Hydroides heterocerus. Variability in forms of opercula from different regions: A-D. Operculum of specimen from the Great Bitter Lake aggregate removed by J.P. Taasen from the M/S "Münsterland" after its journey to the Hapag-Lloyd dry dock in Bremerhaven (18.VI.1975, 7 m). A-Lateral view, B-D-Apical views, B-Focus on tips of verticil spines, C-Focus on basal spinules of verticil, D-Enlargement of marginal teeth of funnel; the expansion of the tips of the marginal teeth in "D" is intermediate between "E" and "F," E- "Bowling-pin-shaped" radii with blunt or even stubby tips, specimen from Little Bitter Lake opposite Kabrit (sample SLC 123), F-More expanded, "T"-shaped tips found in specimen from the Sudanese Red Sea (BM(NH) 1972.23, legit C. Crossland, 1904-1905). Lessepsian migrants with marginal radii like "D" or like "E". Scale: $1 \mathrm{~mm}$. 

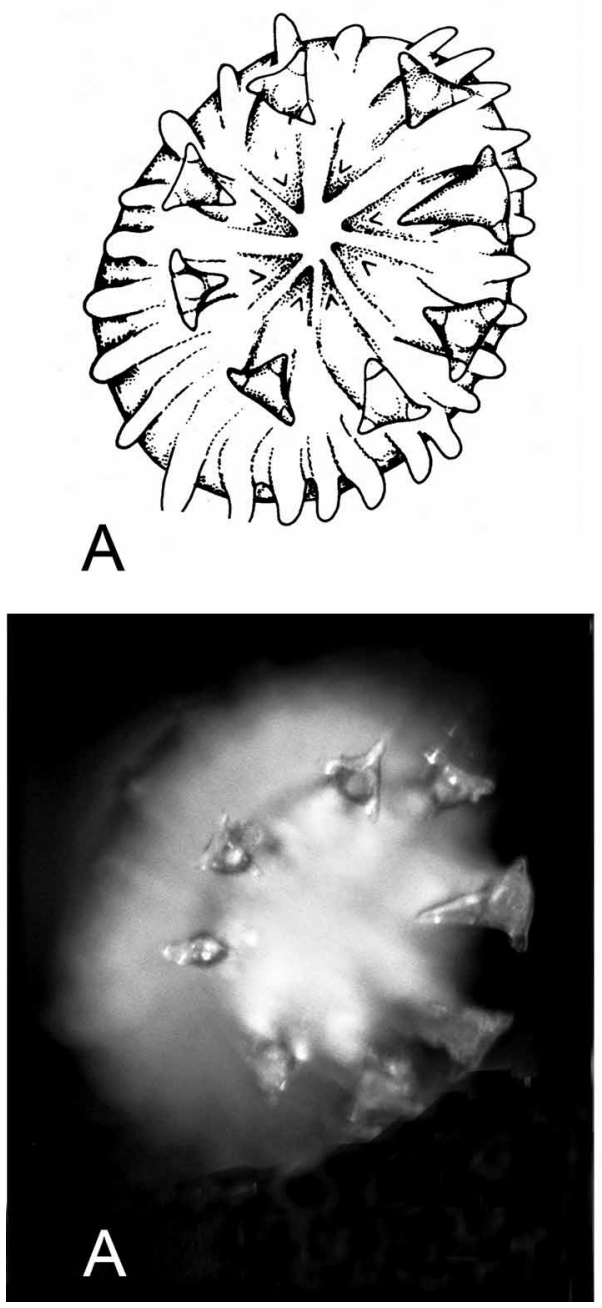
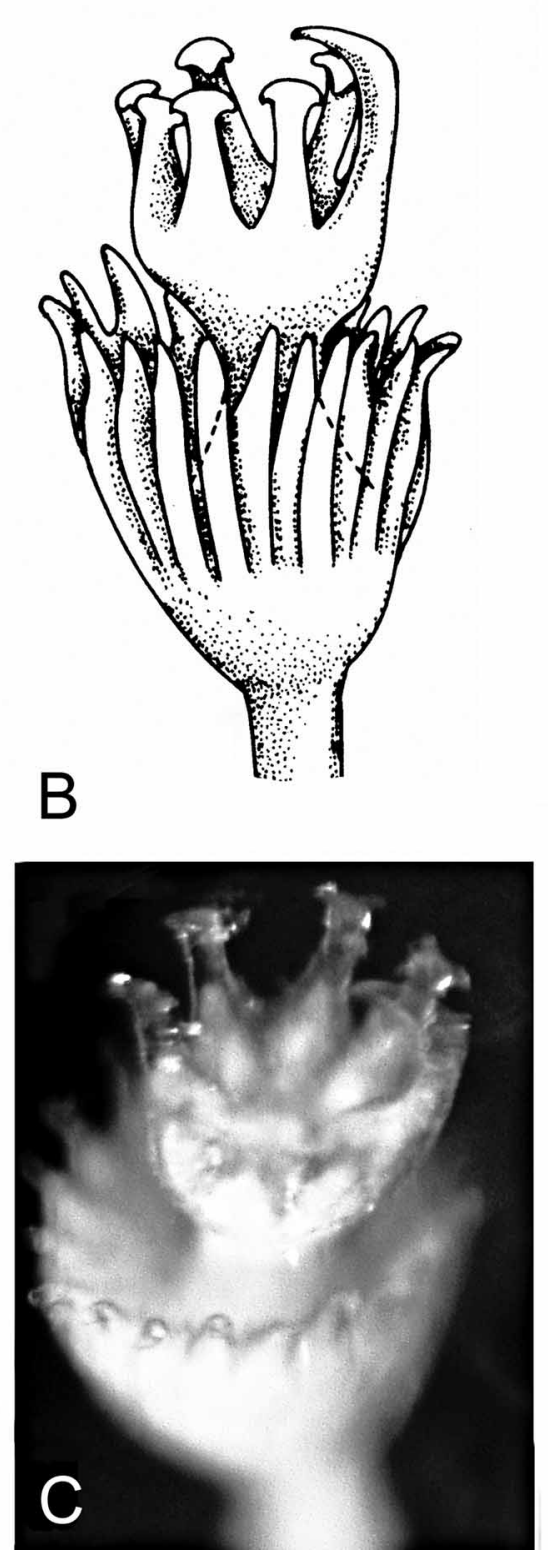
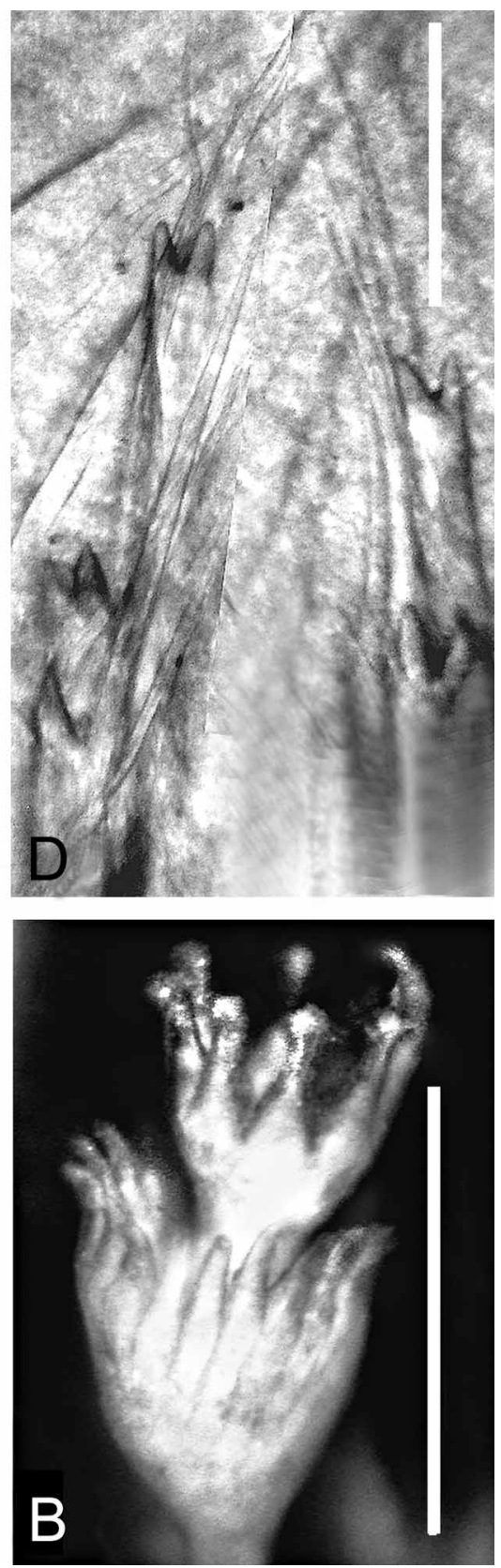

FIGURE 9. Operculum of Hydroides heterocerus juvenile form no. 1 (specimen from Cambridge Expedition mollusc deposited at the Natural History Museum in London, precise location unknown [See App. Table 2A]). A-Apical view, drawing and photograph, respectively, B-Profile view of drawing and photograph, C-Three-quarters view; note sharply pointed marginal teeth of funnel radii (in contrast with those in Fig. 8), D-Collar chaetae (magnification, $<10$ x). Scales: $\mathrm{B}-0.5 \mathrm{~mm}, \mathrm{D}-100 \mu \mathrm{m}$.

Material examined (Figs 8-10, presumably also Fig. 11): Locations adjacent to the Suez Canal, Mediterranean side: Israel: 20 samples, [1]-[8-10]-[18-22]-33 m (830 m outlier record); INCNH unpublished data, first Israeli sample, Haifa Port, legit G. Haas, 22.III.1937, det. M.N. Ben-Eliahu, HUJ-Poly-878 (previously AN-II-05).

Suez Canal proper: Cambridge Expedition, El Qantara, det. F.A. Potts, CUZM-AN.I.1930, 1 spec., verticil with taller dorsal spine +6 spines with lateral spinules, processes with lateral spinules positioned rather high (subdistally); 32 radii in funnel, 21 radioles, ca. $22 \mathrm{~mm}$.

Suez Canal material reported herein: 35 samples with 106+ ?4 specs of which 4 belong to juvenile forms 1 and 2: One "new" Cambridge Expedition sample separated from a mollusc deposited at BM(NH); this 
single juvenile specimen preliminary named "form no. 1" (Fig. 9) proved to be a Hydroides heterocerus juvenile (precise location in the canal not known [see App. Table 2A]). - Hebrew University-Smithsonian Expeditions, 1967-1973: 4 samples, 4 specs of which two were the juvenile forms named nos. 1 and 2. Great Bitter Lake, east of Deversoir-Km 97: SLC 72, 1 spec.; SLC 74, 1 spec., juvenile form no. 1. Great Bitter Lake: SLC 117, 1 spec., juvenile form no. 2 (Fig. 10). SLC 123, 1 spec.-Great Bitter Lake "Yellow Fleet" Biofouling Samples, January 13-20, 1975: 25 +? 1 subsamples, 90 (1 juvenile) + ?4 specs.-Bremerhaven dry dock, 18.VI.1975, 3 subsamples, 11 specs, all decaying; one notably large tube, ca. $4 \mathrm{~mm}$ outer diameter; worm without operculum $4.7 \mathrm{~cm}$ (branchia $6 \mathrm{~mm}$ ) / $3 \mathrm{~mm}$ width.-Lake Timsah, El Tawan Beach, legit S.B. Shazly 10 / 19.XI.1988, ZMA V.Pol. 3819, 1 spec.

Locations adjacent to the Suez Canal, Red Sea side: Gulf of Suez, J.K. Lord Expedition of 1870, det. H.A. ten Hove 1969 (separated from a mixed sample BM(NH) 1870:12:23:31 by HAtH 1969, see Material Examined S. tetraceros), BM(NH) 1870:12:23:61, specimen bioperculate, body rotted with epidermis abraded.-Gulf of Suez, Suez Quay, 3.7-18.3 m, legit J.S. Gardiner 1905 (the Percy Sladen Trust Expedition), det. H.L.M. Pixell (1913, Pl. 8, figs 2a-c), confirmed M.N. Ben-Eliahu, several specs.—?Gulf of Suez, Suez, Stn R5, Cambridge Expedition, 1924, CUZM AN.I.1930, empty coiled tube, present in test-tube with Serpula vermicularis not Linnaeus, sensu Potts (1928: 700), presumably tube of Hydroides heterocerus (Fig. 11).

Gulf of Aqaba: No records.

Red Sea: Sudan, Suakin Harbour, legit C. Crossland 1904-1905, det. H.L.M. Pixell, H. Zibrowius, $\mathrm{BM}(\mathrm{NH})$ 1972.23, tube lacking, permanent mount dated 20.VII.1904.-Eritrea, Dahlak Archipelago, Musseri Island, 15³7’ N, 4043' E, 27.5 m, Israel South Red Sea Expedition 1965, Stn 10, legit Ch. Lewinsohn 23.X.1965, det. F. Rullier, TAU-NS-1873, $1 \mathrm{spec}$.

Gulf of Aden: Somalia, Ras Katib, outside harbour on a block of dead coral, legit, det. T.G. Pillai 29.III.1982, ZMA V.Pol. 3851, 2 specs.

Suez Canal depth and substrates: Shallow, 1-2.5 m, $10 \mathrm{~m}$; on sponges; on bivalves, Brachidontes pharaonis and Spondylus spinosus; on barnacles, bryozoans, tunicates; on sandstone; on artificial substrates: Rubber fenders and iron frames.

Distribution. Indo-West Pacific: Red Sea, Zanzibar, Madagascar, Persian (Arabian) Gulf, Sri Lanka, ?New Caledonia. Lessepsian migrant to the Mediterranean: Israel, Lebanon, Cyprus, Turkey.

Remarks. Potts (1928: 700-701) noted: "In one specimen, lateral processes of spines were 1/3 length from the apical process, in the other, just under the apical process. Other authors have shown that there is a great deal of variation in their position." A non-quantitative survey of the present material showed that most of the lateral spinules were positioned close to the apical process (e.g., Fig. 8A) and there appeared to be some variability in height of the spines in different individuals (a more thorough analysis of these characters is intended). Much more pronounced is the variability in the form of the marginal radii of the opercular funnel, ranging from "bowling-pin-shaped" radii with blunt or even stubby tips (Wesenberg-Lund 1949 and Ishaq \& Mustaquim 1996, respectively; Fig. 8E) to those with more developed side spinules as in Fig. 8D, "T" or "anchor-shape" tips (Pixell 1913, Zibrowius 1971; Fig. 8F), with intermediate forms between them. Specimens from the Sudanese Red Sea (Fig. 8F) had much more developed side spinules than those in the Suez Canal population where the most developed of the side spinules were like those of Fig. 8D; and less like Fig. $8 \mathrm{E}$. The number of verticil spines with lateral spinules in the both the Suez Canal population and the Lessepsian migrant population ranged from 5-7, $5.59 \pm 0.53$ spines, $N=59$, Suez Canal and $5.78 \pm 0.64, N=27$, the Lessepsian migrant population, respectively, the differences between them were not significant (T-test, $p=$ 0.198). Çinar (2006 fig. 4a, b) shows the tips of the marginal radii of the Lessepsian migrant from the Levant coast of Turkey to be like those of the Suez Canal population (Fig. 8E).

Specimens removed from the "Münsterland" in the Great Bitter Lake in January 1975 were large: The largest, $63 \mathrm{~mm}$; verticil with 1+6 spines; funnel with anchor-tip to rounded marginal radii. However, the material sampled from the "Münsterland" in the Bremerhaven dry dock (in June 1975, 6 months later) gave the impression of even larger size (one tube had an outer diameter of $4 \mathrm{~mm}$; the tubes were the largest of any taxon present in the assemblage) and many tubes were coiled. Most of the Hydroides heterocerus tubes from 
the Suez Canal were rounded (anterior end not attached to substrate) with marked transversal ridges; only 3 showed three longitudinal ridges, most marked in a small specimen (Fig. 5G), less marked in the two others. We believe that the large coiled tube found in Potts' (1928) nominal Serpula "vermicularis" sample from the Gulf of Suez rather belongs to H. heterocerus (Fig. 11). Lessepsian migrant $H$. heterocerus specimens had marginal teeth like Figs $8 \mathrm{D}$ or $\mathrm{E}$, or forms ranging between them.

Juvenile specimens: The operculum of the juvenile form from the Cambridge Expedition (form we named, "no. 1", App. Table 2A), had sharply pointed radii tips in the funnel (Figs 9B, C), a marked deviation from the species description. A second specimen was obtained when searching through Brattström and Taasen's biofouling material from the Great Bitter Lake. We attribute form "no. 1" to Hydroides heterocerus, taking note of the variability in form that can prevail during Hydroides ontogeny (see ten Hove \& Ben-Eliahu 2005). A single juvenile specimen, "form no. 2", was similarly found in the biofouling samples. In contrast, the funnel of this specimen had expanded T- or anchor-shaped marginal teeth; some of its verticil spines were characteristic for Hydroides heterocerus, while others appeared to be deviant, malformed (Figs 10A, B). We attribute this specimen to Hydroides heterocerus as well. In studying the Hydroides heterocerus population from the Great Bitter Lake, we encountered additional specimens with malformations such as a lateral spinule on the dorsal verticil spine, or a stub of a verticil spine rather than a fully developed one.
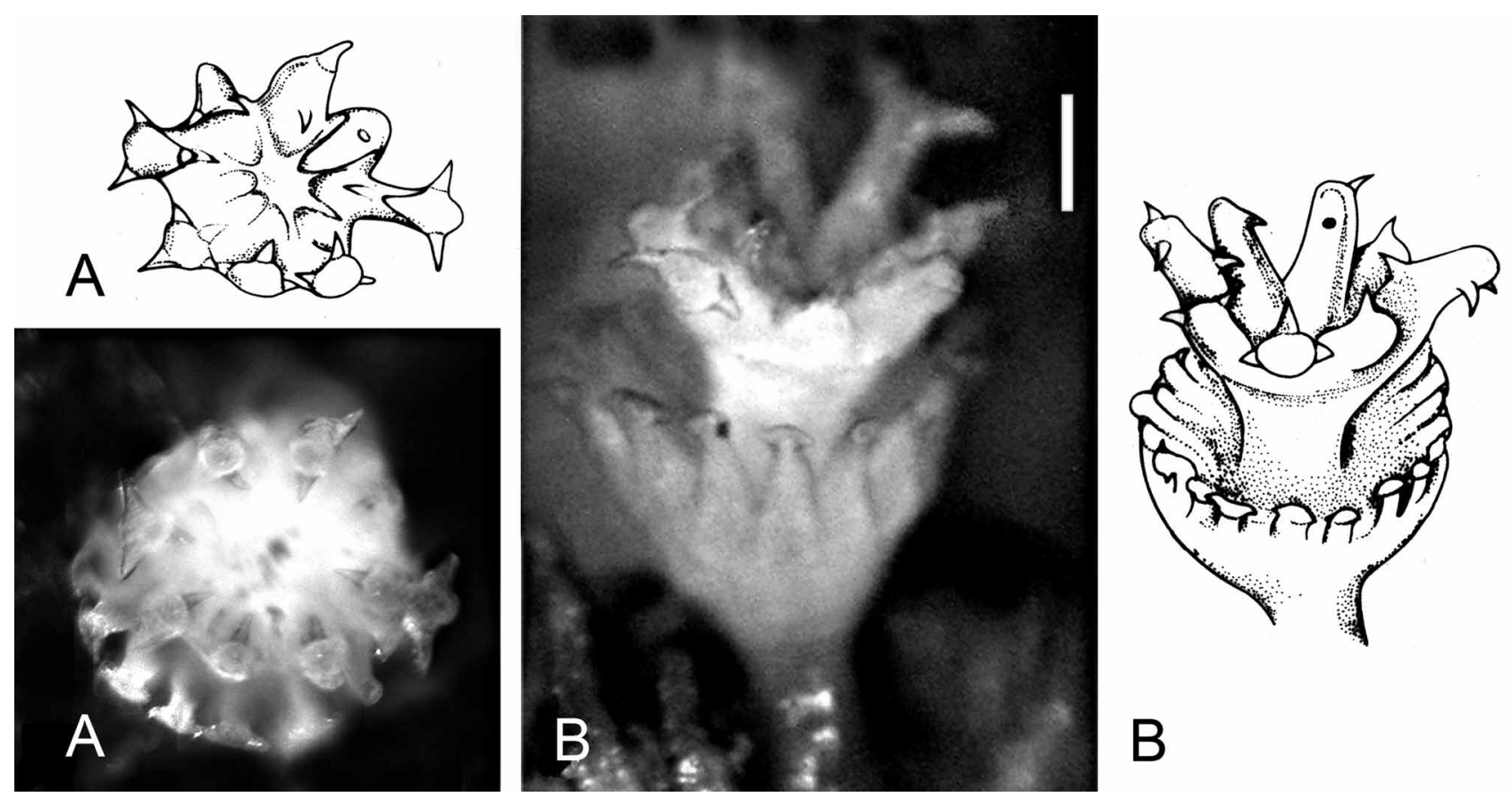

FIGURE 10. Operculum of Hydroides heterocerus juvenile form no. 2 (specimen scraped from mollusc from the Great Bitter Lake [SLC 117, Y. Eytam, St. 4]). A, B-Funnel radii with some typical "anchor-shaped" (T-shaped) tips; some verticil spines approaching typical adult form, other spines deviating from the typical form, e.g., dorsal spine, upper right, bifid, aberrant. Scale: $100 \mu \mathrm{m}$. 

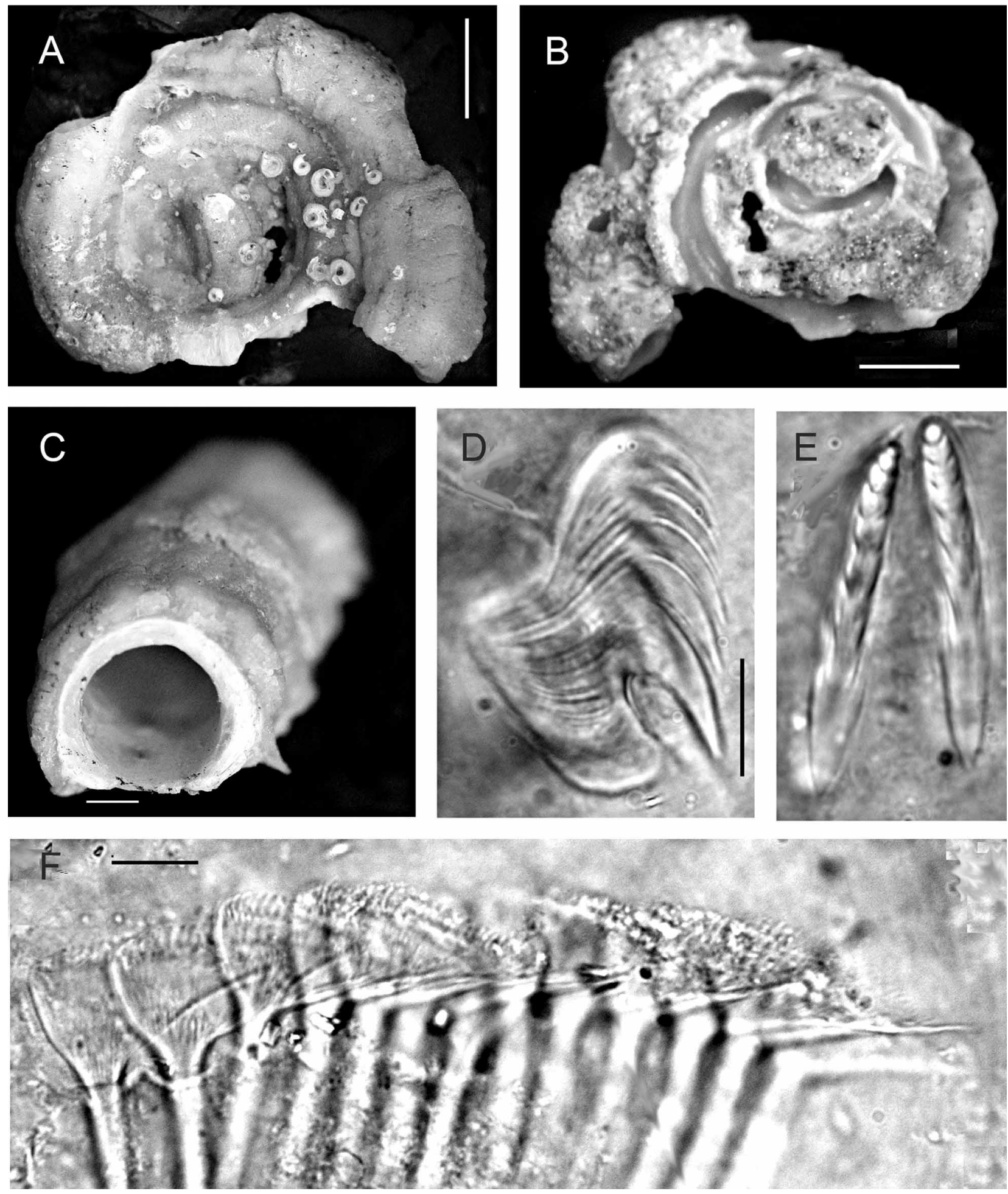

FIGURE 11. Large spiralled serpulid tube. The tube was present in the test-tube labelled "Serpula vermicularis" by F.A. Potts but should rather be attributed to Hydroides heterocerus (The nominal "Serpula vermicularis" specimen collected by the Cambridge Expedition in the Gulf of Suez that was described in detail by Potts 1928 was no longer present [CUZM]). The abdominal uncini and chaetae shown below were found on skin still attached to the lumen of the tube. A-Upper view of tube (note spirorbid tubes encrusted on outer surface of the tube), B-Ventral view of tube, C-3/4 frontal view of tube, D-Abdominal uncinus, lateral view, F+5, E-Same, frontal view, left, F+10, F-Abdominal chaetae. Scales: A, B-5 mm, C-1 mm, D, F-10 $\mu \mathrm{m}$. 


\section{Hydroides homoceros Pixell, 1913}

Figs 5H, I, 12

Hydroides homoceros Pixell, 1913: 74-75, pl. 8 fig. 1 [Type localities: Red Sea, Sudan, Suakin; Indian Ocean, Zanzibar, Maldives (9 syntypes, see "Material examined", below)]; Zibrowius 1979b: 133-134 [France, Toulon Port, biofouling removed from the aircraft carrier "Foch"; marginal radii of specimens with 2 pairs of lateral processes (H. Zibrowius, pers. comm.)]; Zenetos et al. 2005: 73 [classified as an "established alien invasive species" in the Mediterranean].

\section{Eastern Mediterranean}

Hydroides homocera: Ben-Eliahu \& ten Hove 1989: 393; Ben-Eliahu 1991b: 515-528, fig. 3 [Israel]; Ben-Eliahu \& ten Hove 1992: 35-53 [Israel]. All three records with single-anchor-shaped marginal radii of funnel (see Fig. 12E).

Hydroides homoceros: Ben-Eliahu \& Fiege 1996: 33-34, 38 [Israel]; ten Hove \& Ben-Eliahu 2005: 127-145, figs 2a, a', a" [Israel, 18-24 m]; Çinar 2006: 228, figs 4 d-f [Levant coast of Turkey, Iskenderun Bay, 1-3 m, X.2005, population with "spur-tipped-anchor-shaped" marginal radii (Fig. 12B, also depicted by ten Hove 1970a figs 1a-c in specimens from the Persian (Arabian) Gulf), differing from the Israeli population that lacks the spur (Fig. 12E)].

Suez Canal

Hydroides homocera: Ben-Eliahu 1991b: 526, fig. 5 [Great Bitter Lake, collected on 13.I.1969, marginal radii of funnel single-anchor-shaped (see Figs 12A, D)].

Gulf of Suez

(1968) Hydroides homocera: Ben-Eliahu 1991b: 526, fig. 5 [Gulf of Suez, El Bilayim lagoon, first record from Gulf of Suez, collected 10.VI.1968, sample SLR1753 (Por et al. 1972); on Pectinidae. Marginal radii of funnel single anchor-shaped]; Selim 1997b: 93-94, figs 6a-e [Gulf of Suez, Port Taufiq, collected in 1988].

Red Sea, proper-Indo-West-Pacific (excluding citations from Gulf of Suez and Gulf of Aqaba already given above) Hydroides homoceros Pixell, 1913: 74-75, pl. 8 fig. 1 [Red Sea spec. with "double-T" (“double-anchor”) marginal radii; Indian Ocean (see "Material examined", below)]; Monro 1937: 316 [Indian Ocean: Zanzibar, Arabian coast, Maldives, 2 specs. First "resembling Pixell's descriptions and figure," thus, with "double-anchor" marginal radii]; Wesenberg-Lund 1949: 356-357, fig. 46a [Persian (Arabian) Gulf; marginal radii of funnel single-anchor-shaped, see Figs 12A, D, E]; ten Hove 1970a: 55, figs 1a-c [Persian (Arabian) Gulf (see "Material examined", below); marginal teeth with "more or less blunt" spur surmounting single anchor-shaped form, see Fig. 12B]; Mohammad 1971: 301 [Persian (Arabian) Gulf, Kuwait; the marginal teeth show a range from Figs. 12B to C as in the Pixell syntypes (present paper)]; Mohammad 1976: 133 [Persian (Arabian) Gulf: Kuwait, the marginal teeth show a range from Figs 12B to C (present paper)]; Mohammad 1981: 131 [Persian (Arabian) Gulf, Kuwait; marginal teeth as above)]; BenEliahu 1991b: 526, fig. 5 [south Red Sea: Dahlak Archipelago, marginal radii double-anchor-shapes, as in Fig. 12C; ten Hove 1994: 107-114 [Indian Ocean, Seychelles Islands; opercula with marginal radii in-between form of Figs 12B and C, thus, with 2 pairs of lateral processes "double-anchor", with the tip not rounded but flat, almost indented), present paper]; Wehe \& Fiege 2002: 127 [Persian Gulf, Arabian Sea; list of references].

Material examined. Locations adjacent to the Suez Canal, Mediterranean side: Israel: 14 samples, 22 specs. First Mediterranean record of this Lessepsian migrant, INCNH data unpublished, Haifa Bay, 32 m, on Mimachlamys varia, legit E. Gilat (Gilat91) 21.X.1955, det. M.N. Ben-Eliahu ca. 1969, marginal radii singleanchor-shaped as figured by Wesenberg-Lund (1949, fig. 46a), see Fig. 12E, TAU-NS (no number), 1 spec.Egypt, Sinai: 2 samples. Depth: 9-[22-32]-55 m.

Suez Canal material reported herein: 8 samples with 38 specs. Beets' Great Bitter Lake samples, no taphonomic residues found, tubes provisionally identified as those of H. homoceros in at least 4 samplesHebrew University-Smithsonian Expeditions, 1967-1973, 3 samples, 33 specs: Great Bitter Lake, SLC 117, 31 specs; east of Deversoir, Km 97, SLC 50, 1 spec.; SLC 52, 1 spec., marginal radii of funnel single-anchorshaped, see Figs 12A, D.—Great Bitter Lake "Yellow Fleet" Biofouling Samples, January 13-20, 1975: 4 subsamples, 4 specs. Bremerhaven dry dock, 1 spec.

Locations adjacent to the Suez Canal, Red Sea side: Gulf of Suez, 1 sample.-Gulf of Aqaba: No records.

Red Sea: South Red Sea: 2 samples (? m, 36.6 m). 
Sudan, Suakin Harbour, legit C. Crossland 7.II.1905, BM(NH) 1924.6.13.145, 1 spec., syntype, marginal radii with 2 pairs of recurved lateral processes, i.e., "double-anchor-shaped" (Pixell, 1913, pl. 8 fig. 1a as in Fig. 12C).-Eritrea, Dahlak Archipelago, 15³5' N, 4044', 36.6 m, on Malleidae, legit Ch. Lewinsohn, 23.X.1965, Israel South Red Sea Expedition, 19085 Stn 12, det. M.N. Ben-Eliahu ca. 1985, marginal radii of funnel double-anchor-shaped, as in Fig. 12C.

Indian Ocean, Tanzania, off Zanzibar, scraped from the bottom of the "Juba," legit C. Crossland, 19011902, 4 syntypes and slide of collar chaetae and uncini, BM(NH) 1924.6.13.147; although Pixell did not refer to variation in the form of the opercular spines, marginal radii of syntypes range from spur-tipped singleanchor to a more developed spur approaching double-anchor form (Pixell, 1913, pl. 8 fig. 1a), i.e., a range in form between Figs 12B to C (present paper).

Arabian Sea: South Arabian Coast, 13.5 m, John Murray stn 53, 2.XI.1933, det. C.C.A. Monro, BM(NH) 1937.9.2.540-1, 2 specs, marginal radii as in Pixell (1913), and as in Figs 12B to C.-Oman, Gulf of Masirah, Masirah Island, Ras Al Ya; low tide, under stones, Stn 91 / 105, legit R.G. Moolenbeek \& H. Dekker, 23.XI.1991, ZMA V.Pol. 3838, marginal radii with spur-tipped single-anchor, see Fig. 12B.

Gulf of Oman, N. Oman, Khor al Quway, north-south running strait, gentle current, from east side of strait, 18.3-36.6 m, Royal Geographical Society (of Great Britain) Musandam Expedition, 1971-72, legit P.E.S. Cornelius; extracted and det. by H. Zibrowius 1972 from dead coral fragments from sandy bottom and limestone area, on coelenterates, BM(NH) 1972:217, marginal radii double-anchor-shaped, as in Fig. 12C.

Strait of Hormuz, 5 miles S.E. of the Tunb light, $26^{\circ} 12^{\prime}$ N, 55 $22^{\prime} \mathrm{E}, 38-60 \mathrm{~m}$, Petersen-grab, 7.IV.1938, gravel and shells, Danish Expedition Stn 118, legit B. Løppenthin, det. E. Wesenberg-Lund (1949: 380-381), redet. H.A. ten Hove II.2000, ZMUC, marginal radii of funnel single-anchor-shaped, see Figs 12A, D, E.

Persian (Arabian) Gulf. Sample details unknown, legit Ø. Støckland ca. 2004, det. M.N. Ben-Eliahu XI.2004, marginal radii with single pair of lateral processes topped by a more or less expanded tip (cf., ten Hove 1970a, figs 1a-c), similarly from the Persian (Arabian) Gulf, Fig. 12B.-Bahrain, 4 miles E.N.E. of Bahrain light-ship, Stn 87, m ?, legit B. Løppenthin 20.III.1928, ZMA V.Pol. 3002, marginal radii with one pair of recurved lateral pinnules, surmounted by spur (as in ten Hove 1970a, figs 1a-c), more recurved, i.e., more anchor-shaped than those in Fig. 12B.

Suez Canal depth and substrates: Shallow-10 m, on algae: Digenea; sponges; on bivalve, Spondylus spinosus; on tunicate.

Distribution. Lessepsian migrant to the Mediterranean: Israel, Turkey; Suez Canal; Red Sea: Gulf of Suez, Dahlak Archipelago; Indian Ocean: Zanzibar, Seychelles, South Arabian coast, Persian (Arabian) Gulf, Maldives. May occur in living corals (Millepora, Porites).

Remarks. Tube with 3 prominent longitudinal ridges of equal height; transversal ridges not prominent, giving the tube relatively smooth sides (ten Hove 1970a: 55, figs 1-8; Figs 5H-I). Very slight pink cast in some tubes. Of ca. 20 inhabited tubes, the longitudinal ridges were prominent in nearly all the tubes (although not equally prominent throughout the length of the tube, e.g., one of four fragments of the single tube in Fig. 5H appears covered with a granular layer). Some of the three-ridged tubes on Beets' shells were provisionally identified as Hydroides homoceros (see App. Table 2B), however, due to the lack of taphonomic residues, presence in the Canal in 1950 is considered as likely but not conclusive. The first complete specimens (inhabited tubes), were collected in the Great Bitter Lake (east of Deversoir-Km 97 [SLC50] in 1969, see App. Table 2C).

The operculum of Hydroides homoceros, and specifically the tips of the marginal radii of the funnels, shows an interesting variability in form (Figs 12A-E) and all of the forms are present in the Persian Gulf. The "double-anchor" (Pixell 1913) and "single-anchor" (Wesenberg-Lund 1949) forms can be considered as the most extreme of these forms. The proximal paired lateral spinules may range in form from anchor-shaped to a more pointed "T-shaped" as in Figs 12D-B. A distal pair of lateral spinules may be developed similar to the proximal pair (= "double-anchor", Fig. 12C), or the distal lateral spinules may be reduced to a more or less rounded spur, "spur-tipped-T-shaped" (Fig. 12B); alternatively, distal lateral spinules may be lacking entirely (Fig. 12D). 


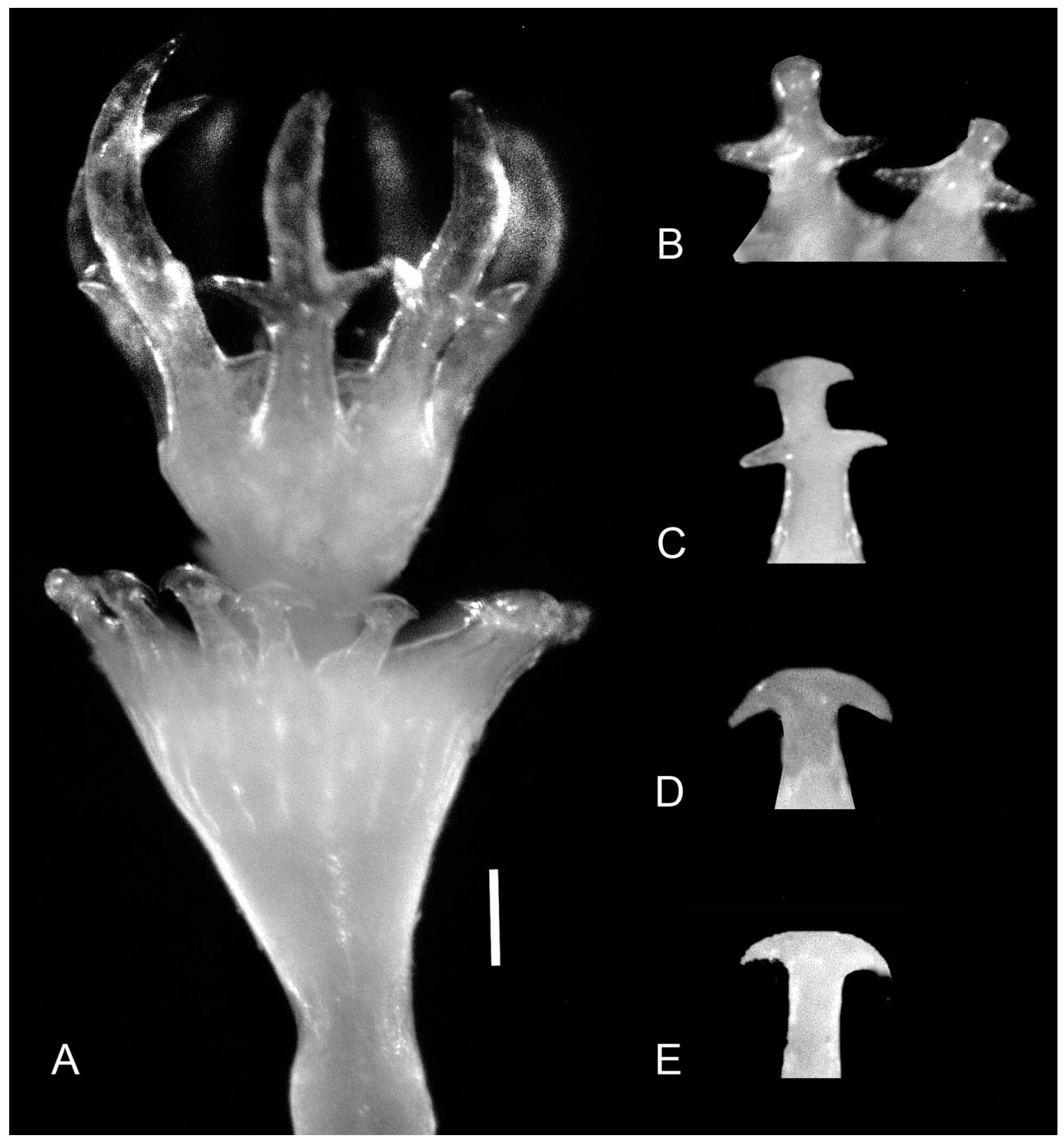

FIGURE 12. Variability in opercula of Hydroides homoceros from different regions. A-Operculum characterized by "single-anchor-shaped" (or T-shaped) marginal radii (see also "D") from Great Bitter Lake population (sample SLC 117, see App. Table 2C), B-Specimen with "spur-tipped-T-shaped" marginal radii from the Persian (Arabian) Gulf, leg. anon., sample sent to NBE for identification via the late T. Holthe, C-Specimen with "double-anchor" marginal radii from the Dahlak Archipelago (Israel South Red Sea Expedition sample ISRSE 65-TAU-MO-Malleidae 1814), DEnlarged tip of marginal radius from Fig. A -5 th radius from left-from Bitter Lake, Suez Canal-resembles that of specimens from Mediterranean population, E-Lessepsian migrant specimen from the coast of Israel (legit E. Gilat, Gilat sample 1821B, 10.XI.1969, Ashqelon, 22 m). Scale: $100 \mu \mathrm{m}$.

The "double-anchor-shape" (Fig. 12C) is similar to that figured in Pixell (1913, pl. 8 fig. 1a) and in Mohammad (1981 fig. 2c), but, in re-examining their material, we also found specimens with marginal radii ranging in form between Figs $12 \mathrm{~B}$ and $\mathrm{C}$. This "double-anchor" form has been reported from the Indian Ocean, Zanzibar, Maldives (Pixell 1913), the Arabian coast, Oman (Monro 1937), from the Persian Gulf, Kuwait (Mohammad 1981, see references above), from the Seychelles (present paper), and the southern Red 
Sea - Dahlak Archipelago (Ben-Eliahu 1991b, Fig. 12C). Specimens from Oman showed some additional variation (present paper). It follows that in these populations there is more variability in the form of the marginal radii than given in their formal descriptions.

The "spur-tipped-anchor-shaped" form is shown in Fig. 12B; ten Hove (1970a, figs 1a-c) illustrated some of the variability in the tip of the spur; the population was from the Persian Gulf. The single-anchor form (Figs 12D, E) reported from the Persian (Arabian) Gulf by Wesenberg-Lund (1949), has been found in the Gulf of Suez (present paper and Selim 1997b: 87, 93-94, figs 6a-e). It also characterizes both the Suez Canal population (Figs 12A, D), and the Lessepsian migrant populations on the Levant coast of Egypt and Israel (ca. 80 individuals) (Figs 12D, E). That only one of several forms present in the Persian (Arabian) Gulf has been found in the Gulf of Suez, colonized the Suez Canal and the Mediterranean coast of Israel, is an illustration of "a founder effect" (Mayr 1966, Ben-Eliahu 1991b). Interestingly, the H. homoceros specimens removed from the aircraft carrier "Foch" in Toulon Port (Zibrowius 1979b) belonged to the "double-anchor" Pixell type (H. Zibrowius, pers. comm.), thus, settlement on the "Foch" presumably occurred in the Indian Ocean or the Red Sea proper (Ben-Eliahu 1991b). A single specimen recently collected from the Levant coast of Turkey (Iskenderun) by Çinar (2006, fig. 4d-e), belongs to the "spur-tipped-T-shaped" form (in Figs 12B, C, closer to B than to C). The distribution of the form (Persian (Arabian) Gulf, ten Hove 1970a, and Turkey, Çinar 2006) provides a convincing illustration of a disjunctive population founded through ship-transport.

Hydroides homoceros has a juvenile 2-tier opercular ontogenetic stage belonging to the $H$. "priscus" type, one of several species in which this stage has been found (ten Hove \& Ben-Eliahu 2005, fig. 2a).

\section{Hydroides norvegicus Gunnerus, 1768}

Type locality. Norway. Not present in the Suez Canal, but see H. elegans.

\section{Hydroides steinitzi Ben-Eliahu, 1972}

Figs 13-15

Hydroides steinitzi Ben-Eliahu, 1972a: 77, figs 1 1-4; figs 2 1-6 [Type locality: Suez Canal, Little Bitter Lake]; Zibrowius 1979b: 133-134 [France, Toulon Port, biofouling removed from the aircraft carrier "Foch"]; Zenetos et al. 2005: 73 [classified as a "casual" alien, i.e., as a non-established alien species in the Mediterranean. Having been recorded only from ship biofouling (Zibrowius 1979b), rather than from an actual Mediterranean habitat, "ship-transported" seems a more appropriate designation than "casual"].

Suez Canal

Hydroides steinitzi Ben-Eliahu, 1972a: 77 [SLC 85, 14.I.1969, on sandstone rock]; Ben-Eliahu 1991b: 524-525, fig. 4 [Suez Canal].

Gulf of Suez and Gulf of Aqaba

Hydroides steinitzi Ben-Eliahu, 1972a: 77 [Gulf of Suez; collected in 1870; BM(NH) 1870.12.23.62 (H. Zibrowius, pers. comm.), see "Material examined", below]; ten Hove 1990: 119, figs 16-18 [confirmed]; Ben-Eliahu 1991b: 524525, fig. 4 [first sample from the Gulf of Aqaba, 6.X.1969 (see "Material examined", below)].

Red Sea proper-Indo-West-Pacific (excluding citations from Gulf of Suez and Gulf of Aqaba already given above)

Hydroides steinitzi: ten Hove 1990: 119 [Philippines, see "Material examined”, below]; Ben-Eliahu 1991b: 524-525, fig. 4 [south Red Sea, Dahlak Archipelago [see "Material examined", below]; Wehe \& Fiege 2002: 128 [Red Sea; list of references]. 

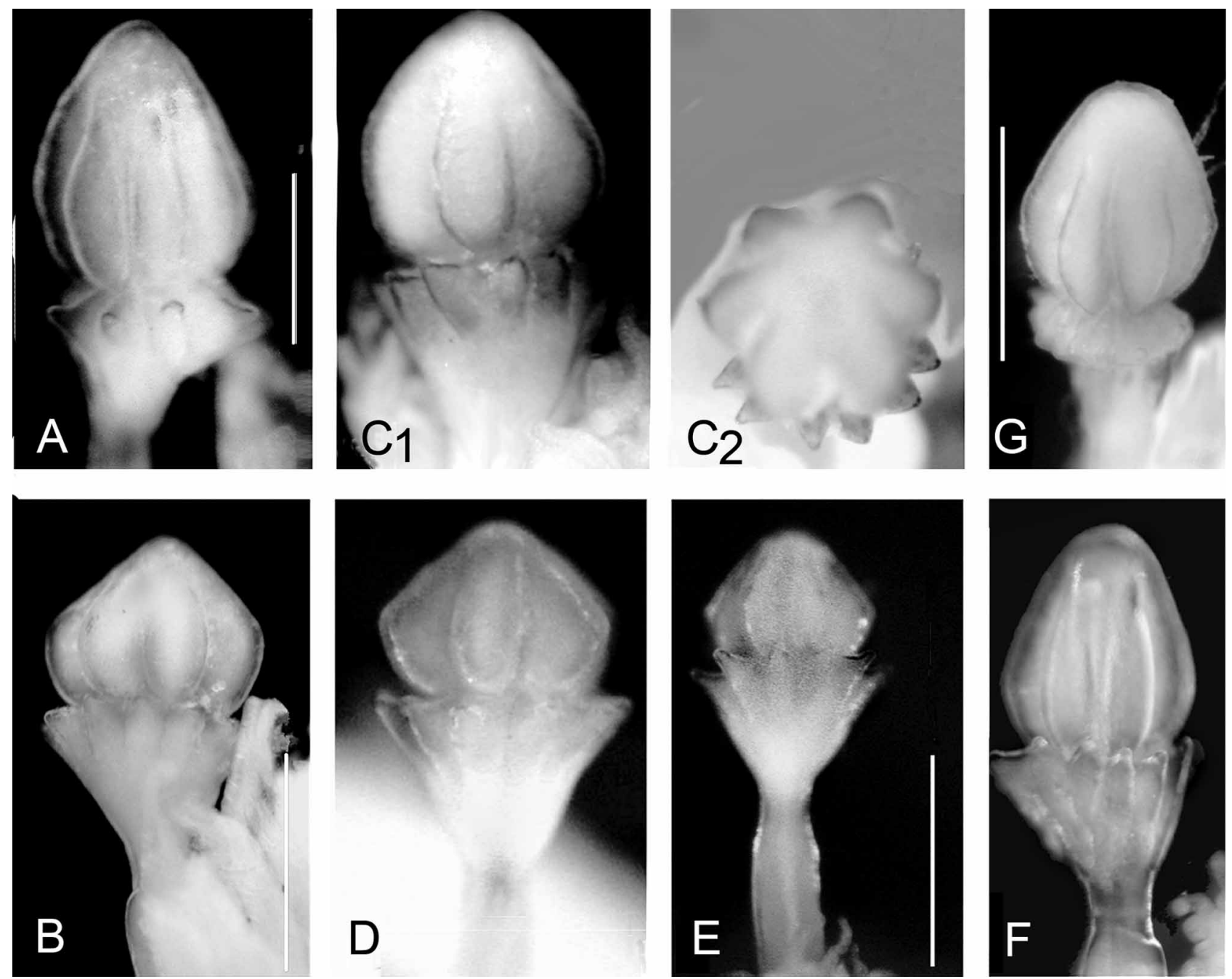

FIGURE 13. Variability of opercula in a population of Hydroides steinitzi from the Great Bitter Lake "Yellow Fleet" aggregation (App. Table 2D). Opercula B-F correspond to tubes B-F in Fig. 15; $C_{1}$-lateral view, $C_{2}-$ apical view of $C_{1}$. Note variability in height of verticil and in the degree of chitinisation of funnel radii and constriction of peduncle. Scales, $0.5 \mathrm{~mm}$.

Material examined. Locations adjacent to the Suez Canal, Mediterranean side: None.

Suez Canal proper: 1 sample, Hebrew University-Smithsonian Expeditions, 1967-1973, Little Bitter Lake opp. opp. Kabrit-Km 120, SLC 85, 14.I.1969, holotype and 2 paratypes.

Suez Canal material reported herein: 17 samples, 28 specimens. Beets' Great Bitter Lake samples, VIII / IX 1950, Stn 15, 10.4 m, from inside an empty Chama asperella shell, single tube with taphonomic residue of verticil, RMNH 18545 (Fig. 14).-Hebrew University-Smithsonian Expeditions, 1967-1973, 2 samples, 4 specs: Lake Timsah opp. Isma'iliya, Km 78: SBE 8, 3 specs; Great Bitter Lake: SLC 117, 1 spec.-Great Bitter Lake "Yellow Fleet" Biofouling Samples (January 13-20, 1975): 14 subsamples, 23 specs. Material deposited in HUJ; BM(NH) ZB.1985.209, 1 spec.; Universidad del Mar UMAR-Poly 118, 3 specs; ZMA V.Pol. 3513, 1 spec.; SMF, 2 specs.

Locations adjacent to the Suez Canal, Red Sea side: Gulf of Suez, legit J.K. Lord ca. 1870, det. H. Zibrowius 1969, Ben-Eliahu (1972a), H.A. ten Hove (1990: 119, figs 16-18), 1 spec., BM(NH) 1870.12.23.62.

Gulf of Aqaba: Egypt, Marsa Abu Samra, 68 m, dredge, on Malleidae TAU-MO-19788, legit Ch. Lewinsohn 6.X.1969, det. M.N. Ben-Eliahu ca. 1985 (Ben-Eliahu 1991b: 525, fig. 4).

Red Sea: Sudan, Sanganeb Atoll, 9 m, near Stn TQ2, SAN 46, coral rubble with Serpula jukesii, legit D. Fiege 
25.III.1991, det. H.A. ten Hove 1999; 10-15 m, near Stn TQ22b, TQ2, coral rubble with Vermiliopsis infundibulum / glandigera-complex, Protula spec., legit D. Fiege 19.IX.1992, det. H.A. ten Hove 1992.—Eritrea: 6 samples (TAU-NS [no numbers], 4 samples, SMF 2 samples), depth range: 9-[9-12]-36.6 m). Dahlak Archipelago, 1458'N, 40¹9'E, 9-12 m, on Plicatulidae, Israel South Red Sea Expedition, ISRSE / 65, Stn 4, legit Ch. Lewinsohn 17.X.1965, det. M.N. Ben-Eliahu ca. 1985 (Ben-Eliahu 1991: 525, fig. 4), TAU-MO1454, TAU-MO-2186; Stn 12, $15^{\circ} 35^{\prime} \mathrm{N}, 40^{\circ} 44^{\prime} \mathrm{N}, 36.6$ m, on Malleidae, legit Ch. Lewinsohn 17.X.1965, TAU-MO-1814; with H. homoceros, S. latiscapus, S. tetraceros, det. M.N. Ben-Eliahu ca. 1985 (Ben-Eliahu 1991b: 525, fig. 4).
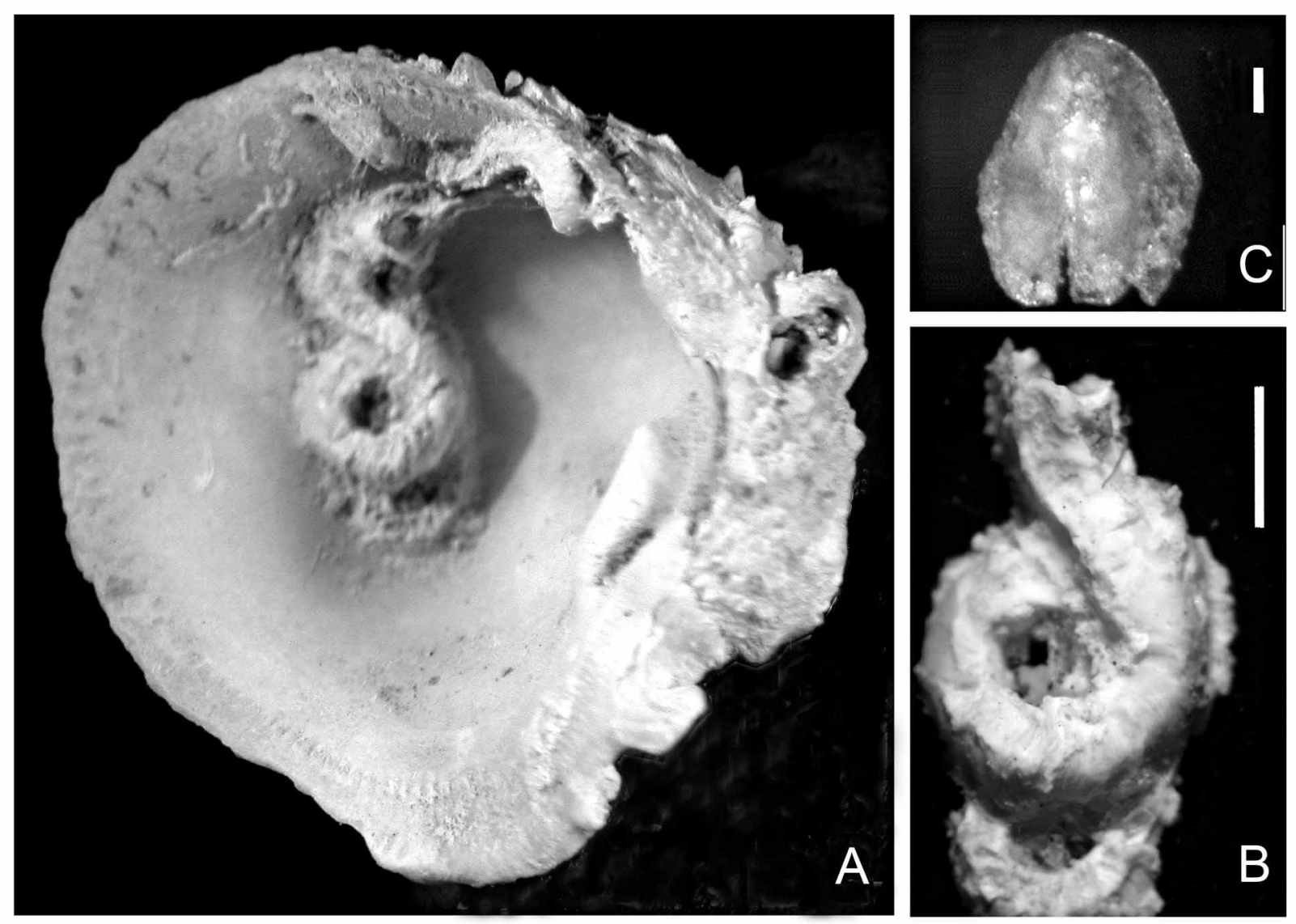

FIGURE 14. First record of Hydroides steinitzi in the Suez Canal from a taphonomic residue of the operculum. Operculum, collected in 1950, was within tube inside Chama asperella valve (Beets' Stn 15, 10.4 m, see App. Table 2B). ATube in situ, B-Tube removed from valve; note upper surface somewhat encrusted with granular layer, C-Dried opercular residue (verticil) found within the tube had "lasted" 50 years (compare with those in Fig. 13). Scales: B-1 mm, $\mathrm{C}-100 \mu \mathrm{m}$.

Indo-West-Pacific: Philippines, Banacon Island, Danajon Bank, N.W. Bohol Island, reef and sand, on clams, legit C. Short, II-III.1976; det. H.A. ten Hove 1986 (ten Hove 1990: 119), Australian Museum, 2 specs.

Suez Canal depth and substrates: 0.4-10.4 m; on sponges, on molluscs: Brachidontes pharaonis, Chama asperella, Pinctada radiata and Spondylus spinosus; on bryozoans, tunicates, sandstone rock, and on a muddy tin can.

Colouration. Lake Timsah field notes describe bodies with red-orange pigmentation.

Distribution. Suez Canal: Lake Timsah, Great Bitter Lake, Little Bitter Lake; Red Sea: Gulfs of Suez and Aqaba, South Red Sea-Dahlak Archipelago; Philippines.

Remarks. There have not been many records of this species. Hydroides steinitzi was described from 3 specimens collected from the Little Bitter Lake in 1969 (Ben-Eliahu 1972a). Its verticil is unusual in being 
comprised of a single element with out-pocketing, somewhat resembling a peeled orange when seen in apical view. The verticil of the holotype had 6 out-pockets (bulges), and the funnel 12 pointed radii (Ben-Eliahu 1972a). Note variability in the shape as well as in the number and the degree of chitinisation of the funnel radii (Figs 13A-G).

Hydroides steinitzi was first collected from the Gulf of Suez by the J.K. Lord Expedition in 1870 (specimen $\mathrm{BM}(\mathrm{NH})$ 1870:12:23:62), presumably from a coral reef habitat (the sample largely consisted of Spirobranchus species that inhabit living coral [ten Hove 1970b: 49-50]). The original sample, BM(NH) 1870:12:23:31, was subdivided into 5 different taxa in 1969, during a visit by one of us (HAtH) to the Natural History Museum, London; two of the taxa were Spirobranchus spp., three taxa, Hydroides spp. In 1971, H. Zibrowius re-identified the provisionally identified specimens of Hydroides, giving them temporary BM(NH) codes. On receiving the Ben-Eliahu manuscript describing Hydroides steinitzi, H. Zibrowius identified one of these Gulf of Suez specimens (BM(NH) 1971: 21), as H. steinitzi, and the newly identified specimen was then assigned a permanent code by the museum, BM(NH) 1870.12.23.62. Unfortunately, Zibrowius' reply to BenEliahu (letter, 26.XI.1971) reporting the existence of the Gulf of Suez specimen came when the issue with the description was already in production, but a "note added in press" was permitted, mentioning the record (BenEliahu 1972a). The Gulf of Suez specimen measured ca. $11 \mathrm{~mm}$ in length, body 65 chaetigers, with ca. 10 radioles per lobe; the operculum had 6 out-pockets in the verticil and 10 radii in the funnel $(\mathrm{H}$. Zibrowius, pers. comm.; ten Hove 1990: figs 16-18). The operculum resembled Figs $13 \mathrm{C}_{1}$ and $\mathrm{C}_{2}$ in form.

The first record of Hydroides steinitzi from within the Suez Canal, from 1950, is from the Great Bitter Lake, from a tube within a shell collected by Beets that contained a taphonomic residue of a verticil (RMNH 18545 [Fig. 14]).

We have no way of knowing the date when the species settled in the canal. Altogether, it has been collected on four separate occasions (see above). Presently, the total number of $H$. steinitzi specimens from the Suez Canal comes to 30, with most of the specimens obtained from the Great Bitter Lake "Yellow Fleet" biofouling aggregation. These later specimens enabled providing a first description of the tube (the tubes of the type specimens were unwittingly damaged). Hydroides steinitzi was considered to be a potential Lessepsian migrant as it had been found both in the Bitter Lake and in Lake Timsah (Ben-Eliahu 1991b). Subsequent reports from the Suez Canal or from the Mediterranean areas adjacent to it (e.g., Alexandria) have not included it, but this may be due to not sampling in its preferred microhabitats or on preferred substrate taxa (e.g., molluscs, bryozoans, etc.). H. Zibrowius (1979b) reported it among ship-transported biofouling taxa removed from the aircraft carrier "Foch" that arrived in Toulon Port (via the Suez Canal) after voyaging for 7 months in the western Indian Ocean.

A first description of the Hydroides steinitzi tube (Figs 14, 15): The tube has three longitudinal ridges close together on the upper surface and transversal ridges, which give it a generally rugose (not delicate) appearance. The median longitudinal ridge may be as prominent as the lateral longitudinal ridges as seen in three of the four tubes figured from above (Figs 15A, B and E) and in some cross-sections (Figs 15D, E); in Figs 14F1 and F2, the median ridge is lower, but it can be discerned. Note that in Figs 14A, B, a median longitudinal ridge cannot be perceived; the tube surface appears to be covered by a granular overlay-as in many of the H. steinitzi specimens-obscuring the surface sculpturing (Fig. 15B); it is not clear whether the overlay is made by the worm. In some cross-sections (Figs 15C, D), the tube appears generally rounded, with a flattened upper surface, but in others (e.g., Figs 15E, F) the tube is sub-trapezoidal, expanded basally; the upper surface may appear flattened. The tube may be somewhat coiled or looped (Figs 14A, B, 15B). 

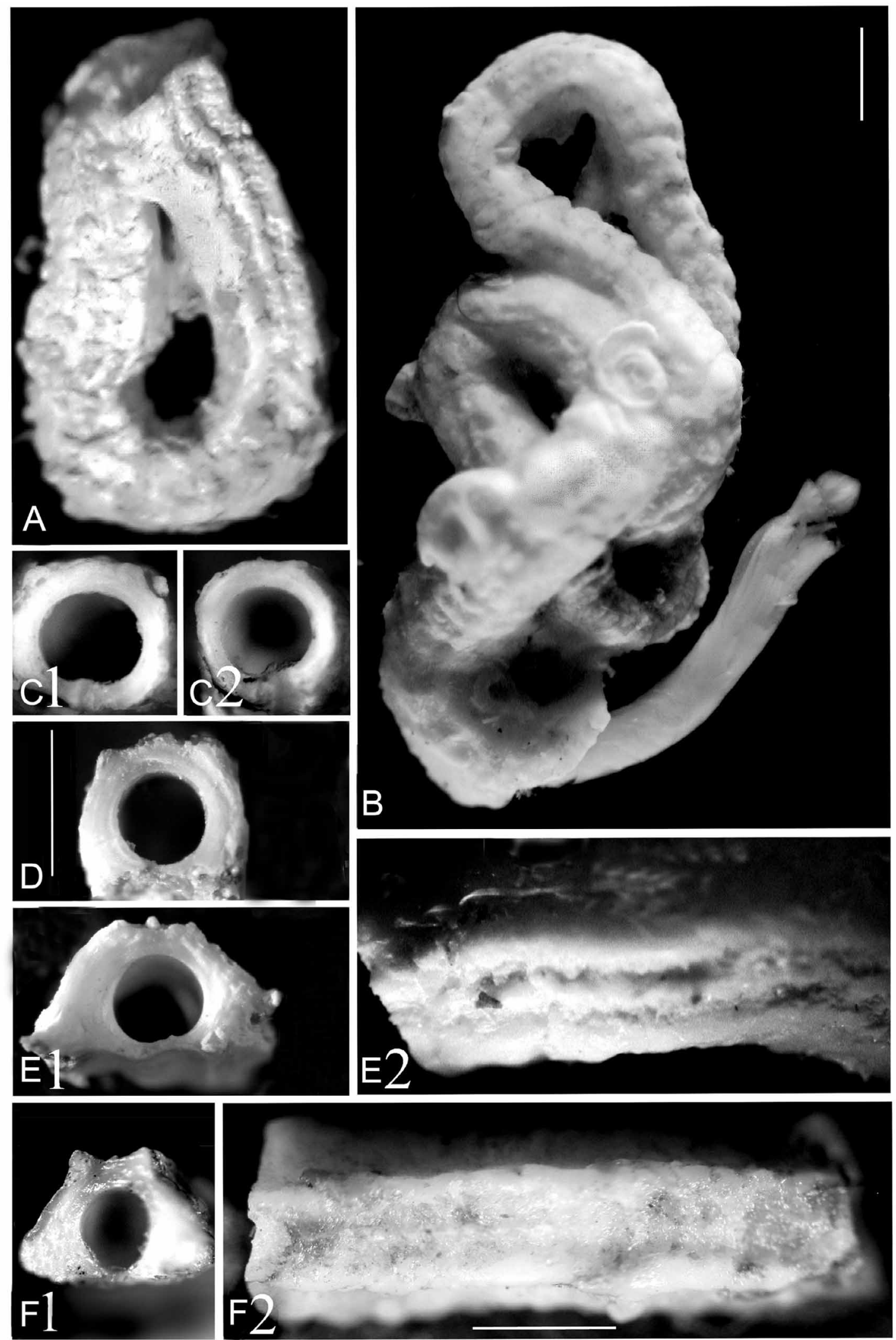

FIGURE 15. First description of Hydroides steinitzi tubes. Tubes rugose with 3 longitudinal ridges on upper surface, more or less developed, with middle longitudinal ridge often lower than lateral ones (e.g., F1), and with transverse ridges. Lumen of tube circular, with tube more or less expanded at base, thus, tubes C, D rounded in cross-section; tubes $\mathrm{E}$ and $\mathrm{F}$ with expanded base, more trapezoidal in cross-section; $\mathrm{C} 1$ and $\mathrm{C} 2$ are sections of the same tube. Figs $\mathrm{E} 1$ and $\mathrm{E} 2$, and F1 and F2 are paired cross-section and upper views (of two different tubes). Tubes B-F correspond to opercula B-F in Fig. 12. Scales: $1 \mathrm{~mm}$. 


\section{Non-identified Hydroides juveniles}

(1) Non-Hydroides elegans juveniles (i.e., juveniles with primary opercula with collar chaetae that differ from those of $H$. elegans [ten Hove \& Ben-Eliahu 2005]).

Material examined. Suez Canal material reported herein: Hebrew University-Smithsonian Expeditions, 1967-1973: Little Bitter Lake: SBE 1, juvenile, tube rather square in cross-section with lateral ridges, 1 spec.; SLC 117, some of the 109 juveniles with collar chaetae spot-checked for presence of characteristic Hydroides elegans chaetae belonged to a different taxon or taxa.-Great Bitter Lake "Yellow Fleet" Biofouling Samples, January 13-20.1975: 6 subsamples, 7 specs.

Suez Canal depth and substrates: On bivalves, Brachidontes pharaonis and Spondylus spinosus; on tunicate; under rock.

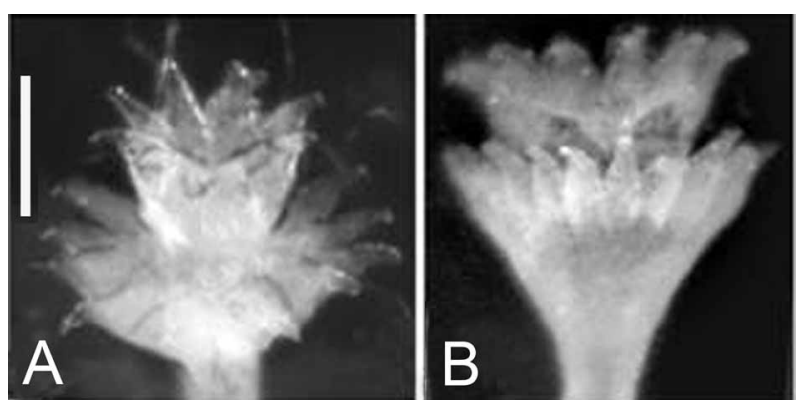

FIGURE 16. The Hydroides "priscus" juvenile stage of Hydroides sp. / spp. A-From Lake Timsah, Isma'iliya, on bivalve Malvufundus normalis, Cambridge Expedition, 26.XI.1924, BM(NH) 1928.3.30.179, B-From sample Great Bitter Lake SLC 117 (see App. Table 2A, C, respectively). Scale: $100 \mu \mathrm{m}$.

(2) Hydroides cf. "priscus" (Pillai, 1971)-type juveniles with a secondary opercular form found in several Hydroides taxa (ten Hove \& Ben-Eliahu 2005), see Fig. 16.

Hydroides grubei not Pillai, 1965, sensu Zibrowius 1979b: 133-134 [France, Toulon Port, biofouling removed from the aircraft carrier "Foch"].

Hydroides "priscus": ten Hove \& Ben-Eliahu 2005, figs 4 c, d [Mediterranean Levant coast: Lebanon, Israel: Haifa; Suez Canal; Red Sea, Gulf of Aqaba, Elat; Indian Ocean, Sri Lanka; Indonesia; Australia].

Eastern Mediterranean

Hydroides grubei not Pillai, sensu Zibrowius \& Bitar 1981: 159-160 [Lebanon, Beirut, Zaitouné].

Hydroides cf. priscus-type: Ben-Eliahu \& ten Hove 1989: 393 [Israel].

Hydroides novaepommeraniae not Augener, 1925, sensu Ben-Eliahu 1991b: 527 [on Mimachlamys varia TAU-MO12644 with Serpula concharum, H. elegans, H. diramphus; spring 1956; det. M.N. Ben-Eliahu.

Indian Ocean

Hydroides "priscus": ten Hove 1994: 108 [Indian Ocean: Seychelles, Sri Lanka].

Material examined. Hydroides grubei not Pillai, sensu Zibrowius \& Bitar 1981: 159-160 [Lebanon, Beirut, Zaitouné, $5 \mathrm{~m}$, on bivalve, 23.IX.1978].

Suez Canal material reported herein: 2 samples, 3 specimens. Cambridge Expedition "new" sample, from $\mathrm{BM}(\mathrm{NH})$ mollusc sample, Lake Timsah, Km 78, Isma'iliya, 1 spec. (App. Table 2A; ten Hove \& BenEliahu 2005, fig. 4c).-Hebrew University-Smithsonian Expeditions, 1967-1973: Great Bitter Lake: SLC 117 (Fig. 16B), 2 specs (ten Hove \& Ben-Eliahu 2005, fig. 4d).

Suez Canal depth and substrates: $10 \mathrm{~m}$, on bivalve, Pinctada radiata; on barnacle.

Remarks. The "Hydroides priscus" ontogenetic stage with a juvenile secondary operculum containing a funnel and verticil was mentioned in Ben-Eliahu \& ten Hove (1989: 393), and again as "Hydroides novaepommeraniae in Ben-Eliahu (1991b: 527) and Ben-Eliahu \& ten Hove (1992: 42, syn. H. grubei). It is a 
juvenile ontogenetic stage, and has been documented in several individuals with different mature opercula on the opposite lobe, e.g., in Hydroides homoceros, H. cf. brachyacanthus (Ben-Eliahu 1991b: 527), as well as in $H$. minax, $H$. cf. albiceps and $H$. trivesiculosus (ten Hove \& Ben-Eliahu 2005). The first three are Lessepsian migrants (Ben-Eliahu \& ten Hove 1992: 42). Hydroides grubei not Pillai sensu Zibrowius (1979b) could be a juvenile stage of these or other taxa, and thus we excluded it from Zibrowius (1979b)'s list of species present in biofouling scraped from the aircraft carrier "Foch" (see Discussion Section below). The Great Bitter Lake SLC 117 "H. priscus" specimen had sharp pointed teeth in the funnel radii (ten Hove \& Ben-Eliahu 2005, fig. 4d) and its bayonet collar chaetae had sharp teeth.

\section{Josephella marenzelleri Caullery \& Mesnil, 1896}

Fig. 3C

Josephella marenzelleri Caullery \& Mesnil 1896: 482-486, figs 1-6 [Type locality: English Channel, France, Cap de la Hague]; Fauvel 1955a: 3-4 [including J. humilis Bush, 1905; eastern Atlantic, English Channel; France, Cherbourg, Roscoff, Wimereux; Mediterranean, Corsica, Lebanon, Beirut]; Zibrowius 1968: 172-174, pl. 9, figs 14-22 [France: Atlantic; Mediterranean]; Bianchi 1981: 133-135, figs 50a, b [Italy]; Ben-Eliahu \& ten Hove 1989: 394.

Eastern Mediterranean

Josephella humilis Bush 1905: 291 [Lebanon: Beirut, first Levant record], synonymised by Fauvel (1927, 1955a).

Josephella marenzelleri: Fauvel 1955a: 3-4 [Lebanon, Beirut; for distribution, see above citation]; Ben-Eliahu 1976: 109 [Israel, intertidal cryptofauna]; Ben-Eliahu 1991b: 518 [Cyprus, Israel]; Ben-Eliahu \& ten Hove 1992: 40 [Israel, entire coast from north to south, 1-24 m]; Ben-Eliahu \& Fiege 1996: 33-38 [western Levant Basin, Turkey, Cyprus, Levant coast]; Ben-Eliahu \& Payiatas 1999: 108-113, figs 3a-d, 4a-d [Cyprus, Israel, J. marenzelleri, s. str. , and the first description of the thick-rimmed form].

Gulf of Suez and Gulf of Aqaba

Josephella marenzelleri: Ben-Eliahu 1976: 113 [Gulf of Aqaba, Sinai Peninsula, intertidal cryptofauna]; Ben-Eliahu \& Dafni 1979: 207 [Gulf of Aqaba, Israel]; Ben-Eliahu \& Safriel 1982: 389 [Gulf of Aqaba, Sinai Peninsula: Israel, Egypt, intertidal cryptofauna].

Red Sea proper-Indo-West-Pacific (excluding citations from Gulf of Suez and Gulf of Aqaba already given above) Josephella marenzelleri: Dew 1959: 52, fig. 21 [Australia, New South Wales]; Wehe \& Fiege 2002: 128 [Red Sea; list of references].

Material examined. Locations adjacent to the Suez Canal, Mediterranean side: Crete: 1 sample (intertidal).-Turkey: 3 samples (intertidal). Cyprus: 24 samples (6 samples included the "thick-rim" form described in Ben-Eliahu \& Payiatas (1999) along with the typical form; 2 samples comprised only the thickrim form, [0-0.5]-[0-8]-[10-18]-92 m]).-Lebanon, Beirut, 1 spec., permanent mount, det. K.J. Bush 1905 Josephella humilis, and several tubes on a bivalve, collectively catalogued as YPM 2969 though not specified as a type, synonymised with J. marenzelleri by Fauvel (1927: 380-381, fig. 129 m-t), confirmed M.N. BenEliahu 1998.-Israel: 7 samples (3 samples with both thick-rim and typical forms, 1 with only thick-rim form, [intertidal-[4-6]-[8-10]-18 m]).

Suez Canal material reported herein (Fig. 3C): Beets' Great Bitter Lake samples, VIII / IX 1950, residues of minute tubes on shells, 2 subsamples, presumed to be Josephella.—Great Bitter Lake "Yellow Fleet" Biofouling Samples, January 13-20 1975, 18 subsamples, ca. 119 specimens.

Locations adjacent to the Suez Canal, Red Sea side: Gulf of Suez: None.-Gulf of Aqaba: Egypt, Israel, typical form, but population from North Beach, Elat included individuals lacking opercula: 6 samples, intertidal-3-8 m, HUJ.

Suez Canal depth and substrates: On sponges; on the bivalves, Brachidontes pharaonis and Spondylus spinosus; on tube of Spirobranchus tetraceros, on barnacles; in crevices of bryozoans; on tunicates; in crevices of biofouling conglomerate. 
Distribution. Worldwide in (sub) tropical to temperate regions. Mediterranean: Israel; Gulf of Aqaba: Israel, Egypt.

Remarks. A cryptofaunal species frequently found in calcareous concretions, e.g., coralligène, calcareous algae. The new record is most likely due to the stable reef-like substrate provided by the biofouling aggregation on the "Yellow Fleet" ships. Erect tubes were also found on Spondylus spinosus between the spines (Fig. 3C) and on tunicates in folds near the siphons. Some tubes were coiled. The Great Bitter Lake individuals seemed typical. A thick-rimmed opercular form, described in Ben-Eliahu \& Payiatas (1999), is present along with the typical form in populations from both Cyprus and Israel. The Red Sea population from the Gulf of Aqaba (Sinai Peninsula) only had typical opercula, suggesting that the Suez Canal population originated from the that population.

\section{Placostegus tridentatus (Fabricius, 1780)}

Type locality. Arctic Ocean, Greenland. Presumed not present in the Suez Canal, but see Placostegus sp., below.

\section{Placostegus sp.}

Suez Canal

Placostegus tridentatus not (Fabricius, 1780), sensu Abd-Elnaby 2009: 10 [listed in Table of taxa from the southern part of the canal, giving Suez Canal and Red Sea distribution (discussed further below)].

\section{Material examined for comparison:}

\section{Locations Adjacent to the Suez Canal, Mediterranean side:}

Placostegus tridentatus: Crete: 9 samples, [60-80]-173-421 m (H. Zibrowius, pers. comm.).-Cyprus: 5 samples, [82-92]-119-183 m (INCNH unpublished data).-Egypt: 2 samples, [191-193]-198 m (BenEliahu \& Fiege 1996).

Placostegus crystallinus (Scacchi, 1836), sensu Zibrowius 1968a: Western Levant, Cyprus, Israel (Ben-Eliahu 1991b: 518; Ben-Eliahu \& ten Hove 1992: 40; Ben-Eliahu \& Fiege 1996: 33, 38; Ben-Eliahu \& Payiatas

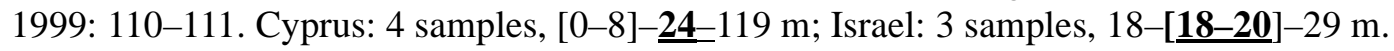

\section{Suez Canal material reported herein: None.}

Locations adjacent to the Suez Canal, Red Sea side: Gulf of Suez:

Placostegus cf. crystallinus sensu Zibrowius, 1968a [Gulf of Suez, 33 ${ }^{\circ} 23^{\prime}-33^{\circ} 24^{\prime}$ long. E, 28 $8^{\circ} 12^{\prime}-28^{\circ} 14^{\prime}$ lat. N, 27-29 m, Dollfus station XVII ter, 25.XII.1928, det. P. Fauvel (1933a: 79-80) P. tridentatus, redet. H. Zibrowius 1971 P. cf. crystallinus, confirmed M.N. Ben-Eliahu 1986, MNHN, 1 spec., see Remarks below.

Distribution. Suez Canal.

Remarks. The Genus Placostegus is characterized by an unusual transparent glass-like tube. Fauvel (1933a) reported as P. tridentatus a single specimen from Dollfus Stn XVII ter, from the Gulf of Suez. Fauvel did not want to break the vitreous tube, thus, he examined the specimen only summarily (Fauvel 1933a: 7980). Instead of the symmetrical cuplike operculum, topped by a flat chitinous opercular plate characteristic of P. tridentatus, Fauvel's Gulf of Suez Placostegus specimen had an infolded flat chitinous plate within an asymmetrical (zygomorphic) bilateral operculum as in P. crystallinus (Bianchi 1981: 118, fig. 45). In 1971, Zibrowius (pers. comm.) redetermined the specimen as Placostegus cf. crystallinus, and, in 1986, Ben-Eliahu noted that each side of the infolded plate had one proximally-directed recurved spine (hook) not characteristic for the Atlantic-Mediterranean specimens of Placostegus cf. crystallinus observed by us or as figured by Bianchi (1981: 118, fig. 45) (Ben-Eliahu, pers. comm. to H. Zibrowius and H.A. ten Hove). As the redetermination of the Gulf of Suez specimen was not widely known (had not been published), nor the rather hidden 
single reference to Placostegus crystallinus from the Andaman Sea (Hartman 1974: 200), we anticipated that the P. tridentatus in Abd-Elnaby's 2009 list from the southern canal might prove to belong to the same taxon found in the Gulf of Suez. However, a figure of the operculum and of some chaetae, very graciously provided to H.A. ten Hove by F.A. Abd-Elnaby indeed resembled that of $P$. tridentatus - the operculum had a symmetrical cuplike form and a flat opercular plate. Nonetheless, $P$. tridentatus $s$. str. is a boreal and deeper water Atlantic-Mediterranean species and its habitat differs greatly from that found in the southern part of the Suez Canal. Thus, from a biogeographic point of view, we consider it to be an unlikely record that can only be determined eventually by genetic analysis. A similar form, with a flat chitinous opercular plate, was reported as Placostegus tridentatus from southern Japan by Imajima (1978: 67-79, fig. 9a-1).In his remarks, Imajima noted the determination as tentative and that the genus needed revision. The disjunctive distribution of $P$. tridentatus sensu auct. supports the notion of there being a cryptic Indo-Pacific species resembling $P$. tridentatus. We therefore generalise Abd-Elnaby's (2009) determination of P. tridentatus to Placostegus sp. H. Zibrowius (pers. comm.) considers the Dollfus specimen to be a distinct species presently known from one specimen. As already noted, the genus requires review.

\section{The genera Pomatoceros, Pomatoleios and Spirobranchus}

Pillai (2009: 146-148) makes a good case for synonymising these three genera on morphological criteria, uniting about 30 taxa that have been kept apart for almost a century in a single genus. A full discussion of this synonymy is not within the province of the present paper. Given the genetic tools available today, however, this synonymy should be backed by genetic data. For the time being, we prefer to use the traditional taxonomy.

\section{Pomatoceros caeruleus (Schmarda, 1861), variant spelling coeruleus}

Type localities: Cape of Good Hope and New Zealand. This nominal taxon is a species inquirendam, already evident from the two "type localities", the material of which refers to two different taxa, Pomatoleios kraussii and Spirobranchus carinifer. For records under the name Pomatoceros caeruleus from the Suez Canal, see Spirobranchus tetraceros.

\section{Pomatoceros triqueter (Linnaeus, 1758)}

Type locality. Not precisely known, but North Atlantic. Not present in the Suez Canal, but see Spirobranchus tetraceros, below. On ecological grounds, it is inconceivable that Pomatoceros triqueter has replaced Spirobranchus tetraceros in the intertidal and splash zone around Alexandria, Egypt as recently reported by El-Rashidy et al. (2009), a finding that contradicts Abd-Elnaby (2005) [quoted by Ghobashy \& Ghobashy (2005: 90-93); see Spirobranchus tetraceros, below]).

\section{Pomatoleios kraussii (Baird, 1865)}

Placostegus cariniferus var. Kraussii Baird, 1865: 14 [Type locality: South Africa, Cape of Good Hope].

Pomatoleios kraussii: Zibrowius 1979: 133-134 [France, Toulon Port, biofouling removed from the aircraft carrier "Foch"]; Zenetos et al. 2005: 73, 93 [classified as an "established and invasive alien species" in the Mediterranean].

Eastern Mediterranean

Pomatoleios kraussii: Ben-Eliahu \& ten Hove 1992: 35-44 [Israel, 0-1 m; Lessepsian migrant, first Levant sample; 27.X.1958, Tel Aviv, on gastropod, Stramonita haemastoma]; Ben-Eliahu \& Fiege 1996: 33-38 [Israel, Suez Canal]; 
Zibrowius \& Bitar 2003: 71 [Lebanon, noted "crusts"]; Ghobashy \& Ghobashy 2005: 90 [citing Belal (2001) that taxon is encrusted on rocks, concrete and metal surfaces in Eastern Harbour Alexandria]; Çinar 2006: 231, fig. 8a-d [first record from Levant coast of Turkey, Iskenderun Harbour, IX.2005, 0.1-3 m, on mytilid Brachiodontes pharaonis, very abundant]; Bitar et al. 2007: 437 [Lebanon, 0-10 m, fouling communities].

Suez Canal

Pomatoleios kraussii: Ghobashy et al. 1986: 322, fig. 5 [Lake Timsah, first report from the Suez Canal]; Ghobashy et al. (1990: 677-686)]; Ben-Eliahu 1991b: 525; Selim 1997b: 88 [for western Lake Timsah, citing Shalla (1985) and Mostafa (1992) (see App. Table 4)]; Shalla \& Holt 1999: 133-137 [western Lake Timsah, western Great Bitter Lake, forming aggregations]; Wehe \& Fiege 2002: 129 [Suez Canal; list of references]; Emara \& Belal 2004: 192-199 [pooled Lake Timsah and Bitter Lakes data]; Ghobashy \& Ghobashy 2005: 93 [Lake Timsah; referring to Ghobashy et al. (1986) and noting its absence in the late 1970s, Barbary (1992, see App. Table 4) and Shalla \& Holt (1999)]; Abd-Elnaby 2009: 10, 17 [at southern part of Lake Timsah]; Selim 2009: 73 [from literature—no new records].

Gulf of Suez

Pomatoleios kraussii: Ghobashy \& Ghobashy 2005: 93 [first report from Suez Bay, citing Belal (2001: 90, see App. Table 4) of encrustation on rocks, concrete and metal surfaces]; Abd-Elnaby 2009: 10.

Red Sea proper-Indo-West-Pacific (excluding citations from Gulf of Suez and Gulf of Aqaba already given above)

Pomatoleios crosslandi Pixell, 1913: 85, pl. 9 figs 10a-d [lacking collar chaetae; Zanzibar, Ras Shangani, Ghwaka; Pillai 1960: 15-17, text-figs 6a-d [western Sri Lanka, intertidal at Beruwala, Hikaduwa, Mount Lavinia, Chilaw and from the Negombo Lagoon].

Spirobranchus maldivensis not Pixell, sensu Wesenberg-Lund 1949: 358 [part] [Gulf of Oman, South Arabian coast, Maldives, Burma (= Myanmar)].

Pomatoleios kraussii: Day 1955: 449 [synonymising P. crosslandi; Zanzibar, Ras Shangani, Ghwaka; Natal, Cape]; Day 1967: 801, figs 38.3.a-f [for distribution, see Day, 1955]; Mohammad 1971: 309 [Persian (Arabian) Gulf, Kuwait]; ten Hove 1973: 5-6, fig. 34 [Indian Ocean, Madagascar]; Fiege 1992: 1-23 [Saudi Arabia, Persian (Arabian) Gulf, “even found on heavily oiled rocks / beaches"]; Wehe \& Fiege 2002: 129 [Persian (Arabian) Gulf, list of references].

Spirobranchus kraussii: Pillai 2009: 168, figs 49e-g [no distribution data].

Material examined. Locations adjacent to the Suez Canal, Mediterranean side: Israel: 11 samples, with one, at the most, two, individuals [0-0.3]-[0.1-1]-[0.5-0.75]-[4-6] m. Substrates along Israeli coast: On gastropod Stramonita haemastoma (TAU-MO-16366), legit J. Krystal 27.X.1958, det. M.N. Ben-Eliahu, 4 specs, first record from Israeli coast; on asbestos plates at Electric Corporation, Haifa; on tide-pool snails; under stones; on Stramonita haemastoma gastropods (TAU-MO-16356; 16370, 16371, 20717), on muricid gastropod; on breakwater, 0.5-0.75 m, and 4-6 m; Tel Aviv, Reading power plant, presumed 0-2 m.

Suez Canal proper: Lake Timsah, legit, det. S.H. Shalla ca. 1984 Pomatoceros triqueter, redet. H.A. ten Hove Pomatoleios kraussii, ZMA V.Pol. 4999, 5 specs.

Locations adjacent to the Suez Canal, Red Sea side: 0 samples.

Distribution. Widely distributed in the Indo-West-Pacific, from the Cape Province in S. Africa to Hawaii. Lessepsian migrant to the Mediterranean: Suez Canal, Israel, Lebanon, Turkey.

Remarks. The species forms mid-littoral "belts" or "zones" in the Pacific parts of its range [e.g., northern Australia, Straughan (1967a: 224)]. According to Miura \& Kajihara (1984), Pomatoleios kraussii prefers sheltered areas. Pillai (1960: 17) reported that the larvae prefer aerated and well-lit water. In the Suez Canal, isolated individuals were reported by S.H. Shalla (1985) and by Ghobashy et al. (1986, 1990) only from the western side of Lake Timsah (most abundant in their "clear-water station", no. I). By April 1997, Shalla \& Holt (1999) reported well-formed intertidal reefs on the western shores of both Lake Timsah and the Great Bitter Lake. As predicted by Shalla \& Holt (1999: 135), this same pattern of pioneer settlement of individuals eventually promoting gregarious settlement and developing into reefs has been repeated in the Lessepsian migrant population along the Lebanese coast (Zibrowius \& Bitar 2003). The species is common along the Lebanese coast, locally in large aggregations (H. Zibrowius, pers. comm.). Within the past two years, aggregations have similarly developed in Haifa Bay, Israel, near the Kishon Port (G. Rilov, pers. comm.; Rilov et al., in prep.). Various aspects relating to gregarious settlement are discussed in ten Hove \& van den Hurk 
(1993: 35). Characters distinguishing this species (the solitary form) from two other shallow-water serpulids with triangular tubes are discussed in the section on Spirobranchus tetraceros, below.

\section{Genus Protula Risso, 1826}

Table 1

For a generic diagnosis, see ten Hove \& Kupriyanova (2009: 81-83).

Preliminary remarks. In their recent review of the taxonomy of serpulid genera, ten Hove \& Kupriyanova (2009: 81) classified Protula as the most problematic serpulid taxon. That is because the phylogenetic basis for this genus is ill-defined and based on negative characters, such as lack of an operculum, lack of special collar chaetae and lack of any characteristic ornamentation of the tubes (mostly). Furthermore, characters for species distinction are scarce and poorly understood (ten Hove 1984: 187; 1994: 109). Not only were the initial descriptions scanty (Table 1), but nearly all were based on only one or, at the most, a few specimens (ten Hove \& Pantus 1985: 421), so that variability in taxonomic characters could not be taken into consideration. Many taxa have been described on at least partly-presumed differences in chaetation (ten Hove 1994: 109), such as, the characters, presence and location of Apomatus chaetae, that figure so importantly throughout the Protula literature, e.g., Uchida (1978) and in Table 1.

To evaluate the extent of variability of diagnostic characters in Protula, ten Hove \& Pantus (1985) carried out a study of live Mediterranean individuals considered to be Protula tubularia (Montagu, 1803). Within the same population, they found individuals that possessed Apomatus chaetae and others that lacked them (ten Hove \& Pantus 1985: 425; ten Hove \& Kupriyanova 2009: 81). Apomatus-chaetae, extremely transparent, are very difficult to discern within the thick bundles of limbate chaetae, so that while presence data can be accepted as valid, absence data might be evaluated as provisional, particularly when the data derive from examination of whole animals under the compound microscope. On the other hand, examining dissected parapodia under high magnification should enable observing Apomatus chaetae if present (Fig. 22F), as well as examining whole specimens with the SEM, where transparency has no relevance. In the studied Mediterranean Protula tubularia population, the location of rows of thoracic uncini also showed variability, with uncinigerous tori typically present from chaetigers $2-7$. However, uncini might also be completely lacking, and, particularly in larger specimens, there was an impression that uncini might disappear secondarily (ten Hove \& Pantus 1985: 429). The variability in both these characters illustrates why inferences based on few specimens should be viewed with the greatest caution, including inferences from literature. The urgently needed revision of this genus must therefore be based both on a comparison of all available types, and of sufficient topotypical material assembled for each taxon to produce statistically evaluated morphological criteria. The proposed review should include modern molecular techniques, providing supplementary evidence as to whether morphologically similar (allopatric) populations belong to one or more taxa (e.g., Golani \& Ritte 1999, Bucciarelli et al. 2002 and Bonhomme et al. 2003).

In our objective of dealing with the Suez Canal as a pathway and / or as a habitat, our first priority is elucidation of the source of the population inhabiting it. A first step entails assembling information on the taxa of the biogeographic regions adjoining the canal, and then excluding those taxa that do not correspond with the present material. (This approach should be carried out with other problematic taxa, as well, e.g., with Vermiliopsis sp. / spp. [see below]). Two Protula taxa from the Mediterranean must be taken into account: A larger taxon, Protula intestinum (Lamarck, 1818), type locality, "European seas", 8-12 cm in length / 8-12 $\mathrm{mm}$ in width, and a smaller one, Protula tubularia (Montagu, 1803), type locality, England, $2-5 \mathrm{~cm}$ in length, 3-8 mm in width (Fauvel 1927: 382-384). In surveying the tropical Indo-West-Pacific Protula literature, the records can roughly be brought together into two taxa: (a) a larger taxon with branchial radioles arranged in a spire of 3-8 whorls, with a tube-diameter of up to $2 \mathrm{~cm}$ (ten Hove 1994: 109; Smith 1985: 92-97, 433, fig. 9e), named Protula bispiralis (Savigny, 1822), type locality, "les mers des Indes" (it was collected by F. Péron, thus, probably Australia [ten Hove 1994: 109; Weinberg 1996]) and, (b) a smaller one, Protula palliata, type locality Sri Lanka, described from a single specimen and characterised by a semicircular arrangement of the branchial radioles, at most in a 3/4 whorl, with a tube diameter of a few millimetres (Table 1). In Willey's type specimen, the body measured $19 \mathrm{~mm}$ in length (without branchial lobes), $3 \mathrm{~mm}$ in width; 
30-40 radioles per lobe. Willey named it for its most exceptional character, the collar, with very long lateral lobes "rolled on themselves" and "probably able to follow the branchial spire to its termination. ..." and "ventral border was slightly concave" (Willey 1905: 316; Table 1). Other characters: Thorax with 7 chaetigers with limbate chaetae, and with Apomatus chaetae and uncini from the $4^{\text {th }}$ chaetiger; thoracic uncini, P+ 20 teeth; Willey only illustrated an Apomatus chaeta, a sickle-shaped abdominal chaeta, and a profile view of the peg of a thoracic uncinus (Willey 1905, pl. 7, figs 183-185). The taxon, Protula palliata, as recorded in the literature, is possibly a complex of species (ten Hove 1994: 109).

Twenty years before Protula palliata was described, McIntosh (1885: 511) published an Indo-WestPacific Protula taxon, P. arafurensis, collected in the Arafura Sea by the Challenger Expedition. Unfortunately, the description was based on a single specimen lacking its branchial crown. As the species cannot be identified with certainty (ten Hove 1994; Table 1), P. arafurensis can only be regarded as a "species inquirendam", one that cannot even be taken into consideration for species identification (Table 1). The single later record, Treadwell's (1906) Protula ?arafurensis, is erroneous, the material was re-examined by one of us (HAtH) and belongs to the Vermiliopsis infundibulum / glandigera-complex. Protula procera Ehlers, 1918, type locality Aru Islands, Indonesia, differs from P. palliata in its short collar, larger size, larger number of radioles in a single lobe (56), and in a pectinate (rather than circular) arrangement of the radioles; the abdominal chaetae appear sickle-shaped (Ehlers 1918 pl. 17, fig. 9). Protula anomala Day, 1955, type locality South Africa, and also reported from E. Australia (Smith 1985: 87-92), also can be excluded since it is clearly differentiated by its compound radiolar eyes and retrogeniculate abdominal chaetae (for a definition of retrogeniculate, see ten Hove \& Kupriyanova 2009: 26).

The present Suez Canal specimens from the Bitter Lakes are small, with a tube diameter of $<4 \mathrm{~mm}$ (Figs 21A, D), see below, and the branchiae are arranged in two semi-circles (Figs 17A, B and 19A-C). Thus, we can confidently exclude the Indo-Pacific taxon, Protula bispiralis, based on its spiralled branchial structure and large size, as well as the Mediterranean taxon, Protula intestinum, on account of its large size. (We have studied material of both nominal taxa from areas more or less adjacent to the Suez Canal). With much greater caution, we need to approach the identification of the smaller taxa from the Indo-Pacific and the Mediterranean that appear to be rather similar morphologically, as the mixed synonymies below suggest. Here the problem of allocation to species is exacerbated by Fauvel's having included the Persian (Arabian) Gulf and the Indian Ocean as part of the range of the Mediterranean species, Protula tubularia, in his "Faune de France," with a citation of the Indo-Pacific taxon, $P$. palliata, as a questionable synonym of $P$. tubularia (Fauvel 1927: 382-383). In his earlier Persian Gulf paper, Fauvel (1911: 433), the Protula included was $P$. palliata, and there Fauvel questioned whether $P$. tubularia was its synonym. However, in the report of the "Siboga" Expedition to the Malay Archipelago, Mesnil \& Fauvel (1939: 35) listed a Protula species as $P$. tubularia, with $P$. palliata as its synonym, and in that paper the authors noted that, "as concerns P. tubularia and P. palliata, neither the tubes, nor the worms showed differences sufficient to distinguish between them." Fauvel's (1953) "Fauna of India" again referred to the nominal species, Protula tubularia, and cited Protula palliata as its synonym. The illustrations were copied from the "Faune de France" (1927 fig. 257). We will never know whether, in arriving at this synonymy, Fauvel took into consideration the collar structure described by Willey, or whether he assumed the character to be of no particular importance, aberrant, or just described in an exaggerated way. In the later Indo-Pacific literature, Wesenberg-Lund (1949) listed Protula palliata and remarked on its very large thoracic membranes; Dew (1959) also listed P. palliata (citing Fauvel's 1911 publication); as did Pillai (1960: 5-7).

Fauvel's taxonomic (biogeographic) philosophy, especially on the occurrence of wide-spread "cosmopolitan" species, impacted not only on his own work but on an entire generation of polychaete researchers as well as on the present generation of non-specialists. In the following section on the genus Salmacina, we quote from Fauvel's remarks on his predisposition to regard similar taxa from different biogeographic regions as belonging to the same taxon (Fauvel 1933b: 144). In mitigation, Fauvel, who died in 1958 (age 92), seven years before the Scanning Electron Microscope became commercially available (Breton 2006), may have been unaware that he lacked an adequate tool for comparison of minute morphological structures. Moreover, in 1933, when he published the report on the Dollfus Expedition polychaetes, he would have been unfamiliar with the concepts of invertebrate sibling species, first introduced by E. Mayr in 1942 (see also Mayr 1963; Grassle \& Grassle 1976), and of cryptic species (e.g., Bucciarelli et al. 2002; Agapow et al. 2004). 


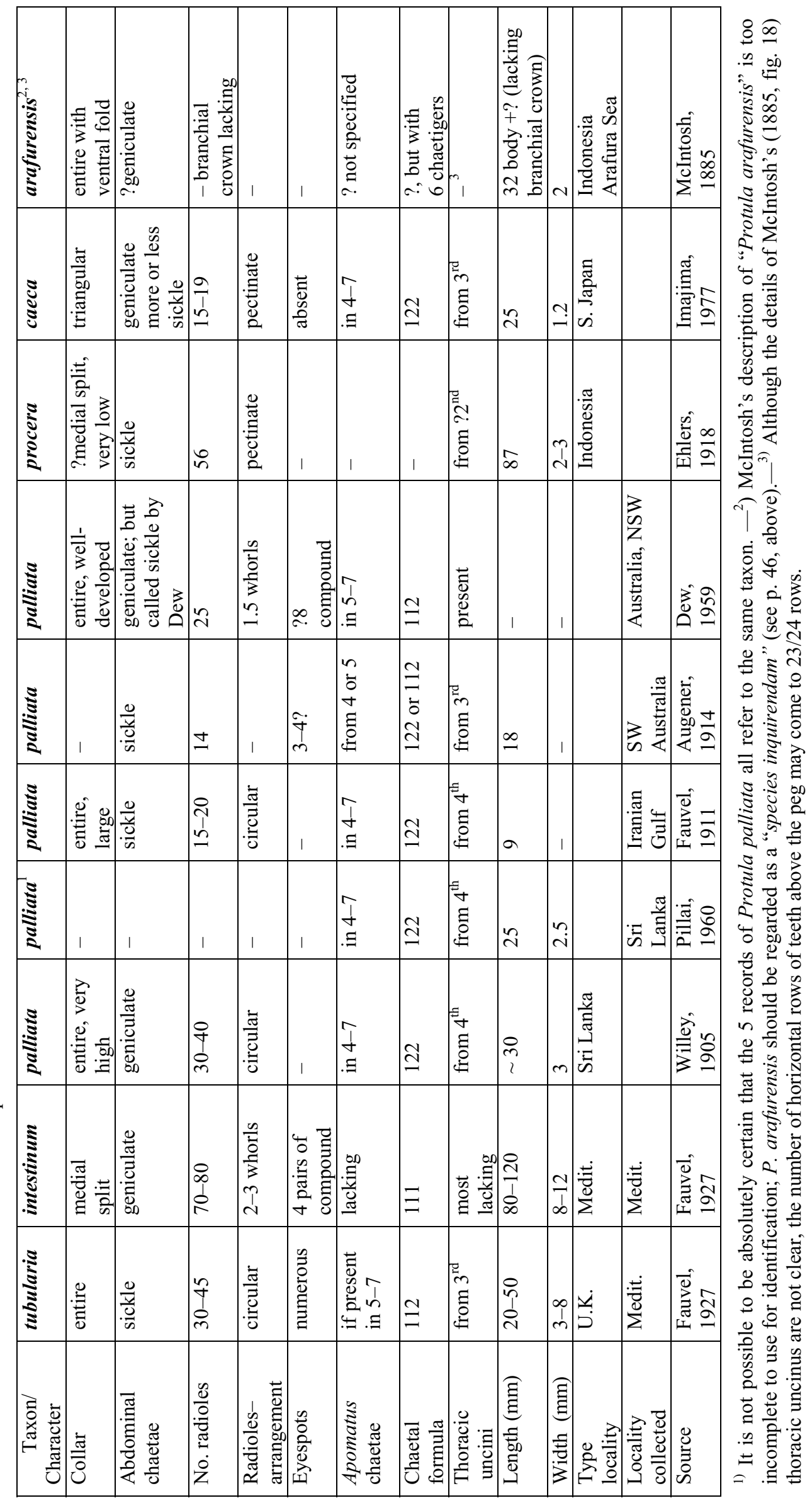


In order to minimize the potential for error due to synonymising similar taxa from different biogeographical provinces, we propose, in contradiction to the philosophy expressed in Fauvel (1933b), to adopt the most conservative biogeographical approach possible, treating Protula taxa from the AtlanticMediterranean and from the Indo-West-Pacific biogeographical provinces as separate species unless / until synonymy can be proved for them. It then follows that the name, Protula tubularia, should be reserved for the Atlantic-Mediterranean forms - as noted, the type locality is England (Montagu 1803) — and P. tubularia-like taxa occurring in the Indo-West-Pacific region should provisionally be assigned to P. palliata or to $P$. cf. palliata including the two unidentified Protula taxa with un-spiralled branchiae from the Seychelles and Amirantes Islands (ten Hove 1994: 109). We intend to continue looking for robust characters to distinguish between these taxa, particularly as the Suez Canal joins both the Atlantic-Mediterranean and Indo-WestPacific regions, in order to establish the provenance of the Suez Canal Protula species that colonized it.

Molecular techniques are not presently applicable to denatured formaldehyde-fixed specimens; thus for comparing the older specimens found in most museum collections, we can still only employ morphological techniques. We consider that some characters used in the past to distinguish between species of the genus Protula are not sufficiently robust to sufficiently discriminate between similar species. For example, the question of type of abdominal chaetae, whether sickle-shaped or geniculate, that Fauvel (1927: 382) used to discriminate between the two Protula species from the Mediterranean, may exist in reality, and may prove to be a workable character to differentiate between taxa. However, ten Hove \& Pantus (1985, fig. 2i-k) showed that the differences between the character states "sickle" and "geniculate" are not absolute but gradual, e.g., form of the abdominal chaetae varied within a single bundle from straight to geniculate, also with more or less sickle-shaped ones, and suggested that this character should be reserved for populations rather than for single specimens. In this regard, note the variability of shapes in abdominal chaetae of Protula specimens collected from underneath the same small rock in the Little Bitter Lake that ranged from sickle-shaped to geniculate (Figs 18G-J). We have even observed these different forms in a single individual from the Little Bitter Lake. Fauvel himself noted a reversal of the contour of abdominal chaetae produced by exposure to different chemicals (Fauvel 1927: 384, legend of fig. 130h, i), putting in question the differences in contour of abdominal chaetae as a robust taxonomic criterion. Differences in the collar structure also may not be a reliable criterion (ten Hove \& Pantus 1985: 427). A character that may prove useful in fresh Protula material (ten Hove \& Pantus 1985: 429-430), but not in preserved specimens, is the presence / absence of radiolar and prostomial eyespots, because eyespots observed in freshly described specimens may fade in preservative (Ben-Eliahu \& Fiege 1996; Table 2), and their durability in preservative is insufficiently well known (e.g., paired crimson eyespots densely positioned on the rachides of Spirobranchus tetraceros radioles faded within three years of formalin-fixation and preservation in alcohol [Ben-Eliahu et al. 2003]).

Presently, the best and most reliable morphological comparisons appear to be of the ultrastructure of the thoracic and abdominal uncini, using SEM micrography as a standard tool to determine, in frontal view, the number of rows of teeth and the number of teeth in the horizontal rows, the shape of the anterior tooth (in Protula, the "peg"), whether pointed, rounded, more or less swollen, truncated, "square-ended" or bilobed (e.g., Figs 18C, D, K, L; Fig. 20A, P:?4:4:4:3:3:1:1:1:1:etc.; Table 3), while the light microscope should be used as well for squash preparations to provide a profile view (Fig. 20B).

Mediterranean material of the nominal Protula tubularia has been studied with SEM by ten Hove \& Kupriyanova (2009) and again by the present authors. However, even with the SEM, due to the very close packing of the uncini in the torus, adjacent structures may be difficult to distinguish clearly. Thus, to better visualise the structure, uncini of Protula tubularia have been "cut" out of the photograph of the torus (Fig. 18K [thoracic uncinus, cut from ten Hove \& Kupriyanova (2009 fig. 39c), see detailed description in the legend]; and Fig. 18L-abdominal uncinus of specimen from the same sample) to compare with the abdominal uncini from specimens from the Little Bitter Lake (Figs 18C, D).

The following key presents some differences noted between these uncini:

1a. In the Suez Canal Protula taxon, both thoracic and abdominal uncini are of "saw-to-rasp-shaped" type, i.e., the teeth in the posterior apical (saw")-part are in single file (Figs 18C, D); the peg tip is bilobed, with 
rounded lobes (Figs 20D-G); the thoracic uncini have ca. $\mathrm{P}+19$ rows with ca. 3-?4 multiple rows, grading to ?4 minute teeth in the row proximal to the peg (Fig. 20A).

1b. In the Mediterranean Protula tubularia (Figs 18K, L), in both the thoracic and abdominal uncini, the teeth in the apical part form an angled double row, the uncini are thus "rasp"-shaped type in both apical (posterior) and proximal (anterior) parts and the tip of the peg appears more blunt (possibly abraded); moreover, the number of teeth is much greater; the thoracic uncini have ca. 21 apical angled double rows and ca. 17 multiple anterior rows grading to ca. 5-7 minute teeth in the rows proximal to the peg, with ca. 7 teeth in the proximal row, ca. 38 rows of minute teeth (counted from enlarged figs 39 a, c in ten Hove \& Kupriyanova (2009) and Fig. 18K).

These differences in ultrastructure of the uncini point to the Mediterranean and Suez Canal Protula taxa as being different. Although recognizing that the ultrastructure may be variable and that the small number of specimens examined lacks a statistical basis of confidence, these differences presumably justify excluding the Mediterranean taxon, P. tubularia, as a founder population for the Bitter Lake specimens and support a Red Sea derivation for the population. That inference is bolstered by the fact that Beets' Protula tubes were found on molluscs dredged from the floor of the Great Bitter Lake, thus, not connected directly to ship fouling, more so, as foulers of this genus have not yet been recorded from the Indo-Pacific (ten Hove 1994: 109). Another factor supporting the inference of a Red Sea derivation is the lecithotrophic nature of the Protula larva that dictates a short-term larval life and rapid settlement (Kupriyanova et al. 2001; See Discussion, Section 6a). Taking these factors and the taxonomic approach discussed above into consideration, we designate the Protula species from the Suez Canal as $P$. cf. palliata, subject to confirmation by comparison with topotypical $P$. palliata material. (Meanwhile, efforts to obtain topotypical specimens have not yet proved successful. Moreover, the National Museum Colombo, where A. Willey had been a director, does not have any specimens [M. Goonatilake, NMC and Dr. T.G. Pillai, NHM, pers. comms.]).

\section{Protula cf. palliata (Willey, 1905)}

Figs 17-22, Table 2

Records from the Red Sea proper-Indo-West-Pacific that (most probably) can be attributed to the nominal taxon Protula palliata are:

Protulopsis palliata Willey, 1905: 316, pl. 7, figs 183-185 [Type locality: Indian Ocean, Sri-Lanka, Galle, 29-55 m depth].

Protula palliata: Fauvel 1911: 433-434 [Persian (Arabian) Gulf, Sri Lanka]; Wesenberg-Lund 1949: 361 [specimen without tube; northern Persian (Arabian) Gulf; Sri Lanka, Australia]; Dew 1959: 50-52 [Western Australia: Shark Bay, Rottnest Island, Ceylon, Persian Gulf]; Pillai 1960: 5-7, text-fig. 2 a, b [Sri Lanka, 18-22 m)].

?Protula palliata: Fauvel 1918: 342 [specimen lacking branchial crown and tube, det. by chaetae; Persian Gulf]; Fauvel 1919: 465-466 [lacking branchial crown and tube; Persian Gulf, Sri Lanka, Australia]. Question mark for both these identifications is that of Fauvel.

Protula (Protula) palliata: Uchida 1978: 37 [no distribution data].

Protula tubularia most probably not (Montagu, 1803) but sensu auct.: Fauvel 1927: 382-383 [Persian Gulf, Indian Ocean]; Mesnil \& Fauvel 1939: 35 [Indonesia, Ternate; Atlantic, Mediterranean, Persian Gulf, Indian Ocean, Malaysia, Japan, Australia]; Fauvel 1953: 472 [Ceylon, Japan, Australia, Malay Archipelago, Indian Ocean, Persian Gulf, Atlantic Ocean, Mediterranean Sea]; Day 1967: 820 [unlikely distribution: Atlantic from Greenland, Scotland, south to English Channel, the Gulf of Mexico, Morocco, Senegal, Mediterranean, Indian Ocean, New Caledonia, Japan]; Amoureux et al. 1978: 151 [Red Sea, Gulf of Aqaba, 70-80 m (in 2005, specimen not located)]; Uchida 1978: 37-39 [unlikely designation as cosmopolitan and see below]; Vine \& Bailey-Brock 1984: 147 [unlikely distribution from Amoureux et al. 1978: Europe, Red Sea, Australia]; Smith 1985: 83-87 [Australia]; Wehe \& Fiege 2002: 130 [compiled list of references, considered as questionable in Red Sea, quoting H.A. ten Hove, pers. comm.].

Material examined for comparison, from locations adjacent to the Suez Canal, Mediterranean side: Protula tubularia: Off Marseilles and Banyuls, 3-55 m, scuba, legit F.J.A. Pantus 1981, det. ten Hove \& Pantus (1985), ZMA V.Pol. 3813, 3816, 4314, 4315, 13 specs-northwest of Crete, 943 m, "Pola" Stn 71, 

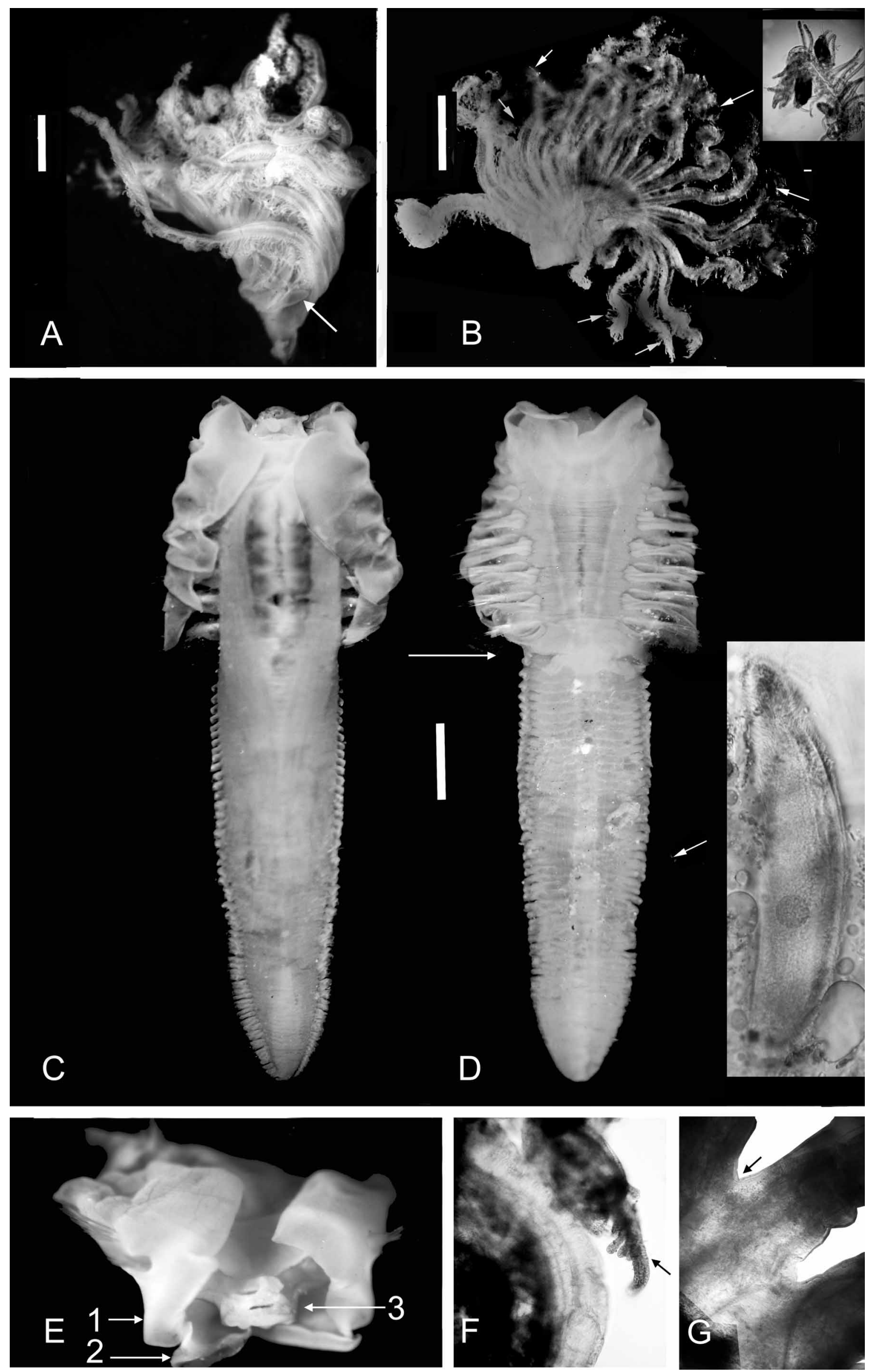
6.VIII.1891, det. E. von Marenzeller, NHMW, Musei Vindobonensis (Evert. varia) 2120, Ak. 6576, 1 spec.; chaetal formula 112, sickle abdominal chaetae, white branchial blotches not present, eyespots reported in Marenzeller (1893) no longer visible in 1995 (Ben-Eliahu \& Fiege 1996: 28). —off central Israel, Tel AvivJaffa, 95-103 m, “Meteor"-V Stn 50 ku, legit M. Türkay 26.I.1987, SMF 5533, 5535, HUJ-Poly-1032, 3 specs + many empty tubes; largest complete, 71 chaetigers, length $33 \mathrm{~mm}$ (branchial crown $8.5 \mathrm{~mm}$ ), width $2.2 \mathrm{~mm}$ (Ben-Eliahu \& Fiege 1996: 28).--Israel, Nitzanim, 80 m, legit B. Galil 23-26.X.1977, det. M.N. Ben-Eliahu, TAU-NS-18634, 2 specs—off Egypt, 196-199 m, “Meteor"-V Stn 25 ku, legit M. Türkay 26.01.1987, SMF 5534, 1 spec.; 66 chaetigers, length $28.5 \mathrm{~mm}$ (branchial crown $12.5 \mathrm{~mm}$ ), width $3 \mathrm{~mm}$ (Ben-Eliahu \& Fiege 1996: 28).

Material examined. Suez Canal material reported herein: 3 samples with 3 empty tubes, and two samples with 4 and 3 (mostly fragmented) specs, respectively.-Beets' Dry Great Bitter Lake mollusc samples, VIII / IX 1950, RMNH, 3 samples, 3 empty tubes: Stn 15, 1 large tube fragment (Figs 21A-C); Stn 19, small tube; Stn 26, 1 tube.-Hebrew University-Smithsonian Expeditions, 1967-1973. Little Bitter Lake, SBE 1: 4 bodies and 2 detached branchial lobes (other branchial lobes lost), bodies and separated branchial lobes assigned individual catalogue numbers (Figs 17, 18, Table 2): 2 small bodies, HUJ-Poly-1569 (Figs 17C-E, 18A, E, F, H) and HUJ-Poly-4427 (Figs 18 C, I, J); one small detached branchial lobe, HUJ-Poly-4428 that could have belonged either to HUJ-Poly-1569 or to 4427 (Figs 17 B, F); 2 larger bodies, largest, HUJ-Poly1570 (Fig. 18D, E), and a branchial lobe, HUJ-Poly-4430 (Figs 17A, G, presumably belonging to HUJ-Poly1570); smaller body, HUJ-Poly-4429 (Figs 18B, G; [see Table 3]).—Great Bitter Lake "Yellow Fleet" Biofouling Samples, January 13-20, 1975, 3 subsamples, 3 specs: B\&T-A-Pol 17 = HUJ-Poly-1564; B\&T-B-Pol 24 = HUJ-Poly-1568, and B\&T-C-Pol 27 = HUJ-Poly-1567 (Figs 18-19, 20D).

Material examined for comparison, from locations adjacent to the Suez Canal, Red Sea side: Gulf of Suez: None.-Gulf of Aqaba: None.-Red Sea proper-Indo-West-Pacific: Protula ?palliata, South Red Sea, Eritrea, Dahlak Archipelago, Moharib Island, east of Dahlak Island, $15^{\circ} 40^{\prime} \mathrm{N}, 40^{\circ} 37^{\prime} \mathrm{E}$, dredge 1, depth unknown, legit A. Ben-Tuvia \& O.H. Oren, 8.II.1958, sample E58 / 229, as P. tubularia, redet. H.A. ten Hove 1990 P. ?palliata, HUJ-Poly-4426, 1 spec. (Fig. 22). - Protula bispiralis, Indian Ocean, Zanzibar, legit C. Crossland, 1901-1902, det. H.L.M. Pixell (1913: 88) Protula intestinum, redet. H.A. ten Hove 19.V.1992 P. bispiralis, noting that Pixell had overlooked the spiralled branchiae, BM(NH) ZB 1924.6.13.181a, 1 spec.Indonesia, Marsegu Island, in coral, legit T. Monod \& R. Serène 18.I.75, Expedition "Rumphius" II, Stn Mars. III (location data from Monod 1976), det. L. Amoureux or F. Rullier Protula tubularia, redet. H.A. ten Hove 19.V.1992 P. bispiralis, noting that the determinator had overlooked the spiralled branchiae, MNHN A $890=$ AS 364.

Suez Canal depth and substrates: Beets' samples: Fragments of empty tubes on shells of bivalves, Brachidontes pharaonis (1 spec.) and Chama asperella (3 specs), from [5-5.5 m]-10.8 m. (Figs 21A-C); SBE 1, ca. $0.4 \mathrm{~m}$, under rocks; Brattström and Taasen samples from biofouling on the "Yellow Fleet" ships, between $0-4 \mathrm{~m}$, presumably no deeper than $1.5 \mathrm{~m}$ (Fig. 21D).

FIGURE 17. Protula cf. palliata from the Little Bitter Lake. Body and branchial lobes of specimens collected under rocks from the eastern bank. A-Semicircular branchial lobe, inside view of left lobe (spec. 4430), showing turning in of lobe, 21 radioles (when flattened); arrow points to dorsal ovoid mouth palp at the base of the lobe, B-Left branchial lobe (no. 4428), outside view, spread flat, shows 24 radioles, estimated length of radioles <4 ( 3.6) mm; arrows point at copepod ectoparasites near tips of radioles, and inset shows radiole tip with several attached copepods, C, D-Body, dorsal and ventral side, respectively (spec. 1569). Note (in C) broad thoracic membranes, two dorsal lobes; and, in D, two ventral lobes; arrow points to apron, 7 thoracic chaetigers and ca. 64 abdominal chaetigers, length 8.9 mm, width, 2.2 $\mathrm{mm}$; inset shows sporozoan endoparasite from abdominal coelom, E-Three-quarters frontal view of specimen (spec. 1569), "l" indicates dorsal lobes of thoracic membranes; " 2 " the ventral lobes; " 3 " marks the mouth, F-Arrow points to "naked" tip of branchial radiole (no. 4428), G-Low inter-branchial membranes designated by arrow (no. 4430). Scales, $1 \mathrm{~mm}$ (Table 2). For details of specimen codes, see Protula section, Hebrew University-Smithsonian Expeditions, sample SBE 1, Appendix Table 2). 

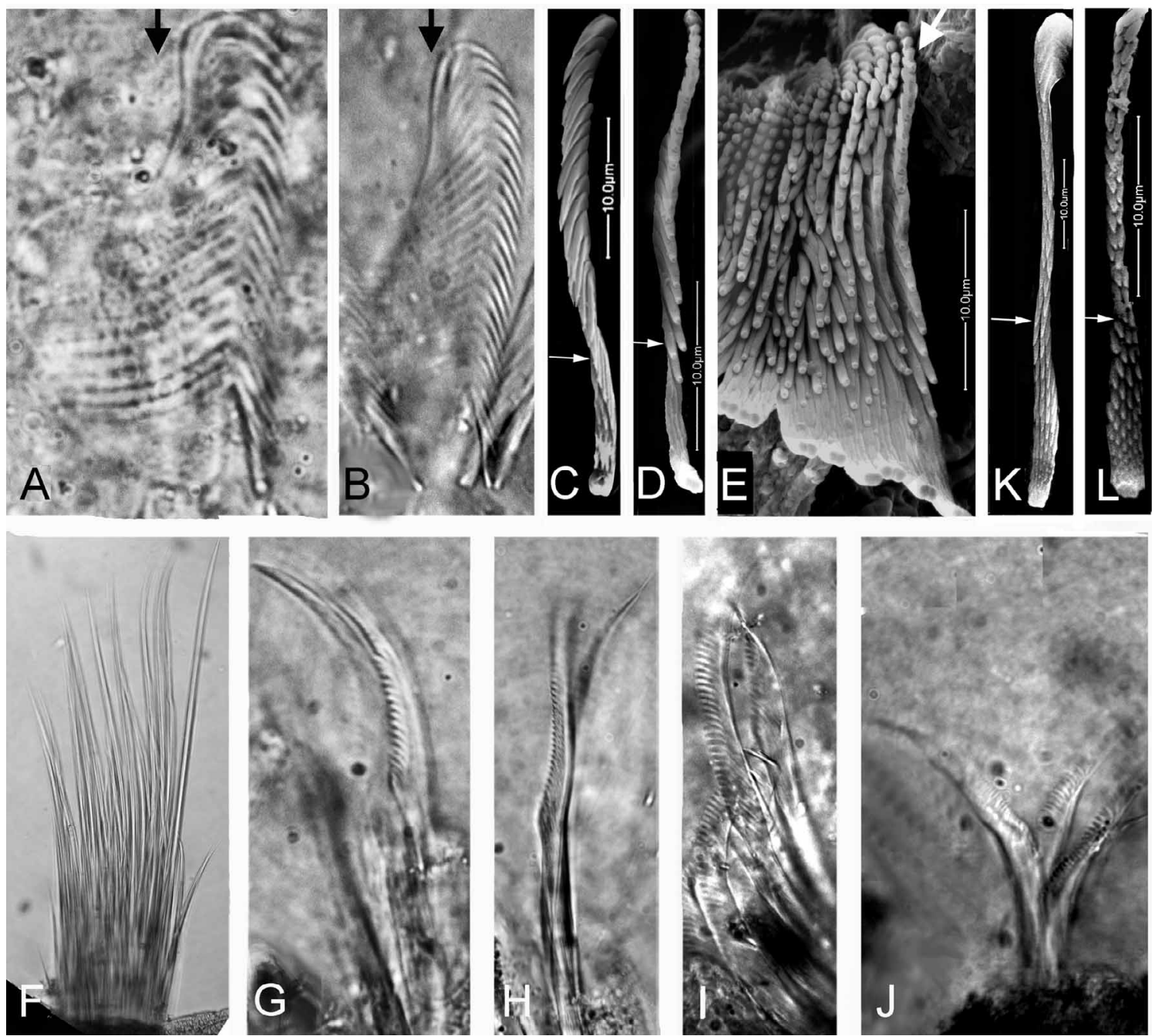

FIGURE 18. Protula cf. palliata from the Little Bitter Lake. Chaetae and uncini (HUJ-Poly-1569, 1570, 4427, 4429, sample SBE1). A-Thoracic uncinus, saw-to-rasp-shaped (spec. 1569) with ca. 19 teeth in profile view $(\mathrm{P}+19)$, length $39 \mu \mathrm{m}$ from apex to tip of peg, B-Abdominal uncinus from mid-body saw-to-rasp-shaped (spec. 4429) with ca. 24 rows of teeth in profile view, length $45.9 \mu \mathrm{m}$ (pegs of additional uncini displaced when squashing the preparation seen in bottom left and right; left of arrow, part of uncinus inserted in the body wall, C, D-Frontal (edge) view of abdominal uncini "cut" from SEM micrographs of the tori, C-Spec. 4427, abdominal uncinus, with apex partially turned to the side, with ca. 24 teeth in profile view; from the apex, 18 teeth in single row, followed by ca. 2 rows with 2 teeth, then 2 rows of 3 teeth, and 2 rows of 4 teeth, arrow demarcates saw-part of the uncinus from rasp-shaped part; length, $\sim 34 \mu \mathrm{m}$ (magnification $6 \mathrm{~K}$ ), D-Spec. 1570, dorsal-most uncinus with 24 teeth in profile view; from the apex, ca. 18 teeth in single file, followed by 2 rows of two teeth, then 2 row of 3 teeth and 2 rows of 4 finer teeth proximal to the bilobed, rounded peg; (arrow demarcates saw-part of the uncinus from rasp-shaped part); length $\sim 28 \mu \mathrm{m}$ (magnification $9 \mathrm{k}$ ), E-Spec. 1570, SEM micrograph of part of the torus, magnification $9 \mathrm{k}$; location of " $\mathrm{D}$ " in torus marked by arrow (another SEM of this torus, presumably most of the torus, magnified only $3 \mathrm{k}$, numbered at least 65 abdominal uncini); note that dorsal-most uncini are longer than the ventral uncini; 6th more ventral uncinus measures $21 \mu \mathrm{m}, \mathrm{F}-\mathrm{Spec}$. 1569, thoracic chaetae limbate (bordered) capillary chaetae only, Apomatus chaetae not observed, G-J-Abdominal chaetae from different specimens belonging to the same sample: G-Rather sickle-shaped with a somewhat prominent "heel" (spec. 4429), HSomewhat concave proximally, less sickle-shaped than G (spec. 1569), I-Somewhat geniculate (spec. 4427), J- Both chaetae somewhat geniculate but also somewhat concave (spec. 4427 [1819]), K-Thoracic uncinus of Mediterranean Protula tubularia (Banyuls, France, ZMA.V.Pol. 3816), 1st torus (adapted from ten Hove \& Kupriyanova, 2009 , fig. 39c); from apex, 16-15 angled double rows of teeth, followed by ca. 3 rows of 3; 1 row of 4, 3 rows of 5, reaching ca. 78 teeth in rows above bilobed peg, length of uncinus $\sim 49.6 \mu \mathrm{m}$; arrow demarcates posterior-part of the uncinus from rasp-shaped part with more teeth in row, L-Anterior abdominal uncinus of Protula tubularia from same population as $\mathrm{K}$, as in thoracic uncini the distal part comprises double row, ca 16 angled rows; proximal part, demarcated by arrow, comprises 9 rows with numbers of teeth increasing from 3 to ca. 7, 27.3 $\mu \mathrm{m}$ (Table 2). For Suez Canal specimen codes, see Protula section, Hebrew University-Smithsonian Expeditions, sample SBE1). 

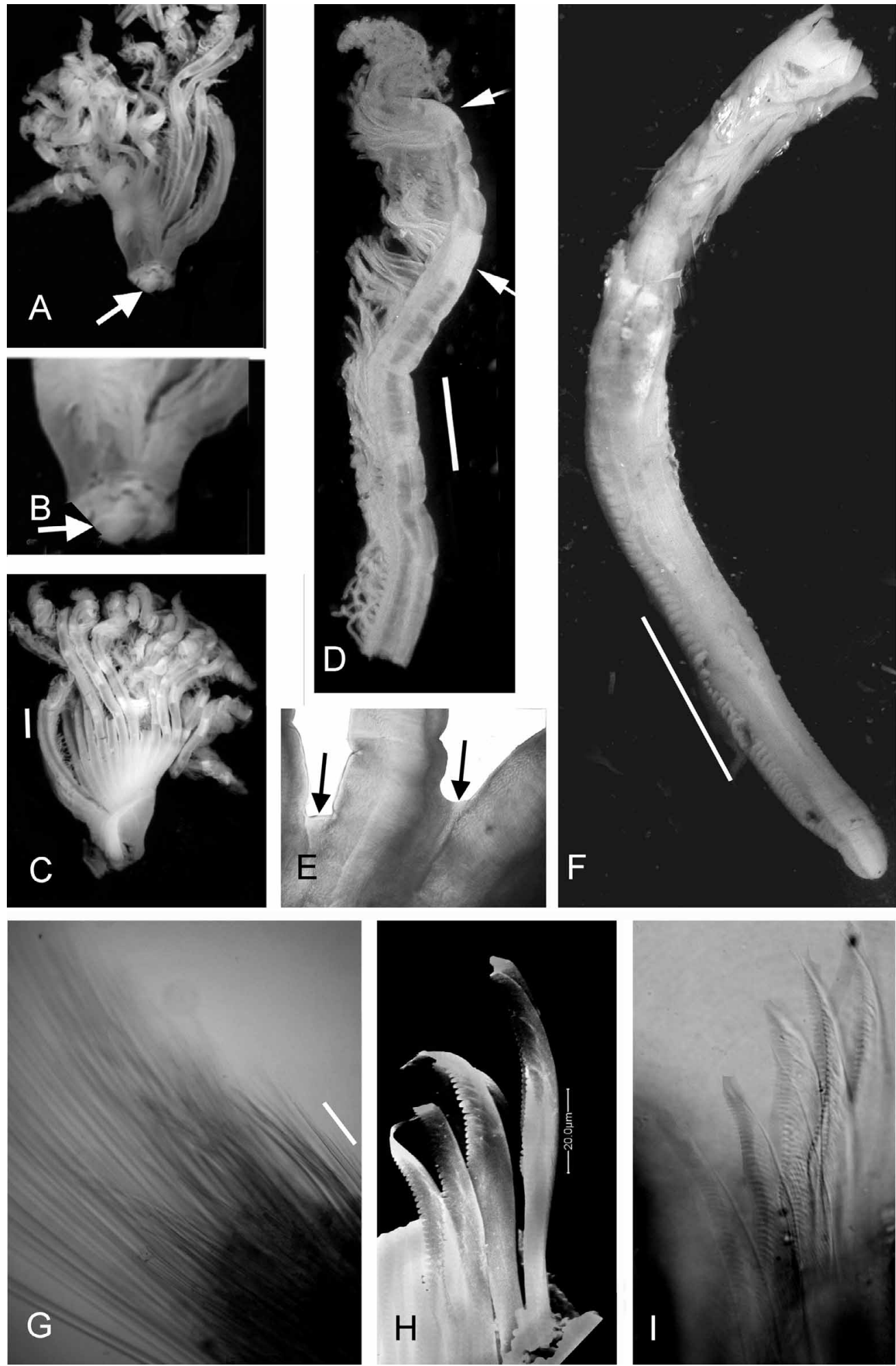

FIGURE 19. Protula $\mathrm{cf}$. palliata from the Great Bitter Lake (B\&T-C-Pol 27- HUJ-Poly-1567), ca. 87 chaetigers, body $\sim 27 \mathrm{~mm}$ length $+\sim 5.6 \mathrm{~mm}$ branchia $=$ total length $\sim 32.6 \mathrm{~mm}$; width, $\sim 2.2 \mathrm{~mm}$. A-Branchial lobe, inside view; arrow designates dorsal ovoid mouth palp; 19+ ?few more radioles, B-Enlargement of base of lobe to show the palp, CBranchial lobe, outside view, D-Radiole; arrows designate white blotches; note the tip appears less filiform than that in Fig. 16A (?likely due to preservation), E-Low interradiolar membrane of branchial lobe at base of branchial lobe (arrows), F-Body, thorax of 7 chaetigers and abdomen of ca. 80 chaetigers (counted from photograph), 3/4 view dorsal side up; note dorsal pygidial glandular pad, G-Thoracic chaetae of 7th (last) chaetiger, Apomatus chaetae not present,. H, I-Abdominal chaetae, sickle-shaped: H-SEM micrograph, 2,400 x, I. Microscopic view with oil immersion. Scales: C, D-1 mm, F-5 mm; G-100 $\mu \mathrm{m}$. 


\begin{tabular}{|c|c|c|c|c|c|c|c|c|c|c|c|c|c|c|}
\hline $\begin{array}{l}\mathscr{D} \\
\mathscr{n} \\
\tilde{D} \\
\mathscr{2} \\
\dot{n}\end{array}$ & 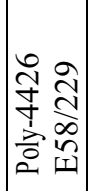 & ส & 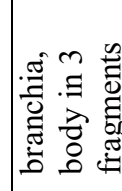 & $\begin{array}{l} \\
0 \\
\dot{r}\end{array}$ & 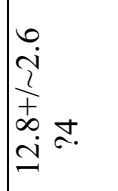 & $\mid \begin{array}{l}0 \\
i \\
i \\
\frac{i}{+} \\
\dot{b} \\
\dot{i}\end{array}$ & 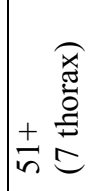 & $\vec{\imath}$ & : & 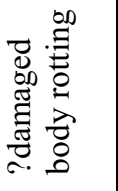 & ‡્ & $\cong$ & 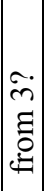 & 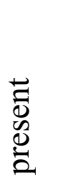 \\
\hline $\begin{array}{l}\widehat{\widehat{A}} \\
\dot{\vec{\sigma}} \\
\stackrel{\sigma}{\sigma}\end{array}$ & 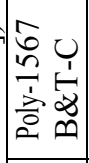 & $\begin{array}{ll}\hat{i} & \\
\hat{2} & \approx\end{array}$ & $\frac{0}{\frac{0}{3}}$ & $\begin{array}{l}0 \\
\dot{i} \\
i\end{array}$ & 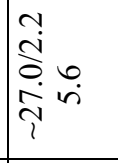 & 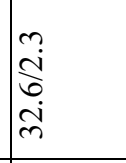 & 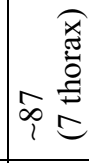 & $\frac{\text { d }}{\bar{Z}}$ & 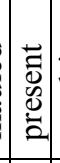 & 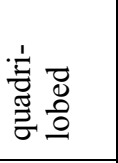 & 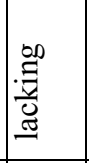 & $\Xi$ & 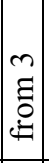 & 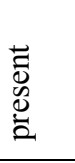 \\
\hline 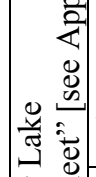 & 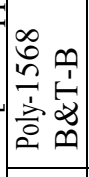 & 1 & 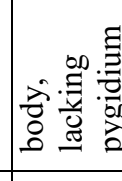 & $\begin{array}{l}\infty \\
\infty \\
\infty\end{array}$ & $\stackrel{+}{m} \vec{i}=$ & $\overline{ \pm} \bar{i}$ & 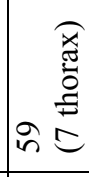 & iें & $\mid \begin{array}{l}\vec{u} \\
0 \\
0 \\
\vdots \\
\vdots \\
\vdots\end{array}$ & 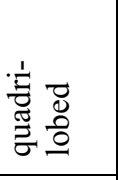 & 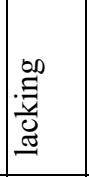 & $\exists$ & $\mid \begin{array}{c}1 \\
n \\
\vdots \\
\vdots \\
0 \\
\end{array}$ & 矛 \\
\hline 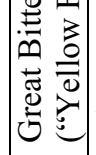 & 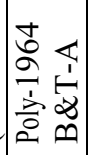 & I & 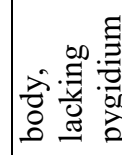 & $n$ & 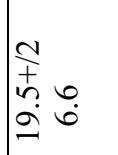 & 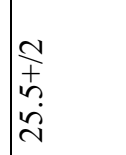 & 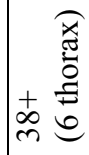 & $\stackrel{\sim}{\imath}$ & $\mid \begin{array}{l}\overrightarrow{0} \\
0 \\
0 \\
0 \\
\vdots \\
0\end{array}$ & 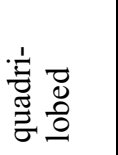 & 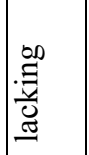 & $\Xi$ & 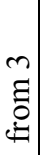 & $\begin{array}{ll}\overrightarrow{0} \\
\overrightarrow{0}\end{array}$ \\
\hline & 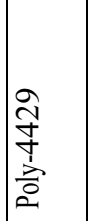 & $\begin{array}{l}0 \\
\infty \\
\infty \\
-\infty\end{array}$ & 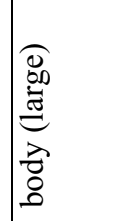 & | & 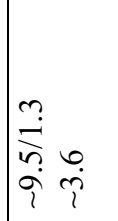 & 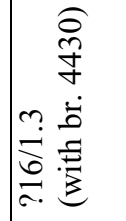 & 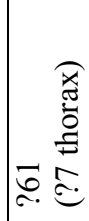 & | & 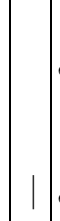 & 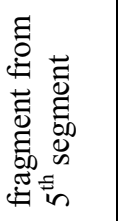 & 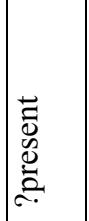 & $\Xi$ & 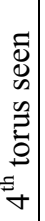 & 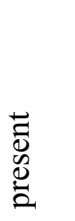 \\
\hline & 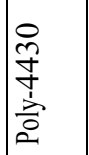 & $\begin{array}{l}0 \\
\mathbb{E} \\
-\end{array}$ & 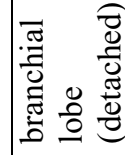 & $\begin{array}{l} \\
0 \\
\dot{r}\end{array}$ & 1 & $\mid$ & & $\bar{\lambda}$ & $\mid \begin{array}{l}0 \\
\stackrel{0}{0} \\
\stackrel{3}{2}\end{array}$ & | & | & 1 & 1 & $\mid$ \\
\hline & $\begin{array}{l}\frac{8}{2} \\
\frac{1}{1} \\
\frac{1}{a} \\
2\end{array}$ & ڤ & 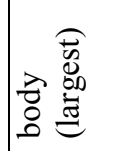 & & 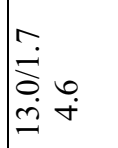 & 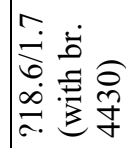 & 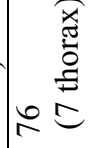 & | & & 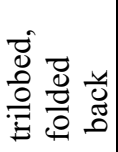 & 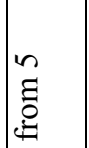 & $\cong$ & & 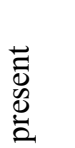 \\
\hline 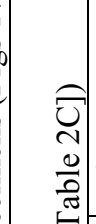 & \begin{tabular}{l}
$\infty$ \\
\multirow{2}{*}{} \\
\multirow{2}{*}{} \\
$\stackrel{2}{a}$ \\
\end{tabular} & 亲 & 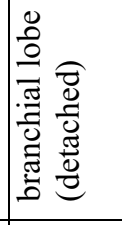 & $\mid \begin{array}{c}n \\
0 \\
0 \\
0 \\
0 \\
0 \\
0 \\
0 \\
\dot{n} \\
n\end{array}$ & 1 & $\mid$ & & 齐 & 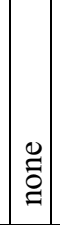 & | & 1 & 1 & 1 & $\mid$ \\
\hline 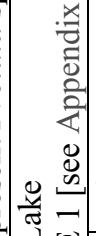 & 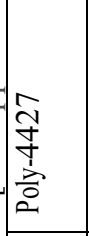 & 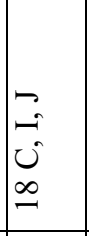 & 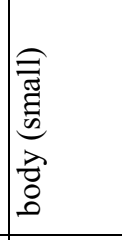 & & 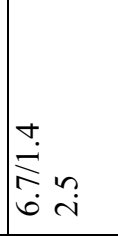 & 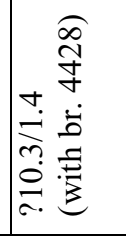 & 形 & & 1 & 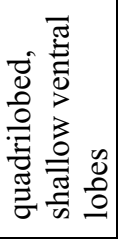 & 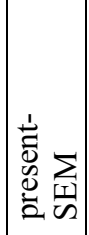 & $\cong$ & 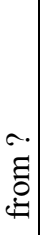 & 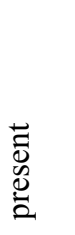 \\
\hline 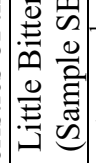 & $\frac{a}{8}$ & 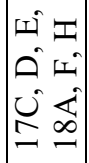 & $\frac{2}{8}$ & & 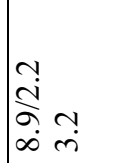 & 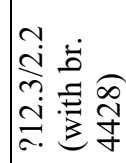 & r & I & 1 & 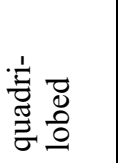 & 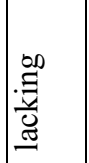 & $\Xi$ & 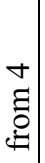 & 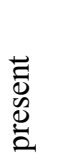 \\
\hline 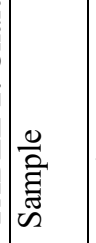 & 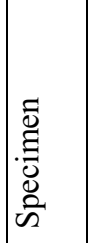 & 然 & $\begin{array}{l}\frac{1}{z} \\
2 \\
2 \\
\text { ż } \\
0 \\
0\end{array}$ & 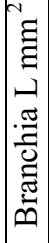 & 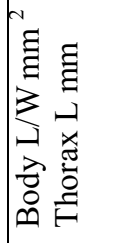 & 莡 & 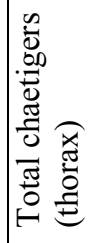 & 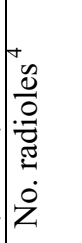 & $\mid \begin{array}{l}0 \\
0 \\
0 \\
0 \\
0 \\
0 \\
0 \\
0 \\
3 \\
3 \\
3\end{array}$ & $\frac{\text { 후 }}{\overline{0}}$ & 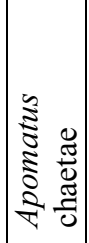 & 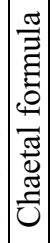 & 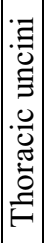 & 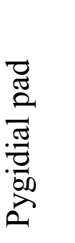 \\
\hline
\end{tabular}




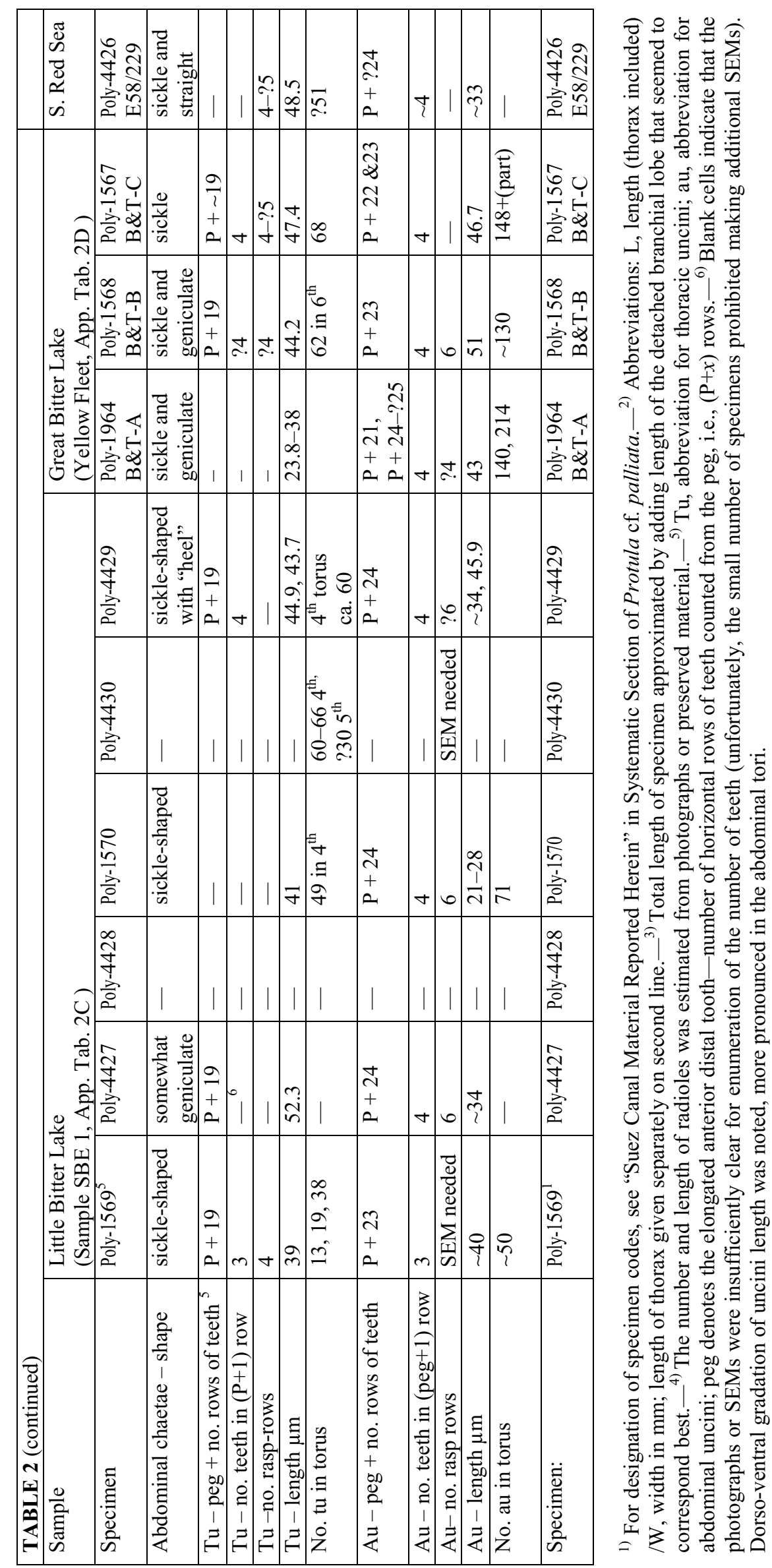


Tubes: Tubes from sample SBE1, Little Bitter Lake, were found beneath rocks at ca. $50 \mathrm{~cm}+$ the sparse field notes mentioned only a small coiled white tube with a flat keel (tubes damaged and now missing). The larger tubes with circular diameters collected by Beets 1950 and Brattström \& Taasen 1975 from the Bitter Lake (widest diameter $3.7 \mathrm{~mm}$ [spec. B\&T-C]) had growth rings with eroded, almost crenulated, rims that form their distinctive sculpturing; these tubes appear to have been erect (Figs 21 A-D). The difference in form and texture in the tubes of the Little Bitter Lake and Great Bitter Lake samples might be due to position and size (age) of the tubes.

Colour (field notes on fresh specimens from sample SBE1 [see App. Table 2C]): Branchia with several cherry-red bands; body with cherry-red colour very concentrated on margins of thoracic membranes (cherryred colour similar to no. 690 of the "Tambour" Paint Co., Israel). The "Yellow Fleet" specimens from the Great Bitter Lake were examined long after their colour had disappeared in the preservative.

Parasites: The branchial crown of a Protula cf. palliata specimen from the Little Bitter Lake was infested by copepod ectoparasites (HUJ-Poly-4428, Fig. 17B) and Sporozoa were found in the coelomic cavity of one specimen (HUJ-Poly-1569, Fig. 17D); regretfully, identifications for these parasites could not be obtained.

Description $^{1}$ : The Protula sample from the Little Bitter Lake consisted of four specimens in poor condition ( 4 bodies and 2 different branchial lobes separated from their bodies); the samples from the Great Bitter Lake ("Yellow Fleet") consisted of three subsamples, each with one specimen (altogether, 3 specs). The "Yellow Fleet" specimens were about twice as large as the Little Bitter Lake specimens, with the largest Great Bitter Lake specimen (B\&T-C), measuring ca. $33 \mathrm{~mm}$ (body ca. $27 \mathrm{~mm} /$ width $2.2 \mathrm{~mm}$ ), its branchial crown comprising ca. 20\% of the total length (Figs 19-20 and 21D), for 87 chaetigers (for details of parameters, see Table 2). ${ }^{1}$ The body of the largest specimen of the Little Bitter Lake sample (HUJ-Poly-1570) measured only $\sim 13 \mathrm{~mm}$ in length, ca. $1.7 \mathrm{~mm}$ in width; for $\sim 76$ chaetigers. Assuming the branchial lobe was about $20 \%$ of the length, the largest specimen might have come to $\sim 18 \mathrm{~mm}$ (including the larger of the unattached branchial lobes in the sample [HUJ-Poly-4428 and 4430, respectively; see Table 2]).

In the branchial crown, radioles in a circular arrangement, at most in a 3/4 whorl; particularly in the Great Bitter Lake specimen B\&T-C (Figs 19A-C), the ventral side appears to have a higher base than the dorsal part (with the palps). The radioles numbered ca. 21-25 radioles per lobe (Figs 17A, B [HUJ-Poly-4430, 21 radioles; 4428, 24 radioles, respectively], Figs 19A-C [spec. B\&T-C], 19+ some damaged radioles). The radioles have short "naked" tips (Figs 17F, 19D). The interradiolar membranes were low (Figs 17B, G; 19C). The mouth palp that extends from the dorsal part of the branchial lobe is short, ovoid, and "leaf-like" with a pointed tip (Figs 17A, 19A, B). While the radioles of the Great Bitter Lake specimens had white blotches(see Smith 1985: 433, fig. 9d)—considered indicative of Protula (Ben-Eliahu \& Fiege 1996: 23), none were seen in the Little Bitter Lake specimens.

The genera Apomatus and Protula differ in the presence or absence of an operculum, absence or presence of white blotches on the radioles, respectively, and the disposition of their radiolar ocelli. Where the rachides of Apomatus species have clusters of ocelli, Protula rachides have simple eyespots or eyespots are lacking (Ben-Eliahu \& Fiege 1996: 27). In an attempt to establish that the Little Bitter Lake specimens lacking the white blotches were not in reality Apomatus specimens that had lost their opercula, i.e., not Protula specimens, the rachides (margins) of the branchial radioles of the Little Bitter Lake and Great Bitter Lake specimens were stained with methylene-blue and carefully examined under oil immersion to look for clusters of ocelli that would be characteristic of Apomatus. In the event, only single eyespots, characteristic of Protula, were found in both the samples. In retrospect, the Little Bitter Lake Protula specimens, freshly collected in 1973, should have been examined for ocelli before preserving the specimens. Brattström and Taasen's Great Bitter Lake (B\& T-C) fouling Protula material, collected in 1975, was also studied only many years after preservation. Thus, the coloration of those specimens was not addressed in the present paper.

Except for one specimen (Little Bitter Lake, HUJ-Poly-1570), that was noted as trilobed with collar folded back, all the collars were noted as quadrilobed (Figs 17C-E shows the median fissure of the ventral lobes to be rather shallow).

1. Concerning meristic data, all measurements and enumerations were done several times (usually from the photographic records), but an approximation sign is given for greater fidelity; as the material was difficult to see, the enumeration was very difficult to carry out, creating a severe constraint for obtaining data. 
The thoracic membranes indeed appeared rather broad (e.g., Fig. 17C of the Little Bitter Lake; and in undamaged specimens from both samples there were well-developed aprons (e.g., Figs 17D, 19F), and dorsal pygidial pads. One specimen from the Great Bitter Lake (B\&T-A) had only six thoracic chaetigers, but all the others had seven.

Chaetae and uncini: The complement of thoracic chaetae includes limbate chaetae (collar and all thoracic chaetigers), with Apomatus chaetae from the $5^{\text {th }}$ chaetiger (ten Hove \& Kupriyanova 2009). Although Apomatus chaetae may be lacking, they are also are very difficult to see when present- they appear to be lacking in all three Great Bitter Lake specimens, and were observed in only two of the specimens from the Little Bitter Lake (HUJ-Poly-4430 and -4427) - the latter seen after having examined the thorax under the SEM. Ten Hove \& Pantus (1985), define the chaetal formulas as 112 and 111, according to the presence of Apomatus chaetae.

As already mentioned above, Protula abdominal chaetae show variability. Figures $18 \mathrm{G}-\mathrm{J}$ shows that abdominal chaetae from different specimens belonging to the same Little Bitter Lake sample vary in form from rather sickle-shaped (with a somewhat prominent "heel" (Fig. 18G, spec. 4429); to somewhat concave proximally, less sickle-shaped than Fig. 18G (spec. 1569) up to rather geniculate or also somewhat concave (spec. 4427), differences that presumably are affected by the position when viewed, but that do not make for robust diagnostic characters. In specimen B\&T-C from the Great Bitter Lake (Figs 19H, I) the abdominal chaetae were sickle-shaped as seen in both SEM and microscope views, respectively).

The most robust taxonomic character is considered to be the structure of the thoracic and abdominal uncini that can be enumerated, although with great difficulty. The number of rows of teeth in the thoracic uncini was P+19 in three of the little Bitter Lake specimens and in one of the Great Bitter Lake specimens; in another Great Bitter Lake specimen the number of rows of teeth was enumerated as P+18-?19 rows. Lengths of the uncini (frontal view) decrease from the dorsal to the ventral part of the torus; the smallest measured was $23 \mu \mathrm{m}$ and the largest, $52.3 \mu \mathrm{m}$, with most thoracic uncini measuring ca. $40 \mu \mathrm{m}$ (Table 2). Frontal views of the thoracic uncinus shows the anterior part (proximal to the peg) to have ca. 4 rasp-shaped rows with 4 teeth in the row proximal to the peg (P: 4), decreasing posteriorly to a single row of teeth in the apical part of the uncinus; the elongate peg is bilobed with two rounded lobes (Table 2). The number of uncini in a torus differed (again, difficult to count). In one specimen (HUJ-Poly-4429), 60-66 uncini were counted in the $4^{\text {th }}$ torus, but ?30 in the $5^{\text {th }}$. The abdominal uncini are slightly shorter than the thoracic ones, but with more rows of teeth, ca. $\mathrm{P}+23-24,4-6$ rasp-like rows with the proximal row numbering 4 teeth, the apical part of the uncini is a single row as in the anterior abdominal uncini. Further examination (if additional specimens become available) should be carried out with the SEM to determine whether the teeth in the apical part of the posterior abdominal uncini form a double row, as the best quality photographs taken under the compound microscope seemed to show; this was most clear in the Red Sea specimen (Fig. 22G) and less so in other specimens; SEM micrographs are needed to determine that definitively, but, as noted, the material was sparse and, after several examinations, in poor condition. Increase in the number of teeth in horizontal rows towards the posterior is found in the rasp-like abdominal uncini of additional taxa, e.g., in Hydroides.

Remarks. Uncini of the genus Protula have a complex structure. In the Mediterranean Protula tubularia, the apical (posterior) part of the uncinus has teeth in double angled rows (thoracic uncini, fig. 39c, ten Hove $\&$ Kupriyanova 2009), thus, the adjective, "rasp-shaped" is applicable. However, in the present $P$. cf. palliata specimens from the Suez Canal and Red Sea, both the thoracic and certainly the anterior abdominal uncini, have an apical part with teeth in a single file, thus, for uncini of this kind, the preferred term should be "sawto-rasp-shaped" uncini. "Saw-to-rasp-shaped uncini" were also reported in two Protula taxa from Japan in Uchida (1978), but only in the thorax: Uchida's nominal P. tubularia taxon (pl. 12 i), was figured with 8 teeth in saw-like rows (single file) +12 rasp-shaped rows of teeth grading in number to 4 teeth in the $P+1$ row proximal to the peg (no. of teeth $=\mathrm{P}+20$ ) and the peg was figured as blunt, not markedly bilobed as in the present material; its structure differs markedly from that of $P$. tubularia from the Mediterranean (described above), and it should be regarded as a different taxon. Although the general structure and number of teeth of the thoracic uncini of the nominal Japanese $P$. tubularia seemed rather similar to those of present Suez Canal $P$. cf. palliata, the abdominal uncini are full rasps (Uchida 1978, pl. 12m). Could Uchida's nominal $P$. tubularia tax on be a member of a $P$. palliata species-complex, whose existence was previously debated in ten Hove (1994: 109)? Another taxon with a saw-to-rasp-shaped thoracic uncinus is P. apomatoides Uchida (1978 pl. $16 \mathrm{~b}, \mathrm{~h})$, but with rasp-shaped abdominal uncini not differentiated into anterior and posterior parts, 
seemingly uniform in the number of teeth in the horizontal rows. The nominal taxon, $P$. tubularia caeca Imajima, 1977 [type locality, Southern Japan] is considered as probably a full species according to ten Hove \& Kupriyanova (2009: 83); it has Protula-contour thoracic uncini that are fully saw-shaped, with only a single vertical row of teeth (an unusual character for Protula). In view of the presence of "rasp-shaped", "sawto-rasp-shaped " uncini and also "saw-shaped" uncini in the genus Protula, the generic description of Protula of ten Hove \& Kupriyanova (2009) might best be modified to "Thoracic and abdominal uncini rasp-shaped, or saw-to-rasp-shaped, or, more rarely, saw-shaped."

Due to the small number of specimens in our Suez Canal samples, we were not able to obtain the desired statistically significant characterization of variability in uncini structure in the Suez Canal population. Nonetheless, it appears that the SEM has provided us with the robust character we hoped to find to distinguish between the Mediterranean and Indo-Pacific Protula taxa, enabling us to confidently determine the provenance of the material.

Colouration and ocelli did not form part of Willey's (1905) description of Protula palliata (the material reached Dr. Willey already two years after being collected). Dew (1959) reported a yellowish colour with conspicuous bands of orange red and white blotches in the radioles and figured a radiole with ocelli along the rachis (Dew 1959, fig 20b), however, neither branchial or prostomial ocelli were mentioned in the text. Dew's figure 20a of a P. palliata tube appears very similar to the larger Suez Canal Protula tubes (Figs 21A-D).

The Red Sea Protula specimen (E58 / 229, Fig. 22), test-tube labelled P. tubularia, was redetermined in 1990 by H.A. ten Hove, who noted, at the base of the $4^{\text {th }}$ chaetiger, a fascicle with $\sim 30$ limbate chaetae and with 5 Apomatus chaetae (in most Protula taxa, the Apomatus chaetae if at all present are found from the $5^{\text {th }}$ chaetiger), the Apomatus chaetae had a distinct sickle shape (not straight as recalled by ten Hove from $P$. tubularia specs) and the ultrastructure of the uncini was different than in P. tubularia. As with the Little Bitter Lake Protula, the rachides of the branchia were checked for ocellar clusters, but clusters were not found; in this specimen, single ocelli were also not found. White blotches on the radioles were also not present. Protula tubularia caeca was reported with Apomatus chaeta on the $4^{\text {th }}$ chaetiger (Imajima 1977).

Ten Hove \& Pantus (1985) had suggested that the character, presence and location of Apomatus chaetae, should be dealt with as a statistically defined character for a population, rather as an absolute character for individual specimens; they considered that a reliable definition of the genus Apomatus should be based first and only on ventral thoracic blood vessel patterns. These are not observed in preserved material, and without that verification we cannot exclude the possibility that the specimen from the south Red Sea had in fact been an Apomatus specimen that lost its operculum! The same dilemma also exists for the Little Bitter Lake material that similarly lacked white blotches and the ocellar clusters characteristic of Apomatus, although single ocelli were found in the Little Bitter Lake specimens, supporting their identification as Protula.

Willey (1905) had described the collar of Protula palliata as being trilobed, with enormous dorsal projections of the thoracic membranes that presumably gave the taxon its name. Of described Indo-WestPacific Protula species (Table 1), the present material most closely resembles P. palliata, but differs from it in possessing unexceptional lateral collar lobes as compared with the very elongate ones described by Willey (1905: 316) for his single specimen. However, the ventral collar lobes in the present material were variable (Table 2). Actually, ten Hove \& Pantus (1985: 427) considered the structure of the collar an unreliable character due to its variability and fragility (see also Ben-Eliahu \& ten Hove 1989: 382, Ben-Eliahu \& Fiege 1996: 29). Of the eight reports of P. palliata sensu auct. (Table 1), from the Persian (Arabian) Gulf to Australia (Fauvel 1911, Augener 1914, Wesenberg-Lund 1949, Dew 1959, Pillai 1960, 1971, Straughan 1967b, c) only Straughan (1967b: 252, 1967c: 41), referred to extraordinarily long lateral lobes of the collar as described by Willey 1905: 316). As concerns the ventral part of the collar, three authors referred to it as "entire" (i.e., "trilobed" - although this is a misnomer), the remaining authors did not refer to this character at all (Table 1). As already noted, Willey (1905) reported P. palliata with Apomatus chaetae from the $4^{\text {th }}$ chaetiger (formula 122) based on a single specimen. Of the different citations mentioned in Table 1, three reported formulas of 122, one of either 122 or 112, and one of 112; two citations did not refer to this character; moreover, all these citations were based on few specimens). The chaetal formula, 122, was considered by ten Hove \& Pantus (1985) as diagnostic for Mediterranean Apomatus, with 112 as diagnostic for Protula tubularia, however, Ben-Eliahu \& Fiege 1996: 28 reported an unusual P. tubularia specimen from the Mediterranean coast of Egypt with formula 122. 

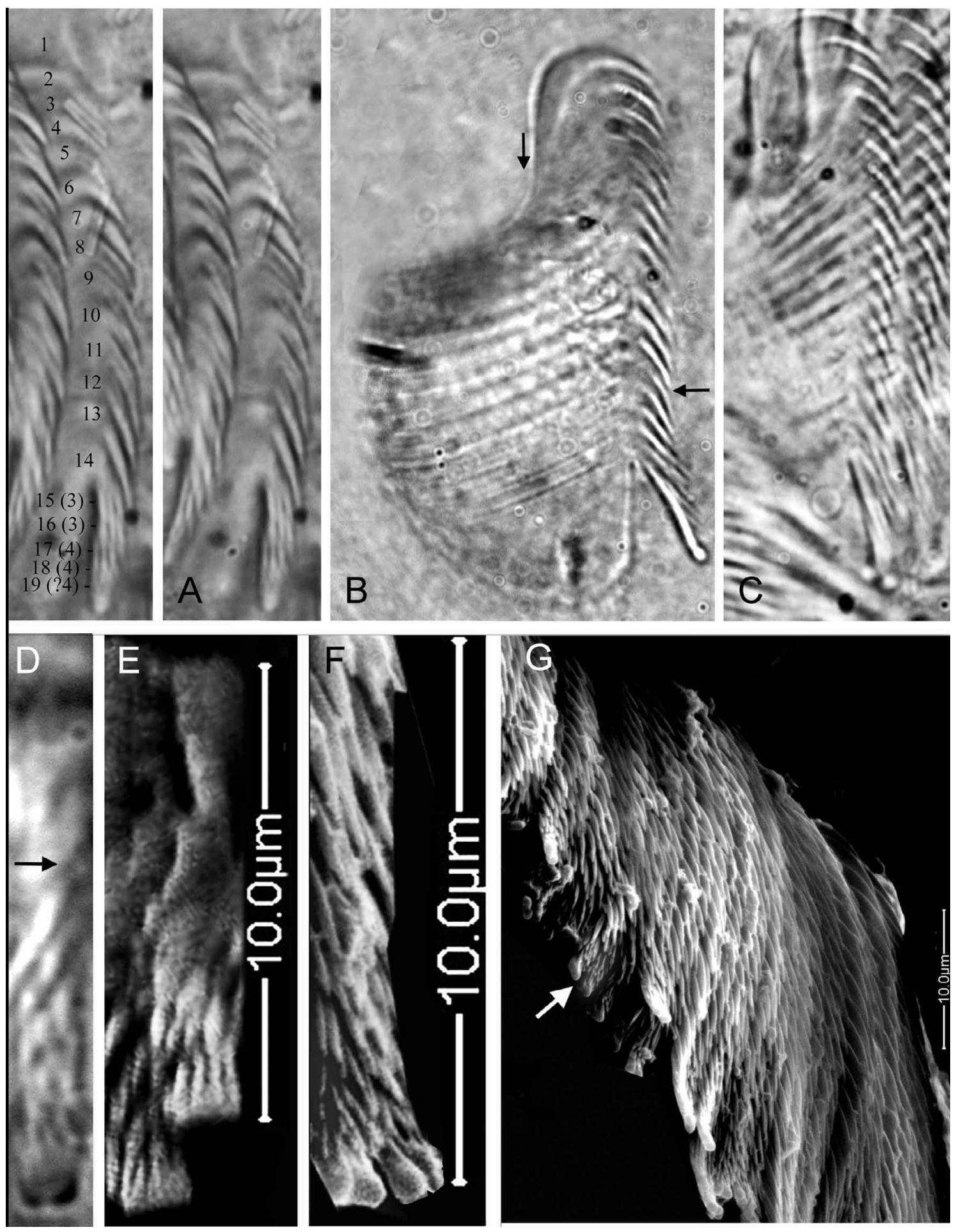

FIGURE 20. Protula cf. palliata from the Great Bitter Lake, uncini (B\&T-C Pol 27-HUJ-Poly-1567). A-Part of torus of thoracic uncini from 7th chaetiger, ca. P+19 teeth in profile view, from apex: 14 teeth in single row, two rows of 3 teeth, 2-?3 rows of 4 teeth (left figure shows method of counting the teeth), B-Abdominal uncinus, profile view, left arrow shows part of uncinus inserted in body wall, right arrow designates section of uncini to the peg corresponding to Fig. D, numbering 23 teeth in profile view, length $46.7 \mu \mathrm{m}, \mathrm{C}-$ Two adjacent abdominal uncini from torus, left uncinus numbering 22 teeth in profile view, length $47.5 \mu \mathrm{m}, \mathrm{D}-\mathrm{F}-$ Three views of enlarged peg, D-View taken under oil immersion, showing bilobed tip of peg, 4 teeth in row proximal to the peg; arrow shows part of uncinus corresponding to that designated by right arrow in Figs B, E-SEM micrograph showing frontal view of peg with 4 teeth in the two rows proximal to the peg (4,000 x magnification), peg appears abraded, F-SEM views of abdominal uncini showing markedly bilobed peg; magnification, 6,000 x, G-Part of torus of abdominal uncini from which $\mathrm{F}$ was taken, as indicated by arrow; the SEM micrograph of incomplete torus numbered 148 uncini (ends of torus not included on micrograph). 

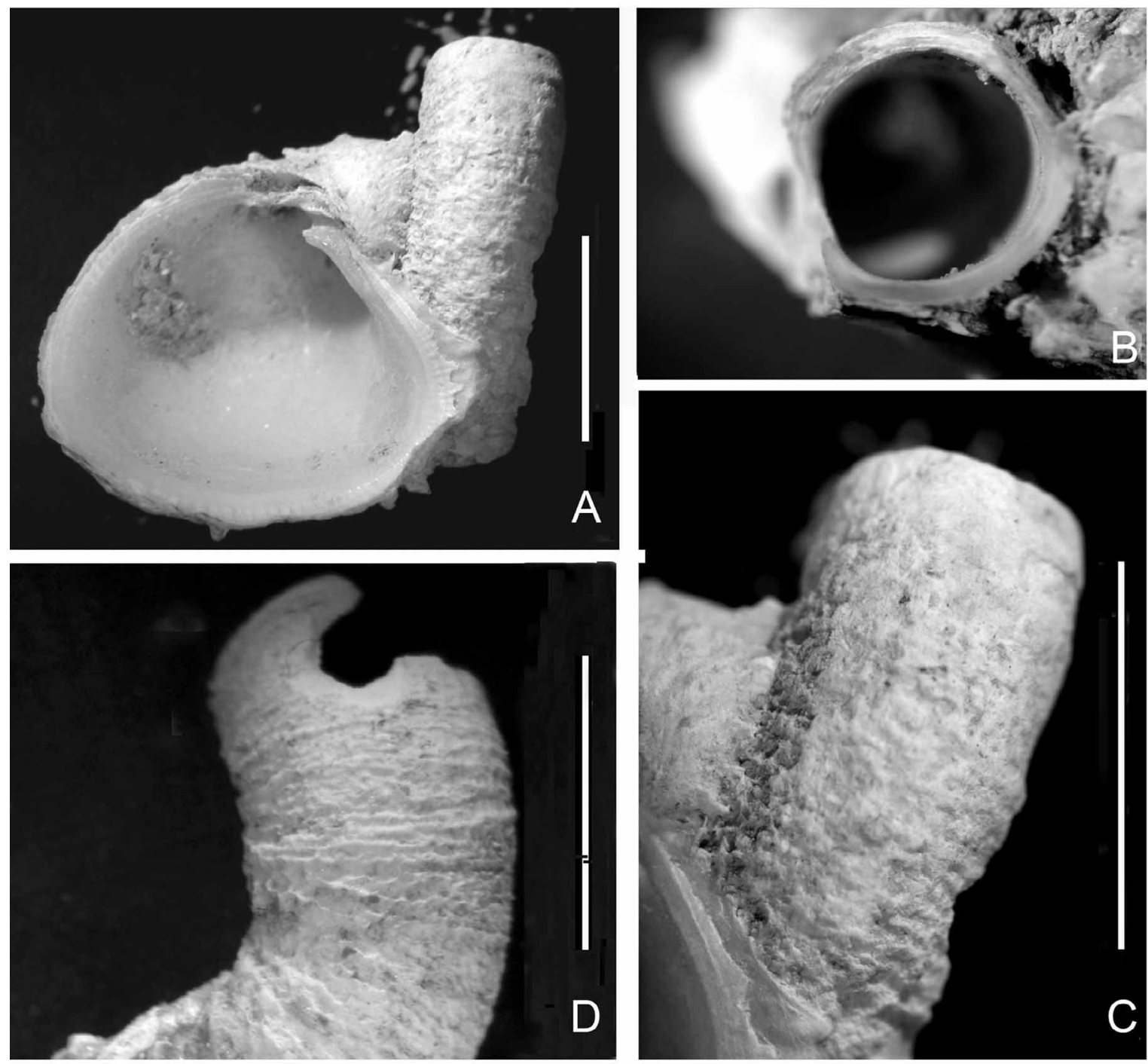

FIGURE 21. Protula cf. palliata tubes from the Bitter Lake with distinctive sculpturing-simple growth striations, but with the rim of the striation seemingly eroded with a somewhat scalloped appearance. A-C-Tube fragment of Protula sp. on Chama asperella from Beets' Stn 15, $10.4 \mathrm{~m}$ (Beets 1953): A-Inner view of Chama valve bearing tube of 3.6 mm diameter, B-Lumen of same tube fragment, diameter ca. $4 \mathrm{~mm}, \mathrm{C}$-Enlargement of A, D—Tube fragments of Protula specimen from "Yellow Fleet" encrustation (B\&T-C-Pol 27-HUJ-Poly-1567), legit H. Brattström and J.P. Taasen, 1975, diameter $4.8 \mathrm{~mm}$. Scales, $5 \mathrm{~mm}$.

FIGURE 22. Protula cf. palliata from Dahlak Archipelago, South Red Sea, Moharib Island, Eritrea, $15^{\circ} 40^{\prime} \mathrm{N} ; 40^{\circ} 37^{\prime}$ E; sample E58 / 229, 8.2.1958, dredge 1, depth unknown, legit A. Ben-Tuvia \& O.H. Oren [HUJ-Poly-4426]), det. as Protula not tubularia by ?, redet. M.N. Ben-Eliahu; Protula cf. palliata poorly preserved specimen, re-examined by H.A. ten Hove in 1990, had, at base of 4th chaetiger, fascicle with 30 limbate chaetae; 5 Apomatus chaetae of a distinct sickle shape. A-Tube fragments; surface slightly rugose (centre tube fragment shows flattish surface and keels), BBranchial crown, poorly preserved (rotted) body, mostly epidermis; arrow points at mouth palp, ca. 21 radioles (see Figs 16A, 18A), C-Torus of thoracic uncini (second) numbers ca. 51 uncini, D-Abdominal chaetae sickle-shaped, E-Part of body (decayed), upper, fragment of thorax, 6 chaetigers; middle, ? chaetigers; posterior abdomen, the best preserved part, ca. 44 chaetigers; fragments total $12.8 \mathrm{~mm}, \mathrm{~F}$ - Thoracic limbate and Apomatus chaeta (recurved, designated by left arrow; serrated inner margin, designated by arrow on the right), G-Middle abdominal uncini, frontal view, $\sim 34 \mu \mathrm{m}$, seems to indicate that from middle abdominal uncini to the posterior, that the posterior part of the uncinus has become a double row (angled). In order to prevent an (unlikely) misinterpretation due to differences in transparency in the microscopic view, this finding has to be verified and confirmed with the SEM, H-Middle abdominal uncini, lateral view, 24 teeth in profile view with several teeth in proximal rows to peg, uncini measure $\sim 33 \mu \mathrm{m}$. Scale: A, B, E-5 mm, G-10 $\mu \mathrm{m}$. 


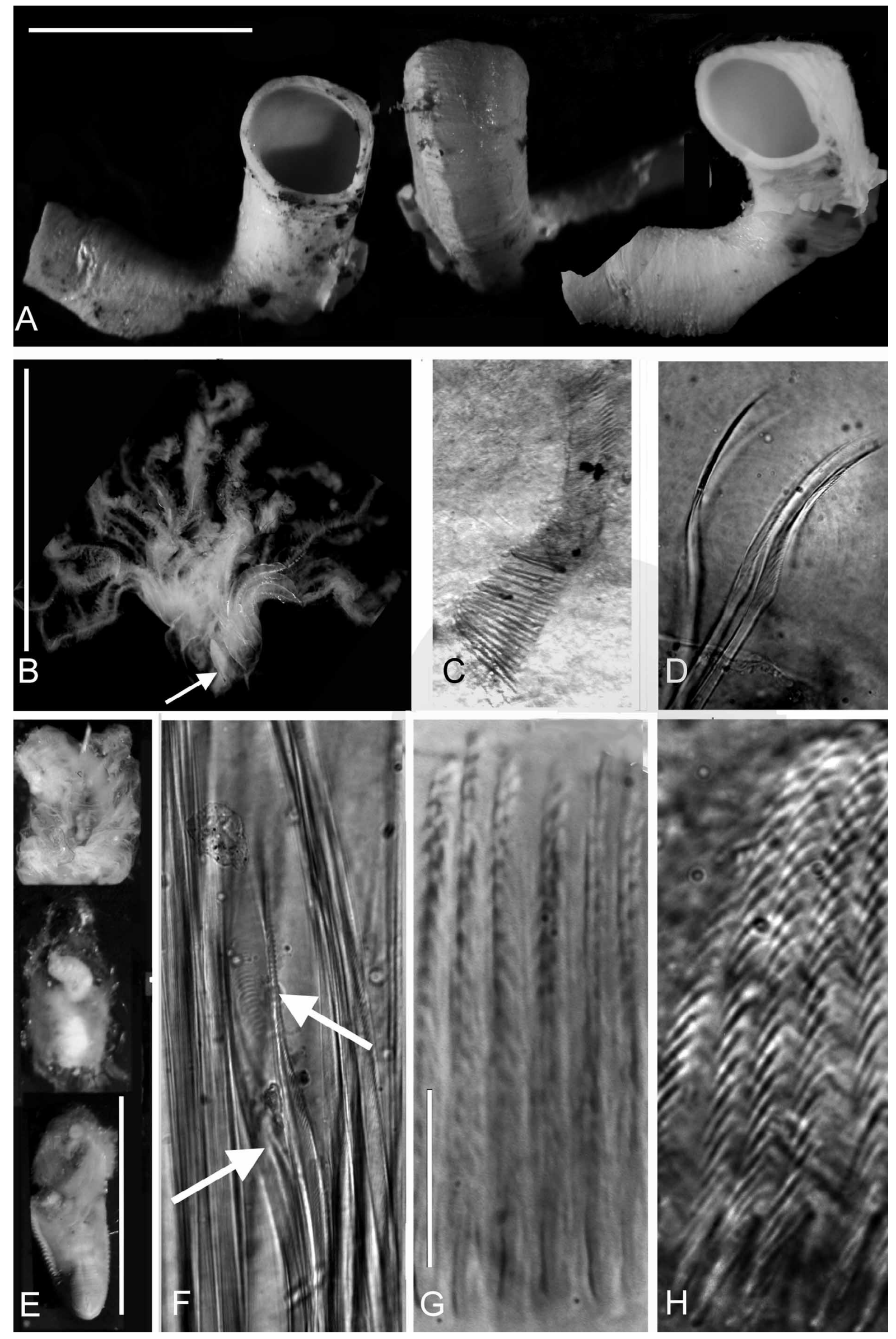


Ten Hove (1994: 109) also dealt with synonymy of the Indo-West-Pacific Protula bispiralis, and included the Indo-West-Pacific P. magnifica Straughan, 1967c, within that taxon contrary to Uchida's (1978: 40) opinion. The Indo-West-Pacific taxon Protulopsis nigranucha Fischli, 1903, a non-operculate species characterised by spiralled radioles, is excluded since referred to Spirobranchus by ten Hove (1989: 136). "Protula" soofita Ben-Eliahu, 1976 (p.113-115, fig. 5), from the Gulf of Aqaba, with a circular arrangement of the branchial crown, should be transferred from the genus Protula due to its different uncini.

\section{Genus Salmacina Claparède, 1870}

Preliminary remarks. Except for the presence / absence of an operculum on the first dorsal pair of radii in Filograna, the nominal genera Filograna and Salmacina are so similar that they have been classified together as indistinguishable by various authors. Moreover, different authors have dealt with the relationship of the operculate Filograna implexa to the non-operculate Salmacina dysteri (Huxley, 1855) in different ways (e.g., Gee 1963; Day 1967). Until it is proven that both the operculate and non-operculate forms are the same genus and that the generic synonymy is warranted, valuable information may be lost by not separating these forms. The nominal taxa F. implexa, S. dysteri, S. incrustans, and even $S$. amphidentata have all been attributed a "world-wide" distribution. This of course may have been the result of ongoing ship-transport, but, in the past, several "world-wide" distributions have been split into more regionally distributed "sibling" taxa. In addition, errors in identification have also impacted on distributions cited in some of the literature (discussed below).

Most of the regional records are presumed to be a melange of the names, Filograna or Salmacina, with some later records cited more cautiously as Filograna / Salmacina-complex. Therefore we have refrained from giving lists of synonyms (including those from samples collected from Cyprus, Israel and Gulf of Suez in different Israeli collections that will eventually be dealt with separately). The Levant, Suez Canal and Red Sea specimens listed in the "Material examined" section below were all non-operculate; thus, we would now attribute them all to Salmacina sp. / spp., and not to Filograna. An updated generic description of both nominal genera is given in ten Hove \& Kupriyanova (2009).

The genus Salmacina comprises very minute taxa requiring use of the SEM in order to elucidate the dentition of the collar chaetae and to count the number of teeth in the transverse rows of the uncini in frontal view (i.e., to determine the dental formula). Re-examination by SEM of some pre-SEM (i.e., pre-1965) voucher specimens showed that some of the regionally pertinent determinations were erroneous (e.g., pp. Pixell 1913, Fauvel 1933a, b, see "Material examined" below). To stabilize the taxa, the descriptions of published type material should be updated, and, when unavailable (as in Salmacina dysteri), material from the type localities and habitats of the described taxa should be examined with the SEM and redescribed, e.g., Nogueira \& ten Hove (2000). Similarly, voucher specimens of regional records published prior to the sixties should be verified and compared with this redescribed type or neotype material. To overcome the morphological variability found in these clonal species (Nishi \& Nishihara 1997), new efforts at redescription should include comparative genetic analysis carried out on in conjunction with the morphological work. Unfortunately most museum specimens have been denatured due to fixation in formaldehyde, necessitating collection of fresh specimens from the type localities and making the revision of the Salmacina taxa a truly Sisyphean project. Although we were warned not to attempt to deal with this intractable genus (by H. Zibrowius, pers. comm.), we were determined to look for clues to the provenance of the "Yellow Fleet" Salmacina species from the Bitter Lake. We examined specimens from different biogeographical regions and sought to find robust characters to distinguish between the taxa. This effort resulted in the present identification of the "Yellow Fleet" taxon as Salmacina incrustans, provenance, Mediterranean Sea. We also succeeded in obtaining a more precise characterization of some Salmacina taxa in regions impacting the Suez Canal.

We introduce the term, "paucidentate-rasp-shaped" uncini (pru-type), to refer to thoracic uncini with few (2-3) teeth in the transverse row proximal to the fang (termed the " $(\mathrm{F}+1)$ " row), the number of teeth not increasing greatly in the transverse rows towards the apex, long and thin (rectangular) in frontal view (extreme form exemplified by the nominal Salmacina dysteri sensu Fauvel (1927; see Fig. 23A). A 
contrasting term, "multidentate rasp-shaped" uncini ( $m r u$-type) refers to thoracic uncini that have the transverse row proximal to the fang, the $(\mathrm{F}+1)$ row, numbering 3 or more teeth, increasing greatly in the number of teeth (and in width of the uncinus) towards the apex, ovoid or wedge-shaped in frontal view (extreme form exemplified by Salmacina amphidentata not Jones, 1962 sensu Fiege \& Sun, 1999; see Fig. 23B). Frontal SEM views of uncini of these two forms are given in Figs 23A and B; see also Figs 27B and E). Data on thoracic uncini-type have been added to verified citations and the "Material examined" section, below.

References for the Filograna / Salmacina-complex names used for material from the Suez Canal or its vicinity.

Protula dysteri Huxley, 1855: 113, figs 1-11 [Type locality: Wales, Caermarthen Bay, Tenby]; referred to Salmacina dysteri by Claparède (1870: 176).

Salmacina incrustans Claparède, 1870: 519 [Type locality: Italy, Naples]; Fauvel 1927: 378-380, fig. 1291 [Atlantic: Madeira, Cape Verde, Mediterranean: Malaga, Valencia, Marseilles, Naples].

Salmacina aedificatrix Claparède, 1870: 519 [Mediterranean, Tyrrhenian Sea, Naples; "Usually synonymised with S. dysteri" (Nogueira \& ten Hove 2000: 158)].

Filograna / Salmacina species complex: Wehe \& Fiege 2002: 124 [Suez Canal].

Material examined for comparison. The number of teeth in the horizontal rows of the rasp-shaped uncini is a comparatively easy morphological character to quantify and to use as a parameter of variability. In the SEM micrographs, we have been able to observe variability between uncini of the same torus; even in the number of teeth in the proximal row to the fang-in the $(\mathrm{F}+1)$ rows of adjacent uncini. In Fig. 26A, for example, the teeth in the $(\mathrm{F}+1)$ row proximal to the fang of the seven adjacent uncini counted from right to left numbered 3,3,2,3,3,2,2 teeth (the remaining uncini in the torus were not distinct). Regretfully, the number of individuals available from different locations or that we could SEM was in most cases very small, thus the observations given below are carried out without performing statistical comparisons. Nonetheless, some differences found between uncini of specimens from different locations were clearly distinct. The abbreviation, "tu" refers to which torus was examined, e.g., "tu1" or "tu2" refer to the first or the second thoracic torus.

Presumed Salmacina dysteri s. str. based on North Atlantic location and description. North Sea, Scotland: Orkney Islands, Mainland, Sound, Point of Hellia, Stn 20, 15.5 m, legit M.H. de Kluyver 1990, det. H.A. ten Hove 1990 Salmacina sp., ZMA V.Pol. 3768. SEM ZMA11-tu1: $(\mathrm{F}+1)=3,2,3,3,3$ (five adjacent uncini counted in SEM micrograph of first thoracic torus). ZMA11-tu2: $(\mathrm{F}+1)=3,2,4 s, 2,3,4 s$ (six adjacent uncini counted from second torus; $s$ denotes an apparently aberrant splitting of the apical end observed in several of these uncini, never remarked until now $)$. ZMA11-tu2: $(\mathrm{F}+1)=2,3,3,3,3,3,3,3,3,2$. ZMA-11-tu3: $(\mathrm{F}+1)=$ 2,?,2,3,3,2,2,2,2.-Hebrides, Isle of Muck, Ruadh leam laranche, possibly legit Mrs. E.A.T. MacEwen 30.VII.1938, Salmacina dysteri, determinator unknown, Royal Scottish Museum, Edinburgh; interlacing tube aggregate, ca. 20 specs with $(\mathrm{F}+1)=2$ or 3. SEM S-14-1-tu2: $(\mathrm{F}+1)=2,3,2,2,3,2$. S-14-1-tu3: $(\mathrm{F}+1)=$ 3,3,3,2,2,2,2. All thoracic uncini of pru-type.

Irish Sea, Wales: Holyhead, Anglesey, Menai Bridge Marine Biological Station, 11.XI.1957, Salmacina dysteri, determinator unknown, NMWZ 1985.042.1957. SEM ATW1-200-w2-007: $(\mathrm{F}+1)=3,2,2,3,2,3,2,2,3$ (sequence of nine uncini). SEM ATW2-1-209-w1-tu: $(\mathrm{F}+1)=3,3,3,3,2,3,3,3,2,2,2,3,2$; thoracic uncini of prutype).-Menai Bridge, Menai Bridge Marine Biological Station, VIII.1953, Salmacina dysteri, det. unknown, NMWZ 1985.042.672, tube aggregations, several small, presumably net-like, clusters. SEM ATW1-219-w3tu: $(\mathrm{F}+1)=4,3,3,3,3,2,3,2,3,3,2$ (thoracic uncini of pru-type).

English Channel, coast of France, Saint-Vaast-La Hougue, legit, det. J.L.A. de Quatrefages Filograna; redet. P. Fauvel S. dysteri, MNHN; subsamples deposited in $\mathrm{BM}(\mathrm{NH})$ : $\mathrm{BM}(\mathrm{NH})$ 1928.4.26.106 and 1928.4.26.886, agglomerated tubes. SEM Paris-Vaast-1-3-016-tu2: $(F+1)=2,2,3,2,3,3,3$. SEM Paris-Vaast-13-018-tu4: $(\mathrm{F}+1)=3,3,3,3,3,3,2,2,3,3,2$ (thoracic uncini of pru-type). 


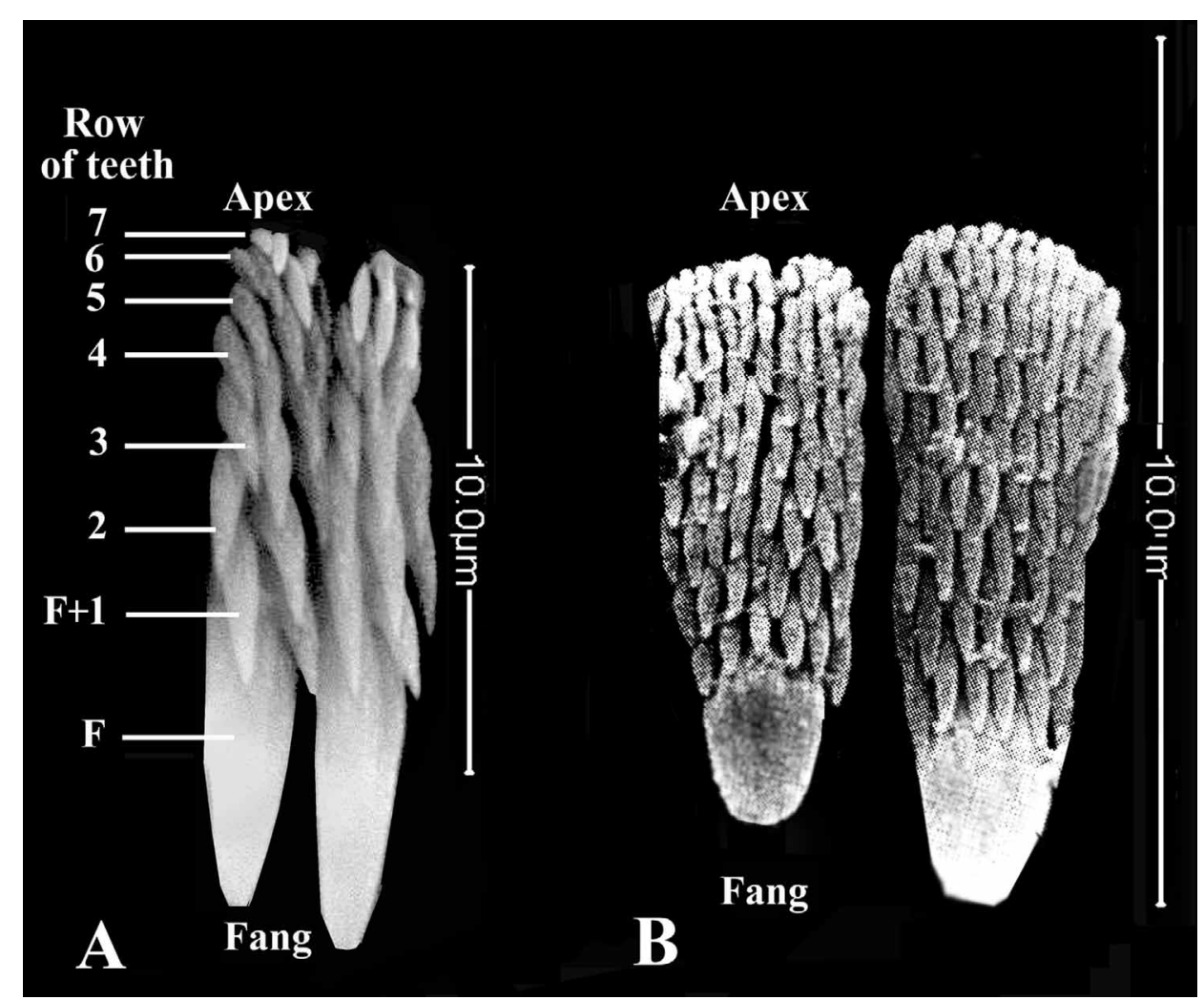

FIGURE 23. Frontal SEM views of the two extreme forms (types) of thoracic uncini in Salmacina spp. A-Paucidentate rasp-shaped uncini (pru-type) of Salmacina dysteri: Uncini from third thoracic torus of specimen from the Isle of Muck, Hebrides, Scotland, 30.VII.1938 (Scottish Museum, Edinburgh); note "above" the fang (the enlarged anterior-most tooth, designated in the figure as F), 7 transverse rows of teeth, with two teeth in the row proximal to the fang (rows in figure numbered and designated by a line); that proximal to fang designated as $(\mathrm{F}+1)$; apical (posterior) row, here, the 7 th row, designated as $(\mathrm{F}+7)$; the detailed dental formula of the left uncinus in $\mathrm{A}$ is then $(\mathrm{F}+1)=2:(\mathrm{F}+2)=2:(\mathrm{F}+3)=3:(\mathrm{F}+4)=$ 3: $(\mathrm{F}+5)=3:(\mathrm{F}+6)=3$ and $(\mathrm{F}+7)=3$, or, briefly, F:2:2:3:3:3:3:3 (as noted above, in the detailed dental formula, the different transverse rows of the uncinus are separated by a colon), B-Multidentate rasp-shaped thoracic uncini (mru-type) present in Salmacina amphidentata not Jones, 1962 sensu Fiege \& Sun (1999) from Hainan Island, near China (from Fiege \& Sun 1999: 135, fig. 22c), "above" the fang, 9 transverse rows of teeth, with six teeth in the (F+1) row proximal to the fang, and with the number of teeth in the transverse rows increasing to 10-11 towards the apex (transverse rows 57); the dental formula of the right uncinus is $F: 6: 7: ? 9: 10: 11: 11: 11: ? 8: 9$.

Salmacina dysteri confirmed based on comparison of specimens with above North Atlantic material. Central Atlantic Ocean, Cape Verde Islands, São Vicente, legit C. Crossland 11.IX.1904, presented by J.S. Gardiner, det. H.L.M. Pixell Salmacina dysteri, BM(NH) 1924.6.13.131. SEM 131-017, left part of torus: $(\mathrm{F}+1)=?, ?, 3,3,2,3,3,2,2,3$ (counted eight of the ten uncini in the micrograph). SEM 131-018, central part $(\mathrm{F}+1)=2,3,2,3,2,3,2$ (maximum no. of teeth in widest horizontal row 4; thoracic uncini of pru-type).Additional sample from same locality, det. H.L.M. Pixell 25.IX.1912, BM(NH) 1938.7.25.61-75 including permanent mount. SEM 61-72-2-tu5: $(\mathrm{F}+1)=2,2,3,3,3,3,2.61-72-2$-tu6: $(\mathrm{F}+1)=3,3,3,3,2,3,3$; thoracic uncini of pru-type).

Questionable nominal Salmacina dysteri records of which voucher specimens are missing, determination generalised to Salmacina sp.

Suez Canal proper: Potts (1928: 701-702) reported Salmacina sp. as S. dysteri from two sites in the southern part of the canal, Stn K2 at km 124 in the Little Bitter Lake from buoys between 0-4 m, and from km 152 , presumably scraped from the pier or from bivalves encrusted on the pier.

Gulf of Suez: Two samples from the entrance to the Suez Canal: (1) The Percy Sladen Trust Indian Ocean Expedition of 1905, sample from a small buoy, det. H.L.M. Pixell (1913: 87) Salmacina dysteri.-(2) The Cambridge Expedition, two sites at Port Taufiq: Stn PT 0, scraped from piers along the avenue; Stn PT 3, 
scraped from a wooden fence along the bathing place, det. F.A. Potts (1928: 701-702) Salmacina dysteri (sample details from Fox 1926).

Nominal Salmacina dysteri records that proved to belong to taxa with multidentate rasp-shaped uncini (i.e., erroneous determinations) generalised to Salmacina sp. / spp.

Gulf of Suez: R. Ph. Dollfus Expedition. stn XI, 32 $2^{\circ} 44^{\prime}-32^{\circ} 47^{\prime} \mathrm{E}, 28^{\circ} 49-28^{\circ} 54^{\prime}$ N, 25-30 m, coralligenous sand, det. P. Fauvel (1933a: 80) Salmacina dysteri, MNHN. SEMs: Paris-GS-1933-004-tu1: $(\mathrm{F}+1)=$ 5,5,5,4,4,?,4,5 (counted seven of eight uncini in first torus). Paris-GS-1933-003-tu2: $(\mathrm{F}+1)=4,5, ?, 4,4,4,4$. Paris-GS-1933-002-tu3: $(\mathrm{F}+1)=4,5,5, ?, 4,4,4,4, ?, 4,4$ (see Fig. 27B, second thoracic uncinus).

Red Sea proper-Indo-West-Pacific (excluding citations from Gulf of Suez and Gulf of Aqaba already given above) Indian Ocean, Tanzania, Zanzibar, Wasin Harbour, legit C. Crossland, 1902, presented by J.S. Gardiner, det. H.L.M. Pixell (1913: 38) Salmacina dysteri, BM(NH) 1924.6.13.152 [SEM not permitted]. In Pixell's permanent mount, studied with oil immersion, the single uncinus in focus showed $(F+1)=4$ teeth; the uncini are F+8, i.e., with eight horizontal rows of teeth "above" the fang (see Fig. 23), and with a maximum number of six teeth in the widest row (formula $\mathrm{F}=8 / 6$ ). - Zanzibar area, legit C. Crossland, 22.VIII.1901, presented by J.S. Gardiner, det. H.L.M. Pixell (1913: 38) Salmacina dysteri, BM(NH) 1938.7.25.13-25 (material previously dried up, specimen extracted from tubes by HAtH). SEM 13-25-09-tu1: $(\mathrm{F}+1)=$ $3,3,3,3,3,3$ (counted sequence of six uncini in first torus); the maximum number of teeth in the transverse rows of both the $1^{\text {st }}$ and $2^{\text {nd }}$ uncini was 7). SEM 13-25-tu3: $(F+1)=3,3,3,3,3,3,3,3$ (in the eight uncini in third torus, only the three anterior horizontal rows exposed, others covered); presumed to be a Salmacina sp. of mrutype.-From Zanzibar area, from bottom of S.S. "Juba", legit C. Crossland 29.VII.1901, presented by J.S. Gardiner, det. H.L.M. Pixell (1913: 38) Salmacina dysteri, BM(NH) 1938.7.25, 26-40. SEM 26-40-023-tu: $(\mathrm{F}+1)=?, ?, 4,4, ?$ (counted only two uncini in torus, other uncini not in focus or covered over). The glycerine mounts of wet material studied with oil immersion showed $(\mathrm{F}+1)=4$ teeth in proximal row to fang, thus, uncini of $m r u$-type. Pixell's slide A, seen with oil immersion, seems to show $(\mathrm{F}+1)=3$ or 4 teeth (none of the details were seen clearly).-Off coast of Zanzibar, Jembani, 22.VIII.1901, legit C. Crossland, presented by J.S. Gardiner, det. H.L.M. Pixell (1913: 38) Salmacina dysteri, BM(NH) 1938.7.25.41-52. SEMs (HAtH) show truncated tips of fang, frontal view of these thoracic uncini more rectangular than others: First torus, tu1: $(\mathrm{F}+1)=3,3,3, ? 4, ?, ?, ?$. Second torus, tu2: $(\mathrm{F}+1)=$ ?, 4, 3, 3,4,5; redetermined herein as Salmacina sp. of mrutype).-Hawaii: Biofouling, legit J.H. Bailey-Brock. tu2: $(\mathrm{F}+1)=5,5,4,4,4,5,4,4$ (counting the last uncinus showed that the number of horizontal rows was 9 and its detailed formula was $F: 4: 5: 6: 7: 8: 10: 99: 9: ? 6$ (formula F+9 / 10), thus it is characterised as a Salmacina sp. of mru-type).

Salmacina sp. of multidentate rasp-shaped uncini-type. Gulf of Aqaba, Elat, North Beach, 5-10 m, legit N. Shashar 24.06.2002, det. M.N. Ben-Eliahu Salmacina sp., on / in crevices of red Bryozoa on rope from fish cages, few; live material with red clusters of prostomial ocelli (Fig. 27E). SEM-A-Elat-003-tu1: $(F+1)=$ $5,4,5,5,4,5,4, ?, 4,4$ (counted nine of 10 uncini of first torus). SEM-B-Elat-tu1: $(F+1)=?, 5,5,4,4,5, ?$. SEM-DElat-009-tu1: $(\mathrm{F}+1)=4,4,3,3,3,3,5,3,4,3,4,4$. Identified as Salmacina sp. of $m r u$-type (Fig. 27E).

Comparative specimens identified as Salmacina incrustans Claparède, 1870 from Atlantic, Mediterranean (consistent with the Fauvel, 1927 description). Spain, Costa Brava near Playa de Aro, Playa de San Pol, S, stones and debris in rock-crevices, 0.5-1 m, legit, det. H.A. ten Hove 11.VI.1971, S. incrustans, ZMA V.Pol. 3814, ZMA-SEM 0032 (number on the ZMA micrograph H 46), uncini with 7 horizontal rows of teeth, proximal row to fang $(\mathrm{F}+1)=3,3,3,3,2$ or 3,3,3 (counted seven uncini in sequence); the only uncinus positioned in full frontal view that could be counted showed maximum no. of teeth, 5-?6, in fifth horizontal row.-Ligurian Sea, Monaco, coll. Prince of Monaco 22.XII.1910, on hull of "Eider", det. P. Fauvel S. incrustans, MNHN, tubes only.-Monaco harbour, det. P. Fauvel S. incrustans, BM(NH) 1928.4.26.144 / 154 (SEM not allowed).-Tyrrhenian Sea, Naples, det. P. Fauvel S. incrustans, BM(NH) 1928.4.26.954.-Croatia, Istria, S. Pomer, outside harbour pier next to Pomer camping ground, boulders, legit, det. H.A. ten Hove VII.2003 S. incrustans, HUJ-SEM (only one uncinus in focus, F:2:3:3:3:3:3:4:4:?2 [covered]). 
Salmacina incrustans Claparède, 1870

Figs 3B, 24-26, 27A

Salmacina incrustans Claparède, 1870: 519 [Type locality: Italy, Naples].

Suez Canal material reported herein: 37 samples, total number estimated as between ca. $200-500$ individuals. Beets' Great Bitter Lake samples, VIII / IX 1950, Stns 8-10, 33, ?42, B3, 5 +? 1 samples with tentatively identified (empty) tube residues (see Appendix Table 2B).-Great Bitter Lake "Yellow Fleet" Ship Biofouling Samples (January 13-20, 1975), 37 subsamples, 200-500 specs (Appendix Table 2D).

Suez Canal depth and substrates: Beets' samples: Residues of empty tubes on shells between 2.5-10.6 $\mathrm{m}$, on Chicoreus erythraeus [as Murex anguliferus], *Murex forskoehlii; *Brachidontes pharaonis and *Gastrochaena cymbium.-Brattström \& Taasen Great Bitter Lake "Yellow Fleet" ship-biofouling; on sponges; bivalves, *Brachidontes pharaonis (Figs 3B, 24), *Malvufundus regulus, *Pinctada radiata and *Spondylus spinosus; as well as on barnacles, crabs, bryozoans, and tunicates. (*Denotes an Indo-Pacific mollusc taxon that has migrated and established populations in the Levant Basin of the Mediterranean, i.e., a Lessepsian migrant mollusc [H.K. Mienis, pers. comm.]).
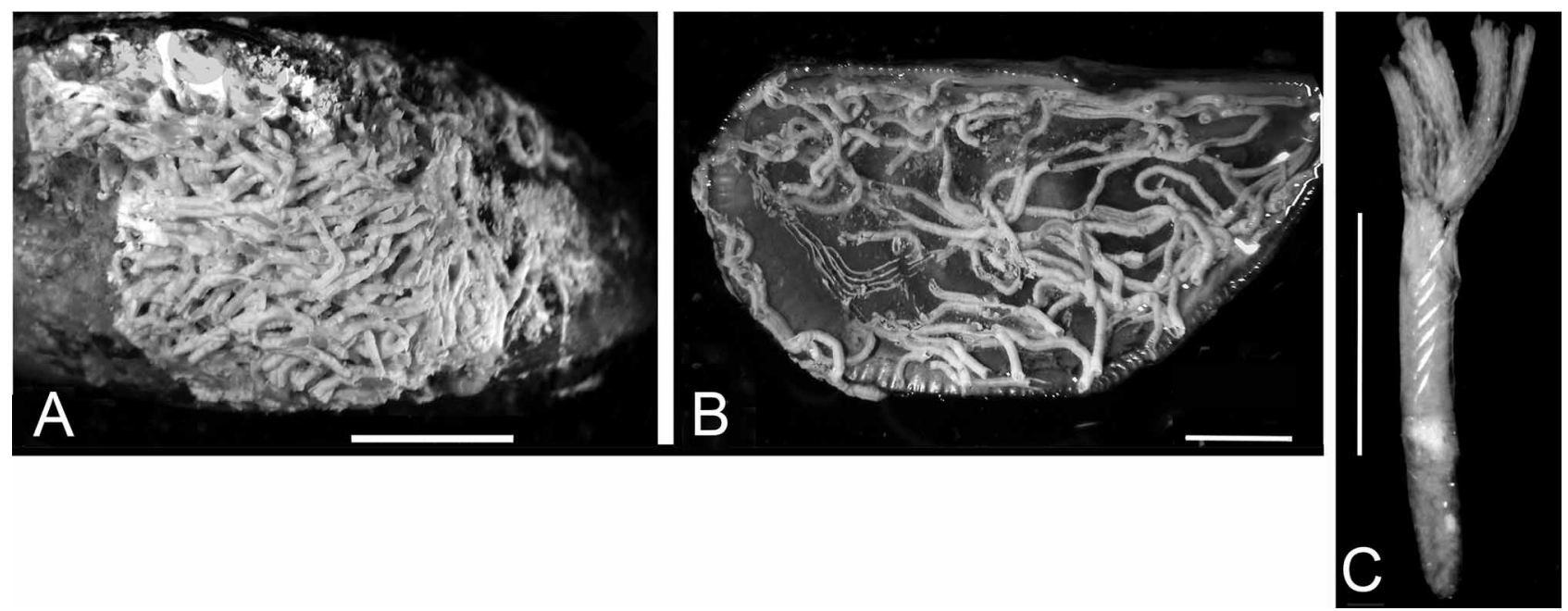

FIGURE 24. Salmacina incrustans encrusted on a Brachidontes pharaonis bivalve from the "Yellow Fleet", Great Bitter Lake. A, B-Encrusting aggregation, outside and inside of a Brachidontes valve, respectively, C-Three-quarters view of worm (subsample Biv11). Scales: A, B-5 mm, C-1 mm. 

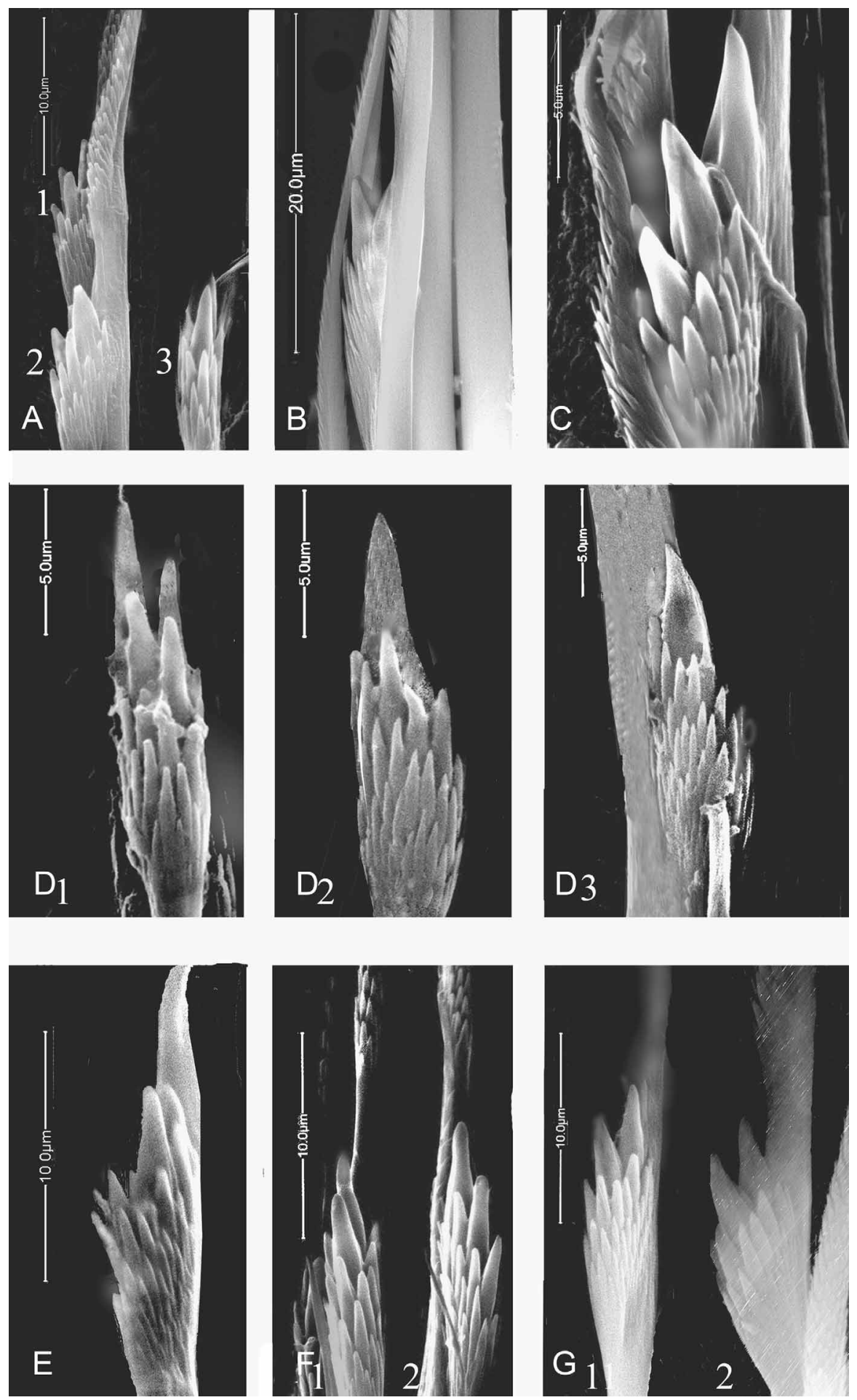

FIGURE 25. Variability in fin and blade collar chaetae of Salmacina incrustans from the Great Bitter Lake sampled by H. Brattström and J.P. Taasen in January 1975. Note morphological variability of the fin structure in chaetae from the same individual. $A_{1-3}$ - Three collar chaetae (spec. no. 15), $A_{1}$-Profile view, slightly darkened, $A_{2}-3 / 4$ view, $A_{3}$-Frontal view of fin, $B$ - Profile view of collar chaeta (spec. no. 8), $\mathrm{C}_{1-2}$-Frontal view of fin (spec. no. 14) with tips of blades of two chaetae to the left, $\mathrm{D}_{1-3}$-Three chaetae of spec. no. 10: $\mathrm{D}_{1}$-Frontal view of most distal fin, $\mathrm{D}_{2}-$ Frontal view of fin positioned between the most distal and most proximal chaetae- the blade of these chaetae are below the focus level of the SEM and thus not visible in the micrograph; $D_{3}-3 / 4$ view of fin of most proximal chaeta, E-Frontal view of fin (specimen no. 16), F-Frontal view of fins (spec. no. 13; note the free (non-denticulate) space between the fin and the blades; the denticulate structure of the blades, $G_{\text {. }} G_{1}$ - Frontal view of fin, $G_{2}$ - Lateral, almost profile view of fin \& blade chaeta (specimen no. 11, 10,000 x). Magnifications: $A_{1}, A_{2}-7,000 x, A_{3}, E-G-10,000 x, B-6,000 x, C-16,000 x$; $\mathrm{D}_{1}-15,000 \mathrm{x} ; \mathrm{D}_{2}, \mathrm{D}_{3}-12,000 \mathrm{x}$. 

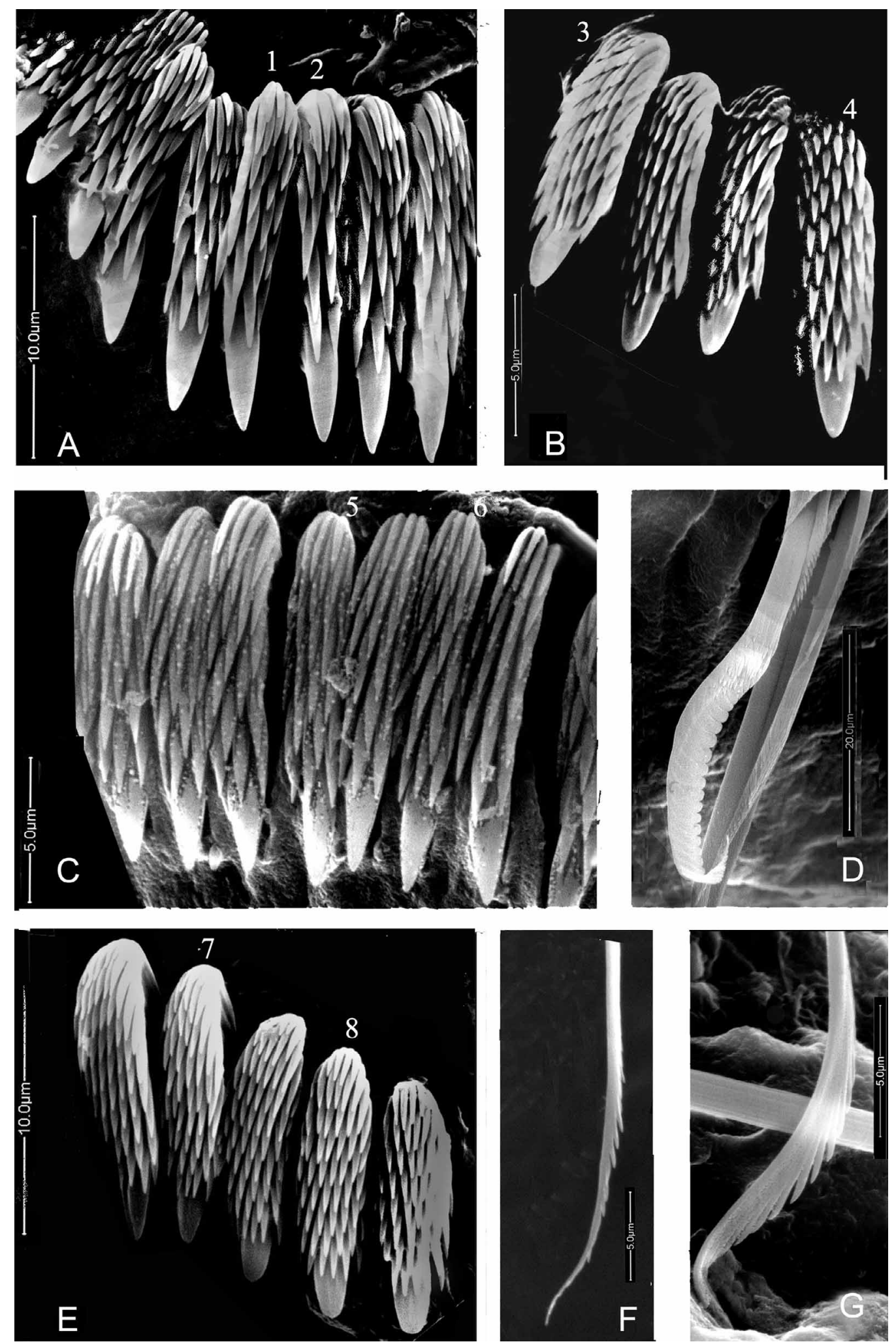

FIGURE 26. Salmacina incrustans: Chaetae (other than collar chaetae) and uncini of specimens shown in Figs 25 . A, B-Thoracic and abdominal uncini of spec. 13-3: A: Thoracic uncini (numbers refer to marked uncini in the figures): (1) $F: 3: 4: 4: 5: 6: 6: 3$ = F+7 rows. (2) F:2:3:3:4:5:4 = F+6 rows, B-Abdominal uncini: (3) F:5:7:7:7:8:8:7:6:4 = F+9 rows; (4) $F: 5: 5: 6: 6: 3: 5: 6: 5: 5: 5=F+10$ rows, C-Thoracic uncini of spec. 10-3, thoracic uncini teeth count: (5) F:3:4:4:4:4:4 = $\mathrm{F}+6$ rows. (6) F:3:4:3:4:5:5:3 = F+7 rows, D—Apomatus chaeta and limbate chaetae (specimen 10-2), E-Abdominal uncini of spec. 13-2, (7) F:4:5:6:7:6:7:7:5:5 = F+9; (8) F:5:5:6:8:7:7:6:7:4 = F+9, F, G-Abdominal chaetae of two specs (15-1 and 8-1. Magnifications: A-13,000 x, B-16,000 x, C-12,000x, D-6,000 x, E-10,000 x, F-12,000 x, G$16,000 \mathrm{x}$. 
Remarks. Salmacina dysteri, originally described from boreal temperate waters (South Wales), was listed in the Cambridge Expedition Report on the Polychaeta Sedentaria (Potts 1928) as present in the southern part of the Suez Canal and reported by Pixell (1913) and Potts (1928) from the Gulf of Suez end of the canal. Regrettably, Potts (1928) provided no details concerning his nominal S. dysteri material other than that there were especially large aggregations at the bathing place at the sites Port Taufiq 3, and Port Taufiq outside the Canal. That description is insufficient even to conjecture whether the Beets' and "Yellow Fleet" Salmacina specimens sampled ca. 50 years later belong to the same taxon as that of Pixell (1913) or Potts (1928).

Fauvel (1933b: 144) reported Salmacina dysteri from the Gulf of Suez, citing Pixell's (1913) and Potts' (1928) reports, and discussed the philosophical basis for his taxonomic work: "Many species considered for a long time as endemic to the Indo-Pacific region appear absolutely identical with European species... One risks, therefore, considering as an important new species a taxon simply designated by a different name although in reality it is synonymous." Fauvel was, very likely, the most redoubtable polychaetologist of his day, and this biogeographical philosophy presumably influenced H.L.M. Pixell (1913) and F.A. Potts (1928) as seen in their "cosmopolitan attribution" of S. dysteri (or they may all have influenced each other). Together, these authors provided an unlikely mix of distributions including those of nominal S. dysteri: The Atlantic, North Sea, English Channel, Cape Verde, Mediterranean, Red Sea, Suez Canal, Gulf of Suez, Zanzibar and Australia (Fauvel 1927).

Regrettably, Pixell's (1913) and Potts's (1928) important voucher specimens from the Suez Canal could not be found, however, we were able to obtain for SEM examination Pixell's nominal Salmacina dysteri specimens from Zanzibar and Wasin Island; one of Fauvel's (1933a, b) samples from the Gulf of Suez; a nominal specimen of $S$. dysteri from Hawaii; as well as live Salmacina specimens from the Gulf of Aqaba (from Elat). Our findings did not support the determination of $S$. dysteri for these specimens or the ascription of $S$. dysteri as a "cosmopolitan species" (see "Material examined for comparison", above). (Interestingly, Fauvel himself had some doubts as to the identification of the Gulf of Suez specimen as he put [three!] question marks after the "Salmacina dysteri" in his handwritten label of the voucher sample although the question marks were not cited in his two Gulf of Suez publications [Fauvel 1933a: 80, 1933b: 1431]). On the contrary, the new findings support our cautious approach of generalising unverified determinations of Salmacina when the identifications cannot be validated by re-examining the specimens (see also Noguiera \& ten Hove 2000).

Here it is important to stress that generalising the species determination applies only to the specific sample examined, as in none of the given areas was the density of sampling sufficiently great as to definitively exclude the possibility of more than one Salmacina taxon being present, particularly in the port areas, such as Port Taufiq, and even in the Suez Canal itself. As the late Prof. Heinz Steinitz noted (pers. comm.), finding a taxon in a given area is meaningful, but not having found it may not be indicative of its true absence unless high density and thorough sampling is carried out. This truism is particularly relevant concerning Salmacina and other taxa that can be transported by ship.

The type locality of Salmacina dysteri is Tenby, Carmarthen Bay, South Wales. Scanning electron microscope examination of nominal $S$. dysteri specimens from nearby biogeographic locations, i.e., the North Sea, the Irish Sea, as well voucher specimens from the English Channel identified by P. Fauvel (see Material examined for comparison, above), establishes that Fauvel's particulars of the thoracic uncini of $S$. dysteri from its biogeographic home region - "7 rows with 2-3 teeth in a row"-were accurate (Fauvel 1927; see also Rioja 1931 and Nogueira \& ten Hove 2000), although in his figure, 129i on p. 379, Fauvel showed only a lateral view of the uncinus. Precise detail was naturally missing in his lateral illustration of the collar chaetae reported as having numerous fine teeth on the fin. Fauvel's illustration of the $S$. dysteri aggregate (Fauvel 1927, fig. 129k, a copy of Huxley 1855, fig. 1) is variously described as "a bundle of intertwining networks of tubes" (Fauvel 1927), a "rope-like twisted mesh" (Knight-Jones et al. 1996: 256) or an "arborescent" aggregate (Nishi \& Nishihira 1997). Examination of the nominal S. dysteri tube aggregations from the Hebrides, from Menai Bridge and Fauvel-identified Saint Vaast-la-Hougue (La Manche) material bears that out. 
The contrasting description of Salmacina incrustans referred to collar chaetae with 4-6 large teeth on the fin (Fauvel 1927: 377-380, fig.129 a-1). Other than "rectangular with several rows of teeth above a larger tooth at the base," Fauvel (1927: 378) did not provide any details of the thoracic uncini of S. incrustans. Although we were not able to obtain specimens of published S. incrustans for SEMming, we SEMmed material from traditional locations of $S$. incrustans from Spain and Croatia. The micrograph of the collar chaetae showed there was a prominent gap between the fin and the blade, as well as a perceptible difference in size between the prominent teeth of the fin and the other more lateral and proximal teeth. Distinct frontal views of a few thoracic uncini in a SEM micrograph of the $4^{\text {th }}$ torus of the $S$. incrustans from the Costa Brava specimen (SEM no. 0016), show three teeth in the F+1 row, with the number of teeth increasing to ca. 5 in the horizontal rows towards the apex. A nominal S. incrustans' uncinus from the Adriatic had F+1 with two teeth. For the tube aggregate of $S$. incrustans (type locality, Italy), Fauvel (1927: 378-379) reported two forms, either, "Tubes more or less aggregated in colonies encrusting algae, shells and stones," or, "More rarely, forming structures analogous to those of Salmacina dysteri."

Fauvel reported prostomial ocelli as present in both Salmacina dysteri and S. incrustans (Fauvel, 1927: 377, 378, respectively). However, in their study of taxonomic characters in Salmacina sp. / spp., ten Hove \& Pantus (1985) found that newly-collected Mediterranean specimens (not determined to species) lacked prostomial ocelli altogether. In live or freshly collected Salmacina specimens from the Gulf of Aqaba, the character, brilliant crimson prostomial ocelli was very distinctive, but we noted that the ocelli faded shortly after alcohol-preservation (Ben-Eliahu et al. 2007). Our conclusion was that the lack of prostomial or branchial ocelli is a robust character only in live or fresh material, not to be taken into consideration when studying preserved museum specimens (Ben-Eliahu et al. 2007). We can provide no explanation for the discrepancy between Fauvel's finding and that of ten Hove \& Pantus (1985). Nonetheless, we have confidence that the chaetal structures described above and the form of the tube aggregate are robust and durable characters despite some variability in structure.
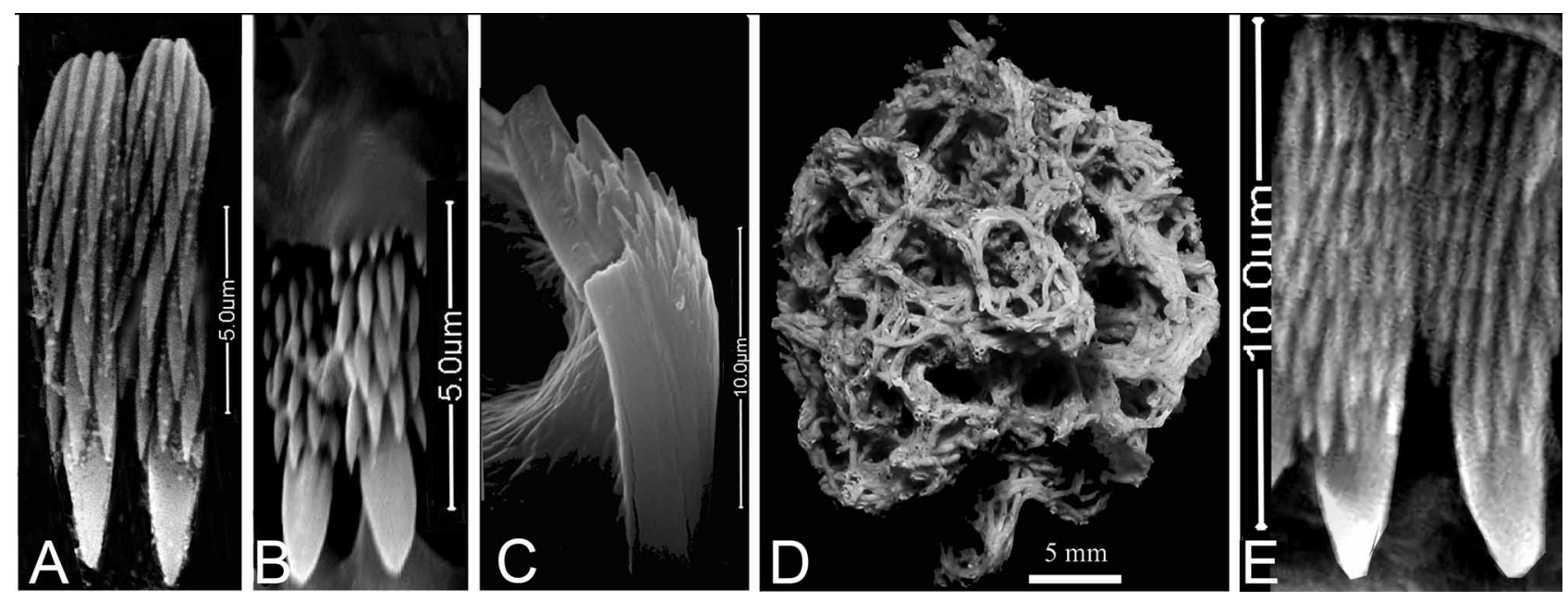

FIGURE 27. Comparison of Salmacina spp. from the Suez Canal, Gulf of Suez, and Gulf of Aqaba. A-Salmacina incrustans from Great Bitter Lake, spec. 10-3, thoracic uncini both $(\mathrm{F}+1)=3$, left uncinus detailed F:3:3:3:3:4:4 (compare Fig. 23), B-Salmacina not dysteri (Huxley) from Gulf of Suez (32 44'-3247’ E., 28 $49^{\circ}-28^{\circ} 54$ N., 25-30 m, legit R. Ph. Dollfus, Stn 11, 8.XII.1928, coralligenous sand, det. P. Fauvel (1933a: 80, 1933b: 143), generalised herein to Salmacina sp.; thoracic uncini from second torus of single (minute) specimen, apical part of uncini covered by a flap; F:4:5:5:? (left uncinus) and F:4:6:6:6:? (right uncinus), C—Collar chaeta fin, blade broken off, D—Intertwining, netlike tube aggregation from which minute specimen was removed, E-Thoracic mru-type uncini of Salmacina specimen from Gulf of Aqaba (from Elat). Magnifications: A-12,000 x, B, C-10,000 x, E-8,000 x.

Both of our present Salmacina samples come from the Great Bitter Lake (Appendix Table 2B, D). The empty tube residues on C. Beets' shells, collected in 1950, can be identified as Salmacina sp. due to their size and aggregate form, similar to those in Figs 3B, 24A, B, thus, presumably, belonging to the same taxon as the Salmacina specimens collected by Brattström \& Taasen in 1975 from the "Yellow Fleet" ships. The flat- 
encrusting form of the tube aggregation corresponds to Fauvel's (1927) description of Salmacina incrustans and excludes a determination of $S$. dysteri. The collar chaetae and uncini also conform to Fauvel's characterisation of $S$. incrustans, taking into account his presumed magnification limitations. Fig. 25 shows the collar chaetae of seven SEM "Yellow Fleet" specimens. Although there was considerable variability in their structure, even within a single fascicle (e.g., Figs $25 \mathrm{D}_{1-3}, \mathrm{~F}_{1-2}$ ), there were nonetheless consistent characteristics: (1) the chaeta has a distinct non-denticulate gap separating the basal fin from the blade; (2) ca. 4 particularly large teeth on the fin, the distal-most tooth being the largest, the other three teeth grading in size proximally in the midline; the teeth grading laterally and proximally into smaller teeth, and then even smaller teeth laterally and more proximally reaching their smallest size in the most lateral and most proximal parts of the fin. Tori of thoracic uncini of two specimens are shown in Figs 26A, C; two uncini were counted in each torus (see legend, Fig. 26A, uncini designated 1 and 2, and in Fig. $26 \mathrm{C}$, designated 5 and 6, respectively). The number of teeth in the proximal row to the fang $(F+1)$ position was 2-3, with the number increasing to 6 and 5 teeth and 4 and 5 teeth in the widest rows, respectively, altogether 6-7 rows of teeth above the fang (for counts of the abdominal uncini, see Figs $26 \mathrm{~B}$ and E). There was considerable variability in structure between the uncini even within the same torus. Both the uncini and the flat-encrusting tube structure of our Salmacina from the Bitter Lake differ from Fauvel's specimen from the Gulf of Suez (Fauvel 1933 a, b) and from that in the Gulf of Aqaba (Figs 27B, E, respectively), as well as from a nominal S. dysteri from Hawaii. With less trepidation than before attempting this comparative study, we feel able to identify our Bitter Lake specimens as S. incrustans sensu Fauvel (1927). Salmacina incrustans had been recorded from Alexandria (101 m), ca. $225 \mathrm{~km}$ west of the Mediterranean opening of the Suez Canal (Fauvel 1937: 47 [again, voucher specimens not available]). Presuming that our determination as S. incrustans from the "Yellow Fleet" population in the Bitter Lake was correct, it is a reasonable inference that this taxon was transported by the ships from the Atlantic and Mediterranean into the Suez Canal, and eventually "infected" the Great Bitter Lake, as most probably did two other biofouling taxa, Hydroides elegans and H. diramphus (see above).

As regards the Salmacina dysteri sample misidentified by Fauvel from the Gulf of Suez (1933a, b; Figs 27B-D), it is worth mentioning that the tube aggregation resembled that of the $S$. dysteri, e.g., from the English Channel (Manche, St. Vaast-la-Hougue (see Comparative material studied). Fauvel's sample contained only a single worm, the one we SEMmed, however, the micrograph clearly showed thoracic uncini of the multidentate-rasp-shaped type, with four teeth in the row proximal to the fang $(\mathrm{F}+1)=4$ (Fig. 27B), rather than the 2-3 teeth characteristic of $S$. dysteri; thus, it is certain that this Gulf of Suez specimen was not S. dysteri s. str. despite the similar tube aggregation structure. An important implication of this finding is that the presence of an aggregation of netlike intertwining tubes (presumably the basis for Fauvel's identification), is not exclusively diagnostic for $S$. dysteri. Our results indicate that the character is present in additional Salmacina taxa.

In the Salmacina populations from the Gulf of Aqaba, the thoracic uncini similarly have multidentate rasp-like uncini with $4-5$ teeth above the fang: $(\mathrm{F}+1)=4-5$, Fig. 27E, and net-like aggregations. This was also true for nominal Salmacina dysteri specimens from Hawaii (Bailey-Brock 1976). Pixell's Salmacina dysteri from Zanzibar, Tanzania, Wasin Harbour (BM(NH) 1924.6.13.152); from the bottom of S.S. "Juba" $(\mathrm{BM}(\mathrm{NH}) 1938.7 .25,26-40)$; off the coast of Zanzibar, Jembani (BM(NH) 1938.7.25.41-52), and presumably also Zanzibar 1938.7.25.13-25, uncini partly covered (Pixell 1913). In the present paper, we are not attempting to deal in detail with all these taxa, except for generalising them to Salmacina sp.- there may be more than one taxon involved. Multidentate rasp-like uncini are also present in Salmacina amphidentata not Jones, 1962 sensu Fiege \& Sun (1999) from Hainan Island as well as in the Caribbean species, S. amphidentata Jones, 1962.

Finally, as concerns tube-aggregate form, if both flat-encrusting and net-like forms of aggregate are characteristic of Salmacina incrustans as Fauvel (1927: 379) suggested, this raises the question whether the form of the aggregation can be related to ecological adaptation, for example, to hydrographic factors, i.e., to a less rather than a more protected environment? 


\section{Serpula concharum Langerhans, 1880}

Type locality. Atlantic Ocean, Madeira. Not present in the Suez Canal; however, for literature records under this name from the Suez Canal, see Hydroides elegans, Hydroides spp. and Serpula hartmanae.

Remarks. The name has frequently been used for the juvenile stage of Hydroides that lacks an upper verticil (ten Hove \& Ben-Eliahu 2005).

As concerns Serpula concharum s. str., with its more than 150 literature records, this AtlanticMediterranean species should be a well-known taxon. Its tube is rounded trapezoidal in cross-section, with five more or less similar longitudinal ridges (e.g., Langerhans 1880: 118-119; Bianchi 1981: 47-49, fig. 14). However, according to Zibrowius (1968: 98-100), the tube may have 3-5 ridges, and intermediate forms exist. Fauvel (1927: 352-353, fig. 121) and Rioja (1931: 404-406, pl. 128) explicitly mention 5 ridges in the text, but figure only three. Material collected by us along the Israeli coast up to depths of 20 meters only showed 3-ridge tubes, with a rather square trapezoidal cross-section, as opposed to the material from deeper localities with 5 ridges and more circular cross-sections. Therefore, Ben-Eliahu \& ten Hove (1992: 41) attributed the shallow water population from Israel to Serpula cf. concharum; subsequently Ben-Eliahu \& Fiege (1996: 6) used $S$. concharum "type B" to indicate this form with 3 longitudinal ridges while Bianchi \& Morri (2000: 260, fig. 2) used Serpula sp. Probably S. concharum sensu auct. from the AtlanticMediterranean is a complex of a complex of - at least— two species and much work remains to be done on the variability of taxonomic characters, particularly in the shallow water material. The revision of the taxon should be based both on the available morphological specimens and on genetic studies. Records under this name from outside the Atlantic-Mediterranean probably belong to other taxa (see Remarks in section of Serpula hartmanae, below). A recent report of Serpula concharum from shallow water off Alexandria in Egypt by El-Rashidy et al. (2009) may well be the same taxon as the material present in shallow depth from the coast of Israel.

\section{Serpula hartmanae Reish, 1968}

Figs 28-32, Table 4

Serpula hartmanae Reish, 1968: 228-229, figs 5, 11-16 [Type locality: Marshall Islands (Fig. 28), Bikini Atoll, Enyu Island]; Imajima \& ten Hove 1984: 36-38, figs 1a-d [Marshall Islands]; Imajima \& ten Hove 1986: 2 [Solomon Islands, Gilbert Islands].

Serpula sp.: Hartman 1954: 641 [northern Marshall Islands, Eniwetok Atoll].

Eastern Mediterranean

No previous records, but see Remarks.

Suez Canal

No previous records.

Gulf of Suez and Gulf of Aqaba

Serpula concharum not Langerhans, sensu Amoureux et al. 1978: 143, fig. 11, as S. c. [part; Gulf of Aqaba, Elat, Stn 6846, underside of a buoy, legit L. Fishelson, 18.IX.1970, on dead corals, 2 specs, synonymised herein (Fig. 29).

Red Sea proper-Indo-West-Pacific (excluding citations from Gulf of Suez and Gulf of Aqaba already given above) Serpula concharum not Langerhans, sensu Imajima 1982: 38-39, figs 1a-i [fide Imajima \& ten Hove (1984), Micronesia, Palau and Yap Islands].

Material examined. Locations adjacent to the Suez Canal, Mediterranean side: Questionable (somewhat similar) material examined (see below).

Suez Canal material reported herein: Great Bitter Lake "Yellow Fleet" Biofouling Samples, January 1320, 1975: 4 subsamples, 4 specs, two specimens with normally developed opercula (larger, B\&T-02, HUJPoly-4388 (Figs 30, 31); smaller, B\&T-01, HUJ-Poly-4387 (Fig. 32); and two with small, regenerating opercula, B\&T-03, HUJ-Poly-4390, respectively B\&T-04, HUJ-Poly-4389). 
Locations adjacent to the Suez Canal, Red Sea side: Gulf of Suez: None.-Gulf of Aqaba: Israel, Elat, Serpula concharum not Langerhans, sensu Amoureux et al.: 1978: 143, fig. 11, as S. c. [part; Gulf of Aqaba, Elat, Stn 6846, underside of a buoy, legit L. Fishelson, 18.IX.1970, on dead corals, 2 specs (Fig. 29)—Egypt, Taba Beach, under rock, 11.V.1988, 3 questionable specs, see remarks below.

Indo-West-Pacific: Marshall Islands, Bikini Atoll, Ocean Side of Enyu Island, legit, det. D. Reish 6.IX.1956, holotype USNM 38400, paratype 38401 (Fig. 28).-Solomon Islands, Mamara Point and Komimbo Bay, British Royal Society Expedition to the Solomon Islands, 1965, attached to coral on reef platform, legit, det. P.E. Gibbs, BM(NH) 1970.833-835, 3 specs.-Palau \& Yap Islands, off Arumonogui, Japanese Expedition to the Palau and Yap Islands, VII.1980, M. Imajima (1982) det. S. concharum, redet. Imajima \& ten Hove (1984) S. hartmanae, ZMA V.Pol. 3452, 1 spec. (of the 15 specs collected), tube.

Suez Canal depth and substrates: On Brachidontes pharaonis bivalves; on a barnacle; on a bryozoan.

Distribution. Red Sea: Gulf of Aqaba; Indo-West Pacific: ?Seychelles; ?India, Micronesia.

Description, based on the largest individual from the Great Bitter Lake with the most differentiated operculum, B\&T-02 (Figs 30, 31, Table 3). Length, $26.5 \mathrm{~mm}$ plus (some posterior chaetigers lacking); ca. 120 chaetigers ( 7 thoracic); operculum with 15 blunt radii without tubercles, apical grooves nearly reaching the centre, surface, concave, cup-like, depth ca. $1 / 2$ the length of the vesicle. Profile bell-shaped with a waist, basal bulb slightly expanded, distal diameter 3.5 times diameter of waist which is positioned $41 \%$ from the base (Fig. 30D); length of external grooves $42.5 \%$. Peduncle with a slight but distinct ventral asymmetrical boss proximal to the marked constriction (more marked in glycerine mount than in alcohol, Figs 30D, F, respectively). Number of branchial radioles per lobe, ca. 11.

Hyaline bodies in the branchial radioles present in all four Suez Canal specimens (Figs 31F, G and 32E) and in a Palau Island individual as well. Apron present.

Meristic characters are detailed for each of the four Suez Canal specimens in Table 3: Length, 12.7-26.5 + $\mathrm{mm}$; width, 0.8-1.2 mm; number of chaetigers, $80-121+$ (7 thoracic), with opercula radii numbering 12-16 (mature opercula with 12 and 15 radii and the regenerating opercula with 15 and 16 radii). The number of radii in Amoureux et al.'s (1978) synonymised nominal Serpula concharum specimen was also 12; the paratype has 18 radii (Fig. 28A). The number of branchial radioles in the lobe $\sim 8-11(\sim 8,10,10,11)$, respectively (largest individual underlined). Length of external grooves, 37-44\%; the maximum opercular diameter 1.8-3.5 times that of waist; waist positioned 28.9-50\% from the base. Contour bell-shaped, with waist less developed in small regenerating opercula. Characteristic asymmetrical peduncular boss present in B\&T-02, much less distinct in B\&T-01, not present in the two regenerating opercula.

Collar chaetae: Bayonet chaetae with 2 conical teeth; in some of the chaetae, a small (fine), very easily overlooked tooth, positioned behind and between the two large teeth and the blade (Figs $28 \mathrm{E}_{1}$, 29I, J; 31A, second chaeta from left; see also Fig. 32F). Collar capillary chaetae present. Other thoracic chaetae "limbate" and capillary chaetae (Fig. 31B). Thoracic uncini saw-shaped, F+5 (Figs 29M, 31D), (F+4, three smaller individuals). Anterior abdominal uncini saw-shaped, $\mathrm{F}+4$, two individuals; both $\mathrm{F}+4$ and $\mathrm{F}+3$ uncini in one individual; $\mathrm{F}+3$ in one individual (Figs 28G, 31E). Abdominal uncini becoming rasp-shaped posteriorly and increasing both in numbers of teeth in vertical row and in numbers of teeth in transversal row (e.g., F:2:3:4:4: plus several rows of smaller teeth towards apex, e.g., Fig. 29L). Abdominal chaetae asymmetric flat-trumpet chaetae with ca. 25 teeth (Figs 28F, 29K; 31C, 32I replaced by capillary chaetae posteriorly (B\&T-02- capillary chaetae in last 17 abdominal chaetigers + a few missing chaetigers. Hyaline bodies were present in the branchial radioles; becoming infrequent towards the proximal part of the radiole, noted in all four individuals from the Suez Canal (Figs 31F, G, 32E).

Tube: White with 3 rounded longitudinal ridges on flat upper surface, trapezoidal in cross-section, with transversal ridges; in more anterior parts of the tube the 3 longitudinal ridges are less pronounced, tube appears less rugose (Figs 28C, D; 29A-C; 30A, B; 32A, B). Thin granular hyaline surface overlay present. 


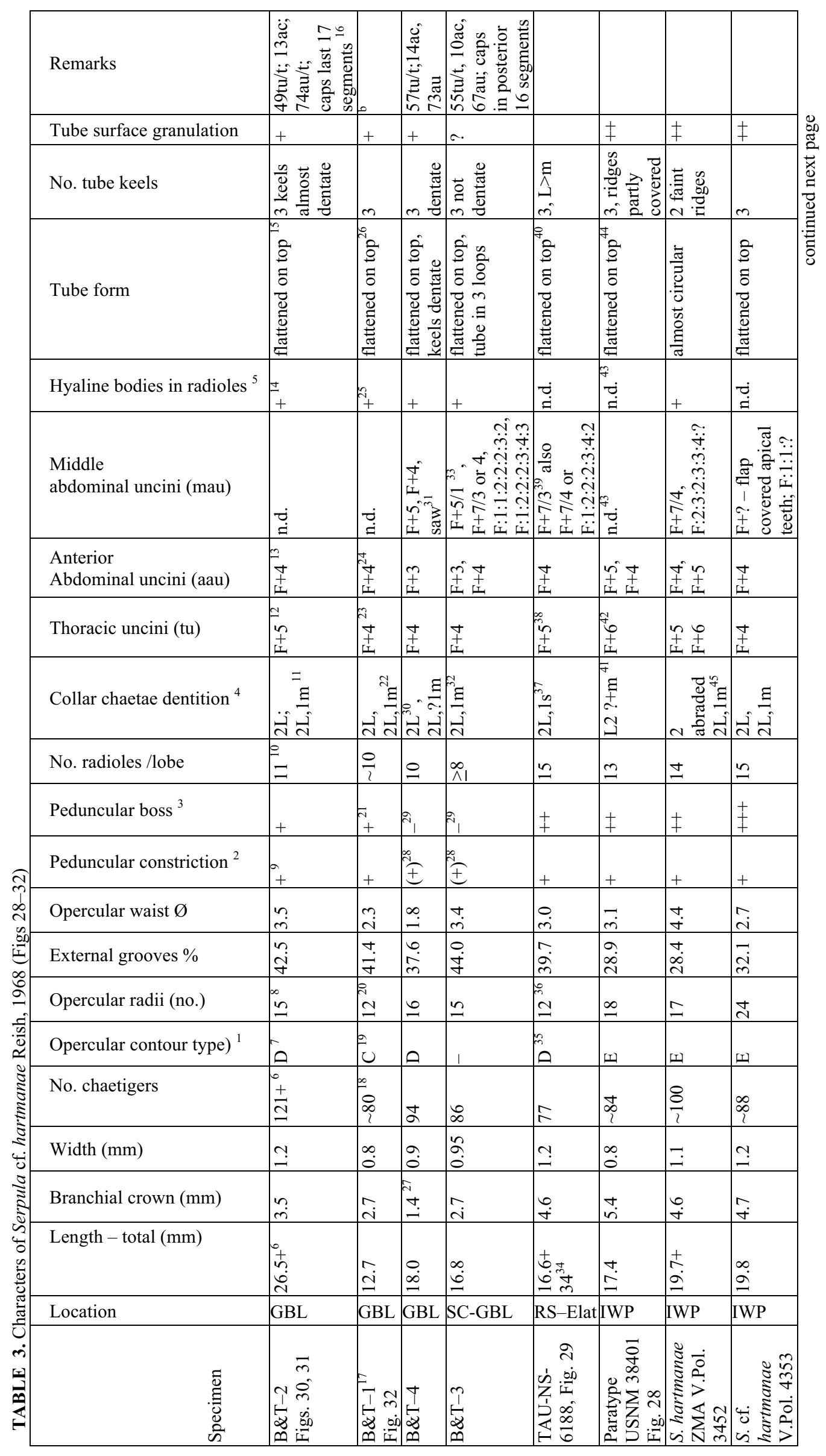




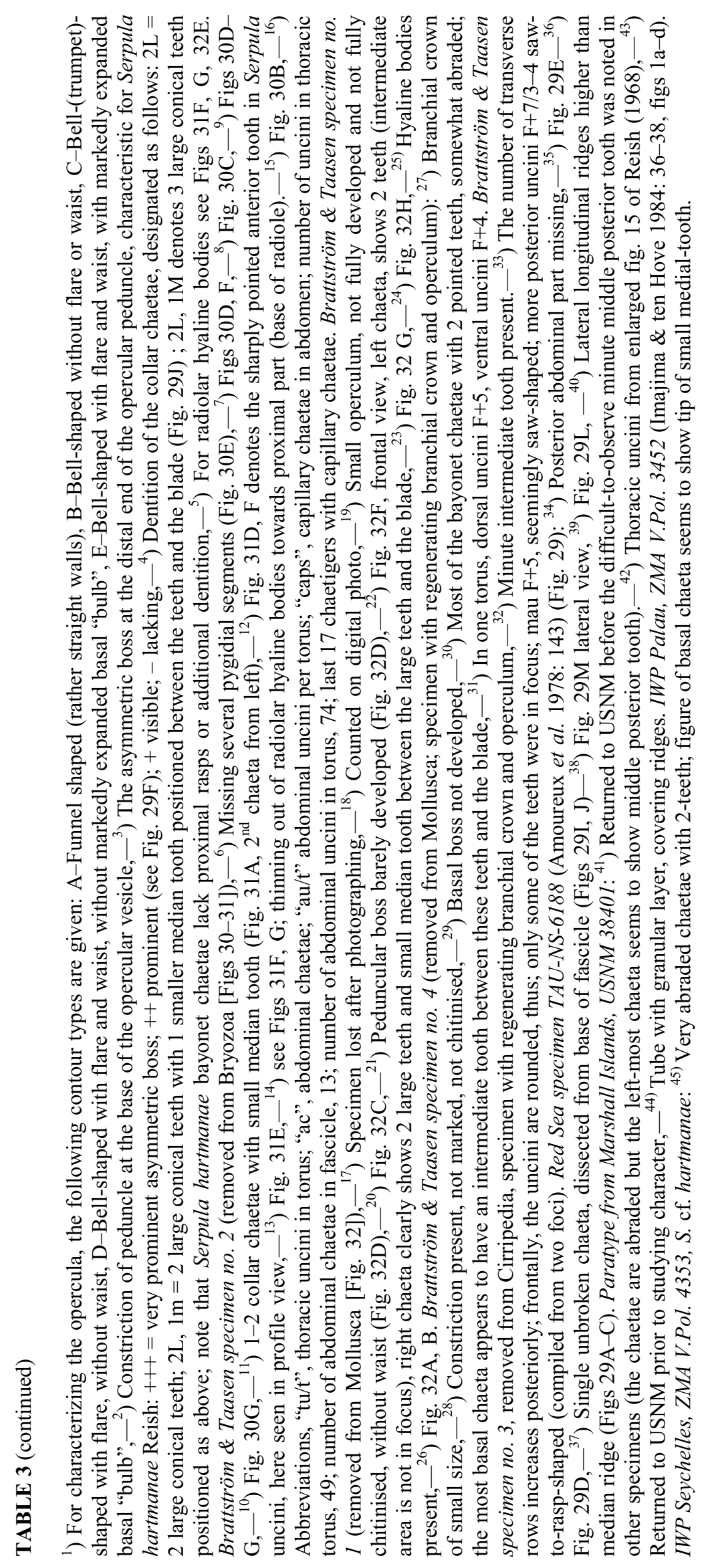



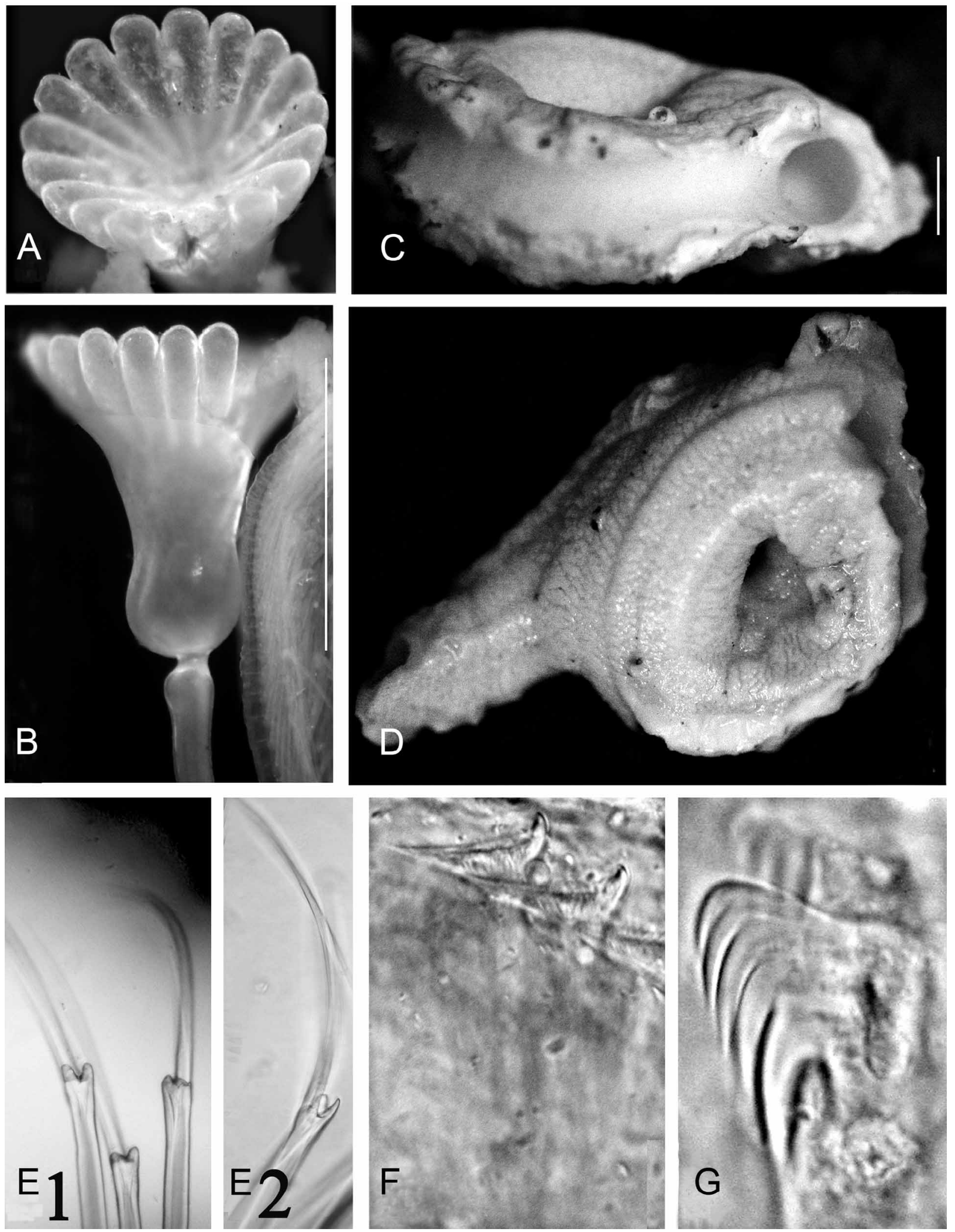

FIGURE 28. Serpula hartmanae paratype from the Marshall Islands (U.S. National Museum of Natural History specimen no. USNM 38401). A-Operculum, apical view, 18 blunt radii (slightly damaged), B-Same, lateral view; note constriction with asymmetric boss, C-Tube, showing cross-section; note granular overlay, D-Tube from above, laterally rugose; note three longitudinal ridges, median ridge lower; upper surface rather flat, E1-Collar chaetae, frontal view, appearing somewhat abraded, E2-Collar chaeta, lateral view, F-Abdominal chaetae, G-Abdominal uncinus, $\mathrm{F}+4$. Scales: $\mathrm{B}-\mathrm{C}-1 \mathrm{~mm}$. 

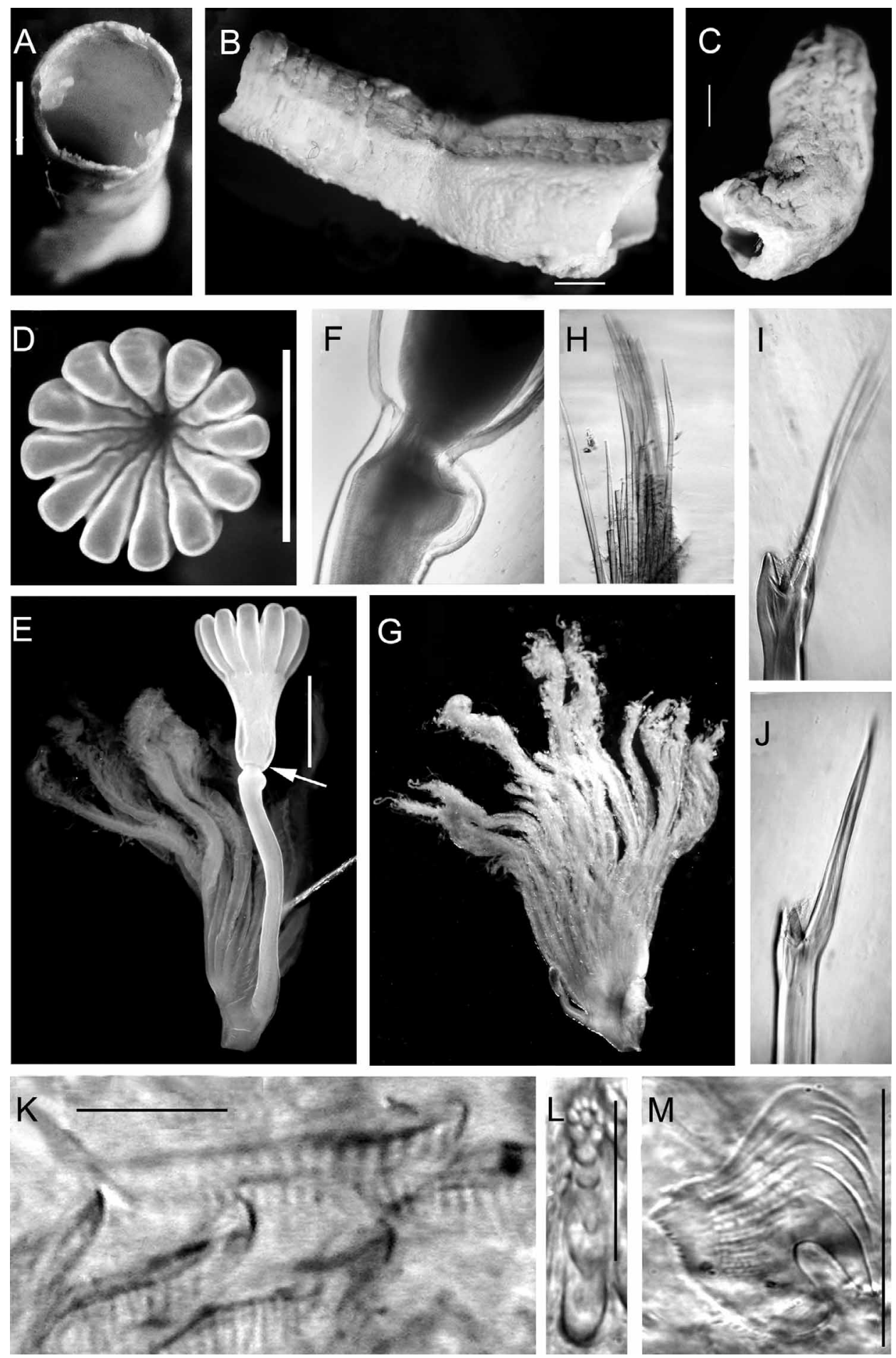

FIGURE 29. Serpula hartmanae from Red Sea, Gulf of Aqaba. Specimen det. as S. concharum in Amoureux et al., 1978: 143, Fig. 11, marked S.c. [TAU-NS-6188], redet. 1990, H.A. ten Hove. A—Cross-section of tube, B-Part of tube, flat surface up, shows 3 longitudinal ridges, middle ridge lower than laterals, $\mathrm{C}$-Part of tube, flat upper part to the right, D-Operculum, apical view, 12 radii, E-Operculum (lateral view) and opercular lobe; arrow designates the peduncular boss proximal to the constriction (also in Fig. 28B), F-View of constriction of opercular peduncle showing characteristic asymmetric proximal boss (enhanced in glycerine mount), G-Branchial lobe, showing pseudoperculum, ca.13 radioles, H-Fascicle of thoracic chaetae (most broken), I, J-Collar chaeta (single unbroken chaeta dissected out from base of fascicle), I-Frontal view, small median tooth between large conical teeth and blade clearly seen, J-Lateral view, $\mathrm{K}$-Abdominal chaetae, L-Posterior? middle abdominal uncinus frontal view (composite picture enables showing rows in focus), detailed dentition, $\mathrm{F}: 1: 1: 1: 1: 2: 3: 3=\mathrm{F}+7 / 3$ rows with maximum number of 3 teeth in the posterior rows, $\mathrm{M}-$ Thoracic uncinus, lateral view F+5. Scales: A-E-1 mm, K-10 $\mu \mathrm{m}, \mathrm{L}, \mathrm{M}-50 \mu \mathrm{m}$. 
Remarks. Narrowing down the identification of our Suez Canal material of the genus Serpula, we considered the species neighbouring the Canal at both sides (and further away as well); see extensive discussion of this approach under Protula. The name Serpula concharum has erroneously been given to IndoWest-Pacific taxa, e.g., Amoureux et al. (1978, see above). Identifying "Serpula concharum"-like taxa with a similar opercular contour and a low number of blunt marginal radii from the Suez Canal area, we can discount both Mediterranean taxa of this nominal species (see remarks on $S$. concharum, above) by the fact that they lack the main diagnostic characters for $S$. hartmanae: The asymmetric ventral peduncular boss (swelling) proximal to the constriction of the operculum, termed by Reish (1968) "2 knobs", and a granular surface overlay on the white tube (ten Hove 1994). However, in the Solomon Island specimens of P.E. Gibbs (1971), a sketch of spec. no. 833 showed a prominent asymmetric boss just below the opercular constriction while that of no. 835 was not prominent (notes, Ben-Eliahu, 1986), an indication as to the variability of this character.

Considering Serpula taxa distributed in the Mediterranean, we excluded S. cavernicola Fassari \& Mòllica, 1991, S. israelitica Amoureux, 1976 and S. vermicularis, all with more (40+) radii than our present material. It should be noted that we consider $S$. vermicularis strictly as an Atlantic / Mediterranean taxon, not cosmopolitan, cf. ten Hove \& Jansen-Jacobs (1984). Serpula lobiancoi Rioja, 1917 has a pronouncedly zygomorphic operculum.

In considering described Indo-West-Pacific (IWP) taxa, we excluded several IWP taxa with more radii such as Serpula indica Parab \& Gaikwad, 1989 (maybe including the very similar S. nudiradiata Pillai, 2009, see further down), or $S$. jukesii, and taxa with a similar number of radii but with more teeth on the collar chaetae such as S. oshimae Imajima \& ten Hove, 1984 that also has a predominantly orange tube and 7-9 thoracic chaetigers (Imajima 1978, as S. cf. kaempferi) or S. vittata Augener, 1914 (syn. S. palauensis Imajima, 1982) that has Hydroides elegans-like collar chaetae and a tube dotted with brownish speckles. Another Indo-West-Pacific species, S. rubens Straughan, 1967b (p. 209-211, fig. 4a-i), with a similar opercular contour and number of radii (16-18), and collar chaetae with a large and several small teeth, is a much smaller species (to $8 \mathrm{~mm}$ in length), with fewer pairs of radioles (a maximum of 7 pairs), and with a variable number of thoracic segments, 8-11 (Imajima \& ten Hove 1984: 38).

The Suez Canal material comprised only 4 individuals and, regrettably, two of them, B\&T-03 and -04, had regenerating opercula. Revising Serpula hartmanae parameters from Imajima (1982, as $S$. concharum) and Imajima \& ten Hove (1984) provides a reported length of up to $24 \mathrm{~mm}$, with up to 105 chaetigers; thorax with typical constant seven chaetigers; 15-16 radioles, and 11-25 blunt opercular radii. Meristic differences between their $S$. hartmanae material and that of Reish (1968) appeared to these authors insufficient for taxonomic distinction (Imajima \& ten Hove 1984: 38). Ten Hove (1994) reported Seychelles material with an even greater number of opercular radii (24-35) as Serpula cf. hartmanae due to the presence of an asymmetric peduncular boss ("peculiar swelling") and a granular tube surface. Moreover, some of the Seychelles specimens' opercular grooves were wavy, not smooth, thus it might well be a separate species. The Red Sea $S$. hartmanae individual had 12 opercular radii (Fig. 29D).

As Table 3 shows, the largest individual from the Suez Canal (B\&T-02) slightly exceeds the compiled length described for Serpula hartmanae. Its operculum shows an asymmetric peduncular boss (Figs 30D-F), though less prominent than that of the Red Sea specimen (Fig. 29E, F) which is similar in size to that of the paratype (Fig. 28B) - it is smaller than that figured for the holotype by Reish (1968, fig. 11). A Palau Island individual had an even larger boss than the paratype or the Red Sea individual (Imajima \& ten Hove 1984: 37, fig. 1a).

The number of chaetigers in these Suez Canal specimens is also slightly greater than that described for Serpula hartmanae, but that is also true for other $S$. hartmanae individuals, e.g., from Palau Island (material of Imajima \& ten Hove 1984); that of the Red Sea specimen with a missing posterior abdomen was 67+. The number of radioles in the Suez Canal material was less than that described for Serpula hartmanae, while the Red Sea individual had 15 radioles in the non-opercular lobe, which conforms to the description.

In the several descriptions, differences in the chaetal dentition of the bayonet collar chaetae also emerge. Reish (1968) figured them with 2 teeth, rather abraded in the paratype (see Figs $28 \mathrm{E}_{1}, \mathrm{E}_{2}$ ); ten Hove \& JansenJacobs (1984: 149, fig. 2q) similarly noted 2 teeth without accessory teeth, however, Imajima (1982) and Imajima \& ten Hove (1984: 36$)$ referred to " $2-3$ heavy conical teeth and a variable number of small accessory 
teeth at base." The collar chaetae of one of their Palau specimens (Imajima \& ten Hove 1984) were abraded, except for a basal chaeta with 2 large conical teeth; whether or not there is an intermediate tooth positioned between these teeth and the blade could not be seen; there were no accessory teeth at the base. The Red Sea specimen had only one unbroken bayonet chaeta at the base of the fascicle; it had a distinct small median tooth positioned between the conical teeth and the blade (Figs 29I, J) similar to some of the Suez Canal bayonet chaetae, described above (Figs 31A, 32F)—the remaining collar chaetae were broken. In a Seychelles specimen (of Serpula cf. hartmanae), the median tooth was larger than that in the Red Sea and Suez Canal chaetae (Table 3).

Thoracic uncini: An enlargement of Reish's (1968) figure of the thoracic uncini (fig. 15) shows a dentition of F+6. The thoracic uncinus given by Imajima (1982: 39, fig. 1f) was F+7 teeth, and Imajima \& ten Hove (1984) reported F+7 thoracic uncini. However, a single torus from a Palau Island individual, showed several uncini of F+6 dentition, while most were F+5. The Red Sea specimen showed F+5 dentition (Fig. 29M). As noted, the largest Suez Canal individual had F+5 uncini (Fig. 31D), while the thoracic uncini of the three others was F+4, a lower number than previously described for Serpula hartmanae.

Abdominal uncini: Reish (1968) did not specify dentition of the saw-shaped anterior abdominal uncini; however that of the paratype was F+4 (Fig. 28G). The abdominal uncini described by Imajima (1982), and Imajima \& ten Hove (1984: 36) are F+7 anterior and posterior uncini, with up to 4 horizontal rows of teeth in the transversal rows of the rasp-shaped posterior uncini. The Red Sea specimen's anterior abdominal uncini were $\mathrm{F}+4$ while the not quite posterior-most uncini were $\mathrm{F}+7 / 4$.

All Suez Canal individuals show a trend of increasing the number of teeth in the vertical rows posteriorly, and the increase in number of teeth in the horizontal rows continued, detailed for some individuals in Table 3 , which also shows the variability of dentition within a single torus (most individuals have a posterior dentition of F+7/4 [see "Treatment of the specimens in "Material and Methods" section]). For example, dentition of a posterior abdominal uncinus of specimen $B \& T-2$ was $F+7 / 4$ (or 5) (detailed $F: 1: 2: 3: 3: 2:[4$ or 5]:4), while in specimen $B \& T-4$, in the same torus, the number of teeth were: $F+8 / 4$ (detailed $F: 1: 1: 1: 2: 3: 4: 4: 2$ ) in one uncinus, and $\mathrm{F}+7 / 4$ (= F:1:1:2:2:3:4:3) in another (seen under compound microscope).

Abdominal chaetae: Abdominal chaetae cannot be properly described without SEM due to their transparent nature (ten Hove \& Jansen-Jacobs 1984: 145); photographs (Figs 28F, 29K, 31C and 32I) show mostly the fibrils and not the transparent distal teeth; thus, counts of the teeth done under the compound microscope are not reliable.

Tube: The Micronesian material from Palau Island (Imajima \& ten Hove 1984: 36-38, figs 1c, d) appears more granular than that of the paratype, the Red Sea or the Suez Canal individuals, but all of the tubes appeared to have a thin granular layer. In the Gulf of Aqaba specimens from Taba Beach, the seeming lack of a granular surface on the tubes, despite a three-ridged cross-section, raises a question regarding the identification of the three specimens taken from under a rock (11.V.1988 [cited above]); the identification as Serpula hartmanae is supported by the low number of opercular radii, 17, 16 opercular radii, 11 radii in a juvenile with marked constriction present at the base of the operculum.

Meristic differences found by Imajima \& ten Hove (1984) did not seem to them sufficient for taxonomic distinction. Similarly, the Suez Canal material, though showing some variation, should be attributed to Serpula hartmanae. Our results suggest that the degree of waistline in the profile of the operculum is a function of the opercular development (size) and this appears to be true also for the development of the characteristic asymmetric peduncular boss. It is not known whether the closely packed hyaline bodies observed in the branchial radioles have disappeared in some preserved specimens. What is clear is that variability in various characters in the taxon $S$. hartmanae needs still to be further explored, and particularly, variability in development of the peduncular boss (bosses), in structure of bayonet collar chaetae, dentition of the uncini as well as the effect of different environmental conditions on the formation and degree of tube granulation, and the thickness of the lateral keels. In this exploration, S. amplilobata Pillai, 2009 (pp.134135, figs $27 \mathrm{a}-\mathrm{k}, 18 \mathrm{~A}-\mathrm{E}$ ), recently described upon a single specimen only, should be taken into account as well. Apparently Pillai was not aware of the existence of $S$. hartmanae, since not referring at all to this taxon in his paper, while it is at least very similar-if not synonymous-with his newly described taxon regarding operculum, granular tube, collar chaetae, etc. 

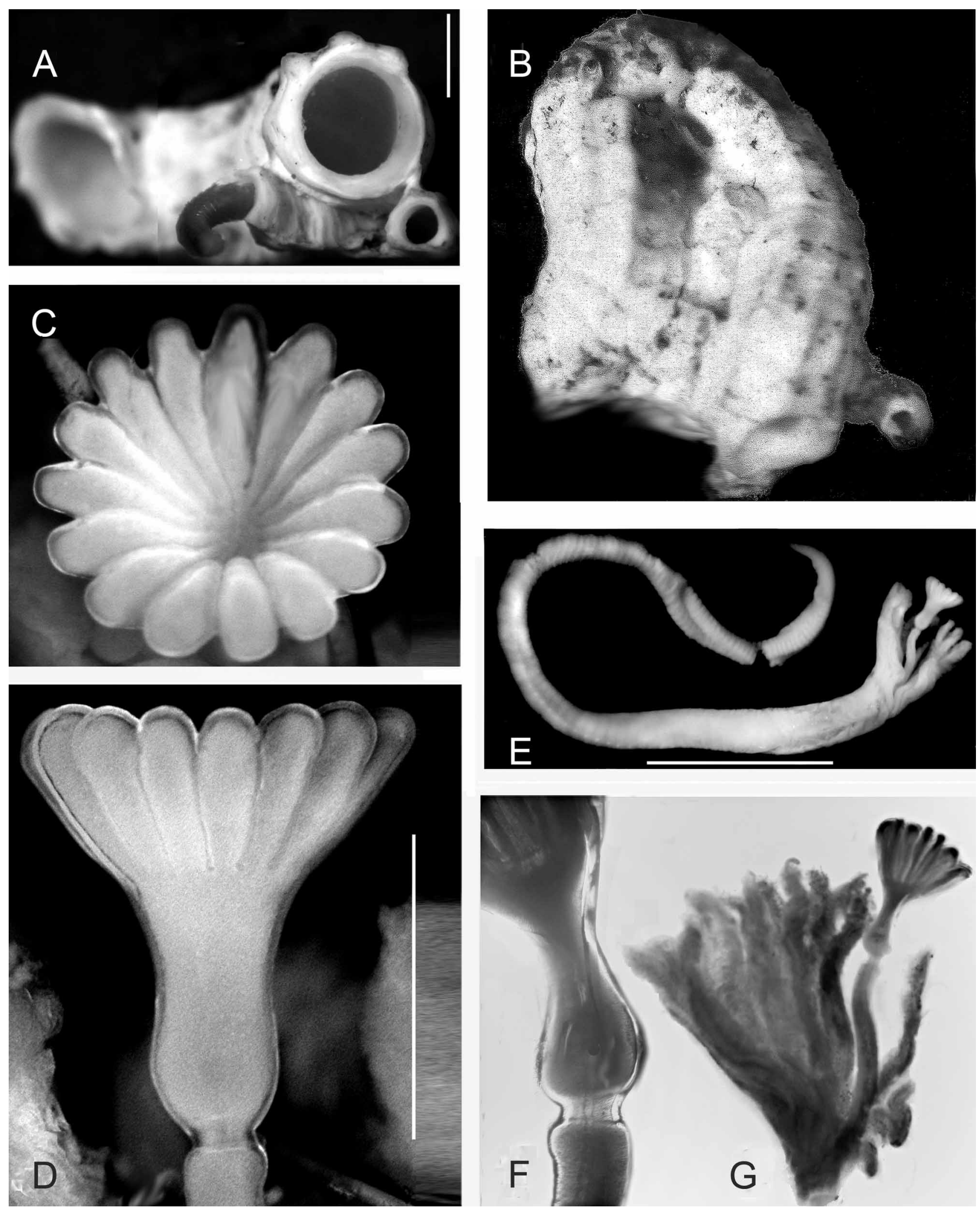

FIGURE 30. Serpula hartmanae from the Suez Canal, Great Bitter Lake (Brattström \& J.P. Taasen specimen no. 2). ATube, showing cross-section; note 3 dorsal longitudinal ridges, tube rather rounded, B-Tube, dorsal aspect, laterally rugose, $\mathrm{C}$-Operculum, apical view, 15 blunt radii, D-Same, lateral view; note constriction with asymmetric boss, EWhole worm, removed from tube, F-Microscope view of base of operculum with constriction and proximal asymmetric boss (methylene-blue glycerine mount medium), $\mathrm{G}$-Opercular lobe, 11 radioles (in methylene-blue glycerine mount). Scales: A, D-1 mm, E- $5 \mathrm{~mm}$. 

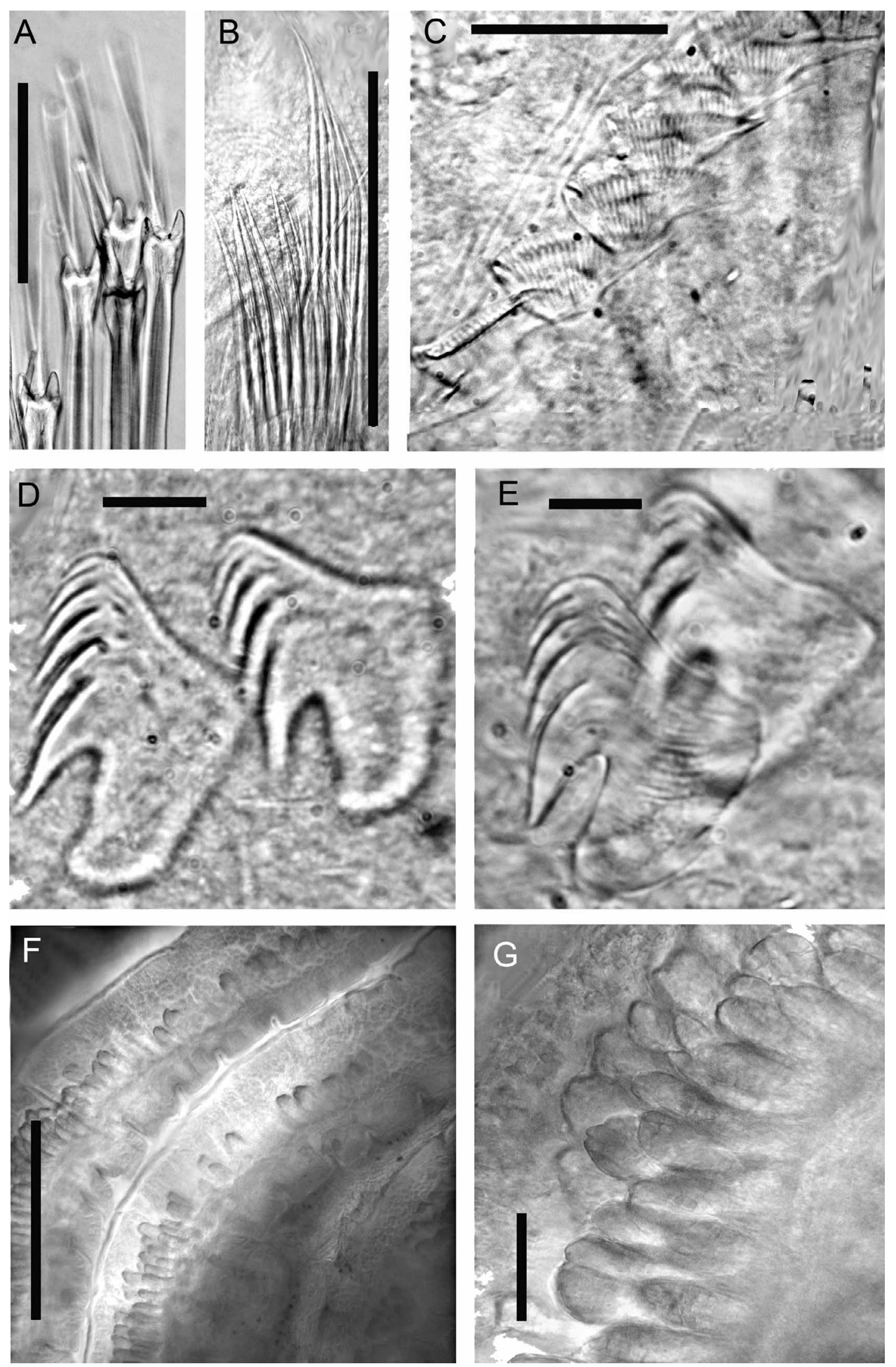

FIGURE 31. Serpula hartmanae from the Suez Canal, Brattström \& J.P. Taasen specimen no. 2. A-Collar chaetae, note that two left chaetae have a small accessory tooth between the two large conical teeth and the blade (see also Fig. 32F), B-Thoracic chaetae, C-Abdominal chaetae, D-Thoracic uncini, F+5, E-Abdominal uncini, F+4, F-Radioles with hyaline bodies, G-Enlargement of same. Scales: A, C, G-100 $\mu \mathrm{m}, \mathrm{B}-1 \mathrm{~mm}, \mathrm{D}, \mathrm{E}-10 \mu \mathrm{m}, \mathrm{F}-1 \mathrm{~mm}$ (estimated from G). 

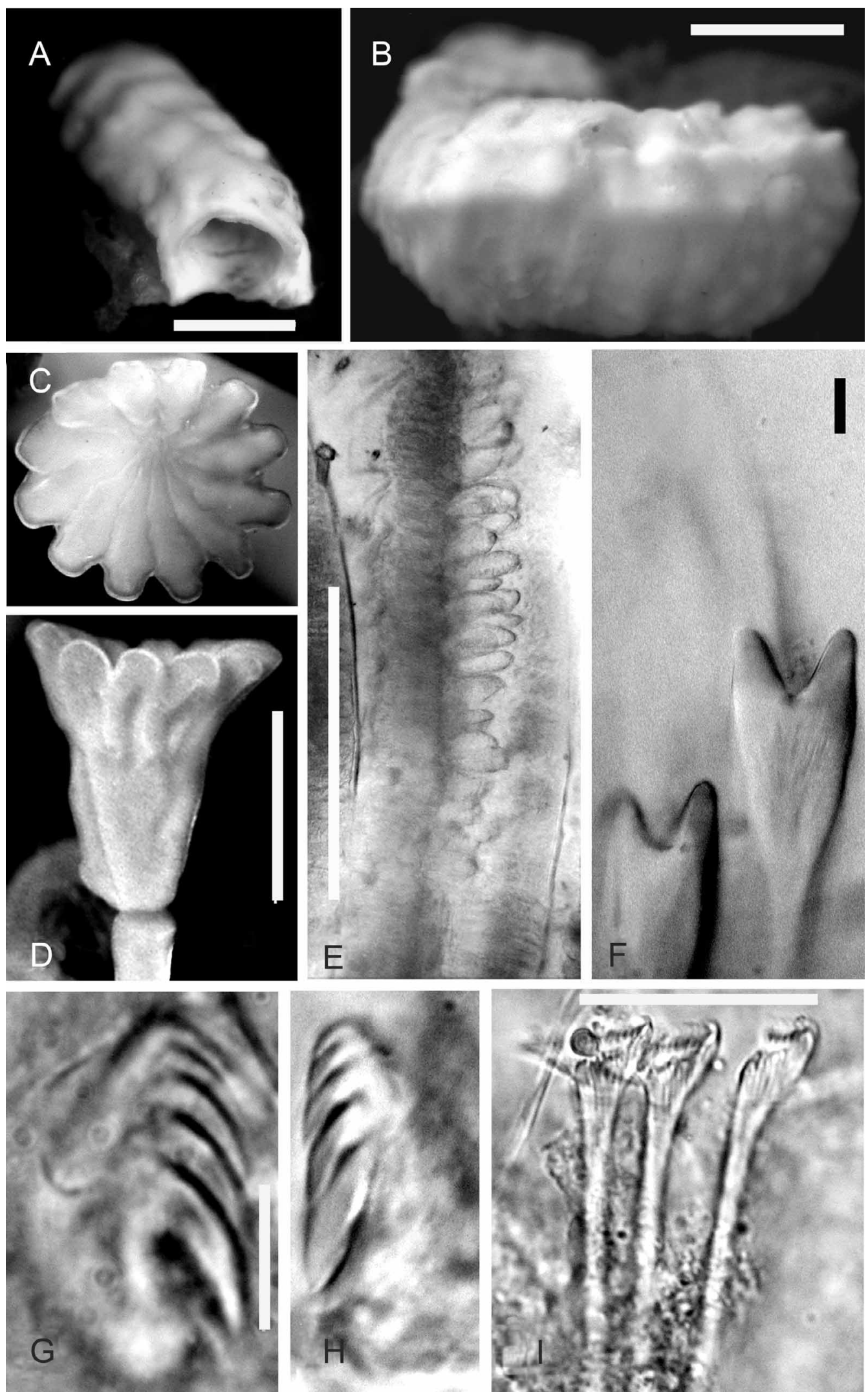

FIGURE 32. Serpula hartmanae from the Suez Canal, Brattström \& J.P. Taasen specimen no. 1. A-Tube anterior, BTube, 3/4 side-top view, C-Operculum, apical view, 12 radii, D-Operculum, lateral view, E-Branchial radiole showing hyaline bodies, F-Collar chaetae, with 2 conical teeth, with small median tooth visible behind large conical teeth, G-?Abdominal uncinus, lateral view, H-?Abdominal uncinus, 3/4 frontal view, I-Abdominal chaetae. Scales: A, B$1 \mathrm{~mm}, \mathrm{C}, \mathrm{D}-0.5 \mathrm{~mm}, \mathrm{E}, \mathrm{G}, \mathrm{H}-100 \mu \mathrm{m}, \mathrm{F}, \mathrm{I}-10 \mu \mathrm{m}$. 
On reviewing the present paper, H. Zibrowius contacted H.A. ten Hove concerning a new finding by Zibrowius \& Bitar that Serpula hartmanae is abundant on the Lebanese coast (Zibrowius \& Bitar, in prep.). This finding should cause it to be classified as a Lessepsian migrant proper, sensu Por (see Introduction). The report galvanized us to examine Serpula material encrusted on recently obtained molluscs (samples of the Tel Aviv University mollusc collection), as well as our own collections from 1990, diagnosed as $S$. cf. concharum (by Ben-Eliahu \& ten Hove 1992: 41). The specimens are clearly different from Serpula concharum Langerhans, 1880 s. str., from deeper waters. All 22 specimens surveyed have a three-keeled tube. However, in some tubes, the two dorso-lateral keels are much more prominent, more rounded, and more blunt than the thinner medial one (as in Serpula hartmanae [Fig. 29B]), but in others (perhaps half of the tubes), the keels are all narrow and rather similar-very likely this is related to size / age, but that still needs verification. Tubes are mostly covered by a thin granular layer. Some of the opercula show a small but distinct ventral peduncular boss proximal to the marked constriction $(\mathrm{n}=3)$ as in Serpula hartmanae (Figs. 29E, F, 30D, F, and 31D), but, in most specimens, the boss is not pronounced. The number of radii range between 10-13.3 $-19(\mathrm{n}=22$, SD 2.3). Perhaps the variability observed in the tube structure and the peduncular boss falls within the range of a single taxon, but we cannot presently be sufficiently certain to make a conclusive determination of that. We assume that Zibrowius \& Bitar's Lebanese record belongs to the same taxon, which, in the past, we had identified as $S$. cf. concharum. This raises the question whether this material belongs to a taxon indigenous to the Mediterranean, as forms with a 3-keeled tube have been mentioned under various names, the oldest probably being Serpula sulfurata Milne Edwards, 1836. Alternatively, there is a reasonable similarity with our specimen from the Gulf of Aqaba (Fig. 29), presumably identical with S. hartmanae, which indeed might make the taxon yet another Lessepsian migrant. In view of the fact that the taxonomy of the genus Serpula is exceedingly problematic (see Remarks under Serpula jukesii, this paper), we have refrained from reaching a decision at the present time. A revision of $S$. concharum sensu lato, and all material of Indo-West-Pacific records of similar taxa, including $S$. hartmanae, is necessary (see remark on variability of this nominal taxon one paragraph above as well), but falls outside the scope of the present paper. Serpula cf. concharum, recently reported in shallow Egyptian waters (Alexandria) by El-Rashidy et al. (2009), is very possibly the same taxon as that found along the Israeli coast (see remarks under Serpula concharum, above).

\section{Serpula jukesii Baird, 1865}

Table 4

Type locality. East coast of Australia. Most probably not present in the Suez Canal proper, see Remarks, below.

Preliminary remarks. Since the presence of Serpula jukesii Baird (1865: 20, pl. 2 fig. 6) in the Suez Canal has not (yet?) been authoritatively demonstrated, we have refrained from a full treatment of the taxon here. For comparison, however, we reviewed the literature of larger Serpula taxa from Indo-West-Pacific origin and studied dozens of samples, as $S$. jukesii (including its holotype BM(NH) ZB 1982: 84), vermicularis sensu auct., vermicularis granulosa, magna, vasifera, originating from Kuwait to Japan, from India to Australia. Some of this has been summarized in Table 4. Below we also comment upon relevant records from the nearby Gulfs of Suez and Aqaba.

Material examined. Gulf of Suez: Cambridge Expedition, stn R5, 5.XI.1924, det. F.A. Potts (1928: 700) Serpula vermicularis, fragments of a specimen discussed in detail below.-33 $23^{\prime}$ E., $28^{\circ} 14^{\prime} \mathrm{N}, 22 \mathrm{~m}$, muddy sand, St. 17 bis, R.Ph. Dollfus Exp., 25.XII.1928, det. P. Fauvel (1933a: 76) S. vermicularis, redet. $S$. jukesii herein, CUZM, 1 spec. Operculum of specimen symmetrical with blunt teeth, its "waist" at mid-point; expanded basal bulb; constriction, deep funnel, 54 marginal radii (teeth); 40 radioles per lobe; tube white, pink inside, tubes without ridges; collar trilobed; apron; collar chaetae with 2 teeth; thoracic uncini F+4; anterior abdominal uncini $\mathrm{F}+5$ and $\mathrm{F}+6$.

Red Sea, legit G. von Frauenfeld, det. Grube (1868: 640) Serpula gervaisii, redet. H.A. ten Hove 1982 S. jukesii (Table 4), Muzeum Przyrodnicze Wroclaw, $1 \mathrm{spec}$. Operculum showing tubercles on inner radii as opposed to type of $S$. jukesii. 


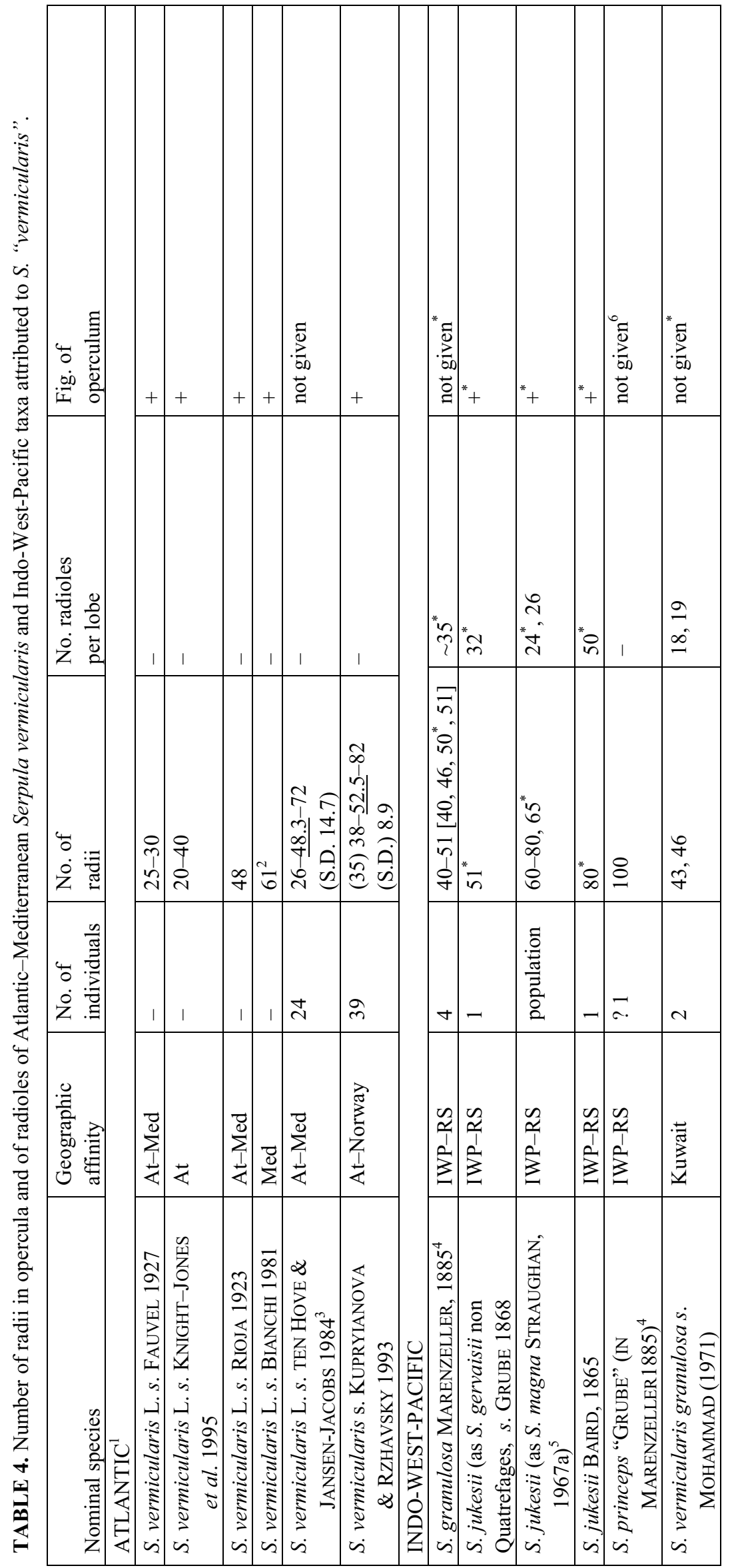

啳 总

亲. 包记

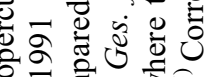
可 政

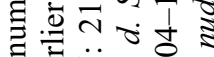
跑茄

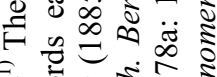
1. 这

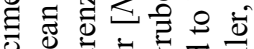

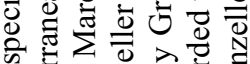
额子

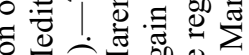
을 0

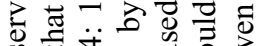
年 品

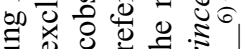
年

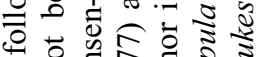

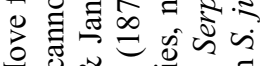

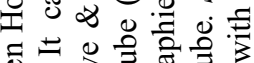
馬 $<1$.

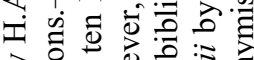

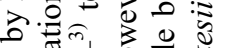

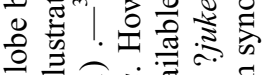

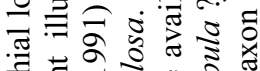

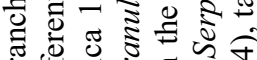

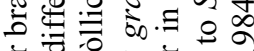
证 के के है

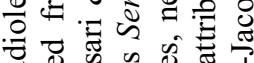

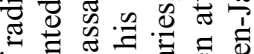

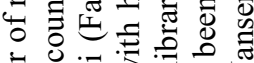

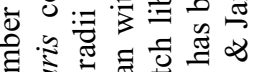

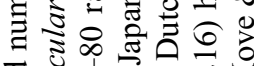

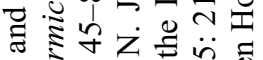

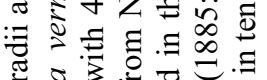
t⿹

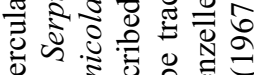

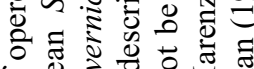

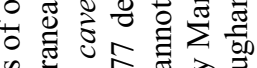

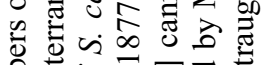
政

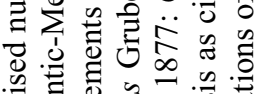

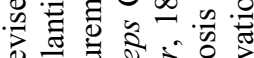

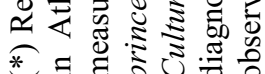


Remarks. The taxonomy of the genus Serpula is exceedingly problematic. Without comparison of specimens to be identified with type specimens, or at least with topotypical material, identification is difficult under the best of circumstances. This is exacerbated when a specimen collected from within a transoceanic canal is unavailable for direct examination. The only record under the name Serpula jukesii was listed in a table (AbdElnaby 2009: 10), without any additional details. Regretfully, it was not possible to forward the material to Amsterdam for direct examination, however, the author generously responded to ten Hove's request to count the number of opercular radii. On the basis of its having too few opercular radii (19 radii after damage, F.A. Abd-Elnaby, pers. comm. to H.A. ten Hove), we excluded the identification as Serpula jukesii for this Suez Canal specimen. In contrast, the taxon is excluded from an identification as Serpula hartmanae due to its having too great a number of radii (see Table 4), bayonet chaetae with 2 teeth, and by lacking an asymmetric boss on the peduncle, proximal to the constriction separating the peduncle from the operculum (F.A. Abd-Elnaby, pers. comm. to H.A. ten Hove). Given the present constraints, the most plausible conclusion is that the specimen is a juvenile Hydroides with a primary operculum (for a discussion of opercular ontogeny in Hydroides, see ten Hove \& Ben-Eliahu 2005). As it lacks the characteristic collar chaetae of Hydroides elegans, we are provisionally identifying it as Hydroides sp. (not enumerated among the verified taxa of the canal, and listing it among the non-determined species below).

A nominal Serpula vermicularis sensu auct. had been collected in the Gulf of Suez and was included in Potts' 1928 article on the Cambridge Expedition Sedentaria although not having been collected from within the Suez Canal proper. Potts (1928) referred to Pixell's (1913) report of S. vermicularis in the Red Sea, which included citations from Antarctica, Patagonia and the Mediterranean Sea, "clearly a very unlikely distribution" (ten Hove \& Jansen-Jacobs 1984). Potts' (1928) Serpula was presumably of Indo-West-Pacific or / and Red Sea affinity, whereas the type locality of Serpula vermicularis is Sussex, England (Heppell 1963: 445). By comparison with the distributions of other boreal-temperate taxa such as Pomatoceros triqueter, it may be safely assumed that Serpula vermicularis also occurs throughout the Atlantic-Mediterranean region. However, even this Atlantic-Mediterranean taxon might not be a single species. Ben-Eliahu \& ten Hove (1992) and Ben-Eliahu \& Fiege (1996) mentioned differences in tube structure and colour, which may have taxonomic importance. Preliminary work done by us (in 1990-unpublished) indicates that there may be statistical differences in number of opercular radii, length of interradial grooves between opercula of the "echinate" form and Serpula vermicularis "s. str.". Earlier Mediterranean records too may have included material of $S$. cavernicola. The cosmopolitan status of Serpula vermicularis has been questioned by ten Hove \& Jansen-Jacobs (1984); as a consequence Kupriyanova \& Rzhavsky (1993) and Kupriyanova (1999) separated 2 valid North Pacific taxa, S. columbiana Johnson, 1901 and S. uschakovi Kupriyanova, 1999, from the previously "cosmopolitan" S. vermicularis.

Potts (1928: 700) nominal Serpula vermicularis reported an operculum with 70 opercular radii ("radiating ridges"), radially symmetrical ("insertion not as in S. lobiancoi"), borne on a lobe with 22 branchial radioles. Potts gave no details on body structure or chaetae. Regretfully, the vial with Potts' nominal S. vermicularis specimen, comprised only a tube and a posterior fragment when reviewed in 1986 at the CUZM by M.N. BenEliahu; the branchial crown and anterior were already missing. However, when rechecked in IX.2002, only the tube was present, along with some abdominal epidermal tissue adhering to it (Fig. 11).

As Fig. 11A-C shows, Potts' description of the tube was both Painstaking and accurate: A massive tube, "coiled in a plane spiral" and "the tube is not free anteriorly over a great part of its length", as Fauvel states is the case in Serpula vermicularis (Fauvel 1927: 352). The number of longitudinal ridges on the tube was difficult to make out" (Potts 1928). The tube resembles an enormous Spirorbis, and has a rather flattened upper surface with two blunt longitudinal ridges. Although the mouth of the tube appears rounded in cross-section, there are pronounced transversal ridges (i.e., former peristomes), and it has a thick granular overlay (Fig. 11C, see discussion below).

Other Indo-West-Pacific records of nominal Serpula vermicularis should be checked individually against the voucher specimens. For example, Serpula jukesii sensu Grube (1878), from Japan should be referred to $S$. uschakovi (fide Kupriyanova 1999). Potts' (1928) questionable Gulf of Suez specimen would fit into the biogeographical pattern of Serpula jukesii. 
Dealing with possible synonymies of nominal Serpula taxa, ten Hove \& Jansen-Jacobs (1984) wrote: Of the small number of useful taxonomic characters in Serpula, the "most important is the number of opercular radii". According to these authors, Serpula vermicularis from Australian waters generally should be named $S$. jukesii (including S. magna).

Serpula vermicularis granulosa sensu Mohammad (1971, Kuwait, 2 specs) and S. gervaisii not Quatrefages, 1866, sensu Grube (1868), Red Sea, 1 spec., were considered to be possible synonyms of S. jukesii. They are characterised by similar form in tubes, thoracic membranes not forming an apron on the ventrum, 3toothed collar chaetae, and a very large number of opercular radii (i.e., marginal teeth) with and sometimes without distinct surface tubercles. Data on the collar chaetae and the thoracic membranes of Potts' Serpula would have provided important support for identifying the specimen. Nonetheless, the described operculum falls within the Serpula jukesii / S. granulosa complex (sensu ten Hove \& Jansen-Jacobs 1984: 143-152). In a later paper, ten Hove (1994: 111) suggested that both taxa might be valid; ten Hove \& Kupriyanova (2009: 94) treated both as separate taxa. The number of opercular radii of these nominal taxa ranges from 40-100 (Table 4). For perspective, Table 4 also gives the range of number of marginal radii for Atlantic-Mediterranean Serpula vermicularis s. str., ranging from 25-61, with an illustration of local differences in this taxon in numbers of radii, as opercula from a purely Norwegian population were of larger size than those compiled from various areas including the Mediterranean. Size differences for warmer and colder-water populations of invertebrate species are a phenomenon described by Gunter (1957: 174) and Mayr (1966: 327) and might be found in $S$. vermicularis as well. Alternatively, the Atlantic-Mediterranean S. vermicularis sensu auct. might prove to be a complex of two (cryptic) species.

Attributing the operculum described by Potts (1928) to the Serpula jukesii / granulosa-complex creates a dilemma, as the tube, with its regular flat tight spiral coiling, is not characteristic for Serpula. It appears certain that the tube and operculum are "mismatched". Flat coiled spiralling is, however, known for an occasional Hydroides (H. Zibrowius, pers. comm. and our own unpublished observations and illustrated by Kupriyanova \& Jirkov 1997), for Spiraserpula (Pillai \& ten Hove, 1994), as well as for the bathyal Nogrobs (cf. ten Hove \& Kupriyanova 2009: 68). A Hydroides identification for the tube is not contraindicated by the abdominal chaetae from the epidermis removed from the tube lumen (Fig. 11D-F). The most plausible solution to this dilemma is that the opercular crown and the tube were fragments of two taxa collected together and placed in the same vial (H. Zibrowius, pers. comm.), so that Potts' record of this sample should be revised to Serpula ?jukesii and to Hydroides sp. Moreover, once the possibility of Hydroides sp. is accepted, we suggest the tube could belong to $H$. heterocerus, the largest of the Hydroides species known from this area, and one with several records from the Gulf of Suez, indeed from the same general location, e.g., Suez quay (Pixell 1913: 75), Gulf of Suez (Fauvel 1933a, b) [see above section dealing with Hydroides heterocerus]). Potts (1928) did not indicate whether he had examined a "loose" branchial crown-one separated from a worm body floating in the sample material—or seen the body belonging to the operculum.

Serpula ?jukesii as understood by ten Hove \& Jansen-Jacobs (1984: 149) shows considerable intraspecific variability in the collar chaetae: One heavy tooth and two accessory ones or three heavy teeth and two accessory ones, or four nearly equal teeth. However, Serpula nudiradiata Pillai 2009 (pp. 136-139) may have been included in S. jukesii by ten Hove \& Jansen-Jacobs, possibly throwing a different light upon this variation, their material should be restudied. It should be noted that Pillai apparently did not see the holotype of Serpula jukesii in the $\mathrm{BM}(\mathrm{NH})$, at least it was not mentioned by him, and he might have observed that the holotype of S. jukesii does not show tubercles, as opposed to Pillai's material of this nominal taxon (and that of $S$. gervaisii sensu Grube (1868)) which both do show tubercles. A further difference between the holotype and Pillai's specimens is the presence of an apron, as the ample thoracic membranes are not joined to form an apron in the holotype of S. jukesii. In fact, this was one of the characters upon which ten Hove \& Jansen-Jacobs (1984) determined synonymy of their $S$. jukesii and of $S$. magna (by comparison of types); however, this characterstate easily may be overlooked if not specifically studied and in some specimens it may be damaged (e.g., in S. gervaisii sensu Grube (1868)). In conclusion, Serpula jukesii too should be revised. Other Indo-WestPacific Serpula taxa listed in ten Hove (1994) or described subsequently have fewer radii or opercula of different shapes than in the $S$. jukesii / granulosa-complex (the following list mentions only opercula for compar- 
ison with the Potts (1928) description, without taking into consideration tube, collar chaetae and other Serpula pacifica (Uchida, 1978), a juvenile specimen, lacks an operculum (and was regarded as of uncertain identity by Pillai \& ten Hove (1994: 103); Serpula japonica Imajima, 1979, 21-24 radii, operculum zygomorphic; Serpula rubens has a bell-shaped operculum with or without a waist, with greater or lesser flare, with only 1518 radii (types restudied by us). Two taxa with opercula with very long external grooves; with hardly any distal flair; elongate, with rather straight sides (basal bulb not expanded, waist not well-defined: Serpula watsoni Willey, 1905, ampulla deeply elongated; 33-55 radii, and Serpula sp. of Ishaq \& Mustaquim (1996) 16-33 radii, ampulla shorter, profile rather squat; 9-31 radioles. Two taxa with opercula with very long external grooves, but distally flared, tapering to the constriction, basal bulb not expanded: Serpula vittata 18-23 radii and $S$. vasifera, 31 radii, respectively (according to their written descriptions, the illustrations are contradictory; other material identified by ten Hove had 25-34 radii). Three opercula with short external grooves, distally flared, tapering to the constriction, basal bulb not expanded: Serpula tetratropia Imajima \& ten Hove, 1984 with 18-20 radii, raised central disc, somewhat pointed radii; S. zelandica Baird, 1865, 13-21 radii (incompletely described) and S. longituba (Imajima, 1979), 31 radii, short external grooves, with a markedly tapered elongated ampulla. Four taxa with distally flared, bell-shaped opercula with rather short external grooves, and with a well-defined waist, basal bulb more or less expanded: Serpula willeyi Pillai, 1971, 10 radii; $S$. hartmanae, 16-25 radii, with an asymmetric boss proximal to the constriction; S. oshimae 19-26 radii, lacking the boss, differs from S. hartmanae in collar chaetae. Similar, but larger, greatly flaring distally, Serpula indica 48-56 radii. Two taxa with hexagonal tusk-like tubes, Serpula crenata (Ehlers, 1908) and S. sinica $\mathrm{Wu}$, Sun \& Chen, 1979 with 17-22 radii and 23 radii, respectively. Three gregarious Indo-West Pacific and Mediterranean taxa were transferred to the genus Spiraserpula because they have internal tube structures (ITS) by Pillai \& ten Hove, (1994): Spiraserpula minuta (Straughan, 1967b: 216, fig. 6 h-m) with only filiform pseudopercula (Australia); Spiraserpula lineatuba Straughan, 1967b: 216, fig. 6 h-m) (Australia, Queensland and New South Wales), operculum slightly zygomorphic with 22-25 radii; outer grooves ca. midway and Spiraserpula massiliensis (Zibrowius, 1968: 102-105, pl.1 figs 24-37, pl. 14 fig.), operculum with elongate funnel and rather flat distal cup with 10-23 radii and short outer grooves. The nominal Indo-WestPacific Serpula philippensis McIntosh, 1885, from abyssal depths, is poorly described (questionable, fide ten Hove \& Kupriyanova 2009: 95), lacking a description for an operculum and the collar chaetae appear to be atypical.

The present, redetermined Serpula jukesii records of Potts (1928) and Fauvel (1933) from the Gulf of Suez are not enumerated among the ca. 16 species reported from within the canal.

\section{Serpula vermicularis Linnaeus, 1767}

Table 4

Type locality. European Seas. Not present in the Suez Canal, but see Hydroides elegans, Hydroides spp., Serpula hartmanae and $S$. jukesii sections, above.

Remarks. As discussed above, the taxon Serpula is difficult to classify. The record of $S$. vermicularis by Selim (2009: 73) from the Suez Canal is unlikely to belong to this boreal-temperate taxon. Given as a listing in a table only, not even with the number of opercular radii, presumably it should be attributed to an unidentified Hydroides species juvenile stage with a primary operculum, or possibly even to Serpula hartmanae. Without verification from direct examination of the specimen, it is presently only possible to regard this record from the northern canal as questionable.

Comparative material examined. Atlantic: North Atlantic: Lervik, Stordoe, Hardanger Fjord, Norway, 183-238 m, VI.1892, det. S.F. Harmer Serpula vermicularis, CUZM, 5 specs. Largest, length 58 mm; opercular diameter, $3 \mathrm{~mm}$; 60 radii $(36-\underline{\mathbf{4 6}}-60$, s.d. $=9.08, \mathrm{~N}=5$, radii). - Mediterranean: Much Levant Mediterranean material in the National Natural History Collections of the Hebrew University of Jerusalem presently determined as Serpula vermicularis (see Ben-Eliahu \& ten Hove 1992; Ben-Eliahu \& Fiege 1996). 
Type locality. West Indies. Not present in the Suez Canal, but see Spirobranchus tetraceros.

\section{Spirobranchus polytrema (Philippi, 1844)}

Type locality. Mediterranean Sea, Italy. Not present in the Suez Canal, but see Spirobranchus tetraceros.

\section{Spirobranchus tetraceros (Schmarda, 1861)}

Fig. 33, Table 5

Preliminary remarks. The nominal taxon, "Pomatoceros triqueter", was reported from shallow fouling panels from Alexandria harbour and from various locations within the Suez Canal (see Mediterranean and Suez Canal Synonymy Sections below). That contradicts what is known of the ecology and depth preferences of Pomatoceros triqueter, a boreal-temperate taxon with an Atlantic-Mediterranean distribution in sublittoral depths (e.g., in the Levant Basin, samples from 38-67 m from Israel $(\mathrm{N}=3)$, and from $119 \mathrm{~m}$ from Cyprus ( $=1$ ) (authors' unpubl. database). Along the coast of Israel and presumably also along the Mediterranean coast of Egypt, there are three rather similar species found in shallow habitats. Like Pomatoceros triqueter, all three have triangular tubes and calcareous opercular plates borne on winged opercular peduncles: Pomatoceros lamarckii (Quatrefages, 1866), an Atlantic-Mediterranean species (Bianchi 1981), Spirobranchus tetraceros and Pomatoleios kraussii, Lessepsian migrant species (Ben-Eliahu \& ten Hove 1992) that may occur on biofouling panels, both of them present in the Suez Canal. Spirobranchus tetraceros is distinguished from the others by its more elaborate opercular spines and its fringed opercular wings (in most specimens) and special collar chaetae (Figs 33A, D and E). The opercular peduncles of both Pomatoceros lamarckii and Pomatoleios have wings with smooth margins. Pomatoleios kraussii has a somewhat concave opercular plate, frequently with a diagnostic sunken (internal) talon (ten Hove 1973 fig. 43); best seen when cleared in glycerine, and it lacks collar chaetae. Pomatoceros lamarckii has fine small limbate collar chaetae (Ben-Eliahu \& ten Hove 1992). Ghobashy et al. (1990) retroactively corrected citations of "Pomatoceros triqueter" for the Suez Canal to Spirobranchus tetraceros. However, given the presence of the similar taxon, Pomatoleios kraussii, we have placed question marks before the problematic citations.

Pomatoceros tetraceros Schmarda, 1861: 30, pl. 21, fig. 129 [Type locality: New South Wales].

Spirobranchus tetraceros: ten Hove 1970b: 3-14, figs 1-34 [redescription and synonymy; Red Sea, Indian Ocean: Natal; Persian Gulf; Malaysian Archipelago, Japan, Australia: Sydney, California: ?Gulf of Catalina; tropical Pacific coast of America; Caribbean Sea; considered as absent thus far on the west coast of Africa (not found in two locations in Dakar, Senegal, by H.A. ten Hove in 1982); however, collected in 2007 in Dakar (H. Zibrowius, pers. comm.); Imajima 1979: 177-178, fig. 8 [Japan]; Zibrowius 1979b: 133-134 [France, Toulon Port, biofouling removed from the aircraft carrier "Foch"]; Imajima \& ten Hove 1984: 51-52 [Japan to Australia]; Wehe \& Fiege 2002: 133-134 [Suez Canal, Red Sea, Gulf of Aden, Arabian Sea, Persian Gulf; list of references]; Zenetos et al. 2005: 73 [classified as an "established alien species" in the Mediterranean].

Eastern Mediterranean

Spirobranchus giganteus coutierei: Laubier 1966: 18-19 (fide ten Hove 1970b: 41-49) [Lebanon: Beirut, 25-30 m, IX.65, on bryozoans and madreporarians; first Mediterranean record of this Lessepsian migrant].

Spirobranchus coutieri [sic]: Amoureux 1976: 1054 [Israel, Haifa Bay, 18 m, rocky substrates].

Spirobranchus tetraceros: Zibrowius \& Bitar 1981: 159-160 [Lebanon, Beirut, Zaitouné, 5 m, on bivalve, 23.IX.1978]; Ben-Eliahu 1991b: 518-524, fig. 2 [Israel, Lebanon; Rhodes, Kallithea, 12.X.1970, HUJ-Poly-585-the earliest record indicating north-westward expansion to the Aegean Sea]; Ben-Eliahu \& ten Hove 1992: 40-48 [Israel, entire coast from north to south, 1-24 m]; Ben-Eliahu \& Fiege 1996: 33-38 [western Levant Basin, Israel]; Selim 1997b: 94-96, figs 7a-c, 8a-e [Egypt, Port Said, collected in 1988]; Ben-Eliahu \& Payiatas 1999: 101, 119 [Cyprus, Larnaca jetty, empty tubes, legit H. Zibrowius 1996; Famagusta harbour, Aya Napa, empty tube, legit M.N. Ben-Eliahu and G. Payiatas 1998, det. H. Zibrowius]; Zibrowius \& Bitar 2003: 71 [Lebanon]; Bitar 2005: 427 [Lebanon, fouling communities, 5-20 m]; Ghobashy \& Ghobashy 2005: 90-93 [Alexandria, Eastern Harbour on solid surfaces, citing 
Abd-Elnaby (2005) that $S$. tetraceros had become very common and was the most abundant serpulid in the harbour on rocks, concrete and metal surfaces, though $H$. elegans was still dominant on the fouling plates.]; Selim et al. 2005: 89-97 [reports replacement of Hydroides elegans as the dominant fouling serpulid species in Abu Kir Bay (Alexandria)]; Çinar 2006: 232, fig. 9 a-d, [Levant coast of Turkey, Iskenderun Bay, 0.1-25 m on stones, IX.2005]; Abd-Elnaby 2009: 10 [Alexandria]; Selim 2009: 74 [Port Said].

?Pomatoceros triqueter not (Linnaeus), sensu Ghobashy \& Selim 1976b: 303, 304 [Alexandria, Eastern Harbour, see preliminary remarks, above]; Ghobashy et al. 1980: 84, table 2 [Port Said]; El-Komi 1991a: 8, 12, tables 3, 4 [Alexandria, harbour]; El-Komi 1991b: 290-291, table 3 [Alexandria, harbour]; El-Komi 1992: 124, 128, tables 2, 4 [Alexandria, harbour]; El-Rashidy et al. 2009, 1 p. [Alexandria].

Suez Canal

Spirobranchus tetraceros: Ben-Eliahu 1972a: 77 [eastern bank, several locations; 21.VI.1967, first reference from within the Suez Canal]; 1972c: 232, table 2; Ghobashy et al. 1986: 319-326, fig. 4 [Lake Timsah]; Ghobashy et al. 1990: 677-685 [Lake Timsah]; Ben-Eliahu 1991b: 519, fig. 2 [el Qantara-Km 45, Lake Timsah, Bitter Lakes]; Selim 1997b: 94-96, figs 7a-c, 8a-e [Suez Canal, "very abundant in all sites investigated", i.e., El-Kab, Lake Timsah, Deversoir, collected in 1988; for Lake Timsah, also citing Shalla (1985) and Mostafa (1992) (see App. Table 4)]; Emara \& Belal 2004: 192-199 [pooled Lake Timsah and Bitter Lakes data]; Ghobashy \& Ghobashy 2005: 91,93 [referring to Ghobashy et al. (1986) and to Barbary (1992, see App. Table 4); Selim 2009: 74 [northern part of the canal]; Abd-Elnaby 2009: 10 [ southern part of the canal].

?Pomatoceros triqueter not (Linnaeus), sensu Ghobashy et al. 1980: 84, table 2 [El Tina, Isma'iliya]; Ghobashy \& ElKomi 1981a: 170 [Lake Timsah]; Ghobashy \& El-Komi 1981b: 181 [southern canal]; Ghobashy 1984: 45 [Lake Timsah]; Ghobashy \& Ghobashy 2005: 91; 93 and referring to Ghobashy et al., 1980. In 1986, Spirobranchus tetraceros was first cited by this research group and all previous records of P. triqueter presumably refer to $S$. tetraceros.

Spirobranchus sp.: Ghobashy 1984: 45 [Lake Timsah]; presumably S. tetraceros.

?Spirobranchus giganteus not Pallas, sensu Selim 2009: 73 [Selim cited Fauvel (1933a, b) that referred to S. coutieri (Gravier, 1908) and S. multicornis (Grube, 1862), both taxa synonymised with S. tetraceros, and thus Selim's record is attributable to what we presently regard to be the $S$. tetraceros-complex].

Gulf of Suez and Gulf of Aqaba

Spirobranchus contieri [sic]: Pixell 1913: 83-84, pl. 9, fig. 8 [Gulf of Suez: Suez; Red Sea: Suakin harbour; Indian Ocean: Zanzibar].

Spirobranchus jousseaumi [sic]: Potts 1928: 701 [Suez, Gulf of Suez] (synonymised with S. tetraceros by ten Hove 1970b: 4).

Pomatoceros coeruleus not (Schmarda), sensu Fauvel 1933a: 77 [Gulf of Suez St 24 ter, 60-80 m, 33⒋'-3345'E, 27 $7^{\circ} 48-27^{\circ} 55^{\prime}$ N, see Spirobranchus tetraceros sensu ten Hove 1970b, fide H. Zibrowius, pers. comm. (18.III.1971)]; Fauvel 1957: 10 [Gulf of Aqaba, Elat (see "Material examined", below)].

Pomatoceros triqueter not (Linnaeus), sensu Fauvel 1933a: 78 [Gulf Suez (see Spirobranchus tetraceros sensu ten Hove 1970b, fide H. Zibrowius, pers. comm. 18.III.1971]; El-Komi et al. 1998: 16, 17 [Suez Bay, 1992-1993, on polystyrene fouling panels and buoys, previously examined Egyptian-identified material showed this name to have been used for S. tetraceros]; Ghobashy \& Ghobashy 2005: 91; 93 [citations from Suez Bay referring to El-Komi et al. 1998].

Spirobranchus giganteus not (Pallas), sensu Fauvel 1933a: 78-79 [Gulf of Suez: 7 stns, 35-[36-80] m; Gulf of Aqaba, 1 stn, 25 m, fide ten Hove (1970b: 4)]; Monro 1937: 317 [Arabian Sea]; Amoureux 1983: 369 [(part) Gulf of Aqaba, on algae, presumably $S$. tetraceros by habitat].

Spirobranchus jousseaumei: Fishelson \& Rullier 1969: 102 [Musseri; redet. H.A. ten Hove 1990 S. tetraceros]; Fishelson 1971: 122, table 3 [Gulf of Aqaba]; Amoureux et al. 1978: 151, fig. 16 S.j. [Gulf of Aqaba, Elat, Venezia lagoon, redet. herein due to the figure as $S$. coronatus, a member of the $S$. tetraceros-complex; both of these taxa appear to be present in the lagoon].

Spirobranchus polytrema not (Philippi), sensu Amoureux et al. 1978: 150-151, fig. 16 “S.p.” [Gulf of Suez, Ras Kanisa; corrected to $S$. tetraceros herein, see remarks below].

Spirobranchus tetraceros: Ben-Eliahu 1991b: 519, fig. 2 [Gulf of Suez, Gulf of Aqaba]; Selim 1997b: 94-96, figs 7a-c, 8a-e [Gulf of Suez, Port Taufiq, collected in 1988]; El-Komi et al. 1998: 16, 17 [Suez Bay, 1992-1993]; Hassan 1998: fig. p. 53 [Aqaba]; Ghobashy \& Ghobashy 2005: 91, 93 [citations from Suez Bay referring to El-Komi et al. 1998].

Spirobranchus elatensis Pillai, 2009: 165-168, figs 50a-f [Gulf of Aqaba; Elat; see Table 5, herein].

Red Sea proper-Indo-West-Pacific (excluding citations from Gulf of Suez and Gulf of Aqaba already given above) Serpula (Pomatoceros) multicornis Grube 1862: 67, fig. 3; 1868: 639-640; 1870: 519 [all three records from Red Sea]. Pomatoceropsis coutierei Gravier 1905: 445-448 [Gulf of Aden: Djibouti and E. Aden; extensive description]; 1906a: 
pl. 8 figs 294-299 [Gulf of Aden]; 1906b: 114 [Gulf of Aden, Djibouti]; 1908: 125-130, pl. 8 figs 294-299, text-figs 482-487 [Red Sea, Musha Island].

Pomatoceropsis jousseaumei Gravier 1906b: 114, pl. 8 figs 292-293 [South Red Sea, Bab el Mandeb, Périm Island; Gulf of Aden, Djibouti]; ?Gravier 1908: 130-132, pl. 8 figs 292-293, text-figs 488-491 [South Red Sea, Périm Island; Gulf of Aden; queried because figures of aberrant specimens cannot be identified with confidence].

Spirobranchus contieri [sic]: Pixell 1913: 83 [Indian Ocean, Zanzibar].

Spirobranchus semperi: Pixell 1913: 82 [Red Sea; Indian Ocean, Zanzibar]; Wesenberg-Lund 1949: 359, fig. 47. [Persian Gulf].

Spirobranchus semperi var. aceros: Pixell 1913: 82-83 [Red Sea, Suakin, Agig Bay; Indian Ocean, Zanzibar, Maldives, Amirante Islands].

Spirobranchus giganteus not (Pallas), sensu Monro 1937: 317 [Arabian Sea]; Fishelson \& Rullier 1969: 102 [part] [Red Sea, Eritrea, Entedebir, Umm Aabak, 3-4 m; on living or dead coral, 14 specs].

Spirobranchus giganteus var. arabica Monro, 1937: 317, fig. 28 [Arabian Sea, South Arabian coast].

Pomatoceros caeruleus not (Schmarda), sensu Fauvel 1955b: 119 [Red Sea, Abulat Island].

Spirobranchus tetraceros: Day 1967: 802, figs 38.3 1-n [Indian Ocean, Zanzibar]; Vine \& Bailey-Brock 1984: 145-146, figs 6a-b [fig. 1c presumably also belongs to S. tetraceros; Red Sea, Suakin harbour, Sanganeb Lagoon, Dunganab Bay]; Vine 1986: 91 and figure [Red Sea]; Ben-Eliahu 1991b: 519, fig. 2 [South Red Sea, Eritrea, Dahlak Archipelago]; Ishaq \& Mustaquim 1996: 180-182, figs 10a-i [Arabian Sea, Pakistan, Karachi]; Abd-Elnaby 2009 : 10 [Red Sea].

Spirobranchus jousseaumei: Fishelson \& Rullier 1969: 102 [part] [Red Sea, Eritrea, on sponge; Bay of Melita, on coral (p.p. redet. herein as $S$. coronatus)].

Spirobranchus tetraceros complex: ten Hove 1994: 113-114 [Indian Ocean, Seychelles, Amirante Islands].

Material examined. Locations adjacent to the Suez Canal, Mediterranean side: Rhodes: 1 sample, littoral.-Cyprus: 1 empty tube, [3-5] m (H. Zibrowius, pers. comm.).-Lebanon: common (H. Zibrowius, pers. comm.).-Israel: 37 samples, 0.2-[3-18] $-31 \mathrm{~m}$; first Israeli sample from Haifa Bay, 5.XI.1967, SLM 272, 27 m, det. M.N. Ben-Eliahu, INCNH unpublished data.

Suez Canal material reported herein: 57 samples, 137 specimens. Beets' Great Bitter Lake samples: No triangular Spirobranchus tetraceros tubes appeared to be present on any of the shells.- Hebrew UniversitySmithsonian Expeditions, 1967-1973, 8 samples, 12 specs: el Qantara, Km 45: SLC 6, 1 spec.; SLC 31, 1 spec.; Lake Timsah, Km 78, opposite Isma'iliya: SBE 7, 1 spec.; SBE 8, 3 specs; Great Bitter Lake, east of Deversoir, Km 97, SLC 50, 1 spec.; SLC 61, 1 spec.; SLC 71, 1 spec.; Great Bitter Lake, SLC 123, 3 specsGreat Bitter Lake "Yellow Fleet" Biofouling Samples, January 13-20, 1975: 45 subsamples, 115 specs; Bremerhaven dry dock, 18.VI.1975, 2 subsamples, 2 specs, both individuals large, decayed.—Lake Timsah, legit, det. S.H. Shalla ca. 1984 Spirobranchus sp., Conopomatus sp., redet. H.A. ten Hove, ZMA V.Pol. 4997 , 4998, 6 specs-El Tawan Beach, 10 / 19.XI.1988, legit S.B. Shazly, det. H.A. ten Hove, ZMA V.Pol. 3820, 2 specs.

Locations adjacent to the Suez Canal, Red Sea side: 7 samples, shallow. Gulf of Suez, J.K. Lord Expedition 1870, det. H.A. ten Hove 1969 S. tetraceros (3 specs left under the original BM(NH) number by HAtH, from a mixed sample of tubes, one Spirobranchus corniculatus (now BM(NH) 1870.12.23.60), three $S$. tetraceros and 3 epibiontic species of Hydroides (now BM(NH) 1870.12.23.61, 62, 63), first listed together under an unpublished ms. name by W. Baird), BM(NH) 1870.12.23.31. Since both Spirobranchus taxa inhabit living coral, the sample was presumably from a coralligenous habitat; same, redet. H.A. ten Hove $1969 S$. tetraceros, $\mathrm{BM}(\mathrm{NH})$ 1870.12.23.30, 2 specs—Gulf of Suez, legit R. MacAndrew, listed under an unpublished ms. name by W. Baird, redet. H.A. ten Hove 1969 S. tetraceros, BM(NH) 1869.7.8.42.—Gulf of Suez, Cambridge Expedition, R6, 6.XI.1924, det. F.A. Potts (1928: 701) Spirobranchus jousseaumi; in 1986, BenEliahu noted opercular wings reduced without crenellations, interradiolar membranes with unilobed processes, characteristic antler-like opercular spines; subsequent re-examination (in 2002) showed the operculum had been cut off at the base of the peduncle, and was missing, $1 \mathrm{spec}$., CUZM AN.I.1930.

Gulf of Aqaba: 10 samples, [0.2-1]-[6-8]-[20-25]-25. Elat, shallow up to 2 m, 1955, E55 / 441, legit H. Steinitz, det. P. Fauvel Pomatoceros coeruleus [sic], specimen lacked tube, operculum and collar chaetae; "branchia and collar characterized by dark indigo blue colour" (Fauvel 1957: 10); redet. herein due to presence of interradiolar processes]. 
Red Sea: South Red Sea, 8 samples, 1-27.4-36.6 m, HUJ.

Indian Ocean: Seychelles, 11 samples, [1-7]-[4-8]-[12-15]-45 m, ZMA, RMNH.

Suez Canal depth and substrates: shallow, 0.4-[3-4] m, on alga: Laurencia; on sponge; on bivalves: Brachidontes pharaonis, Malvufundus regulus, Pinctada radiata and Spondylus spinosus; barnacles; bryozoans; tunicates; rocks; artificial substrates: Canal walls, tin can submerged in mud; rubber fenders and iron frames.

Distribution. Circumtropical, but see Remarks. Red Sea: Gulfs of Suez and Aqaba. Lessepsian migrant to the Mediterranean: Israel, Lebanon, Cyprus, Turkey and Rhodes.

Colouration (Field notes for Lake Timsah specimen): Ventral side of operculum pink, dorsal side bluebrown. Radioles, from distal to proximal part, with white band, short blue band, white band, brown band, white band at base. Thorax dark red-brown. Noted very pink tube (Great Bitter Lake subsample Biv 11 [App. Table 2D]). One of us (HAtH) has the impression that individuals with bluish tubes that are buried in living corals and attached to dead Pocillopora damicornis (Linnaeus) skeletons may belong to a different taxon than the pink tube specimens found on various hard substrates, which might lend some support to Pillai's (2009) distinction between $S$. tetraceros and S. semperi.

Remarks. The taxon Spirobranchus tetraceros as redefined by ten Hove (1970b) is presently considered to be a complex of species, with some taxa in the Indo-West-Pacific and another in the Caribbean (Smith 1985; ten Hove \& Kupriyanova 2009). Some of the Indo-West-Pacific species have been defined as " $S$. tetraceros s. str., S. coronatus and S. decoratus", but, according to Smith (1985) there may be further subdivision that should be done within the taxon S. tetraceros "s. str." based on characters such as the number of the main spines, colouration of the tube and the tube lumen, the extent of serration of filiform processes on the peduncular wings, and the presence and number of pairs of radiolar ocelli on the radioles.

When we were finalizing the present paper, Pillai (2009) published his discussion on Spirobranchus. As he did with other taxa, Pillai split $S$. tetraceros sensu ten Hove (1970) (i.e., the S. tetraceros-complex) into about 8 different taxa, based on different character combinations (Pillai 2009: 158, notably the discussion on p. 162). In order to evaluate this attempt to clarify the Spirobranchus tetraceros-complex, we compared the main characters used by Pillai with our material from the Suez Canal (see Table 5). By Pillai's standards, the Suez Canal material is characterized by a unique combination of characters meriting the description of yet another species, intermediate between his definition of Spirobranchus tetraceros and S. semperi. Using Pillai's criteria, ten Hove's (1970) figures, from a single Bahrain sample, should be named $S$. tetraceros (figs 23-24), S. semperi (figs 25-26, 28-29) and S. arabicus (figs 1-2, 15-16). We are not prepared to accept this approach since most of Pillai's taxa are based upon single samples with 1-6 specimens only and variability of various character states has not been studied by Pillai. For instance, Pillai's (2009) description of S. elatensis, from the Gulf of Aqaba, was distinguished from S. tetraceros mainly by it's conical operculum, based only on a single specimen. Our work is based on hundreds of samples, with several hundreds of specimens (admittedly not consistently enumerating all character states dealt with recently by Pillai). As regards $S$. tetraceros, we have found both conical and fully branched opercula and intermediate forms in the same Suez Canal samples, and consider them to belong to a single species (see Figs 33C-E; see also ten Hove 1970, figs 6, 30 for a Caribbean population of what we nowadays would identify as the Caribbean $S$. dendropoma Mörch, 1863; $c f$. Smith 1985:66). We have noted that the presence / absence of papillae, and the shape of these papillae / fringes, seems to be dependent on their position, dorsal or more ventrally, in the radiolar circles. Without population studies, and without genetic support, we find Pillai's splitting difficult to accept. Thus, we prefer not to adopt the classification given by Pillai (2009), but to retain the more "traditional" concept of this taxon as both in the present paper and Selim (1997b), thus synonymising S. elatensis with S. tetraceros s. str. A review of all the literature citations, taking into consideration Smith's (1985) and Pillai's (2009) hypotheses is not within the province of the present paper. However, when the review of this taxon will finally be carried out, it should comprise both morphological and genetic evidence from populations. 


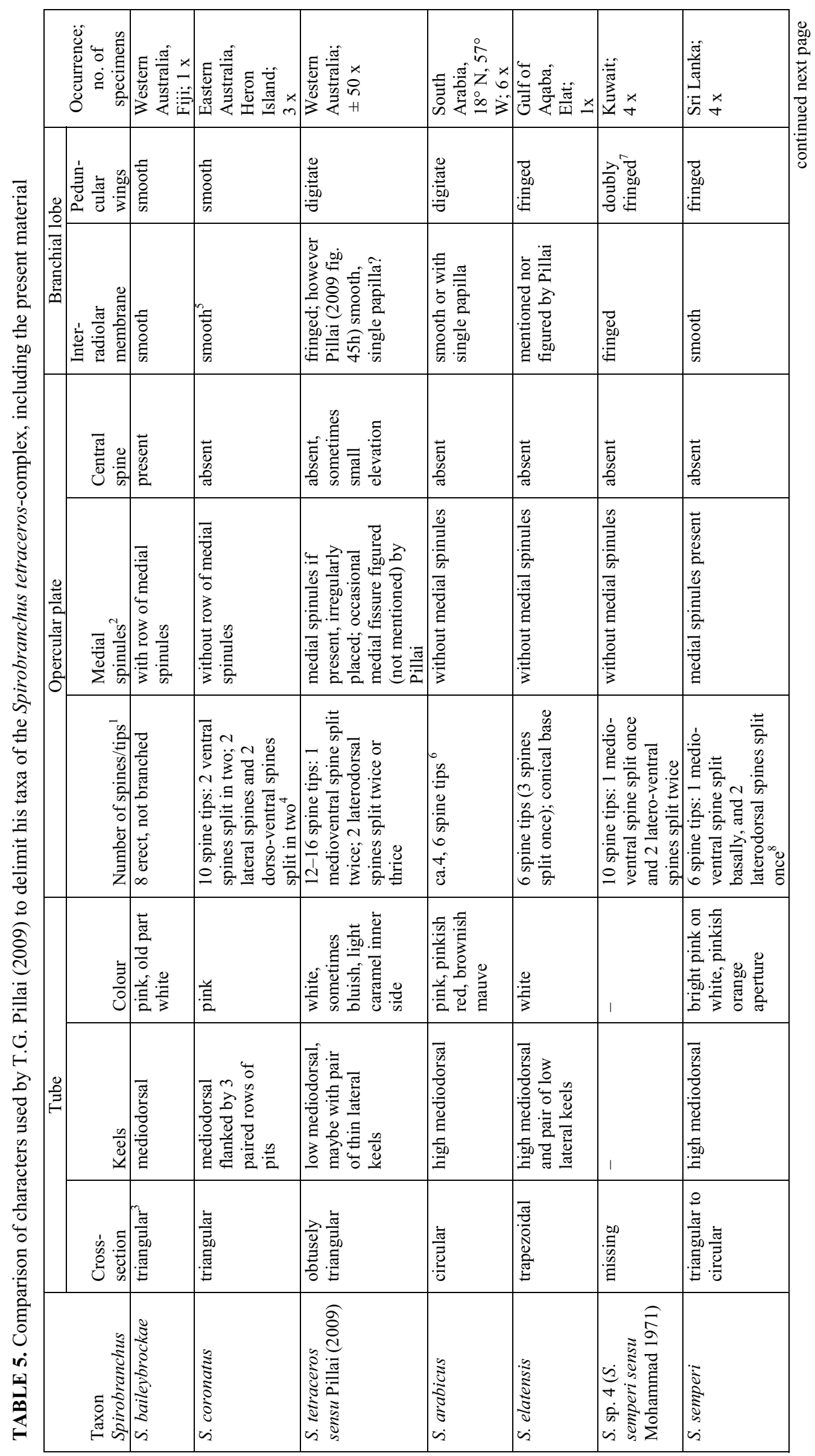




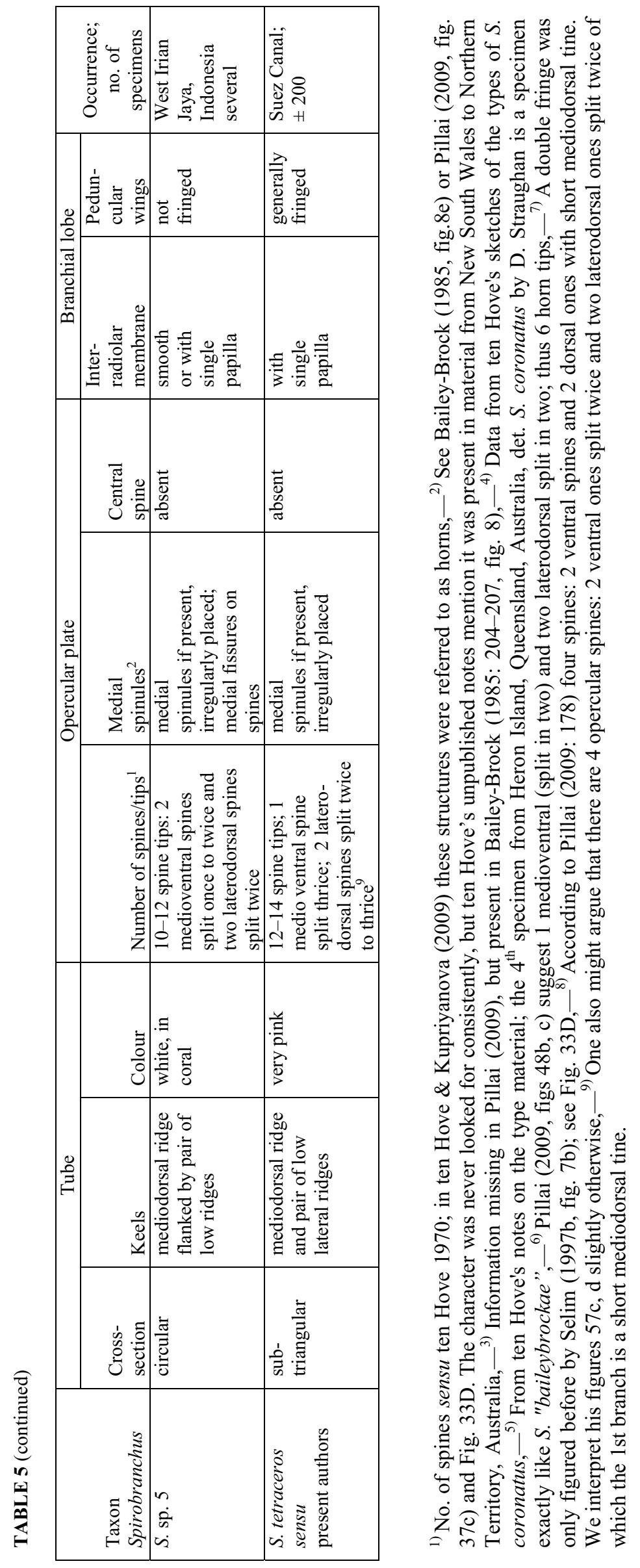



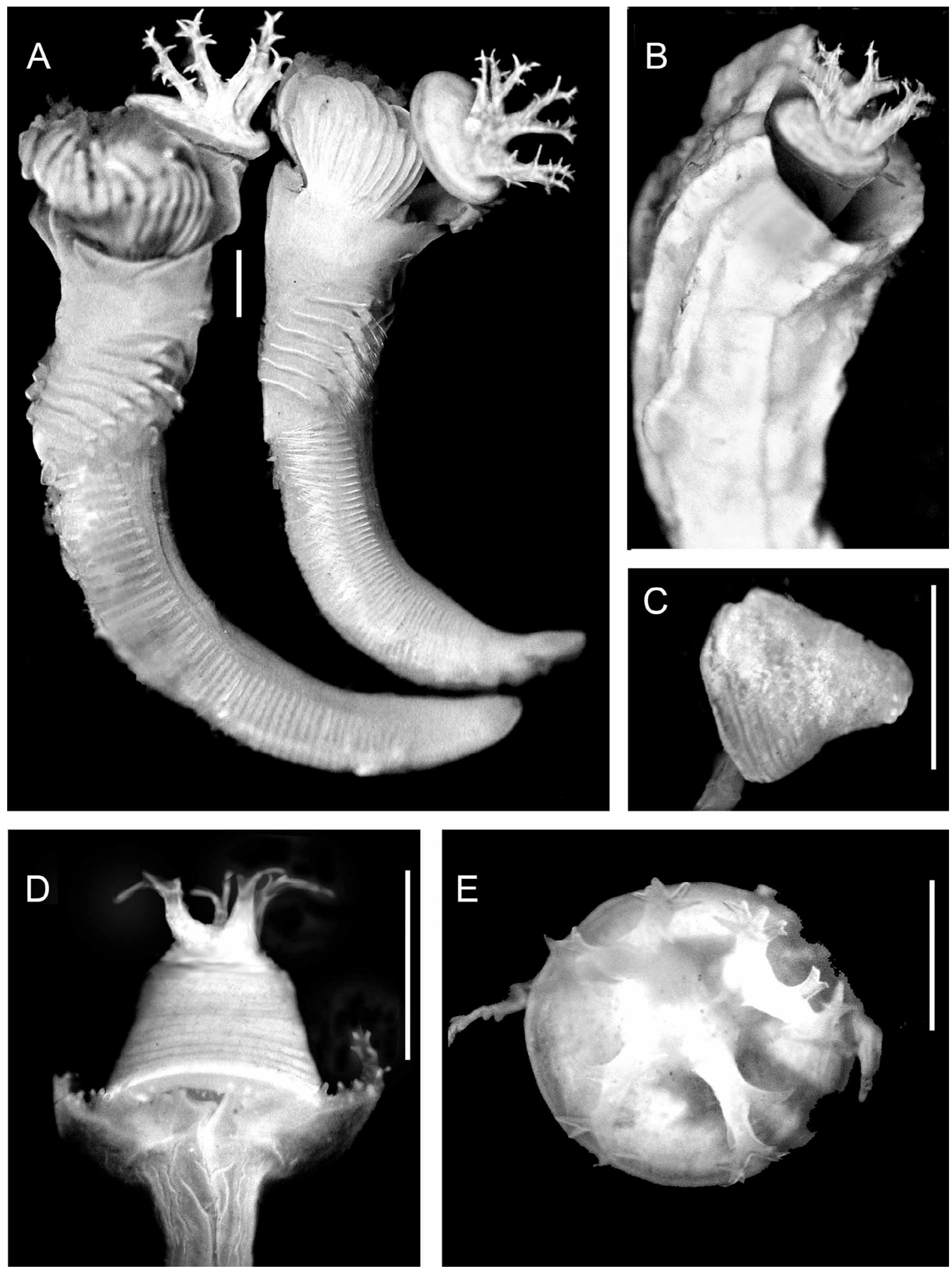

FIGURE 33. Variability in opercula of Spirobranchus tetraceros specimens from the Great Bitter Lake "Yellow Fleet". A-Fringed wings of opercular peduncle visible on specimen to the right, B-3/4 lateral view of tube with partly emerged operculum, C-Lateral view of conical form of operculum, without antler-like spines (subsample Bry1), D—Lateral view of conical operculum with antler-like spines; fringes (even a double one) seen on wings (D-E, subsample Ships Hulls Poly 24), E-Frontal view of operculum with spines; fringes seen on wings. Scales: $1 \mathrm{~mm}$. 
Regional citations given above are for the species complex as known subsequent to ten Hove (1970b). We should note, however, that fig. 16 S.j. of Amoureux et al. (1978: 150) from the Gulf of Aqaba, Elat, Venezia lagoon appears to be that of Spirobranchus coronatus; thus, both $S$. tetraceros and S. coronatus are present in the northern Gulf of Aqaba. Spirobranchus polytrema not Philippi, sensu Amoureux et al. (1978: 150) is corrected to $S$. tetraceros based on the illustration marked S.p. in his fig. 16; thus the nominal taxon S. polytrema, was not a Mediterranean migrant to the Red Sea via the Suez Canal as stated by these authors.

The Suez Canal population appears to belong to a single taxon (Figs 27A-E), a fouling species characterised by small peduncular wings with a pointed tip, generally fringed (Figs 27A, D, E), sometimes with a double fringe (clearly visible in Fig. 33D, right wing; see note Table 5); interbranchial membranes usually with unilobed processes and the specimens examined from the Levant Basin of the Mediterranean appear to belong to the same taxon, known also from the Gulf of Aqaba and the Gulf of Suez (Ben-Eliahu 1991, fig. 2). Examination of live material from Elat showed two dense rows of bright crimson ocelli with minute lenses on each side of the rachis of the radioles (base of prostomium not looked for in this live specimen), suggesting the Elat population might be the same as Smith's "Spirobranchus tetraceros species C" (Smith 1985, Table 5). Selim (1997b fig. 7) remarked and illustrated the polymorphism of the operculum of $S$. tetraceros, and we have also included examples in Figs 33A-E. Ten Hove (1970b: 4, 48) noted that Pixell (1913) had dealt with the variability of Spirobranchus tetraceros opercula of the C. Crossland collection in the Natural History Museum, London by giving them a variety of names (see synonymy above).

In their ranking of the Lessepsian migrants within the category, "Worst Invasive Species", Zenetos et al. (2005) appear to underestimate the importance of Spirobranchus tetraceros, known from Beirut from 1965 (Laubier 1966, as Spirobranchus giganteus coutierei), and as far as Rhodes already in 1970 (Ben-Eliahu 1991, collected by the "Biota" project). Selim et al. (2005) reported that S. tetraceros had replaced Hydroides elegans as the dominant fouling species in Alexandria Mediterranean waters, such that it amply fulfils the criterion "having an serious impact on diversity" (Zenetos et al. 2005).

\section{Genus Vermiliopsis Saint Joseph, 1894, s. str.}

The genus Vermiliopsis is in urgent need of revision. For the time being, the taxa Vermiliopsis infundibulum sensu (Philippi, 1844), V. glandigera Gravier, 1906 and V. pygidialis (Willey, 1905) are considered to belong to a complex of morphologically indistinguishable species (or taxa which at least have been confused in the literature) and it is not known whether they represent one or more species (cf. Zibrowius 1968: 123, ten Hove 1975: 55-59, Ben-Eliahu \& Fiege 1996: 8, ten Hove \& Kupriyanova 2009: 100-102). Since 1976, many authors just refer to Vermiliopsis infundibulum / glandigera-complex (e.g., Imajima 1976: 139, 1978: 57, 1979: 169, ten Hove 1994: 113, Fiege \& Sun 1999: 133), although recently "similar" species with more restricted distributions have been named (e.g. Vermiliopsis zibrowii Nogueira \& Abbud, 2009, South Brazil; V. cylindrica Pillai, 2009, western Australia). Vermiliopsis infundibulum was considered to be present throughout the Mediterranean (Bianchi 1981), while V. glandigera and V. pygidialis were usually regarded as Red Sea and Indo-West Pacific taxa (see Systematic Section below).

In view of these taxonomical problems, morphology cannot be used to determine the provenance of Vermiliopsis infundibulum / glandigera / pygidialis in the Suez Canal [contrary to the somewhat formalistic distinction by Pillai (2009: 108, fig. 8), made on literature comparison only]. In contrast, the Mediterranean / Atlantic species, Vermilopsis striaticeps (Grube, 1862), can be distinguished from V. infundibulum (e.g., Zibrowius 1979a) by marked taxonomic characters, although it has been confused with this taxon in the past. For example, Monro (1930: 209-211, fig. 88), figured four opercula in describing his "Vermiliopsis glandigerus" from the Atlantic Gulf of Guinea, two of them with clear longitudinal striations belonging to Vermiliopsis striaticeps, the other two belonging to the Vermiliopsis infundibulum / glandigera complex (material studied by HAtH). It appears that the Vermiliopsis infundibulum / V. glandigera-complex and V. striaticeps are both present in the Mediterranean and also in the Suez Canal. Vermilopsis striaticeps was reported from Deversoir [as V. infundibulum in Selim (1997b), citing Ghobashy et al. (1980) and Ghobashy \& Ghobashy 
(2005), who referred to the same single specimen]. The excellent illustration in Selim (1997b, fig. 9a) enables confirming this specimen confidently as Vermiliopsis striaticeps. However, that finding called into question other citations based on Selim's identifications, e.g., those of Vermiliopsis infundibulum from the Mediterranean. For example, Selim (1997b: 97) cited a record of Ghobashy et al. (1980) from the Suez Canal for Vermiliopsis infundibulum without providing morphological detail. Similarly, it is not possible to know whether the record from Alexandria harbour (Ghobashy 1984) belongs to the Mediterranean Vermiliopsis infundibulum or V. striaticeps. Determinations of Vermiliopsis infundibulum based on empty tubes must also be considered as questionable and are therefore cited with a question mark before the date of publication in the synonymy section below.

\section{Vermiliopsis infundibulum / V. glandigera-complex Vermiliopsis infundibulum s. auct.}

Vermilia infundibulum Philippi 1844: 193, pl. 6, fig. g [Type locality: Mediterranean Sea].

Vermiliopsis infundibulum: Zibrowius 1968: 121-124, pl. 2 figs 30-33; pl. 3 figs 1-15; pl. 14 fig. b [part]; ten Hove 1975: 57 [included V. pygidialis within Vermiliopsis infundibulum / glandigera-complex]; Bianchi 1981: 71-73, figs $25 \mathrm{a}-\mathrm{h}$.

Vermiliopsis infundibulum glandigera-group: Imajima 1976: 139-141, fig. 11.

\section{Eastern Mediterranean}

?Vermiliopsis infundibulum: Fauvel 1937: 47 [Egypt, Alexandria, 46 m; empty tube, indeterminable]; Ben-Eliahu 1972b: 90 [Cyprus, littoral]; Ghobashy 1984: 43, table 1 [Alexandria harbour]; Ghobashy \& Ghobashy 2005: 94 [Alexandria, Eastern Harbour, 1.5 m; citing Ghobashy \& Selim (1976a, b), Ghobashy (1977), Selim (1978), as discussed under V. striaticeps, below]; all these records might (partly) be misidentified V. striaticeps as well.

Vermiliopsis infundibulum: Amoureux 1976: 1054 [Israel, Haifa Bay [part, 1 spec., the other specimen V. striaticeps, redet. M.N. Ben-Eliahu 1985]; Ben-Eliahu 1991b: 518 [Cyprus, Israel]; Ben-Eliahu \& ten Hove 1992: 40 [Israel]; Ben-Eliahu \& Fiege 1996: 7-8, 33, 38 [western Levant Basin, Turkey, Cyprus, Levant coast]; Ben-Eliahu \& Payiatas 1999: 110-111 [Cyprus]; Çinar 2006: 233 [Levant coast of Turkey, Bogsak, Anamur, [0.1-5], 200 m].

Suez Canal

?Vermi[o]liopsis infundibulum: Emara \& Belal 2004: 196, 199 [pooled Lake Timsah and Bitter Lakes data].

Vermiliopsis glandigera: Abd-Elnaby 2009: 10 [reported from southern part of the canal and Red Sea].

Gulf of Suez and Gulf of Aqaba

Vermiliopsis pygidialis: Pixell 1913: 86-87, pl. 9, figs 11a, b [Gulf of Suez, Suez; Red Sea, Suakin; Indian Ocean, Zanzibar, Maldives; Pacific Ocean, Tuvalu Islands, Funafuti]; Por \& Dor 1975: 39, figs 1, 8b, c, 10, 12 [Gulf of Aqaba, Sinai Peninsula, El Kura hypersaline lagoon near Dahab, salinity 40-60 \%o]; Ben-Eliahu 1976: 111-112, fig. 3a, b [Gulf of Suez, Gulf of Aqaba: Sinai Peninsula, intertidal Dendropoma cryptofauna; Indian Ocean, Zanzibar, Sri Lanka; Pacific Ocean; Australia]; Ben-Eliahu \& Dafni 1979: 207 [Gulf of Aqaba, Sinai Peninsula, el Kura hypersaline lagoon, near Dahab]; Ben-Eliahu \& Safriel 1982: 389 [Gulf of Aqaba, Sinai Peninsula, intertidal cryptofauna].

Vermiliopsis glandigera: Fauvel 1933a: 77 [Gulf of Suez, st. 17 ter, $33^{\circ} 23^{\prime}-33^{\circ} 24^{\prime}$ E, 28 $22^{\prime}-28^{\circ} 14^{\prime} \mathrm{N}$; $27-29 \mathrm{~m}$, 25.XII.1928, on madreporarians, 2 specs; Gulf of Suez; Red Sea; western Indian Ocean, Madagascar; Gulf of Manaar; eastern Atlantic Ocean, western coast of Africa; Fauvel 1957: 10 [E55 / 349 f, g and j, tubes with 5 longitudinal ridges. Gulf of Aqaba: Elat, 0-2 m; Red Sea proper; Indian Ocean, Madagascar; Atlantic Ocean, Congo, Gulf of Guinea].

Vermiliopsis glandigerus: Amoureux et al. 1978: 149 [Gulf of Aqaba, Elat, on float, coral rubble, 3 m; Red Sea; Indian Ocean; Persian Gulf; tropical zone of west Africa]; Goren 1979: 24 [det. F. Rullier, Gulf of Aqaba, Elat, Venezia lagoon, asbestos panel $0.20 \mathrm{~m}$, XI.1971].

?Vermiliopsis infundibulum: Amoureux et al. 1978: 149 [Gulf of Aqaba, coral rubble, 0-30 m; Red Sea; Atlantic, Mediterranean]; Ghobashy \& Ghobashy 2005: 94 [these records probably do not belong to the Mediterranean Vermiliopsis infundibulum, but to an Indo-West Pacific representative of the species complex].

Red Sea proper-Indo-West-Pacific (excluding citations from Gulf of Suez and Gulf of Aqaba already given above) Vermilia pygidialis Willey 1905: 318-319, pl. 7 figs 194-196 [Type locality: Indian Ocean, Sri Lanka, South west Cheval Paar]. 
Vermiliopsis pygidialis: Pillai 1960: 26, figs 10a-g [Sri Lanka, Pearl Banks]; Vine \& Bailey-Brock 1984: 142-143, fig. 3a-c [Suez; Red Sea, Suakin, Port Sudan, ship fouling, Sanganeb lagoon under coral rock from 12-75 m; on dead coral at $4 \mathrm{~m}$; Indian Ocean, Zanzibar; Pacific, Australia].

Vermiliopsis glandigerus Gravier 1906b: 112-113, pl. 8 figs 290-291 [Type locality: Red Sea, Météore Reef, Pingouin, Marabout, Pascal, Mission, Héron, Bounhoure, Ormiers reefs; Gulf of Aden, Djibouti, on branching corals Pocillopora, Stylophora, Madrepora to 20 m]; Gravier 1908: 121-124, text-figs 476-481; pl. 8 figs 290, 291 [locations as in 1906b]; Day 1967: 813-814, fig. 38.6.g-i [Red Sea, Djibouti; Gulf of Aden, Aden]; ten Hove 1970a: 59-60, figs 17-25 [Red Sea; tropical Indian Ocean; Persian (Arabian) Gulf; Tasmania; W. Africa, Annobon Isl.]; Mohammad 1971: 301 [Red Sea; Indian Ocean, Madagascar; Persian Gulf, Kuwait; India; Tasmania; tropical Atlantic Ocean, Panama; West Africa, Gulf of Guinea]; Mohammad 1976: 133 [Persian Gulf, Kuwait].

Vermiliopsis acanthophora not Augener, 1914, sensu Monro 1937: 318 [south Arabian coast, north Arabian Sea, Gulf of Oman, 38-609 m]; Mohammad 1971: 301 [Persian Gulf, Kuwait]; both records fide ten Hove (1975: 59).

Vermiliopsis glandigera: Monro 1937: 318 [in part, Red Sea, Arabian coast; for records from Panama and western Africa, part, see above].

Vermiliopsis infundibulum: Rosenfeldt 1989: 238-239 [Red Sea depths, 757-1554 m; this record probably does not belong to the Mediterranean Vermiliopsis infundibulum, but to an Indo-West Pacific representative of the speciescomplex.

Vermiliopsis pygidialis / glandigera-complex: ten Hove 1994: 113; [circum-sub-tropical]; Fiege \& Sun 1999: 133-135, figs 21a-e [S. China Sea; Australia; Atlantic, Mediterranean; circum-sub-tropical]; Wehe \& Fiege 2001: 134-135 [list of references].

Material examined. Locations adjacent to the Suez Canal, Mediterranean side: Vermiliopsis infundibulum: Rhodes 1 sample, shallow-Turkey 2 samples, [108-135] m-Cyprus 59 samples, [3-5]-[1878]-2432 m-Israel 30 samples, 1-[ㅌ-66]-1435 m-Egypt (incl. Sinai) 6 samples, 18-[137-198]-[19932025] $\mathrm{m}, \mathrm{HUJ}$ and SMF.

Suez Canal material reported herein: 2 samples, 2 specimens. Hebrew University-Smithsonian Expeditions, 1967-1973: Exp. 11.VII.1968: SLC 45, 1 spec.-East of Deversoir-Km 97: SLC 71, 1 spec.

Locations adjacent to the Suez Canal, Red Sea side: As Vermiliopsis infundibulum / glandigera (see introductory note): Gulf of Suez, Suez, det. H.L.M. Pixell (1913: 86-87) V. pygidialis, redet. ten Hove (1975: 68) Vermiliopsis infundibulum / glandigera, BM(NH) 1924.6.13.140, 2 specs_Gulf of Aqaba: 14 samples, [intertidal-3]-[6-9]-[22-25] m. Red Sea proper 9 samples, 1-[5-15]-50 m, HUJ.

Indian Ocean, Seychelles 18 samples, [1-7]-[4-11]-[30]-[45-55] m, ZMA.

Suez Canal depth and substrates: ?from pool and "sublittoral", on alga; on Pectinidae.

Remarks. Particularly the non-Atlantic-Mediterranean Vermiliopsis taxa are in need of revision.

\section{Vermiliopsis striaticeps (Grube, 1862)}

Vermilia striaticeps Grube 1862: 65 [Type locality: Mediterranean Sea].

Vermiliopsis striaticeps: ten Hove 1975: 57-58 [Atlantic-Mediterranean]; Zibrowius 1979a: 216-217 [notes distinguishing V. striaticeps from Vermiliopsis infundibulum; Tunisia, from infralittoral to $50 \mathrm{~m}$ ]; Bianchi 1981: 74-75, figs. 26a-f.

Eastern Mediterranean

?Vermiliopsis infundibulum: Fauvel 1937: 47 [Alexandria, 46 m, empty tube, indeterminable].

Vermiliopsis infundibulum not (Philippi), sensu Ben-Eliahu 1972b: 90 [Cyprus, littoral]; Amoureux 1976: 1054 [Israel, Haifa Bay, part, 1 spec., re-examined M.N. Ben-Eliahu 1985, redet. herein].

Vermiliopsis ?striaticeps: Ben-Eliahu 1976: 107 [Israel, intertidal cryptofauna, herein confirmed as present in this habitat].

Vermiliopsis striaticeps: Zibrowius \& Bitar 1981: 159-160 [Lebanon, Beirut, Zaitouné, 5 m, on bivalve, 23.IX.1978]; Ben-Eliahu 1991b: 518 [Cyprus, Israel]; Ben-Eliahu \& ten Hove 1992: 40 [Israel, along entire coast from north to south, 0-24 m]; Ben-Eliahu \& Fiege 1996: 8, 33, 38 [western Levant Basin, Turkey, Cyprus, Levant coast]; Ergen \& Çinar 1997: 237 [Antalya Bay, Turkey]; Ben-Eliahu \& Payiatas 1999: 110-111 [Cyprus]; Çinar 2006: 233 [Levant coast of Turkey, Iskenderun Bay, Bogsak, 0.5-60 m, on bivalve, IX.2005].

?Vermiliopsis infundibulum: Selim 1997b: 96-97, fig. 9a-f [?Alexandria, harbour, citing Selim (1987, see App. Table 4)]; Ghobashy \& Ghobashy 2005: 94 [as discussed above]. 
Suez Canal

?Vermiliopsis infundibulum: Ghobashy et al. 1980: 75-92 [Suez Canal, location not known; citing Selim (1997b), see introductory note above].

Vermiliopsis infundibulum: Selim 1997b: 96-97, fig. 9a-f [Deversoir, northern tip of Great Bitter Lake; Selim's excellent figure of the operculum enables correcting the particular determination herein to V. striaticeps]; Emara \& Belal 2004: 192-199 [pooled Lake Timsah and Bitter Lakes data]; Ghobashy \& Ghobashy 2005: 94 [in part, the single record from the Suez Canal (Ghobashy et al. 1980, Selim 1997b) is referred by us to V. striaticeps].

Material examined. Locations adjacent to the Suez Canal, Mediterranean side: Turkey, 2 samples, $0.5 \mathrm{~m}$-Rhodes, 1 sample-Cyprus, 26 samples [0.5-0.8]-[3-5]-46 m-Israel, 36 samples, intertidal-10 -67 $\mathrm{m}$.

No additional specimens from the Suez Canal in addition to those reported by Selim (1997b) as Vermiliopsis infundibulum.

Distribution. Mediterranean, Atlantic (from the Gulf of Guinea to Cornwall, U.K.)

\section{Results and discussion}

Various efforts to obtain additional serpulid material from the Suez Canal by searching through samples that had not previously been examined by a "tubeworm person" provided many previously unstudied specimens: Appendix Table 2 lists ca. 140 "new", i.e., previously unstudied samples from four different sources. This material enables us to make a belated report of several new species for the Suez Canal and to antedate two previous "first records" for the canal. Using the compiled data from the Suez Canal, as well as from our IndoWest-Pacific and Mediterranean data-bases, we attempt in the present paper to address some of the assumptions and questions that have been raised relating to the Lessepsian migration process for the Serpulidae (Steinitz 1968, Por 1978 and others, see below).

Serpulid tubeworms settle and build tubes on various natural substrates, e.g., plants, sponges, corals, bryozoans, mollusc shells, crustacean shells and rocks, as well as on fortuitous artificial substrates, such as rubber, metal, asbestos, and plastic (Ben-Eliahu \& Fiege 1996, Bastida-Zavala \& ten Hove 2003a). Some serpulid taxa form an important part of the biofouling pests on ship hulls, piers, and other submerged marine installations, and have significant economic impact (Ben-Eliahu \& ten Hove 1992, Zibrowius 1994).

The biofouling from the hulls of the immobilized ships of the "Yellow Fleet" in the Great Bitter Lake, when sampled in January 1975 by Brattström \& Taasen, had developed into a thick, massive, structurallycomplex aggregate with many crevices, rather similar in its complexity to coral reefs. Natural coral reefs are lacking in the Suez Canal (Por 1978, Hoenselaar \& Dekker 1998). Thus, this aggregate provided a biogenic microhabitat in the Great Bitter Lake on which serpulid larvae could settle. In January 1975, the structuring taxa of this aggregate were the molluscs, Brachidontes pharaonis (most abundant), Spondylus spinosus (fewer), Pinctada radiata and Malvufundus regulus (even fewer [H.K. Mienis, pers. comm.]), the barnacle Balanus amphitrite (Darwin), the bryozoan Schizoporella errata (Waters), sponges, and at least two species of tunicates (Por \& Ferber 1977). We found a considerable cover of serpulid tubeworms in the interstices, as well as on the exposed surfaces of the aggregate, particularly on or within the empty mollusc shells (Figs 2, 3).

\section{On the morphology of tubes of some Suez Canal serpulid taxa}

Below, we have summarized our findings on intra- and inter-specific variability in the tube morphology. In the C. Beets collection from the Great Bitter Lake, sampled in 1950, both the mollusc shells and the encrusted serpulid tubes had undergone scouring on the floor of the lake. Beets dried the shells, rather than placing them in a preservative, and most of the encrusted serpulid tubes appeared to be empty. In contrast, Brattström \& Taasen's samples of the biofouling aggregation were stored immediately in preservative, and were a source of many inhabited tubes.

Analyzing Beets' serpulid tubes, we pried open the tubes with coiled parts, as it seemed that coiled tubes were most likely to retain dried residues. We succeeded in finding fragments of chitinous opercula, collar 
chaetae, even dried bodies including inquiline syllid, eunicid, spionid, and maldanid polychaetes that had endured for more than 50 years. There were recognizable fragments of Hydroides elegans verticils and a complete upper verticil of $H$. steinitzi (Figs 7A-I and 14C, respectively). The very fine tubes of Josephella, and to a lesser extent, of Salmacina, could be expected to dissolve in the mud (ten Hove \& van den Hurk 1993: 25). In the event, only tubes from 3 samples were tentatively identified as Josephella, while many empty damaged tubes were attributed to Salmacina sp. due to their size and form of aggregation (as in Fig. 3C). A Protula sp. tube, recognized by its large size and its reticulated surface (Figs 21A-C), was similar to that collected on the "Yellow Fleet" ships in 1975 (Fig. 21D). Tubes with the transverse peristomes of Vermiliopsis sp. and the durable "triangular" tubes with the prominent median longitudinal ridges typical of both Spirobranchus tetraceros and Pomatoleios kraussii were apparently not present on Beets' mollusc shells. Of the remaining serpulids reported in the Canal, the tube characteristics do not seem to be sufficiently distinctive to attribute the empty tubes confidently to species, particularly when considering the intraspecific variability observed in tubes whose determination could be verified from their inhabitants (Figs 5A-I, 6D, E, 14B, 15A-F, 24A, B, 27D , 28C, D, 29A-C, 30A, B, 31A, B).

The tube of Serpula hartmanae, with its three not pronounced longitudinal ridges and surface granulation, does not appear to be perceptibly different from tubes of some Hydroides species. In Hydroides, the most speciose genus, the problem of identification of empty tubes is exacerbated as phenotypes may show considerable intraspecific variability. Hydroides tubes have a tendency towards 3 longitudinal ridges; they are generally rounded, with a wider or narrower flattened upper surface. The flattened upper part is typically bordered by longitudinal ridges, more or less marked, which separate it from the lateral walls, and, most frequently, there is an upper median ridge of equal or less height than the lateral ridges, but sometimes it is almost indistinguishable (e.g., in Hydroides diramphus, H. elegans). Longitudinal ridges may be seen in the posterior (oldest part) of the tube and become obliterated anteriorly along the tube with increasing size, whereas transverse ridges appear to become increasingly prominent with increased diameter, i.e., in the anterior end (Figs 5A-I). Often, tubes showed variability in the sculpturing along their lengths, e.g., note the variability in the tubes of Hydroides steinitzi (in Figs 14 and 15); other H. steinitzi tubes had an overlay that concealed the sculpturing. In Fig. 5H of Hydroides homoceros, an overlay on only part of the tube concealed its typical distinct 3-ridge pattern. We do not presently know whether the overlay is exogenous or if it is made by the worms. Bastida-Zavala \& ten Hove (2003b: 84) similarly remarked on variability in Hydroides diramphus tubes from California and Hawaii (see Systematic Section) and this is confirmed from the present Suez Canal material.

Of thirty-three Hydroides heterocerus tubes from the Suez Canal, only three showed 3 longitudinal ridges, one of them from a small specimen (Fig. 5F); the ridges in two of these tubes were very difficult to distinguish; in contrast, transverse ridges were prominent in the larger tubes (Fig. 5G). It appeared that Hydroides tubes with 3 longitudinal ridges might belong to any one of the following species already found in the Suez Canal-Hydroides diramphus, H. homoceros, and H. steinitzi-or even to additional Hydroides taxa not yet reported from the canal. The Hydroides diramphus tubes appear to be more rugose than the H. elegans tubes of comparable size. Hydroides steinitzi is seemingly even more rugose and more encrusted than both these taxa. The Hydroides homoceros tube, typically with three ridges on the upper surface, seems to have rather smooth side-walls, i.e., lacks prominent transverse ridges, while H. heterocerus, the largest of these taxa, often has a round apical part with more marked transverse ridges (Figs 5A-I show a range of tube phenotypes in several Hydroides species).

Hydroides elegans differs from these other above-mentioned species in usually having a smooth (rounded) transition between the upper surface and the sidewalls, in lacking flanges or peristomes, and lacking prominent longitudinal ridges, or otherwise with only two prominent ridges (e.g., Figs 5D-E); however, tubes of small $\mathrm{H}$. elegans individuals from the Great Bitter Lake had a nearly indistinguishable median line (see Systematic Section). Their characteristic form and size make the Hydroides elegans tubes the most recognizable in this assemblage and they were omnipresent on the different mollusc shells, particularly on those of Fusinus polygonoides (Figs 5D, E, 6D, E, 7J, K). In unexceptional cases, we reported our identifications of C. 
Beets' empty-tube material as tentative (App. Table 2B); the Systematic Sections, "Suez Canal depth and substrates", do not include enumeration from empty tubes.

\section{The serpulid fauna of the canal: Which taxa, how many?}

Nine serpulid taxa were previously reported from within the Suez Canal, some under their synonyms (Systematic Section, Tables 4 and 5): Hydroides diramphus, H. elegans, H. heterocerus, H. homoceros, $H$. steinitzi; Pomatoleios kraussii, Salmacina sp. (reported as S. dysteri), Spirobranchus tetraceros, and Vermiliopsis striaticeps [as Vermiliopsis infundibulum: Selim (1997b, fig. 9a-f)]. V. glandigera (presumably not $V$. striaticeps, but belonging to the Vermiliopsis infundibulum / glandigera-complex) was recently cited in Abd-Elnaby 2009 (bringing the total number to 10 taxa). From the present research, we report the following five taxa, Ficopomatus enigmaticus, Josephella marenzelleri, Protula cf. palliata, Salmacina incrustans and Serpula hartmanae. As noted, the Salmacina specimens collected by the Cambridge Expedition (Potts 1928) from the southern part of the canal and from Port Taufiq in the Gulf of Suez (CUZM) cannot be verified, thus we cannot know whether they belong to the same taxon as that collected by Brattström \& Taasen in 1975 (i.e., to Salmacina incrustans, Figs 24-26A). However, allowing for the possibility that two (or more) different Salmacina taxa might be involved [questionably S. dysteri, see Systematic Section]), we are reporting the number of verified taxa known from within the Suez Canal as at least 14 (possibly 15). Though unverified, recent papers provide an additional two taxa, Hydroides dianthus from the northern end (Selim 2009), and Placostegus sp. from the southern part (Abd-Elnaby 2009), bringing the present maximum number of taxa in the canal to at least 16 (possibly 17).

\section{What are the biogeographical affinities of the Suez Canal populations?}

Due to the predominantly northern currents, Mediterranean species are expected to contribute only slightly to the Suez Canal fauna, particularly as concerns the southern part of the canal (Por 1978, Agur \& Safriel 1981 and Safriel \& Ritte 1986).

Six of the taxa derive unequivocally from the Indo-West-Pacific Red Sea: Hydroides heterocerus, $H$. homoceros, H. steinitzi, Pomatoleios kraussii, Serpula hartmanae and Spirobranchus tetraceros; the identification of the Protula specimens as P. cf. palliata adds a seventh taxon. The provenance of Josephella marenzelleri is inferential: It is a minute circumtropical, cryptofaunal species that has been reported from both the Mediterranean and in the Gulf of Aqaba (Ben-Eliahu 1976). However, the typical operculum of the Bitter Lake population more closely resembles that of the Gulf of Aqaba (Elat) population; it lacks the thick-rimmed opercular form found in some individuals of the proximal Mediterranean population, supporting the southern end inference (see Systematic Section)—-thus, an eighth taxon. The lecithotrophic reproductive mode of both Protula and Josephella requires them to settle within relatively few hours after the larvae are released (Kupriyanova et al. 2001), thus, their being found in the southern part of the canal lends support to the inference that these taxa originally entered the canal from the southern end. With regards to the Vermiliopsis infundibulum / glandigera specimens; it is likely that the southern specimen entered the canal from the Red Sea end, while the northern specimen, found so close to the northern mouth of the canal, may have arrived from the Mediterranean end (see Systematic Section). For biogeographic reasons, the new record of Placostegus sp. (as P. tridentatus sensu Abd-Elnaby 2009, see Systematic Section), would presumably be of southern origin. This brings our tally to 10 taxa, of which three are questionable, whose derivation is from the Red Sea end of the Canal (i.e., 10 of sixteen taxa). Note that the Vermiliopsis infundibulum / glandigera found close to the Mediterranean end of the Canal may also have entered the canal from the Mediterranean end. Moreover, this may be an instance of cryptic species (the taxonomy of Vermiliopsis infundibulum / glandigera requires much working out).

Vermiliopsis striaticeps, an Atlantic-Mediterranean species that has been reported only once from Deversoir, just north of the Great Bitter Lake (as Vermiliopsis infundibulum, Selim 1997b, fig. 9a-f) entered the canal from the Mediterranean side. Similarly, Salmacina incrustans from the "Yellow Fleet" ships presumably entered the Bitter Lake by ship coming from the Mediterranean end. 
As already mentioned, previous records (Pixell 1913, Potts 1928, and Fauvel 1933a, b) of Salmacina dysteri from canal and from the Gulf of Suez cannot be verified. Fauvel's (1933a, b) Gulf of Suez voucher sample of "Salmacina dysteri" proved to belong to a different taxon, so these so-called "cosmopolitan" records cannot be not accepted without verification.

The biogeographic distribution and the Suez Canal records of the ship-fouling taxa Hydroides elegans, $H$. diramphus and Ficopomatus enigmaticus, and more recently of $H$. dianthus, supports their presumed entrance via the northern entrance. All four have been classified as "established cryptogenic alien invasive species" in the Mediterranean (Zenetos et al. 2005: 73). The two well-known marine ship- or port-fouling species, $H$. elegans and $H$. diramphus, were brought into the Canal on barges or ships traversing the canal. Hydroides elegans appears to be a more widely-dispersed fouling species than $H$. diramphus, and there have been several records from the Gulf of Suez (e.g., Pixell 1913, Zibrowius 1971, Ghobashy \& El-Komi 1981b, Ghobashy \& Ghobashy 2005, see above), as well as from the Gulf of Aqaba (e.g. Amoureux et al. 1978 and new data, above). Except for the present "new" record from Suez, "Barge 568", dating from 1924 (Appendix 1), $H$. diramphus has only been reported once from the Gulf of Suez, from Port Taufiq (Selim 1997b, see Section 4 below); there are no records of it from the Gulf of Aqaba, or from the main basin of the Red Sea. The estuarine fouling species, Ficopomatus enigmaticus, well-known from estuarine locations in Egypt and Israel (Fauvel 1937, Ben-Eliahu \& Dafni 1979, Ghobashy 1984) has also been widely distributed by ship (Zibrowius 1991: 91). However, it seems more likely that it navigated a short distance, for example, on boats utilizing the Isma'iliya fresh-water canal, adjacent to Lake Timsah, rather than being translocated over long marine distances, e.g., from Hawaii, Australia or South Africa. The biogeographical origins of Hydroides diramphus may be the tropical American Atlantic (Caribbean), that of H. elegans, Australia (Zibrowius 1971: 705, 721-722 and ten Hove, unpublished). Some researchers have similarly placed the origin of Ficopomatus enigmaticus as Australia, however, this is contraindicated by finding that it became established in New Zealand only a few decades ago (Read \& Gordon 1991); its origin will probably remain an enigma (H.A. ten Hove, unpublished). Thus, 6 (or 7) taxa, Vermiliopsis striaticeps, Salmacina incrustans, Hydroides elegans, H. diramphus, H. dianthus, Ficopomatus enigmaticus, and possibly also Vermiliopsis infundibulum / glandigera most probably derive from the Mediterranean side. In summary, the number of taxa coming from the southern end of the canal (Indo-Pacific Red Sea taxa), does appear to be somewhat greater that that presumably entering the canal from the northern end. However, except for Vermiliopsis striaticeps, and possibly including Salmacina incrustans, the taxa invading the canal from the northern end are notable shiptransported invasive species (Zenetos 2005), and this enables them to "circumvent" the prevalent northward currents in the canal (Por 1978, Agur \& Safriel 1981 and Safriel \& Ritte 1986) referred to above).

\section{Setting the record straight-revising the earliest records for colonization of the canal by the various serpulid taxa, with some remarks on the taxa and on sampling for serpulids (Table 6)}

The first serpulid record from within the Suez Canal dates from 17.X.1895, when the "Pola" Expedition collected Hydroides elegans (as H. norvegicus) at Isma'iliya on gastropods removed from a boat hull (Sturany 1899, Zibrowius 1971 [Figs 6D, E, Table 6]). C. Crossland collected H. elegans again in 1904 / 5 at Suez, on a ship that came from Alexandria (Pixell 1913; Zibrowius 1971) as well as H. heterocerus from Suez Quay (Pixell 1913), though not from within the canal itself.

Hydroides elegans, H. heterocerus and Salmacina sp. (as S. dysteri) were collected within the canal by the Cambridge Expedition of 1924 (Potts 1928), and Potts noted that H. elegans (as H. norvegicus) was the most abundant serpulid in the canal. Subsequent Israeli and Norwegian sampling collected $H$. heterocerus in the Great Bitter Lake and just north of it (Appendix Table 2 C, D). However, Selim (1977b) reported it as extremely rare, having found only a single individual at Deversoir.

Potts reported three additional taxa that were collected outside of the canal proper, two of them from the Gulf of Suez, Spirobranchus tetraceros (as Sp. jousseaumi, fide ten Hove 1970b: 4) and Serpula jukesii (as $S$. vermicularis, see Systematic Section). From Port Said at the Mediterranean end, Hydroides diramphus (as $H$. lunulifera) was collected along with $H$. elegans (as $H$. norvegica) from a buoy by the Cambridge Expedition 
of 1924 (Potts 1928). This 1924 sample provided the first record of both these fouling species in the southeastern Levant Basin (Potts 1928). In 1950, the tube of H. elegans was still the most frequently encountered on Beets' mollusc shells from the Great Bitter Lake (see Results and App. Table 2B) and it has consistently been reported as the most abundant serpulid in every subsequent sampling (e.g., Ben-Eliahu 1972a, Ghobashy et al. 1980, Ghobashy \& El-Komi 1981a, b, Ghobashy, Ghobashy et al. 1986, 1990, Selim 1997b and Emara \& Belal 2004 [Table 6, App. Table 2A-E]). Additionally, Ghobashy 1984: 47 remarked on Hydroides elegans' resistance to oil pollution. Some lists of taxa from the biofouling research have included, along with $H$. elegans, the nominal species Serpula concharum, S. vermicularis or Serpula sp. (e.g., Ghobashy et al. 1980: 84; Ghobashy \& El-Komi 1981a: 172, 1981b: 181; Ghobashy 1984: 45; Ghobashy \& Ghobashy 2005: 94; Abd-Elnaby 2009). We suggest that these three names refer to the juvenile primary stage of Hydroides that lacks an opercular verticil (ten Hove \& Ben-Eliahu 2005; see Hydroides sp. juveniles in the Systematic Section, App. Table 2A, C-E).

Salmacina sp. (as $S$. dysteri) was reported from a small buoy at the southern entrance to the canal by Pixell (1913), and from Port Taufiq by Potts (1928), but, as noted above, the identifications cannot be verified, and have been generalised to Salmacina sp.

Concerning Hydroides diramphus, Potts (1928) asserted that, in 1924, "There is no evidence as yet of a migration through the canal". However, the Cambridge Expedition had inadvertently collected two $H$. diramphus specimens encrusted on Crenatula picta bivalves: One, sampled within the canal, from Toussoum, south of Lake Timsah, and the other from the southern end at Port Taufiq from "Barge 568" (see App. Table 2A). The Cambridge Expedition molluscs had been deposited in the Natural History Museum Mollusc Section in London, thus, the serpulid specimens encrusting the shells were discovered only in 1986 when one of us (NBE) visited the museum to look for additional Cambridge Expedition serpulid specimens that might have settled on these molluscs. We are thus able to bring Hydroides diramphus' "first record" for the Canal forward from ca. 1984 (Ghobashy 1984: 45) to 1924. (This anecdote illustrates the necessity of sampling all the appropriate substrates when documenting a serpulid fauna). Adding at least 60 years to the onset of Hydroides diramphus' colonization of the canal would very likely bear on its comparative abundance in later collections (present material, Table 6 and App. Table 2A, ?B, C-E; Ghobashy et al. 1986, 1990, Mona 1992, Selim 1997b, Emara \& Belal 2004 and Ghobashy \& Ghobashy 2005: 94).

In 1950, empty Salmacina tubes were present on the shells Beets collected from the Great Bitter Lake, and in 1975, similar aggregations of inhabited tubes, identified as Salmacina incrustans, were common on Brattström \& Taasen's shell substrates on the ships in the Great Bitter Lake (see Fig. 3B).

Spirobranchus tetraceros was first collected in the Gulf of Suez in 1870, by the J.K. Lord Expedition (Pixell 1913, as S. contieri); in 1924, the Cambridge Expedition collected it in the Gulf of Suez again, opposite Km. 155 of the Canal (as S. jousseaumi, Potts 1928). As noted above, Spirobranchus tubes appeared to be lacking on the shells Beets' collected in the Bitter Lake 1950, however, from 1967-1973, Israeli expeditions sampled S. tetraceros in several locations along the eastern bank (e.g., Ben-Eliahu 1972a). It was particularly abundant in the biofouling encrustation on the ships in the Great Bitter Lake collected by Brattström \& Taasen in 1975 (Fig. 3A). Ghobashy et al. (1990: 684) first noted its resistance to oil pollution; Selim (1997b) remarked that it was very abundant throughout the Canal and Selim et al. (2005) reported that Spirobranchus tetraceros had replaced Hydroides elegans as the dominant fouling serpulid species in Alexandrian waters, Egypt (Abu Kir Bay).

Finally, Potts' (1928) Serpula "vermicularis" was not reported from within the Suez Canal, but only from the Gulf of Suez. We consider that the taxon is likely to have been Serpula jukesii. There have not been additional reports of a Serpula species fitting Potts' description in subsequent Suez Canal material. As already noted, the nominal Serpula vermicularis of Ghobashy \& Ghobashy (2005: 94) in their compiled list of various Suez Canal, Gulf of Suez and Red Sea biofouling taxa, presumably refers to a juvenile Hydroides taxon with a primary operculum. As noted above, the Abd-Elnaby (2009) nominal record of Serpula jukesii did not in fact belong to this taxon (as seen in the small number of remaining opercular radii of the specimen, see above); it is more likely to be a juvenile Hydroides sp. with a primary operculum. 
The first record of Hydroides steinitzi in the Suez Canal, in 1969 (Ben-Eliahu 1972a), is advanced to 1950, due to finding an opercular residue in a serpulid tube on one of C. Beets' molluscs (present paper, Fig. 14). The types of H. steinitzi were collected in the Little Bitter Lake in 1969; and it was found again in 1973 by two Israeli field expeditions, and again in 1975 by the Norwegian expedition (Ben-Eliahu 1991b: fig. 4, App. Table 2B-D). Tubes on Beets' (1950) molluscs provided tentative first records of other serpulid taxa: Protula cf. palliata, identified by its great size and the tube sculpturing (Fig. 21); of Hydroides homoceros, and of Josephella marenzelleri.

After Beets' 1950 expedition, the next Suez Canal serpulid data came from several Israeli collecting trips to the eastern bank of the canal carried out between June 1967 and January 1973. Two specimens of Vermiliopsis infundibulum / glandigera were collected, from Port Fouad and from Deversoir, in 1968 (first record) and 1969, respectively. In 1969, specimens of Hydroides homoceros were first reported from the Great Bitter Lake (Ben-Eliahu 1991b: fig. 5), collected on two occasions (empty H. homoceros tubes were tentatively identified from Beets' 1950 molluscs that we obtained later for examination); H. homoceros was collected again from the Great Bitter Lake by the Norwegian expedition in 1975 and from Port Taufiq in 1988 (Selim 1997b). In 1973, the mixo-hyperhaline brackish species (ten Hove \& Weerdenburg 1978; ten Hove \& van den Hurk 1993), Ficopomatus enigmaticus, was collected both in Lake Timsah and in the Little Bitter Lake (App. Table 2C). In 1973, Protula cf. palliata was collected in the Little Bitter Lake; it was collected again in the Great Bitter Lake in 1975 during the Norwegian biofouling sampling carried out by Brattström \& Taasen on the "Yellow Fleet" ships. Similarly, from the biofouling encrustation on the "Yellow Fleet" ships we add the first firm record for Josephella marenzelleri and a first record for Serpula hartmanae (App. Table 2D).

Pomatoleios kraussii, a species that forms reefs in the Pacific intertidal zone (Straughan 1969, ten Hove \& van den Hurk 1993: 34-35), was first reported in Lake Timsah in the years 1983-1984 as isolated individuals on the western side (Ghobashy et al. 1986, 1990, Shalla \& Holt 1999). By April 1997, Pomatoleios kraussii had developed well-formed intertidal reefs on both the western shores of Lake Timsah and the Great Bitter Lake (Shalla \& Holt 1999, confirmed by Emara \& Belal 2004). In 1988, Vermiliopsis striaticeps was collected from Deversoir, a single specimen (Selim 1997b: 96-97, fig. 9a-f, as Vermiliopsis infundibulum)—Selim's excellent illustration of the operculum enabled us to correct the identification.

Two additions to the list of taxa come from sampling carried out in April 2007 by F.A. Abd-Elnaby and S. A. Selim: Placostegus sp. (as P. tridentatus), from the southern part of the canal (Abd-Elnaby 2009), and Hydroides dianthus, from Lake Timsah (Selim 2009) - H. dianthus, a fouling species, had been collected from Egyptian Mediterranean ports close to the canal by S.A. Selim in the early 1970's (Ghobashy 1977).

The research focusing on biofouling in the Canal (e.g., Ghobashy et al. 1980; Ghobashy \& El-Komi 1981a, b; Ghobashy et al. 1986, 1990; Selim 1997b; Emara \& Belal 2004 and by Ghobashy \& Ghobashy $2005)$ has yielded comparatively few serpulid taxa. The taxa, Ficopomatus enigmaticus, Hydroides homoceros, H. steinitzi, Josephella marenzelleri, Protula cf. palliata, Salmacina incrustans / sp. or Serpula hartmanae have not figured in their lists of component taxa from within the canal, although some of the taxa, e.g., Salmacina sp., had previously been considered as common in the southern canal (Potts 1928). As with the above anecdote on Hydroides diramphus, this is presumably due to not having sampled the appropriate substrates or depth and / or the specific microhabitats for them. As a consequence, a non-existing geographic or chronological gap might appear to be present although it does not exist in actuality. Similarly, Selim's (1997b) report of Hydroides heterocerus as rare in the Suez Canal is most likely due to restricting the sampling to substrates associated with fouling, and even more to the shallow depths of the fouling samples, and the same is true regarding H. homoceros where Selim (1977b) reported only a single specimen from a structure in Port Taufiq. Both these taxa are Lessepsian migrants, and along the Mediterranean coast of Israel, they are more frequently found in greater depths than those sampled in the biofouling research: Fifty percent of the Levant samples of $H$. homoceros come from 22-32 m, while H. heterocerus has frequently been collected in depths between 14-22 $\mathrm{m}$ in association with coralligenous habitats, such as the Cladocora caespitosa (Linnaeus) conglomerate or Peysonnelia conglomerate (Ben-Eliahu \& Fiege 1996). It is also possible that some taxa might have been overlooked due to their small size, e.g., Josephella marenzelleri. Both when planning sampling and when processing the samples, there is a need for a serpulid-oriented "search image" to facilitate discovery of specimens that might otherwise be overlooked. 


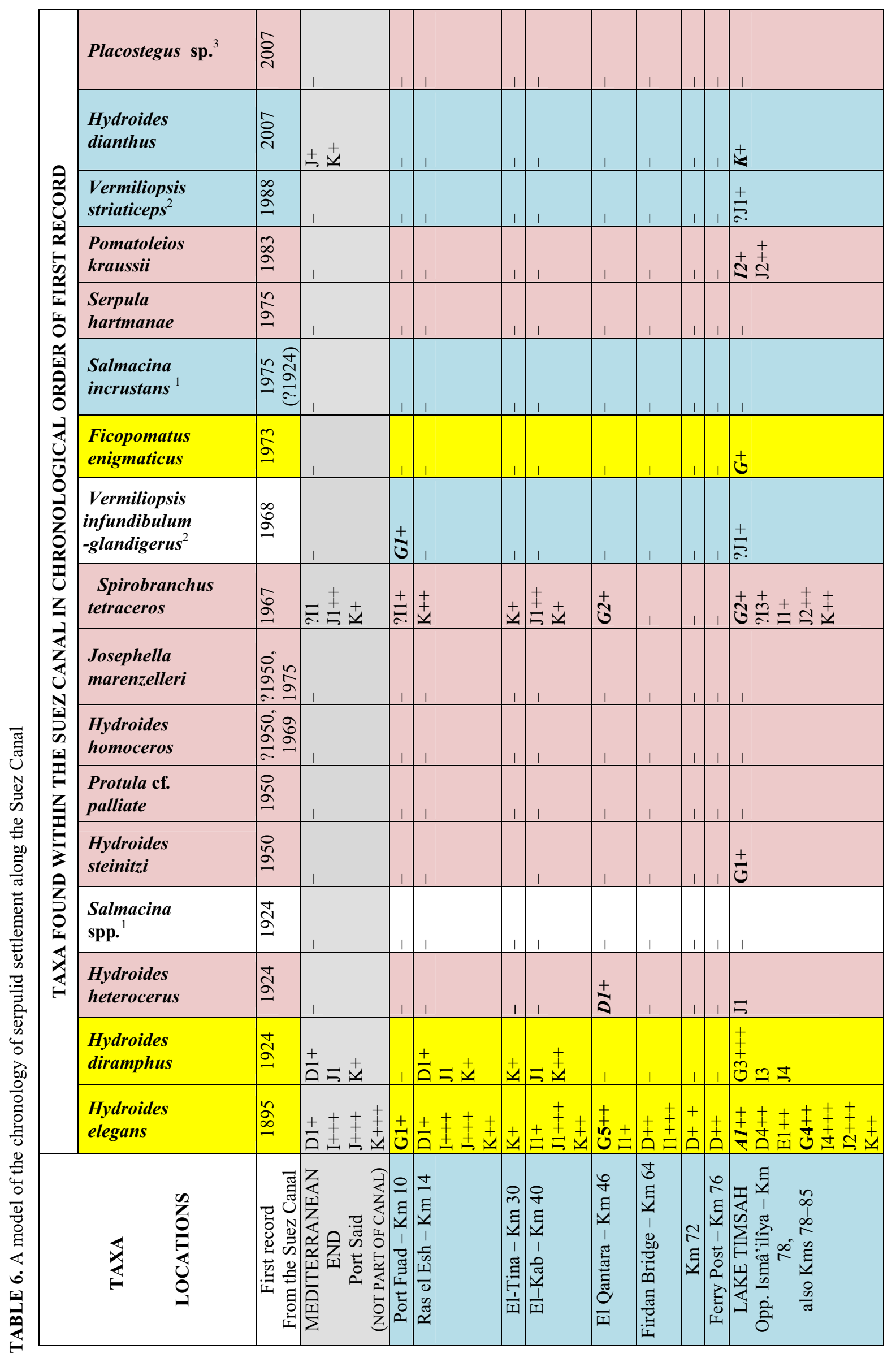




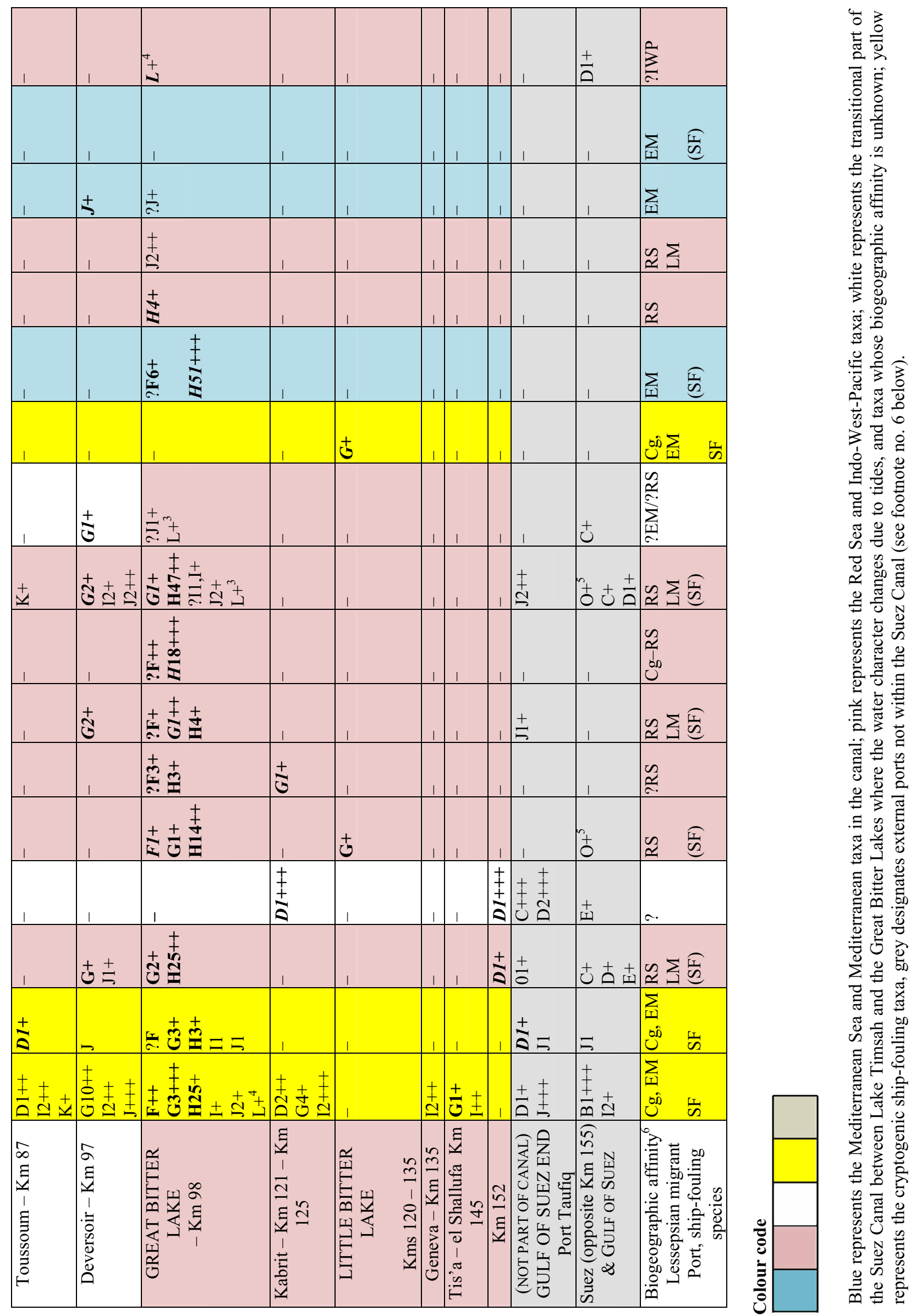



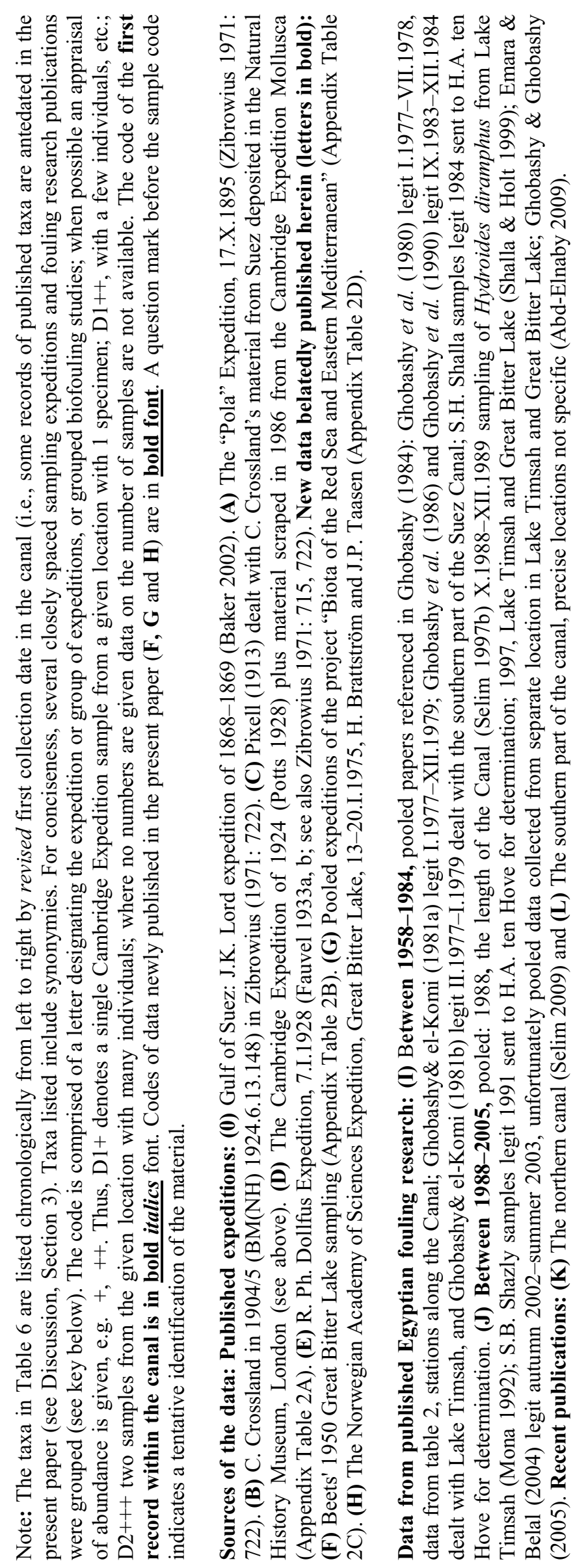

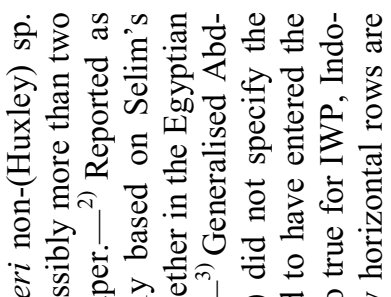

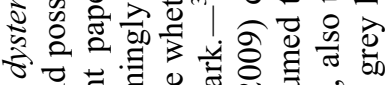

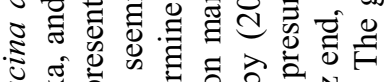

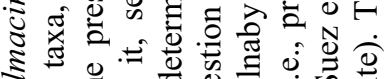

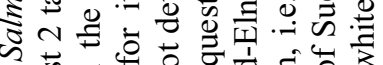

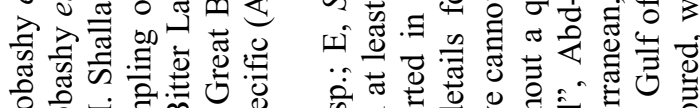

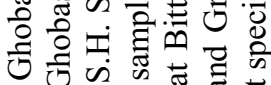

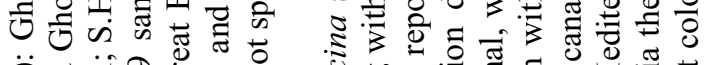

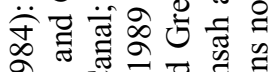

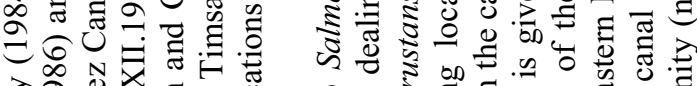
入o

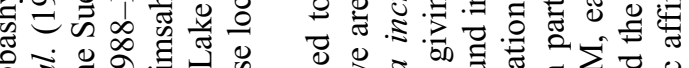

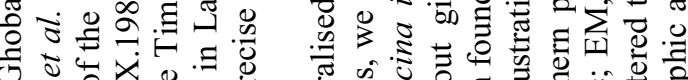

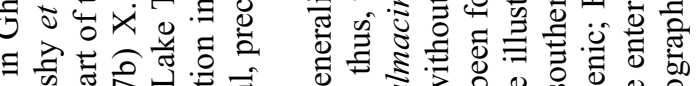

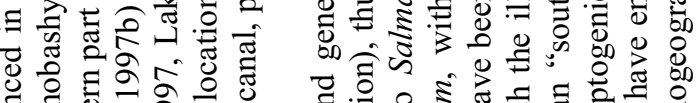

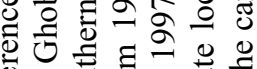

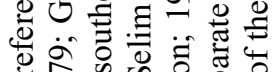
3ิ

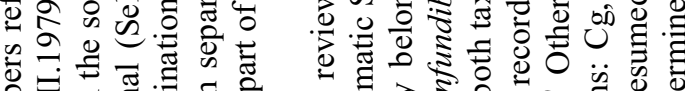

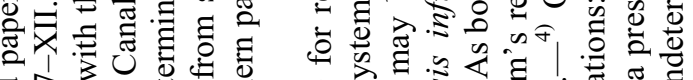

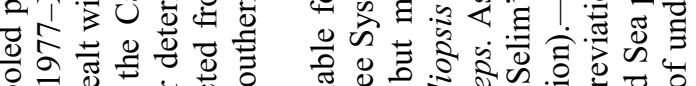

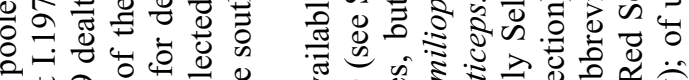

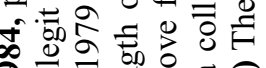

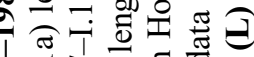

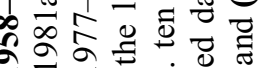
$\exists=$

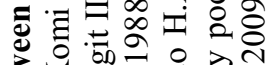

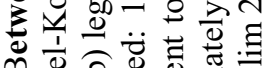

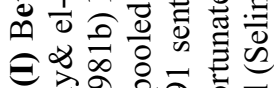

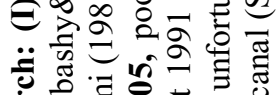

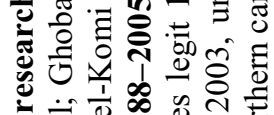
on

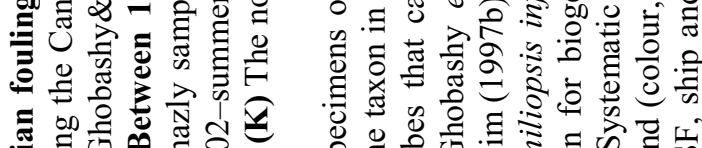

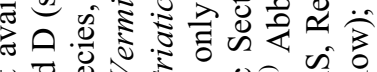

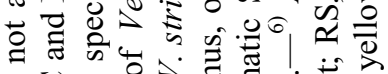

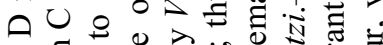

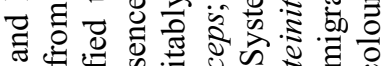

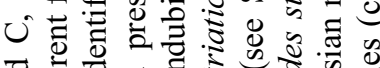

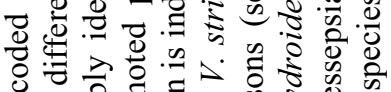

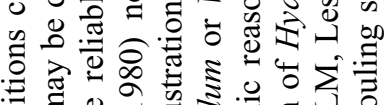

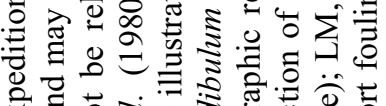

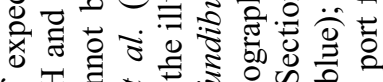

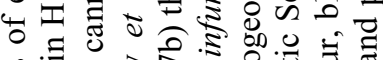

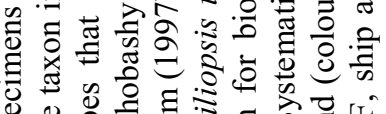

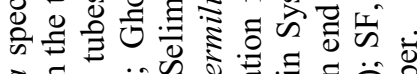

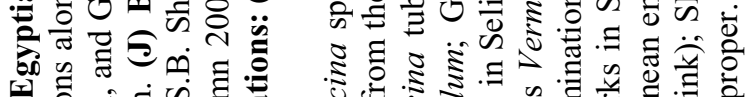

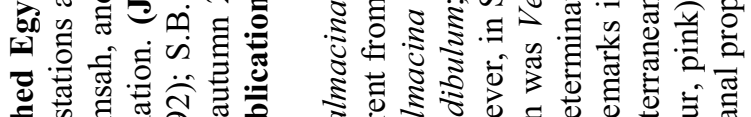

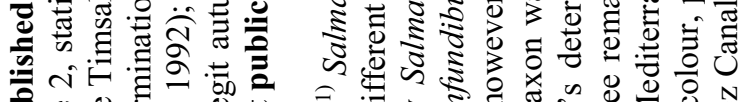

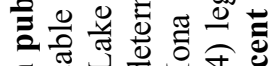

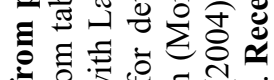

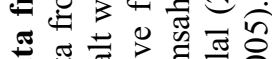

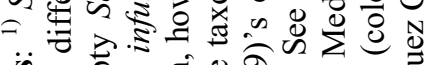

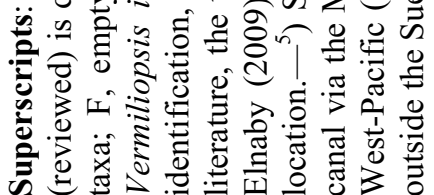


Due to the sparse sampling, we have no way of determining when taxa did actually colonize the Suez Canal. The cited species as well as additional species might have been present in the Canal earlier, with the chronological findings mainly reflecting the lack of sampling thoroughness and / or of comparatively sparse populations at a given time. As already pointed out, when surveying such a "biogeographically- and hydrographically-complex system" as the Suez Canal (Ghobashy et al. 1980: 89), negative evidence is rarely considered to be robust. A statement that a species is not present is "reliable only when sampling has been closely spaced and extremely thorough" (H. Steinitz, pers. comm.). Considering the remarkable colonization "experiment" that the Suez Canal represents (Por 1978), it is truly regrettable that, from its inception, the canal has never been studied in a regular and detailed manner, but rather in an infrequent, sporadic way and by employing different sampling approaches that make it difficult to compare species richness and abundance within the different parts of the Canal at different times.

\section{What do the Suez Canal data on serpulids add to our understanding of the chronology of settlement of Lessepsian migrants in the Levant Basin, or of the Lessepsian migration process of step-wise migra- tion? (Tables 6, 7)}

Seven serpulid species out of a total of 48+?4 (Selim 1978, Ben-Eliahu \& ten Hove 1992, Ben-Eliahu \& Fiege 1996, Selim 1997b, Ben-Eliahu \& Payiatas 1999) inhabiting the Levant Basin of the Mediterranean are presently recognized by us as Lessepsian migrants. Of these, only four have been reported from within the Suez Canal, Hydroides heterocerus, Spirobranchus tetraceros, H. homoceros and Pomatoleios kraussii, with first Suez Canal records in 1924, 1967, 1969, and 1983, respectively, all of them known from the Indian Ocean and the Red Sea (Tables 6, 7). The first Mediterranean record of Hydroides heterocerus, 1965 (from Lebanon), is later than its first Suez Canal record; however, the Levant records of the last 3 species precede their first Suez Canal records by 2, 14 and 25 years, respectively (a reflection on the infrequent sampling in the canal). The first Levant records of Hydroides heterocerus and Spirobranchus tetraceros both date from 1.IX.1965 (Beirut, Lebanon [Laubier 1966]); that of H. homoceros from 21.IX.1955 (Haifa Bay [Ben-Eliahu 1991b: 520]); and that of Pomatoleios kraussii, from 27.X.1958 (north of Tel Aviv, Israel [Ben-Eliahu \& ten Hove 1992: 42]; the total number of records of these species from the Israeli coast (until 2009) is given in the Systematic Section).

Three presumed Lessepsian migrants have not been reported from the Suez Canal; Por (1989a) termed them "lower-probability" Lessepsian migrants (the possibility exists that they may still be present, undiscovered, in the canal): Hydroides cf. brachyacanthus, H. minax, and H. operculatus. Hydroides cf. brachyacanthus and $H$. operculatus have records from the Indian Ocean, but not from the Red Sea or the Gulfs of Aqaba and Suez. Hydroides cf. brachyacanthus was first collected from Jaffa Port in 1933, the first Israeli record for any of the presumed Lessepsian migrants - and the first serpulid sampled off the Israeli coast (INCNH data); besides two records from Tel Aviv, 13 of its 15 records are more to the north (INCNH data) (Table 8). Hydroides operculatus was first collected in 1959, from Haifa Bay, and there are 38 subsequent records from the length of the Israeli coast (INCNH data). In contrast, $H$. minax has numerous records (sometimes as H. monoceros) from the Indian Ocean, Red Sea, as well as from the Gulfs of Aqaba and Suez. However, in the Mediterranean, it was first collected only in 1978 near Beirut (Zaitouné), Lebanon (Zibrowius \& Bitar 1981); as noted below (Section 6c) it was not present among the many Israeli samples collected during the "Biota" project (Por et al. 1972) —its first Israeli record dates from 1990 (Ben-Eliahu \& ten Hove 1992; Table 8); there are altogether 18 records from the northern border to Hadera, $60 \mathrm{~km}$ north of Tel Aviv (see section $6 \mathrm{c} 2$ below).

In 2002, the first two taxa, Hydroides cf. brachyacanthus and H. operculatus were appraised by Zibrowius \& Bitar (2003) as being "less evident" relative to other Lessepsian migrant taxa sampled in Lebanon, while $H$. minax had become "omnipresent" on the Lebanese coast, even forming crusts in port environments (Zibrowius \& Bitar 2003: 71), and aggregations have recently formed in Haifa Bay (see above). (In 2002, H. Zibrowius reported that Hydroides minax was the most frequent Lessepsian serpulid off Lebanon [H. Zibrowius, pers. comm.]). 
Pomatoleios kraussii forms thick shallow encrustations in Beirut Port and on the airport jetty in Beirut, and more diffuse masses in various natural, but always shallow, habitats (Zibrowius \& Bitar 2003: 71). Although individual settlement of Pomatoleios kraussii was previously known from the Israeli coast, massive crust-like aggregates have only recently been found in Haifa Bay (see above). All seven Lessepsian migrant serpulids have recently been collected along the Levant coast of Turkey. With two additional alien species, Hydroides elegans and $H$. diramphus, they form a very important part of the serpulid biota in shallow habitats, rocks, molluscs, artificial substrates, and algae, 9 of the 16 serpulid taxa present, but about $95 \%$ of the specimens collected in these habitats (Çinar 2006: 237, fig. 13).

Unfortunately, just as with the sparse Suez Canal sampling discussed above, the sparse Mediterranean sampling for serpulids makes it impossible to reconstruct the actual chronology of the Mediterranean colonization events, or even when the aggregations recently described from the Lebanese coast were formed (Table 7).

As already noted in the Systematic Section on Serpula hartmanae, H. Zibrowius (pers. comm.) recently informed us that this taxon is present on the Lebanese coast, which would increase the present number of Lessepsian migrant serpulids to eight. However, we believe that taxon is the same as the Serpula cf. concharum that has had several previous reports in the Levant literature. Consequently, the determination of its derivation must be deferred until the revision of the taxon Serpula in the Levant is carried out (see discussion in the Systematic Section) when it can be confidently included in the verified list of Lessepsian migrants.

\section{Possible dispersal modes for the Lessepsian migrant serpulid taxa}

As with any biological invasion, for Lessepsian migration to be accomplished, a species needs to establish viable populations in the new habitat (Safriel \& Ritte 1983, 1986). Dispersal of Red Sea serpulid species from the Suez Canal into the Mediterranean is passive whether it takes place as plankton (Sections 6a, b) or as a transported sessile stage encrusted directly on a ship or on other taxa (e.g., Mollusca) encrusted on the ship (Section 6c). Our supposition that the migration of the four "high-probability" tubeworm migrants, Hydroides heterocerus, H. minax, Pomatoleios kraussii and Spirobranchus tetraceros, took place by step-wise progression (as plankton or as flotsam) is based on their overall location data rather than on chronological data. We have no real proof that these populations had not been dispersed from ships. In fact, for any of these migrant serpulids, at any given time, dispersal could be taking place using any or all of these following modes simultaneously.

6a. Planktonic dispersal, planktotrophic vs. lecithotrophic larvae. If there are well-established source populations within the Suez Canal, migration through larval dispersal is likely to be a recurrent event. Repeated colonization may bridge the fragile period until a critical population size is achieved, as small populations are more easily subject to random extinction than large ones (Safriel \& Ritte 1983, 1986).

As regards the three Hydroides species presumed to lack Suez Canal populations (H. brachyacanthus, $H$. minax and $H$. operculatus, mentioned in Section 5, above), how likely is it that their larvae (propagules) or indeed, larvae of other taxa crossed the Canal by drifting in a through-going current, i.e., "one-jump" planktonic migrations (Agur \& Safriel 1981) rather than in stages after first settling within the canal (Steinitz 1969)? This possibility must take into consideration both the estimated duration of drift in the current through the Suez Canal and the duration (length) of the planktonic life of the larvae before metamorphosis and settlement. During spring, the minimum time for planktonic stages to be swept through the Canal by the prevailing northwards through-current is 12 days (Agur \& Safriel 1981). Kupriyanova et al. (2001) listed a planktonic life for up to 9 days for the two Hydroides fouling species, H. elegans and H. dianthus, though noting a 17-day life as planktonic larvae for Pomatoleios kraussii. However, experimental observations have shown that when appropriate cues for settlement are lacking (e.g., substrates, bacterial films, presence of conspecifics, sufficient algal food for larvae, etc.-cues that differ for different species) - the duration of larval life of planktotrophic larvae, i.e., the length of period until the planktotrophic larvae lose their competence to carry out metamorphosis, can be much prolonged (Hadfield 1998, Scheltema et al. 1981, Kupriyanova et al. 2001). Hadfield et al. (2001) reported experimental prolongation of competence in Hydroides elegans as greater than 3 weeks. 


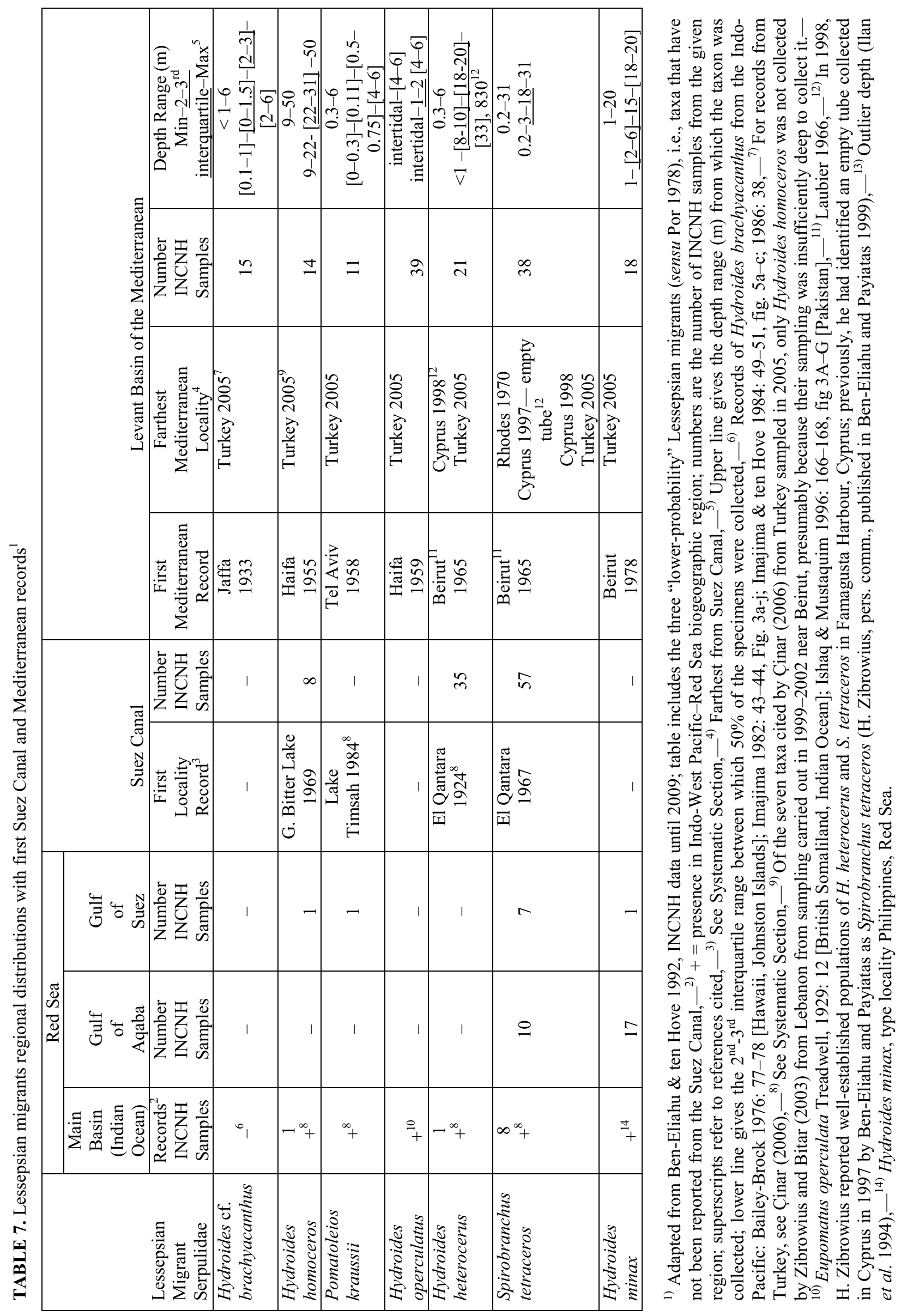


A list of planktotrophic serpulids compiled by Kupriyanova et al. $(2001: 36,45)$ included the "alien invasive species" in the Levant Mediterranean, Hydroides dianthus, H. elegans, Ficopomatus enigmaticus and Pomatoleios kraussii, as well as a number of other species. It seems possible that a through-current might transport larvae of a planktotrophic species across the canal. In contrast, "one-jump" transport is excluded in the case of non-feeding or lecithotrophic larvae that must settle within a few hours after being shed, e.g., Protula (lecithotrophic), Salmacina sp. (lecithotrophic) and possibly also Josephella marenzelleri (presumed lecithotrophic), taxa reported from within the canal (in lecithotrophic larval development, the embryo is largely or completely non-feeding, living on yolk provided in the egg).

6b. Ballast water. Much attention has been given to the role of ships' ballast-water in promoting worldwide dispersal of alien species (e.g., Carlton 1985). However, given the low survival rate in the difficult conditions of the ballast tanks over long distances, we query the likelihood that ballast water is the source of the alien serpulid populations, despite the importance of ballast water in dispersal of other taxa. For example, the harpacticoid copepod, Tisbe graciloides (Sars), thrived in a 23-day journey from the Indian Ocean to the North Sea when other taxa decreased sharply in numbers during a few days (Gollasch et al. 2000). Larvae of spionid polychaetes, Polydora sp. and others survived in ballast water of ships sampled in German ports after long voyages from Chile, Vancouver, South Korea and Baltimore (Gollasch 1996); however, some spionid taxa are well-known as particularly tolerant of pollution and their larvae may also be resistant (Behrens et al. 2005). The Marine Invasions Research Laboratory (Smithsonian Environmental Research Center former homepage [http://www.serc.si.edu]), in an internet article accessed ca. 2008, defined short distances as voyages of less than 10 days, in which survival of the zooplankton in ballast water is unpredictable, whereas long voyages of 16-22 days showed large declines in survivorship. If a serpulid larva could survive the journey in ballast water, it could possibly also survive the physiological stress of being discharged in a new environment, but, as noted above, there remains the matter of a threshold population size for a population to be established.

6c. Dispersal of the sessile adult stage. Passive transport of the sessile stage could be accomplished over short distances by rafting on flotsam or as an epibiont on a migrating animal, e.g., on a swimming decapod (Galil \& Lützen 1998) or on a sea-turtle (Kitsos et al. 2005). Long-distance anthropogenic transport of sessile serpulid tubeworms on ship hulls has been a recognized phenomenon for many years (Zibrowius 1973a, 2002 [see below]).

A particularly relevant illustration of hull fouling was provided by an examination of the aircraft carrier "Foch" (Zibrowius 1979). Carrying eleven serpulid taxa, the "Foch" arrived at the Mediterranean port of Toulon after spending 7 months in the western Indian Ocean (Djibouti, Mayotte, La Réunion, Colombo, etc.) having passed through the Suez Canal in both directions. The serpulids removed from the hull in Toulon included three Indo-West-Pacific species not reported from the Suez Canal, Hydroides albiceps, and the two Lessepsian migrants, H. minax and $H$. operculatus, along with a fourth taxon reported as Spirobranchus polytrema-a widely-distributed common Mediterranean fouling species in the western and eastern Mediterranean, though quite rare along the Levant coast (Ben-Eliahu \& Fiege 1996: 36, Ben-Eliahu \& Payiatas 1999). (H.A. ten Hove considers the Indo-West-Pacific records under this name as a mix up of "definitely two distinct species", or, possibly, S. polytrema settled on the "Foch" in the Mediterranean?) The remaining taxa on the ship were all known from the Suez Canal, the Lessepsian migrants, Hydroides heterocerus, H. homoceros, Spirobranchus tetraceros and Pomatoleios kraussii, along with H. steinitzi, H. diramphus, and H. elegans. (Zibrowius's nominal taxon, Hydroides grubei Pillai, 1965, an undeterminable juvenile opercular stage, is excluded from the list of taxa carried by the "Foch" [Zibrowius 1979b—see Systematic Section under H. priscus]). The Hydroides homoceros specimens on the "Foch" belonged to the opercular form with two pairs of lateral spinules on the marginal radii (H. Zibrowius, pers. comm.), rather than the "single-anchor" form characteristic of the Suez Canal and the Israeli coast populations, supporting the inference that this taxon had settled on the "Foch" in the Indo-West-Pacific area.

That serpulids may survive very long distance travel as hull fouling is made plausible by the observation in Lewis et al. (2006: 669) that Pomatoceros minutus Rioja, 1941 and Hydroides brachyacanthus survived a trans-Pacific voyage on a tall ship (square-rigger) from Acapulco, Mexico to Sydney, Australia. In 
considering dispersal by the adult stage, Minchin \& Gollasch's (2003) theory of triggering reproduction suggests the mechanism for success: Exposure to different environmental conditions prevailing in ports (e.g., temperature, salinity) from those of the open sea triggers synchronized spawning of mature biofoulers on the ship hulls in a variety of taxa. Breaking open serpulid tubes is known to trigger spawning (indeed, ever since Strathmann 1987: 145, breaking open serpulid tubes appears to be the standard method of obtaining gametes for reproductive studies, e.g., Unabia \& Hadfield 1999: 56, Toonen \& Pawlik 2001: 105, Gopalakrishnan et al. 2007: 172). Thus, cleaning a ship's hull of dense serpulid fouling in a harbour dock might similarly trigger mass spawning, facilitating the attainment of a critical population size in the area of the port. Moreover, when ships are berthed in a harbour (and stay a while), the likelihood of reproduction and spawning is greater than when the ship is moving quickly through the canal, thus, increasing the possibility of exceeding critical population sizes for establishing new populations (Ghobashy et al. 1980: 90). Interestingly, the last authors presented this issue from the point of view of the ships: In the 1980s, ships passing through the Canal would stop for several hours in Port Said, the Bitter Lakes, and the Suez Bay, providing an opportunity for the ship "to become infected". Fortunately for the ships, they did not usually stop in Lake Timsah, the "most fouled area of the Canal", which greatly reduced the likelihood of "infection" by biofoulers (Ghobashy et al. 1980).

In addition to actually finding serpulids on ship hulls, several different kinds of indirect evidence support the inference of ship translocation: 1) reports from islands and knowledge of currents; 2) distribution studies; 3) disjunctive aggregations of the alien species in proximity to ports; and, 4) morphological evidence.

1) The two Lessepsian migrants with the most records from within the Suez Canal, Spirobranchus tetraceros and Hydroides heterocerus, appeared to have the widest and the earliest Levant distributions (Table 7). Records of these taxa from two distant islands, a 1970 record of S. tetraceros from Rhodes (Ben-Eliahu 1991b) and records of both these species from Famagusta, Cyprus in 1998 (H. Zibrowius pers. comm.), are attributed to translocation on ship hulls because there is no current connecting the Levant coast and these islands that would support natural larval transport or rafting on flotsam (S. Brenner, pers. comm.).

2) The distribution of the Lessepsian migrant, Hydroides minax, in the Levant Basin, is similarly suggestive of ship-hull translocation. In 1978, its report from the Lebanese coast (Zibrowius \& Bitar 1981), precipitated an unsuccessful search for it in samples from the Israeli coast dating from the 1960s and 1970s (i.e., review of the extensive material deposited in the Israel National Natural History Collections in the Hebrew University of Jerusalem and at Tel Aviv University). Although lacking in these samples, by 1990, when Ben-Eliahu and ten Hove sampled the length of the Israeli coast, it had become common on concretionary and rocky substrates between 1-18 m from the northern Israeli border to Caesarea (Ben-Eliahu $\&$ ten Hove 1992). To achieve this distribution, H. minax must have overcome the counter-clockwise current prevailing along the Levant coast, and carried out a step-wise southward migration.

H.K. Mienis (pers. comm.) has documented successful dispersal against the local counter-clockwise current of three gastropod taxa clearly originating in harbour fouling: (1) Strombidae: Conomurex persicus (Swainson) (reported as Strombus decorus persicus), origin Persian (Arabian) Gulf, 1979 record from Turkey, 1983 record from northern Israel; (2) Muricidae: Ergalatax junionae Houart, origin Persian Gulf, 1995 records from Turkey, 2004 record from northern Israel (Akhziv-Rosh HaNiqra); and (3) Muricidae: Thais sacellum (Gmelin), origin Persian Gulf-India, 2003 record from Beirut Harbour, Lebanon; 2004 record from northern Israel (Akhziv-Rosh HaNiqra).

C. Crossland's collecting of Hydroides dipoma (as Eupomatus spinosus) at Suez in 1904 / 5 is presumably another outcome of ship-translocation. When Zibrowius (1973b: 33-35) synonymised these taxa, he found that, although there were several records of H. dipoma from the western coast of Africa, there were none from the Indian Ocean or Red Sea except for Suez itself-a port location. Zibrowius (1973b) proposed two alternatives for this disjunctive distribution - that the species is present, though unnoticed, along the east African coast, or that its Suez record was due to "accidental introduction on a ship-hull" (Zibrowius 1973b).

3) Finding disjunctive aggregations of the alien species only in proximity to ports supports inferences of their dispersal by ship fouling (Zibrowius 1991, Boudouresque 1994, Çinar 2006). This is illustrated by the dispersal of Hydroides elegans, $H$. diramphus and $H$. dianthus, the earliest alien serpulid polychaetes 
recognized in the Mediterranean, collected together as early as 1888 from harbour fouling in Naples (Zibrowius 1991); they must have arrived even earlier on slow vessels with wooden hulls (Zibrowius 1973a). Ships with sails, often becalmed, are known to have been effective vectors of biofouling (Zibrowius 1973a, Carlton 1985, Carlton \& Hodder 1995, Gaut 2001). Although the species are widely distributed in Mediterranean harbours and coastal lagoons, they are not found in natural habitats of full marine salinity, except in areas adjacent to harbours (Zibrowius 1973a). The many Israeli samples of $H$. elegans and $H$. diramphus have similarly been sampled from or near harbour-port milieus.

Ship-borne dispersal is likely to account also for the presence of Hydroides cf. brachyacanthus and $H$. operculatus along the Levant coast of Turkey. Although Çinar (2006) reported from the Levant coast of Turkey all 7 alien taxa considered by us to be Lessepsian migrants, he specifically designated these taxa as possibly ship-translocated because Red Sea and Suez Canal records are lacking for them. This argument has been buttressed for $H$. operculatus by Çinar's comparison of its density in samples adjacent to and far from Mersin Harbour. His results showed that, while there were great densities of H. operculatus in Mersin Harbour, it was nearly absent in Iskenderun Bay (Çinar 2006: 229). The focus of the Turkish distribution would thus be Mersin Harbour and the ship-translocated species would disperse from there into other parts of the Turkish Levant Sea.

4) Morphological evidence supports the hypothesis of ship-translocation for the Turkish population of Hydroides homoceros; the population has an opercular form with a markedly disjunctive distribution (i.e., "spur-tipped-anchor-shaped" marginal radii [Fig. 12 C; Çinar 2006, figs 4 d, e]), a form present in the Persian (Arabian) Gulf (ten Hove, 1970a), but not found in the Suez Canal or in the Israeli Lessepsian migrant population. H.K. Mienis pointed out that ship-borne transport of Indo-West-Pacific taxa to the Turkish coast is facilitated by Mersin Port's being a routine port of call for tankers carrying Arabian oil to Turkey (H.K. Mienis, pers. comm.).

Following Çinar's report of the cadre of alien Lessepsian migrant serpulids from the Levant coast of Turkey (Çinar 2006), areas that should be monitored for possible range expansion appear to be the Aegean and the Ionian Seas. Spirobranchus tetraceros had previously been collected on Rhodes near the Aegean coast of Turkey by the "Biota" project (Ben-Eliahu 1991). However, Knight-Jones et al.'s (1991) sampling along the Aegean coast of Turkey in 1987 did not "produce" additional new records of Lessepsian serpulids, nor did Bianchi \& Morri's (2000) more recent sampling of the Island of Milos. The former sampling should have been sufficiently shallow to collect some migrants, if present, while the latter sampling was mostly deeper and other migrant taxa could have been excluded (Ben-Eliahu \& ten Hove 1992, Ben-Eliahu \& Fiege 1996). The Mediterranean African coast remains an "unknown", so far as serpulids and other polychaetes are concerned. A recent report of Lessepsian migrant fishes off the coast of Libya (Shakman \& Kinzelbach 2008) suggests that the north African coast merits further exploration.

\section{A comparison between the Lessepsian migrant taxa and other members of the biofouling assemblage vis-à-vis resistance to environmental change}

7a. Tolerance to differing salinities as indicated by presence in different parts of the Suez Canal

(Fig. 1, Table 1). Presence in both the Great Bitter Lakes and Lake Timsah attests to osmotic tolerance: Three of the four "high-probability" migrants, Hydroides heterocerus, Pomatoleios kraussii and Spirobranchus tetraceros (though not $H$. homoceros) have records both from the Bitter Lakes and from Lake Timsah and to the north. This is also true of $H$. steinitzi, and that is the reason it is considered to be a potential Lessepsian migrant (Ben-Eliahu 1991b). The presence of Hydroides diramphus and H. elegans throughout the canal in 1988 (Selim 1997b) is also indicative of osmo-tolerance. Ghobashy et al. (1986: 325) noted that both could withstand great differences in salinity, and flourish in 30-40\% in Lake Timsah in temperatures between 25$30{ }^{\circ} \mathrm{C}$.

Salinity values for the Canal (in 1977-1979) ranged between: Southern Canal, 41.9-50.3\%o, winter, at Shalloufa; spring, at Kabrit, respectively; Lake Timsah between 28-40.3\%o, winter and summer, respectively 
(Ghobashy \& El-Komi 1981 b, a). However, Shalla et al. (1995) gave salinities at Lake Timsah for 1988-89 as $10-45 \%$, surface, and $45 \%$, bottom; the low Lake Timsah salinity value reflects the input in the surface waters from the Isma'iliya freshwater canal. The salinity values of Emara \& Belal (2004) differed somewhat (autumn 2002-summer 2003) in the southern Canal (36.1-41.8\%o, winter, Kabrit to summer, Shandora, respectively) with Lake Timsah surface salinity $(2 \mathrm{~m})$ ranging between 19.3-38.0\%o, autumn and winter, respectively.

Ghobashy (1984: 41) mentioned the high abundance of Hydroides elegans in Alexandria Harbour in both pre-and post-Aswan Dam salinity conditions, as indicative of a marked euryhaline capacity of this fouling species. He noted, however, that its populations had increased following the greater stabilization of the salinity once the Aswan Dam was built and the impact of the Nile flood was reduced (Fig. 1). Ghobashy et al. (1986: 325) noted that Pomatoleios kraussii is stenohaline, a factor that had then restricted its distribution. Later, it expanded its distribution from the south-western part of Lake Timsah to the Bitter Lakes (see Systematic Section). Spirobranchus tetraceros was also considered as intolerant of the variation of salinity in Lake Timsah although tolerant of turbid conditions (Ghobashy et al. 1986: 326; the latter confirmed by Frank $\&$ ten Hove 1992).

7b. Differential survival of Suez Canal fouling on the trip from the Suez Canal to the North Sea. Samples of the biofouling aggregation taken from the ship, "Münsterland" in the Great Bitter Lake were compared with those taken at the Bremerhaven Hapag-Lloyd dry dock (North Sea) following its 18-day passage and its exposure to the differing salinities in traversing the Suez Canal, the Mediterranean, the North Sea, up the Elbe estuary (estuarine-riverine conditions) to Hamburg and again via the Elbe, North Sea to Bremerhaven (P. Maas, pers. comm.). That the journey had impacted differently on different taxa was evident. Many of the specimens, including molluscs, bryozoans and tunicates, suffered trauma, e.g., Spondylus spinosus shells were empty although most of the Brachiodontes pharaonis shells in the preserved samples still contained mollusc bodies. The serpulid tubes were mostly empty and tubes of the smaller taxa, Salmacina incrustans and Josephella marenzelleri, were missing. Even Hydroides elegans appeared to be lacking. However, four species had decaying but still operculate worms in their tubes, Hydroides diramphus, and the Lessepsian migrants, H. heterocerus (several large specimens), Spirobranchus tetraceros and H. homoceros, in descending order of abundance (App. Table 2D'). Finding decaying bodies is indicative of these worms having survived longer than the others and could indicate a greater tolerance to the changes in salinity and temperature conditions encountered during the journey (although, possibly larger worms with more body mass will rot and dissolve more slowly). However, we consider that the inability to collect food while the ship was in motion may have contributed to the trauma. Interestingly, amphipods found in the vials of the Bremerhaven samples (presumably attracted by the decaying bodies of the serpulids) proved to belong to a freshwater taxon (D. Bellan-Santini, pers. comm.), reflecting the effect of the passage through the Elbe and / or the Weser Rivers (see above).

\section{Temperature and reproduction (Appendix Table 5).}

Ben-Tuvia considered temperature to be among the most important factors influencing the distribution of fishes. "A successful immigration depends not only on the passage of the adults, but on their ability to adjust their reproductive cycle to the new ecological conditions" (Ben-Tuvia 1973). Minimum winter temperatures must be above their lethal limits, and fish species that reproduced through the year in their tropical habitats must shift their reproductive season to late spring and summer in the Levant Mediterranean to ensure that temperatures would be high enough for the reproductive processes and development of eggs to take place and that appropriate food for the larvae would be available (Ben-Tuvia 1973). Golani (1990) confirmed this reproductive shift hypothesis for species belonging to several families of fishes.

As indicated above, eastern Mediterranean surface temperatures are below the minimum of the Gulf of Suez (Fig. 1, footnotes 2, 9). Temperatures in the Gulf of Suez are the lowest in the Red Sea area; it is the northern-most water body where reef-building corals are found. Oren (1970: 226) noted that the temperatures 
in the Gulf of Suez do not fall below $18^{\circ} \mathrm{C}$, however, Por (1972: 114, 1978: 57) reported water temperatures of $15-16{ }^{\circ} \mathrm{C}$ and even lower in some inshore lagoons (Fig. 1, footnote 9). The annual temperature range in the Gulf of Suez is greater than that in the south Red Sea (Ben-Tuvia 1973; Fig. 1, footnote 10).

Suez Canal monthly mean temperatures were noted as ranging between $16-30{ }^{\circ} \mathrm{C}$ by Ghobashy \& ElKomi (1981b: 180, II.1977-I.1979; Fig. 1, footnote 7). Slightly higher figures-Lake Timsah, $16.5-32{ }^{\circ} \mathrm{C}$ and $17.5-31.5^{\circ} \mathrm{C}$ for the southern Canal [Kabrit]) —were given by Emara \& Belal (2004, autumn 2002-summer 2003).

The presence of the 7 serpulid migrants in the Levant Basin, Israel (Ben-Eliahu \& ten Hove 1992) and Turkey (Çinar 2006) shows that they have overcome not only the problem of surviving the changed conditions but also of reproducing - the most sensitive stage of their life cycle-under the atypical environmental conditions (Thorson 1950, Gunter 1957) of the Levant Mediterranean Sea. To determine whether or not a shift in the reproductive period occurs in Lessepsian migrant serpulid tubeworms, the reproductive period in the Indo-West-Pacific source areas must be compared with that in the Mediterranean target area. Concerning tubeworms, "Settlement of serpulids living in temperate climates is seasonal and generally the length of the settlement period coincides with the length of the reproductive period. In tropical species that reproduce throughout the entire year, settlement also takes place throughout the entire year. However, the intensity of the settlement period may vary significantly within the reproductive period and may show one or more peaks as seen on settlement on submerged panels" (Kupriyanova et al. 2001: 51).

Only two Lessepsian migrants figured in the Suez Canal fouling literature, Spirobranchus tetraceros (sometimes as "Pomatoceros triqueter", see Section 3 above) and Pomatoleios kraussii. The available information on reproduction of Pomatoleios kraussii is from biofouling studies in western Japan, Australia, Hawaii, and Kuwait (Miura \& Kajihara 1984: 345, Straughan 1969, and Mohammad 1975) and from the Suez Canal (Ghobashy et al. 1986, 1990, Emara \& Belal 2004 [see Table 10]). A seasonal pattern emerges in which breeding of Pomatoleios kraussii (defined as greatest settlement on seasonal fouling panels) stops at cold temperatures and is also inhibited by hot temperatures (see Table 10). Mohammad (1975: 12) considered that Pomatoleios kraussii “... conforms to a different type of seasonal breeding behaviour in different parts of its range" and Miura \& Kajihara (1984: 352) stated similarly that, "The reproductive season may be shortened at the northern and southern extremities of its (circumtropical) distribution". Çinar (2006: 235) found juveniles in a Pomatoleios kraussii population sampled quantitatively in September 2005. He suggested that Pomatoleios kraussii reproduced along the Levant coast in the summer (up to now there are no Turkish data from other seasons).

No data have been found concerning settlement of Spirobranchus tetraceros in its tropical source areas. However, there are some data on seasonal settlement from Alexandria in which a possible Lessepsian migrant serpulid with a "triangular" tube may figure ("Pomatoceros triqueter" sensu El-Komi 1991a, b, and 1992 (see Appendix Table 5). More recently, Selim et al. (2005) reported a long spawning period for S. tetraceros, from late May to October. The results appear to show inconsistencies in peaks of settlement. There is insufficient information to evaluate whether a reproductive shift has taken place in the migrant population of Spirobranchus tetraceros or indeed whether El-Komi's results might not refer to two different species with triangular tubes, Spirobranchus tetraceros, and / or Pomatoleios kraussii (H. Zibrowius, pers. comm.). This is a valid question as Suez Canal serpulids labelled "Pomatoceros triqueter" sent to H.A. ten Hove in 1984 for determination belonged to both these species (see Systematic Section).

\section{Hard substrates—a prerequisite for serpulid settlement (Table 8)}

With the exception of the free living Ditrupa spp., which only need a sand grain for initial settling (Charles et al. 2003: 440), serpulids require hard substrates for settlement and their post-settlement sessile life cycle. Where the bottom substrate is soft (as it is in the Suez Canal), molluscs can serve as hard substrates. Altogether, more than 180 mollusc taxa have been collected in the Canal, of which 149 were of Red Sea Indo-West-Pacific origin and, of these, 46 are themselves Lessepsian migrants (H.K. Mienis, pers. comm.). Although there are hard concrete walls and piers in the Canal, some taxa may find them less attractive for 
settlement than "natural" mollusc substrates, and the same is true of the various artificial substrates, e.g., polystyrene plates, that have replaced asbestos plates in settlement research (El-Komi et al. 1998: 12).

The canal could even "select" for species with mollusc preference, as the floor of the Canal is covered with mollusc shells (Ghobashy et al. 1980: 90). Ben-Eliahu (1991b) suggested that a preference for settlement on molluscs facilitates step-wise settlement between the Mediterranean mouth of the canal, the adjacent sandy coast where hard bottoms are lacking, and the first rocky coast, $240 \mathrm{~km}$ to the north (Palmahim Beach just south of Tel Aviv). However, also bridging this distance are the boulders of the breakwaters and the concrete piers of Gaza, Ashqelon and Ashdod Ports. Until now, comparatively little sampling effort has been directed to these breakwaters. However, Pomatoleios kraussii was found on the Ashdod breakwater (in 1969), and in other Ashdod locations, while Spirobranchus tetraceros was collected on fouling panels set in Ashdod Port (in 1974 and 1985 [Ben-Eliahu, unpublished data]). More recently, Mienis et al. (1993) found rocky outcrops in Haifa Bay at 15-18 m depth to be completely covered with the Lessepsian migrant bivalves, Chama pacifica (Broderip) and Spondylus spinosus, with these molluscs encrusted by the serpulid migrants, Hydroides minax and Spirobranchus tetraceros (as well as by H. elegans). In contrast, the population of Pinctada radiata, a migrant bivalve "exploited" as a substrate for serpulid settlement (Table 8), declined with increasing temperature in Haifa Bay (Brit 2000). Examination of natural hard substrates, e.g., boulders and molluscs near the northern mouth of the Canal, e.g., from the vicinity of Alexandria, would very likely lead to finding both recognized and as yet unrecognised Lessepsian migrant taxa.

Do Lessepsian serpulid tubeworms prefer Lessepsian mollusc substrates? Are the specific identity and the biogeographical origin of the molluscs relevant to substrate selection by the Lessepsian serpulid larvae? In our catalogue of serpulid samples from the Levant Coast (to 2009), the migrant bivalve, Pinctada radiata, has more records for Lessepsian migrant serpulids than any other mollusc (22 records). Sharing second place in the number of records of Lessepsian migrant serpulids were the Lessepsian bivalve, Spondylus spinosus, and an indigenous Mediterranean gastropod, Stramonita haemastoma (7 records each), followed by another Lessepsian bivalve, Malvufundus regulus (3 records). Other Lessepsian migrant molluscs bearing Lessepsian migrant serpulids include the gastropods, Thais lacera (Born) [synonym, Thais carinifera (Lamarck)], and Diodora ruppellii (Sowerby)* ${ }^{1}$. Unfortunately, data on substrates from which they were collected were lacking for up to $30 \%$ of the Lessepsian migrant serpulid samples (Table 8). H.K. Mienis (pers. comm.) has pointed out that shells of some bivalve and gastropod species, both Lessepsian migrants and indigenous Mediterranean species, are never covered with epibionts while shells of other species always are. This may be a matter of texture or colour of the shell, or of position on the sea floor, i.e., on the surface or buried within it. This is another question that should eventually be addressed experimentally as the present data cannot give us conclusive results using a statistical approach. Note that four of the Lessepsian migrant serpulids, Hydroides heterocerus, H. minax, and H. operculatus and, particularly, Spirobranchus tetraceros, have even more records from plant coralligène and stones than from molluscs, and the last species, almost as many records from (asbestos) fouling panels as from natural coralligène and stones $(\mathrm{N}=19$ and 23 records, respectively [Table 8]).

\section{Characteristics of Lessepsian migrant serpulids}

The present results illustrate two clearly defined characteristics of the Lessepsian migrants, planktotrophy, tolerance of osmotic change and plasticity in choice of substrates for settlement. Other studies have discussed $r$-strategy as a characteristic of successful migrants (see Introduction); regretfully, the present study has little to contribute in this important area. It is interesting how well F.D. Por's characterization of migrants transported by ship-vectors: “...ecological valences which enable a marine organism to become an adventive diaspore on a ship's hull, a fouling-cosmopolite, ... an animal with a sessile life, a nonspecific filter feeder, very adaptive in its reproduction requirements, euryhaline; resistant to current, and resistant to pollutants" (Por 1978: 2) appears indeed to fit Spirobranchus tetraceros, a very "successful" Lessepsian migrant serpulid. 


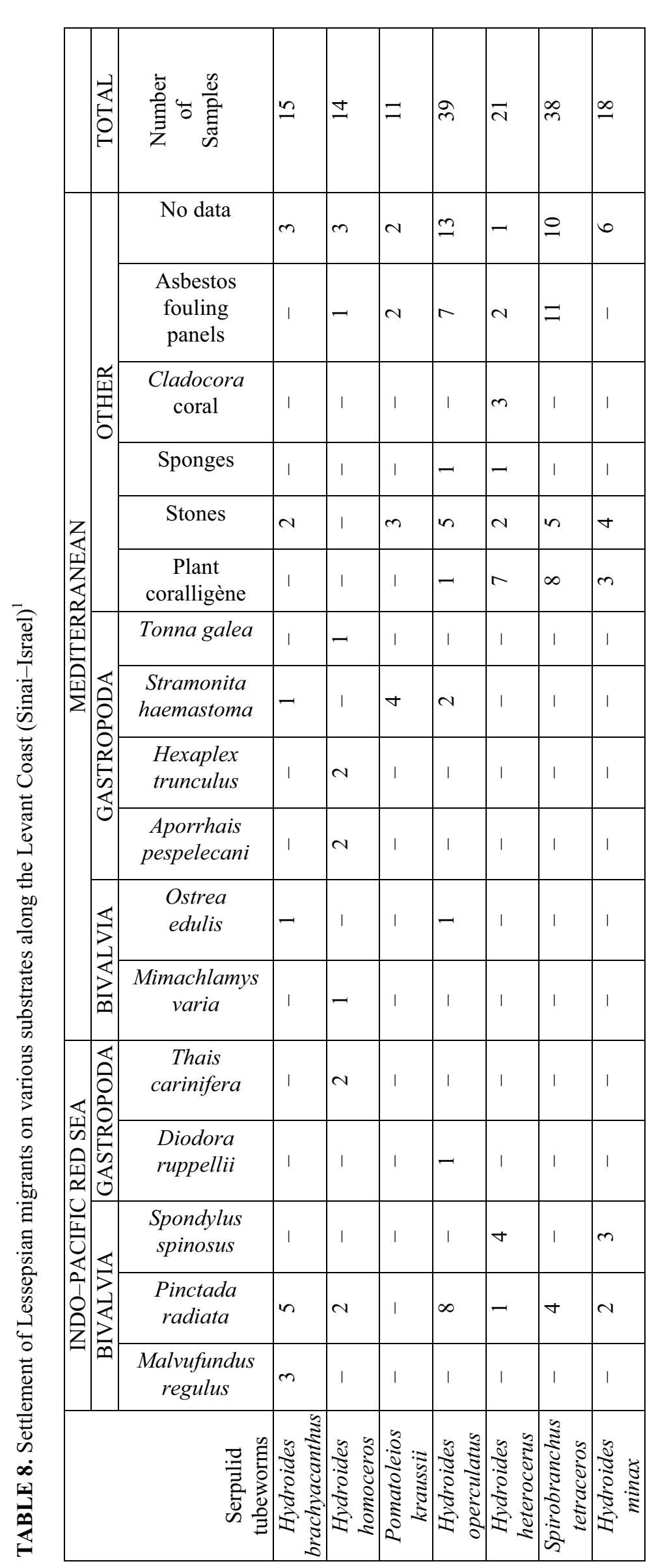

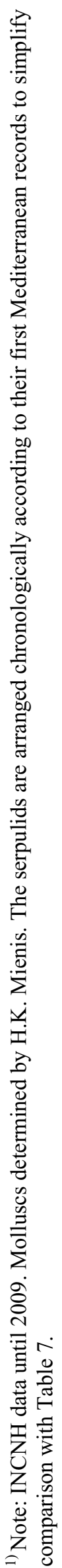




\section{The species richness of the Suez Canal with respect to the adjacent Red Sea-Gulf of Suez}

The Gulf of Suez is the nearest source for propagules - a staging area-for the southern part of the Suez Canal (Por 1997, Golani 1999). Our compiled list of serpulids for the Red Sea areas presently numbers ca. 55 taxa, 37 for the Red Sea proper, 43 for the Gulf of Aqaba, and ca. 21 for the Gulf of Suez, respectively. In some measure, the numbers reflect the difference in the sampling intensity between these bodies, with much less sampling having been carried out in the Gulf of Suez than the Gulf of Aqaba or even the Red Sea proper (Por et al. 1972, ten Hove et al. 2006). Almost $50 \%$ of these taxa are undescribed, or are just preliminarily identified, or belong to complexes of species of which all identifications should be checked after revision (ten Hove et al. 2006).

The low species richness of the Suez Canal fauna is indubitably related to the low diversity of the adjacent Gulf of Suez fauna (Por 1978, Heck 1979) as well as to the turbidity and salinity conditions prevailing within the canal (Por 1978). As already noted above, Ghobashy et al. (1980: 89) also emphasized that the strong winds from the Gulf of Suez, as well as the tidal currents, cause turbidity and sedimentation, limiting the development of coral habitats (along with the low temperature [El-Komi 1996]), scouring the substrates, and reducing settlement, conditions generally inimical to filter-feeders (Fishelson 1971: 114, Por 1978, Thorson 1971, El-Komi 1996, 1998). These conditions similarly reduce settlement in the southern part of the Suez Canal. The shallow Gulf of Suez is also subject to greater fluctuations in temperature than the deeper Gulf of Aqaba (Golani 1990) and has very low winter temperatures of $15-16{ }^{\circ} \mathrm{C}$ (Por 1972: 114). Moreover, in past decades, oil pollution has been heavy in the northern Gulf of Suez (Por 1972: 114, 1978: 62, El-Komi 1996). Contributing to the low number of serpulid taxa (and other coral-associated taxa) in the Gulf of Suez is the restriction of fringing coral reefs habitats to a small blotch of the southern shore of the Sinai Peninsula from Ras Muhammad to Et Tur, 70-80 km to the north (El-Komi 1996: 8). As noted above, the number of taxa in the Suez Canal is at least 16 of which at least six are not Red Sea marine taxa (see Section 3 of the discussion). Only 11 of the compiled ca. 55 serpulid taxa of the Red Sea and only 8 of the 21 Gulf of Suez taxa have been reported from the Suez Canal [Table 7]).

One of the questions relating to selection of fauna by the Canal, i.e., which taxa do not enter the canal, is the effect of depth (Por 1978, Galil \& Zenetos 2002)-i.e., that the shallow Canal selects for shallow-water species. Ordering the 21 serpulid taxa from the Gulf of Suez into the two groups, taxa reported vs. taxa not reported from the Suez Canal, we compared first their depth distributions to evaluate whether there is any significant difference between these groups as regards depth. Regrettably, the number of samples from the Gulf of Suez is presently too small to enable a proper comparison. Nonetheless, we had the definite impression that the group of taxa that did not enter the canal had somewhat greater depth distributions (note that deeper-water taxa in the Gulf of Aqaba, e.g., Serpula crenata, Hydroides fuscus, and even the shallower Spirobranchus latiscapus that is common in the Gulf of Aqaba, appear to be lacking in the Gulf of Suez [INCNH data]).

\section{The sources of the Lessepsian migrant populations}

Safriel \& Ritte (1985) found that a common feature of all colonization preceded by migration through a narrow passage is the small size of the founding populations, and this finding was supported by Achituv \& Sher (1991) for Asterina burtoni Gray, and, in the serpulids, we find indications of this in morphology of the operculum, particularly in the Lessepsian migrant populations of H. homoceros, that resemble those found in the Suez Canal (Figs 8 and 12, respectively).

Even assuming that the Levant Lessepsian populations were established by propagules originating in the Suez Canal, the source populations in the Canal presumably themselves reflect different colonization events of the Canal and possibly different genetic backgrounds of the colonizing taxa. As already noted, the Levant populations could be a product of step-wise events deriving from a single colonization event, or from repeated events, or from dispersal from ballast-water or ship hulls. Today's biochemical genetics methods can substantiate whether populations originate from single-event or multiple-event colonization. Unfortunately, samples of the previous 50 years were usually fixed in formaldehyde, denaturing the material and presently excluding them (at least for now) from being suitable candidates for these modern biochemical techniques. 
Schander \& Halanych (2003) offer hopeful developments regarding this problem. In future, the subject of genetic stocks of source and migrant populations is one that can be better elucidated (e.g., Golani \& Ritte 1999, Bucciarelli et al. 2002, Hassan et al. 2003, Shefer et al. 2004, Hassan \& Bonhomme 2005, Azzuro et al. 2006).

Morphological comparisons of the opercula in populations of Hydroides heterocerus from the Suez Canal and from the Mediterranean Lessepsian migrant population are intended, although preliminary analysis of the number of opercular spines (Figs 8A-F) did not show any significant difference between the Canal and the Lessepsian migrant populations (t-test, $p=0.198$ ). As already pointed out, there is marked morphological evidence in Hydroides homoceros populations confirming Safriel \& Ritte's (1985) proposition, that a common feature of all colonization preceded by migration through a narrow passage is the small size of the founding populations. While there are several forms in the marginal radii of the operculum in populations from the Persian (Arabian) Gulf and the south Red Sea (e.g., Figs 12B, C, D and intermediate forms) only one form was found in the Suez Canal population (Figs 12A, D) and that same form is present in the Lessepsian migrant populations found off the coast of Israel (Fig. 12E); the single Gulf of Suez specimen in the HUJ collections has this form as well.

A preliminary checklist of Red Sea molluscs provides some indication of difference-of a faunal breakbetween the southern and northern Red Sea. It cites 1,766 mollusc taxa for the Red Sea, of which 36 of them are cited as present only in the southern end of the Red Sea, 3 as only present in the northern Red Sea and one as only present in the Gulf of Suez (Dekker \& Orlin 2000). Thus it is quite possible that a reduction in the number of Hydroides homoceros forms similarly takes place between the southern and northern Red Sea or even in the Gulf of Suez. Unfortunately, we presently lack sufficient data on both the Red Sea and the Gulf of Suez populations to draw any firm conclusions.

\section{Conclusions}

There is a need for thorough monitoring of the Suez Canal, and the adjacent coasts, including the North African coast, the Levant coast, and westward, particularly as the Suez Canal is a conduit for taxa that may be alien invasive species in the Mediterranean, as seen in the replacement of Hydroides elegans in the Eastern Harbour, Alexandria, by Spirobranchus tetraceros (see above). The last survey for Serpulidae along the Mediterranean coast of Israel, carried out by ten Hove and Ben-Eliahu in 1990 found an increase in both numbers and frequency of the Lessepsian migrants as compared with only ca. 15 years earlier (Ben-Eliahu \& ten Hove 1992). This also appears to be true of recent sampling along the Lebanese coast (Zibrowius \& Bitar 2003). Some Lessepsian migrant serpulids were recently found off the Turkish side of Cyprus, where in previous years they appeared to be lacking (Ben-Eliahu \& Payiatas 1999; H. Zibrowius, pers. comm.). The deepening of the canal (Al Ahram weekly, 2000, no. 497) would increase the flow of water through it and effectively increase the possibility of step-wise migration of taxa (Galil \& Zenetos 2002). Thus, at this very moment, unknown Lessepsian migrants may be establishing populations in the Mediterranean, particularly in the littoral waters between 0-50 m (Ben-Eliahu \& Fiege 1996). The need for monitoring is made more urgent by the present phenomenon of global warming - "tropicalisation of the Mediterranean"-with a dramatic influx of tropical taxa into the Mediterranean anticipated as the almost certain consequence (Por 2009, 2010), providing a renewed opportunity to observe the process of colonization by invasive species.

The prominent declarations of the importance of biodiversity and intentions to maintain it (e.g., by various action plans under United Nations and other auspices), suggest that a new widespread sampling program to monitor fauna along the Gulf of Suez, the Suez Canal, and the adjacent Red Sea and Levant coasts is timely; and when finally undertaken it should be carried out with quantitative as well as qualitative sampling techniques, and genetic population analyses.

Spirobranchus tetraceros is an excellent taxon to carry out a comparative study of reproductive season in the Red Sea and Lessepsian migrant population; Selim et al.'s (2005) excellent study of reproduction of the population in Alexandria (Abu Kir) could easily be compared with a study carried out in the Gulf of Aqaba 
(e.g., in the sheltered Venezia Lagoon, Elat) to evaluate whether a shift in reproductive period has taken place in the Lessepsian migrant population. Similarly, the question of whether Lessepsian migrant serpulids prefer Lessepsian migrant mollusc substrates to indigenous Mediterranean ones is one that could easily be addressed experimentally.

\section{Acknowledgements}

The Ben-Gurion University of the Negev and U.N. Safriel are thanked for enabling M.N. Ben-Eliahu's participation in the 1973 Hebrew University expedition to the Suez Canal. Y. Eytam is thanked for samples of benthos from the Suez Canal collected in 1973. J.P. Taasen and the late H. Brattström (University of Bergen, Norway) contributed their invaluable samples of the biofouling aggregation on the "Yellow Fleet" ships trapped in the Great Bitter Lake to the Section of Invertebrates of the National Natural History Collections at the Hebrew University. Their expedition, in January 1975, was funded by the Norwegian Council for Research and Humanities. Twenty-six years later, in 2001, J.P. Taasen graciously responded to a request for particulars on their sampling. Details concerning the voyage of the "Münsterland" from the Suez Canal to the Hapag-Lloyd dry-dock in Bremerhaven were provided separately by D. Albers and P. Müller, and by P. Maass of the Hapag Lloyd-AG archives. D. Bellan-Santini kindly resolved the mystery of finding freshwater amphipods in the Bremerhaven serpulid samples. For permitting removal and loan of unstudied Suez Canal serpulid material encrusted on their collections of Mollusca, we thank K. Way of the Natural History Museum, London, where Mollusca of the Cambridge Expedition are deposited (visit to the Museum in 1986). For specimens collected in 1950 in the Great Bitter Lake by C. Beets, deposited at the National Natural History Museum Naturalis, Leiden, we thank E. Gittenberger and especially, J. Goud, and C. Fransen (visited in 2003). For loan of comparative specimens, we thank J.H. Bailey-Brock (University of Hawaii at Manoa); A. Cabrinovic and E. Sherlock (The Natural History Museum, London); S. Chambers and F. Ware (The National Museums of Scotland, Edinburgh); D. Fiege (Senckenberg Forschungsinstitut und Naturmuseum, Frankfurt a. M.); M. Goren, Y. Benayahu, A. Schlagmann and O. Kerman (The Tel Aviv University Zoological Museum); K. Fauchald and W. Moser (The National Museum of Natural History, Washington, D.C.); the late T. Holthe (The Norwegian Museum of Natural History); A.S.Y. Mackie (National Museum of Wales); R. Preece (The Cambridge University Zoological Museum); H. Sattmann (Naturhistorisches Museum Wien); and M. Sidall (The American Museum of Natural History, New York). For samples from the Mediterranean coast of Israel: A. Glazer (the Israel Electric Corporation); S. Hayat; B.S. Galil and G. Rilov (Israel Oceanographic and Limnological Research). N. Shashar provided live Salmacina samples from Elat, (the northern Gulf of Aqaba). M.N. Ben-Eliahu thanks K. Fauchald (The U.S. National Museum of Natural History, Washington, D.C.); J.D. George and A. Muir (The Natural History Museum, London); the late C.B. Goodhart (Cambridge University Museum); E. Lazo-Wassem (Yale University Peabody Museum) and M. Sidall (The American Museum of Natural History, New York) for study visits to their departments related to this paper. F.A. Abd-Elnaby (the National Institute of Oceanography and Fisheries, Alexandria), provided H.A. ten Hove with drawings and data on some specimens. For hunting up missing data on specimens and literature, we thank J. Pickering, E. Sherlock, A. Muir and T.G. Pillai (The Natural History Museum, London); M. Goonatilake (National Museum Colombo, Sri Lanka); E. Lazo-Wassem (Yale University Peabody Museum); L. Ward (The National Museum of Natural History, Washington), D. Fiege and F. Krupp (Senckenberg Forschungsinstitut und Naturmuseum, Frankfurt a. M.) and E. Apt (The Israel Oceanographic and Limnology Research, Ltd.). For partial support of this research, M.N. Ben-Eliahu thanks the Hebrew University-Smithsonian Institution joint project, "Biota of the Red Sea and eastern Mediterranean" and the Albert Alberman Fellowship of the Hebrew University. A British Council grant funded M.N. Ben-Eliahu's 1986 research at the Natural History Museum in London. We thank the Israel Academy of Sciences and Humanities for funding H.A. ten Hove's visit to Israel in 1990 and the Large Scale Facilities Grant of the European Community for M.N. Ben-Eliahu's 1999 visit to the Zoölogisch Museum Amsterdam. S. Brenner (Bar Ilan University) discussed Levant Basin currents; E. Spanier (Haifa University) provided sea temperature data for Haifa. We thank Mrs. E. Beglinger and Dr. D. Platvoet (Zoölogisch Museum Amsterdam) and Dr. E. Rahamim (the Hebrew University-Hadassah Medical School) for help with the SEM. At the Hebrew University of Jerusalem, E. Elah redrew Fig. 1; S. Halbreich inked in Figs 9 and 10; the late A. Neev photographed Fig. 3; D. Darom put finishing touches on some plates and was immensely helpful in facilitating M.N. Ben-Eliahu's first 
encounters with digital micro-photography. Thanks for that also go to J. Steinberg of Photoprisma, Jerusalem. For help with statistics, we thank U. Motro and N. Sivan. The Arabic abstract (Arabic with Latin names) was first translated by A. Simaan, later by O. Efrati, and again by B. Horvitz after the bilingual text, justified in opposite directions, became scrambled each time it was sent by e-mail; it was also scrambled in the proof. This transmission problem was solved by M. Komem of Orientation Ltd., Jerusalem, who translated, formatted the abstract in Zootaxa style, and prepared it as a photograph for insertion as a plate. R. Jaskow proofread parts of the manuscript. For many years, H.K. Mienis (the Hebrew University of Jerusalem and Tel Aviv University) has identified molluscs on which serpulids settled and unearthed obscure literature and information on the Israel National Natural History collections. Both he and D. Golani are thanked for many useful discussions, commenting on earlier drafts and for moral support. The late S. Ashkenazi, E. Lachman, N. Shashar, and F.D. Por commented on earlier drafts. M.N. Ben-Eliahu thanks Prof. F.D. Por for many years of continued encouragement and useful discussions. We both thank H. Zibrowius, Station Marine d'Endoume, for his extremely generous and invaluable contributions to our research on serpulids for more than 40 years. We thank him again, and Dr. E.K. Kupriyanova, for taking the trouble to review this long manuscript and for their helpful suggestions. We thank the University of Amsterdam (Dr. R.W.M. van Soest) and the National Collections of Natural History at the Hebrew University (Prof. A. Matthews) for supporting Open Access of this monograph.

\section{References}

Abd-Elnaby, F.A. (2009) New records of polychaetes from the south part of Suez Canal, Egypt. World Journal of Fish and Marine Sciences, 1 (1), 7-19.

Achituv, Y. (1999) Recent changes in the distribution of two species of Asterina (Echinodermata: Asteroidea) along the Mediterranean shore of Israel. Israel Journal of Zoology, 45 (1), 121-125.

Achituv, Y. \& Safriel, U.N. (1980) Euraphia depressa (Poli) (Crustacea, Cirripedia), a recent Mediterranean colonizer of the Suez Canal. Bulletin of Marine Science, 30 (3), 724-726.

Achituv, Y. \& Sher, E. (1991) Sexual reproduction and fission in the sea-star Asterina burtoni from the Mediterranean coast of Israel. Bulletin of Marine Science, 48, 670-678.

Agapow, P.-M., Bininda-Edmonds, O.R.P., Crandall, K.A., Gittleman, J.L., Mace, G.M., Marshall, J.C. \& Purvis, A. (2004) The impact of species concept on biodiversity studies. The Quarterly Revue of Biology, 79 (2), 161-179.

Agur, Z. \& Safriel, U.N. (1981) Why is the Mediterranean more readily colonized than the Red Sea by organisms using the Suez Canal as a passageway? Oecologia, 49, 359-361.

Al-Ahram (2000) Suez Canal Boost. Al-Ahram Weekly On-line, 31 August-6 September 2000, Issue no. 497, 1 Available from: http://weekly.ahram.org.eg/2000/497/eg10.htm /(2000).

Amoureux, L. (1976) Serpula (Paraserpula) israelitica, nouvelle espèce de Serpulidae (Annélides Polychètes) et une petite collection annélidienne de la Méditerranée orientale. Bulletin du Muséum d'Histoire Naturelle, Paris, (3) 404 (Zoologie 281), 1047-1059.

Amoureux, L. (1983) Note taxonomique et écologique sur une collection d'annélides polychètes du golfe d'Aqaba (Mer Rouge). Cahiers de Biologie Marine, 24 (3), 363-369.

Amoureux, L., Rullier, F. \& Fishelson, L. (1978) Systématique et écologie d'annélides polychètes de la presqu'île du Sinaï. Israel Journal of Zoology, 27, 57-163.

Aron, I.W. \& Smith, S.H. (1971): Ship canals and aquatic ecosystems. Science, 174, 13-20.

Augener, H. (1914) Polychaeta II: Sedentaria. In: Michaelsen, W. \& Hartmeyer, R. (Eds), Die Fauna Südwest-Australiens. Ergebnisse der Hamburger südwest-australischen Forschungsreise 1905, 5, 1, 170 pp.

Augener, H. (1934) Polychaeten aus den zoölogischen Museen von Leiden und Amsterdam. IV. Schluss. Zoölogische Mededeelingen uitgegeven door het Rijksmuseum van Natuurlijke Historie te Leiden, 17 (1/2), 67-160.

Avian, M., Spanier, E. \& Galil, B.S. (1995) Nematocysts of Rhopilema nomadica (Scyphozoa: Rhizostomeae), an immigrant jellyfish in the Eastern Mediterranean. Journal of Morphology, 224, 221-231.

Ayal, Y. (1978) Geographical distribution, ecological niche and the strategy of reproduction of the colonizer Cerithium scabridum Phil. (Gast.: Cerithiidae) as compared with those of some other sympatric non-colonizing congeneric species. Ph.D. dissertation, the Hebrew University of Jerusalem.

Ayal, Y. \& Safriel, U.N. (1989) Has the Indopacific gastropod Cerithium scabridum partly outcompeted the Mediterranean Cerithium rupestre? In: Spanier, E., Steinberger, Y. \& Luria, M. (Eds), Environmental Quality and Ecosystem Stability, Vol. IV-B. Jerusalem (Society for Ecology \& Environmental Quality Sciences (ISEEQS) Publication), pp. 169-176.

Azzuro, E., Golani, D., Bucciarelli, G., \& Bernardi, G. (2006) Genetics of the early stages of invasion of the Lessepsian rabbitfish Siganus luridus. Journal of Experimental Marine Biology and Ecology, 333, 190-201.

Bailey-Brock, J.H. (1976) Habitats of tubicolous polychaetes from the Hawaiian Islands. Pacific Science, 30, 69-81. 
Bailey-Brock, J.H. (1985) Polychaetes from Fijian Coral Reefs. Pacific Science, 39, 195-220.

Baird, W. (1865) Description of several new species and varieties of tubicolous annelides = Tribe Limivora of Grube, in the collection of the British Museum. I \& II. Journal of the Linnean Society, London (Zoology), 8, 10-22.

Baker, D.B. (2002) John Keast Lord: Materials for a Life. Backhuys Publishers, Leiden, 65 pp.

Banoub, M.W. (1961) Notes on the fouling of glass plates submerged in the Eastern Harbour, Alexandria, 1958. Alexandria Institute of Hydrobiology, Notes and Memoires, 64, 1-17.

Barash, A. \& Danin, Z. (1972) The Indo-Pacific species of Mollusca in the Mediterranean and notes on a collection from the Suez Canal. Israel Journal of Zoology, 21, 301-374.

Barracca, P.S. \& Thomas, W.D. (1975) Clearing the Suez. Ocean Industry: Engineering, Construction and Operations, March 1975, 1-7.

Bastida-Zavala, J.R. \& Hove, H.A. ten (2003a [2002]) Revision of Hydroides Gunnerus, 1768 (Polychaeta: Serpulidae) from the western Atlantic Region. Beaufortia, 52, 103-178.

Bastida-Zavala, J.R. \& Hove, H.A. ten (2003b) Revision of Hydroides Gunnerus, 1768 (Polychaeta: Serpulidae) from the eastern Pacific Region and Hawaii. Beaufortia, 53, 67-110.

Beets, C. (1953) Notes on dredging in the Great Bitter Lake of the Suez Canal. Zoölogische Mededeelingen uitgegeven door het Rijksmuseum van Natuurlijke Historie te Leiden, 32 (10), 97-106.

Behrens, H.L., Leppäkoski, E. \& Olenin, S. (2005) Ballast water risk assessment guidelines for the North Sea and Baltic Sea. N.T. Technical Report TR 587: 11-36, Appendix A 16 pp., Appendix BG 5 pp., Nordic Innovation Centre, Oslo. http://www.nordicinnovation.net/nordtestfiler/rep587.pdf (accessed 11, 2010).

Bellan, G. (1964) Contributions à l'étude systématique, bionomique et écologique des Annélides Polychètes de la Méditerranée. Recueil des Travaux de la Station Marine d'Endoume, 49 (33), 1-371.

Ben-Eliahu, M.N. (1970) Polychaete worms—what are they (in Hebrew). Fisheries and Fishbreeding in Israel, 5, $26-28$.

Ben-Eliahu, M.N. (1972a) A description of Hydroides steinitzi n. sp. (Polychaeta: Serpulidae) from the Suez Canal with remarks on the serpulid fauna of the canal. Israel Journal of Zoology, 21, 77-81.

Ben-Eliahu, M.N. (1972b) Littoral Polychaeta from Cyprus. Téthys, 4 (1), 85-94.

Ben-Eliahu, M.N. (1972c) Some Polychaeta Errantia from the Suez Canal. Israel Journal of Zoology, 21, $189-203$.

Ben-Eliahu, M.N. (1976) Polychaete cryptofauna from rims of similar intertidal vermetid reefs on the Mediterranean coast of Israel and in the Gulf of Elat: Serpulidae (Polychaeta Sedentaria). Israel Journal of Zoology, 25, $103-119$.

Ben-Eliahu, M.N. (1977) A comparison of species diversity of polychaete cryptofauna from similar intertidal vermetid reefs on the Mediterranean coast of Israel and in the Gulf of Elat. Ph.D. dissertation, the Hebrew University of Jerusalem, Jerusalem, Israel, $129 \mathrm{pp}$.

Ben-Eliahu, M.N. (1989) Lessepsian migration in Nereididae (Annelida: Polychaeta). Some case histories. In: Spanier, E., Steinberger, Y. \& Luria, M. (Eds), Environmental Quality and Ecosystem Stability, Vol. IV-B, Society for Ecology \& Environmental Quality Sciences (ISEEQS) Publication), Jerusalem, pp. 125-134.

Ben-Eliahu, M.N. (1991a) Nereididae of the Suez Canal-potential Lessepsian migrants? Bulletin of Marine Science, 48 (2), 318-329.

Ben-Eliahu, M.N. (1991b) Red Sea serpulids (Polychaeta) in the eastern Mediterranean. In: Petersen, M.E. \& Kirkegaard, J.B. (Eds), Systematics, Biology and Morphology of World Polychaeta. Proceedings of the $2^{\text {nd }}$ International Polychaete Conference, Copenhagen, 1986. Ophelia Supplement, 5, 515-528.

Ben-Eliahu, M.N. \& Dafni, J. (1979) A new reef-building serpulid genus and species from the Gulf of Elat and the Red Sea, with notes on some other gregarious tubeworms from Israeli waters. Israel Journal of Zoology, 28, 199-208.

Ben-Eliahu, M.N. \& Fiege, D. (1996) Serpulid tube-worms (Annelida: Polychaeta) of the central and eastern Mediterranean with particular attention to the Levant Basin. Senckenbergiana Maritima, 28 (1/3), 1-51.

Ben-Eliahu, M.N. \& Hove, H.A. ten (1989) Redescription of Rhodopsis pusilla Bush, 1905, a little known but widely distributed species of Serpulidae (Polychaeta). Zoologica Scripta, 18, 381-395.

Ben-Eliahu, M.N. \& Hove, H.A. ten (1992) Serpulid tubeworms (Annelida: Polychaeta)—a recent expedition along the Mediterranean coast of Israel finds new population buildups of Lessepsian migrant species. Israel Journal of Zoology, 38 (1), 35-53.

Ben-Eliahu, M.N. \& Hove, H.A. ten (2007) A comparison of some Salmacina populations (Serpulidae) from different biogeographic regions, 9th International Polychaete Conference, Aug. 12-18, 2007, Portland, Maine, USA. Book of Abstracts, p. 93.

Ben-Eliahu, M.N., Hove, H.A. ten \& Shashar, N. (2003) Fouling serpulid taxa from the north beach of Elat: Coloration and some preliminary observations on radiolar and prostomial photoreceptors. Proc. $39^{\text {th }}$ Meeting of the Zoological Society of Israel, 1 December 2002, Tel Aviv University. Abstract, 2003. Israel Journal of Zoology, 49, 74.

Ben-Eliahu, M.N. \& Payiatas, G. (1999) Searching for Lessepsian migrant serpulids (Annelida: Polychaeta) on Cyprussome results of a recent expedition. Israel Journal of Zoology, 45, 101-119.

Ben-Eliahu, M.N. \& Safriel, U.N. (1982). A comparison between species diversities of polychaetes from tropical and temperate structurally similar rocky intertidal habitats. Journal of Biogeography, 9, 371-390.

Ben-Eliahu, M.N., Safriel, U.N. \& Ben-Tuvia, S. (1988) Environmental stability is low where polychaete species diversity is high: Quantifying tropical vs. temperate within-habitat features. Oikos, 52, 255-273.

Ben-Tuvia, A. (1966) Red Sea fishes recently found in the Mediterranean. Copeia, 2, 254-275.

Ben-Tuvia, A. (1970) Man-made changes in the Eastern Mediterranean and their effect on the fishery resources. Jour- 
nées ichthyologiques, Rome, Commission Internationale pour l'exploration Scientifique de la Mer Méditerranée, 179-185.

Ben-Tuvia, A. (1973) Man-made changes in the eastern Mediterranean and their effect on the fishery resources. Marine Biology, 19, 197-203.

Berkeley, M.J. (1835) Observations upon the Dentalium subulatum of Deshayes. Zoological Journal, London, 5, 20, 424-427.

Bianchi, C.N. (1981) Policheti Serpuloidei. Guide per il riconoscimento delle specie animali delle acque lagunari e costiere italiane. Consiglio Nazionale delle Ricerche AQ / 1 / 96, 5, 1-187.

Bianchi, C.N. \& Morri, C. (2000) Serpuloidea (Annelida: Polychaeta) from Milos, an island in the Aegean Sea with submarine hydrothermism. Journal of the Marine Biological Association, U.K., 80, 259-269.

Bitar, G., Osama, O. \& Ramos-Esplá, A.A. (2007) Contribution of the Red Sea alien species to structuring some benthic biocenosis in the Lebanon coast (eastern Mediterranean). Rapport Commission Internationale pour l'exploration Scientifique de la Mer Méditerranée, 38, 437.

Bonhomme, F., Baranes, A., Golani, D. \& Harmelin-Vivien, M. (2003) Lack of mitochondrial differentiation between Red Sea and Mediterranean populations of the Lessepsian rabbitfish, Siganus rivulatus (Perciformes: Siganidae). Scientia Marina, 67 (2), 215-217.

Boudouresque, C.F. (1994) Les espèces introduites dans les eaux côtières d'Europe et de Méditerranée. In: Boudouresque, C.F., Briand, F. \& Nolan, C. (Eds), Introduced Species in European Coastal Waters. European Commission Ecosystems Research Report (DG XII), 8, 8-27; Luxembourg (European Union Research EUR 15309).

Breton, B. (2006) The early history and development of the Scanning Electron Microscope. Available from http:// www2.eng.cam.ac.uk/ bcb/history.htm/ (May 2009)

Briggs, J.C. (1967) Relationship of the tropical shelf regions. Studies in Tropical Oceanography, 5, 569-578.

Briggs, J.C. (1974) Marine Zoogeography. McGraw-Hill, New York, 475 pp.

Brit, N. (2000) The use of bivalves in the past and aspects of the ecology of the pearl oyster, Pinctada radiata, in the rocky shore of Haifa. Recanati Institute for Maritime Studies (R.I.M.S.) Newsletter, 27, 1-3.

Bucciarelli, G., Golani, D. \& Bernardi, G. (2002) Genetic cryptic species as biological invaders: The case of a Lessepsian fish migrant, the hardyhead silverside Atherinomorus lacunosus. Journal of Experimental Marine Biology and Ecology, 273, 143-149.

Bush, K.J. (1905 [1904]) Tubicolous annelids of the tribes Sabellides and Serpulides from the Pacific Ocean. Harriman Alaska Expedition Report, 12, 169-355.

Bush, K.J. (1910) Description of new serpulids from Bermuda with notes on known forms from adjacent regions. Proceedings of the Academy of Natural Sciences, Philadelphia, 62, 490-501.

Carlton, J.T. (1985) Transoceanic dispersal of coastal marine organisms: The biology of ballast water. Oceanography and Marine Biology: An Annual Review, 23, 313-374.

Carlton, J.T. \& Hodder, J. (1995) Biogeography and dispersal of coastal marine organisms: Experimental studies on a replica of a 16th-century sailing vessel. Marine Biology, 121, 721-730.

Caullery, M. \& Mesnil, F. (1896) Note sur deux serpuliens nouveaux (Oriopsis Metchnikowi n. g., n. sp. et Josephella Marenzelleri n. g., n. sp.). Zoologischer Anzeiger, Leipzig, 19 (519), 482-486.

Charles, F., Jordana, E., Amouroux, J.-M., Grémare, A., Desmalades, M. \& Zudaire, L. (2003) Reproduction, recruitment and larval metamorphosis in the serpulid polychaete Ditrupa arietina (O.F. Müller). Estuarine, Coastal and Shelf Science 57 (3), 435-443.

Çinar, M.E. (2006). Serpulid species (Polychaeta: Serpulidae) from the Levantine coast of Turkey (eastern Mediterranean), with special emphasis on alien species. Aquatic Invasions, 1, 223-240.

Çinar, M.E. (2009) Alien polychaete species (Annelida: Polychaeta) on the southern coast of Turkey (Levantine Sea, eastern Mediterranean), with 13 new records for the Mediterranean Sea. Journal of Natural History, 43 (37), $2283-$ 2328.

Çinar, M.E., Bilecenoğlu. M., Öztürk, B. \& Can, A. (2006) New records of alien species on the Levantine coast of Turkey. Aquatic Invasions, 1, 84-90.

Çinar, M.E. \& Ergen, Z. (2005) Lessepsian migrants expanding their distributional ranges; Pseudonereis anomala (Polychaeta: Nereididae) in Izmir Bay (Aegean Sea). Journal of the Marine Biological Association of the United Kingdom, 85, 313-321.

Çinar, M.E., Ergen, Z. \& Dagli, E. (2002) Occurrence of the Lessepsian species Leonnates persicus (Polychaeta: Nereididae) in Izmir Bay, Aegean Sea, Journal of the Marine Biological Association of the United Kingdom, 82, 811815.

Claparède, E. (1870) Les Annélides Chétopodes du Golfe de Naples. Annélides Sédentaires. (Supplément). Mémoires de la Société de physique et d'histoire naturelle de Genève, 20, 365-542.

Day, J.H. (1955) The Polychaeta of South Africa. 3. Sedentary species from Cape shores and estuaries. Journal of the Linnean Society of London (Zoology), 42, 407-452.

Day, J.H. (1967) A monograph on the Polychaeta of Southern Africa. Part II. Sedentaria. British Museum (Natural History), London, pp. 459-878.

DeFelice, R.C., Eldredge, L.G. \& Carlton, J.T. (2001) Salmacina dysteri. In: Eldredge, L.G. \& Smith, C.M. (Eds), Nonindigenous Marine Invertebrates, A Guidebook of Introduced Marine Species in Hawaii, Bishop Museum Technical 
Report, 21, pp. B-25-26.

Dekker, H. \& Orlin, Z. (2000) Check-list of Red Sea Mollusca. Spirula, 47, 1-46.

Dew, B. (1959) Serpulidae (Polychaeta) from Australia. Records of the Australian Museum, 25 (2), 19-56.

Dulĉić, J., Lipej, L., Pallaoro, A. \& Soldo, A. (2004) The spreading of Lessepsian fish migrants into the Adriatic Sea: A review. Rapport du $37^{\circ}$ Congrès de la Commission Internationale pour l'exploration Scientifique de la Mer Méditerranée, Barcelona (Espagne), 2004, p. 49.

Durand-Claye, L. (1874) Essai des vingt-un échantillons d'eau salée du Canal maritime de Suez. Annales de chimie et de physique (série 5), 3, 188.

Ehlers, E. (1908) Die bodensässigen Anneliden aus den Sammlungen der deutschen Tiefsee-Expedition "Valdivia”. Deutsche Tiefsee-Expedition auf der Dampfer "Valdivia” 1898-1899, Wissenschaftliche Ergebnisse, 16, 1-168.

Ehlers, E. (1913) Die Polychaeten-Sammlungen der deutschen Südpolar-Expedition 1901-1903. Deutsche Südpolar-Expedition, 13, 4, 397-598.

Ehlers, E. (1918) Polychaete Anneliden von den Aru- und Kei-Inseln. Abhandlungen Senckenbergischen naturforschungs Gesellschaft, 35 (2), 227-250.

Ekman, S. (1953) Zoogeography of the Sea. Sidgewick \& Jackson Limited, London, 417 pp.

El-Komi, M.M. (1991a) Incidence and ecology of marine fouling organisms in the Eastern Harbour of Alexandria, Egypt. Bulletin of the Institute of Oceanography and Fisheries, Arab Republic of Egypt, 17 (1), 1-16.

El-Komi, M.M. (1991b) Incidence and ecology of marine fouling organisms in the Eastern Harbour of Alexandria, Egypt. Marine Pollution Bulletin, 23, 289-296.

El-Komi, M.M. (1992a) Field and laboratory studies on the ecology of marine fouling in Alexandria Harbour, Egypt. Bulletin of the Institute of Oceanography and Fisheries, Arab Republic of Egypt, 18, 115-140.

El-Komi, M.M. (1992b) Observations on the fouling settlement in Red Sea waters (el-Ghardaqa). Bulletin of the High Institute of Public Health, 22 (3), 637-648, Arabic abstract.

El-Komi, M.M. (1996) Coastal development and pollution impact on the distribution of macrobenthic communities along the eastern coast of the Gulf of Suez (Egypt). Pakistan Journal of Marine Sciences, 7 (1), 1-13.

El-Komi, M.M. (1997) Ecology and distribution of macro benthos in Lake Manzalah, Egypt. Journal of the Egyptian German Society for Zoology, 24 (D), 105-122.

El-Komi, M.M. (1998) Dynamics of the buoys macrofouling communities at Alexandria Harbour, Egypt. Journal of the Egyptian German Society for Zoology, 25 (B), 259-281.

El-Komi, M.M. \& El-Sherif, Z.M. (1992) Marine fouling and periphyton growths on test panels in the Eastern Harbour of Alexandria. Bulletin of the High Institute of Public Health, 22 (3), 255-270.

El-Komi, M.M., Emara, A.M. \& Mona, M.H. (1998) Ecology and settlement of marine fouling in the Suez Bay, Egypt. Pakistan Journal of Marine Sciences, 7 (1), 11-26.

El-Rashidy, H.H., Atta, M.M., Dorgham, M.M. \& Hamdy, R. (2009) New northward polychaetes immigrants through the Suaz [sic] Canal. Proceedings of Coastal Zone 09, Boston, Massachusetts, July 19 to 23, 2009, 2 pp.

El Sabh, M.I. (1968) Effect of the Aswan High Dam on the distribution of salinity in the Suez Canal. Nature 218 (5143), 758-760, London.

El-Sayed, S. \& van Dijken, G.L. (1995) The southeastern Mediterranean ecosystem revisited: Thirty years after the construction of the Aswan High Dam. Quarterdeck Online, 3.1, 1-4 (http://www-ocean.tamu.edu/Quarterdeck/QD3.1), Texas A \& M Department of Oceanography, College Station, Texas 77843-3146.

Emara, A.M. (2002) A comparative study of marine fouling organisms in the northern regions of the Gulf of Suez, Red Sea. Journal of the Egyptian Academy Society for Environmental Development, 3(2), 159-185.

Emara, A.M. \& Belal, A.A. (2004) Marine Fouling in Suez Canal, Egypt. Egyptian Journal of Aquatic Research, 30 (A), 189-206.

Ergen, Z. (1979) The effects of pollution on the distribution of the Polychaeta in the Bay of Izmir. Genel Kurul Toplantisi, 1979-Ankara. Türkiye Ulusal Jeodezi Jeofizik Birliği, 10, 77-82 (in Turkish, English abstract).

Ergen, Z. \& Çinar, M.E. (1997) Polychaeta of Antalya Bay (Mediterranean coast of Turkey). Israel Journal of Zoology, 43, 229-241.

Eytam, Y. (1974) Shores and bottom substrates of the Great Bitter Lake. Jerusalem, Field Report to the Hebrew University (in Hebrew), 12 pp.

Fabricius, O. (1780) Fauna Groenlandica. Copenhagen \& Leipzig, 452 pp.

Fassari, G. \& Mòllica, E. (1991) Una Nuova Specie di Serpulidae (Annelida Polychaeta) di grotta. Animalia, Catania, 18, 261-267.

Fauvel, P. (1911) Annélides Polychètes du Golfe Persique récueillés par M.N. Bogoyawlensky. Archives de Zoologie Expérimentale et Générale, (5) 4 (11), 353-439.

Fauvel, P. (1918) Annélides Polychètes des côtes d'Arabie récoltées par M. Ch. Pérez. Bulletin de la Muséum d'Histoire Naturelle, 24 (5), 329-344.

Fauvel, P. (1919) Annélides Polychètes des îles Gambier et Touamotou. Bulletin du Muséum d'Histoire Naturelle, Paris, 25 (5), 336-343.

Fauvel, P. (1923) Un nouveau serpulien d'eau saumâtre Mercierella n. g., enigmatica n. sp. Bulletin de la Société zoologique de France, 47, 424-430.

Fauvel, P. (1927) Polychètes Sédentaires. Addenda aux Errantes, Archiannélides, Myzostomaires. Faune de France, 16, 
$1-494$.

Fauvel, P. (1933a) Annélides Polychètes. Mission Robert Ph. Dollfus en Égypte. Annélides Polychètes. Mémoires de l'Institut d'Égypt, 21, 31-83.

Fauvel, P. (1933b) Résumé analytique du mémoire de Pierre Fauvel sur les Polychètes. Mission Robert Ph. Dollfus en Égypte. Annélides Polychètes. Bulletin de l'Institut d'Égypt, 25, 131-144.

Fauvel, P. (1937) Les fonds de pêche près d'Alexandrie. XI. Annélides Polychètes. Notes et Mémoires, Ministère du Commerce \& Industrie, Direction de Recherches Pêcheries, 19, 1-60.

Fauvel, P. (1953) Annelida Polychaeta. The Fauna of India, including Pakistan, Ceylon, Burma and Malaya. The Indian Press, Ltd., Allahabad, 507 pp.

Fauvel, P. (1955a) Contribution à la faune des Annélides Polychètes des côtes d'Israël. Bulletin of the Sea Fisheries Research Station, Haifa, 10, 3-12.

Fauvel, P. (1955b) Annélides Polychètes de la croisière de la "Calypso" en Mer Rouge en 1952. Résultats Scientifique de les Campagnes de la "Calypso" I. Annales de l'Institut Océanographique, Paris, 30, 101-120.

Fauvel, P. (1957) Sur quelques Annélides polychètes du Golfe d'Akaba. I. Bulletin of the Sea Fisheries Research Station, Haifa, 13, 3-11.

Fiege, D. (1992) Polychaeta of the intertidal zone in the Ras Az-Zawr Marduma Bay Region, Saudi Arabia. Unpublished Progress Report of the Senckenbergische Forschungsinstitut, Frankfurt am Main, 23 pp.

Fiege, D. \& Sun, R. (1999) Polychaeta from Hainan Island, South China Sea, Part I. Serpulidae (Annelida, Polychaeta, Serpulidae). Senckenbergiana biologica, 79, 109-141.

Fischli, H. (1903) Polychäten von Ternate. Abhandlungen herausgegeben der Senckenbergischen Naturforschenden Gesellschaft, 25, 90-136.

Fishelson, L. (1971) Ecology and distribution of benthic fauna in the shallow waters of the Red Sea. Marine Biology, 10, 113-133.

Fishelson, L. \& Haran, T. (1987) Epifauna of algae on a rocky platform near Mikhmoret (Mediterranean Sea, Israel): Composition and dynamics. Israel Journal of Zoology, 34 (3-4), 105-123.

Fishelson, L. \& Rullier, F. (1969) Quelques Annélides polychètes de la Mer Rouge. Israel Journal of Zoology, 18, 49117.

Fouda, M.M (1995) Life history strategies of four small-size fishes in the Suez, Egypt. Journal of Fish Biology, 46 (4), $687-702$.

Fox, H.M. (1926) Cambridge Expedition to the Suez Canal, 1924. Transactions of the Zoological Society of London, 22 (1), 1-64.

Fox, H.M. (1929). XXXIX. Summary of results. Zoological Results. Cambridge Expedition to the Suez Canal, 1924. Transactions of the Zoological Society of London, 22, 843-863.

Frank, U., \& Hove H.A. ten (1992) In vitro exposure of Spirobranchus giganteus and S. tetraceros (Polychaeta, Serpulidae) to various turbidities; branchial morphologies an expression of filtering strategies? Oebalia, 18, N.S., 45-52.

Galil, B.S. (1986) Red Sea Decapods along the Mediterranean coast of Israel: Ecology and Distribution. In: Dubinsky, Z. \& Steinberger, Y. (Eds), Environmental Quality and Ecosystem Stability, Vol. III-A, Jerusalem. Israel Society for Ecology \& Environmental Quality Sciences (ISEEQS) Publication, Jerusalem, pp. 179-183.

Galil, B.S. (1989) Bathymetric distribution and habitat preferences of Lessepsian migrant Decapoda along the Mediterranean coast of Israel, or: Do decapods have cold feet? In: Spanier, E., Steinberger, Y. \& Luria, M. (Eds), Environmental Quality and Ecosystem Stability, Vol. IV-B, Society for Ecology \& Environmental Quality Sciences (ISEEQS) Publication, Jerusalem, pp. 147-155.

Galil, B.S. (1992) Eritrean Decapods in the Levant. Biogeography in motion. Bulletin de l'Institut océanographique, Monaco, numéro spécial, 9, 115-121.

Galil, B.S. (1993) Lessepsian migration: New findings on the foremost anthropogenic change in the Levant Basin fauna. In: Della Croce, N.F.R. (Ed.). Symposium Mediterranean Seas 2000. Istituto Scienze Ambientali Marine-Università di Genova, Genova, pp. 307-318.

Galil, B.S. (1997) Two Lessepsian migrant decapods new to the coast of Israel. Crustaceana, 70 (1), 111-114.

Galil, B.S. (2000) A sea under siege_-alien species in the Mediterranean. Biological Invasions, 2, 177-186.

Galil, B.S. (2006a) The Marine Caravan-The Suez Canal and the Erythrean invasion. In: Gollasch, S., Galil, B.S. \& Cohen, A.N. (Eds), Bridging Divides-Maritime Canals as Invasion Corridors. Monographiae Biologicae, 83. Springer, Dordrecht, The Netherlands, pp. 207-300.

Galil, B.S. (2006b) Alien species in the Mediterranean Sea which, when, where, why? Hydrobiology, 606, $105-116$.

Galil, B.S. \& Golani, D. (1990) Two new migrant decapods from the eastern Mediterranean. Crustaceana, 58 (3), $229-$ 236.

Galil, B.S. \& Lützen, J. (1998) Jeopardy: Host and parasite Lessepsian migrants from the Mediterranean coast of Israel. Journal of Natural History, 32, 1549-1551.

Galil, B.S., Pisanty, S., Spanier, E. \& Tom, M. (1988 / 89) The Indo-West-Pacific lobster Panulirus ornatus (Fabricius, 1798) (Crustacea: Decapoda): A new Lessepsian migrant to the Eastern Mediterranean. Israel Journal of Zoology, 35 (4), 241-243.

Galil, B.S., Spanier, E. \& Ferguson, W. (1990) The Scyphomedusae of the Mediterranean coast of Israel including two Lessepsian migrants new to the Mediterranean. Zoölogische Mededeelingen uitgegeven door het Rijksmuseum van 
Natuurlijke Historie te Leiden, 64 (7), 95-105.

Galil, B.S. \& Zenetos, A. (2002) A sea change-exotics in the eastern Mediterranean Sea. In: Leppäkoski, E., Gollasch, S. \& Olenin, S. (Eds), Invasive Aquatic Species of Europe. Distribution, Impacts \& Management. MARBEF-EU, pp. $325-336$.

Gaut, A. (2001) The biofouling problem. Marine Life Society of South Australia (MLSSA) Newsletter, 273, 2-5 (http:// www.mlssa.asn.au.nletters/january2001.htm).

Gee, J.M. (1963) On the taxonomy and distribution in South Wales of Filograna, Hydroides and Mercierella (Polychaeta: Serpulidae). Annals and Magazine of Natural History, London, Series (13) 6, 705-715.

Gertman, I. \& Hecht, A. (2002) Annual and long-term changes in the salinity and the temperature of the waters of the South-eastern Levantine Basin. In: Millot, C. \& Briand, F. (Eds), Tracking long-term hydrological change in the Mediterranean Sea, Monaco, 22-24 April 2002, CIESM Workshop Series, 16, 75-78, Monaco.

Ghobashy, A.F.A. (1977) Seasonal variation and settlement behaviour of the principal fouling organisms in the Eastern Harbour of Alexandria. In: Centre de Recherches et d'Études Océanographiques, Boulogne (Eds), Proceedings of the $4^{\text {th }}$ International Congress on Marine Corrosion and Fouling, Antibes-Juan-les-Pins, pp. 213-220.

Ghobashy, A.F.A. (1984) Polychaetous fouling in Egyptian marine waters. Proceedings of the $6^{\text {th }}$ International Congress on Marine Corrosion and Fouling (Athens), pp. 39-51.

Ghobashy, A.F.A., Abdel Hamid, M. \& Mona, M.H. (1981) Morphology and reproductive potential of Hydroides elegans Haswell (Serpulidae Polychaeta). Journal of the Faculty of Education, Ain Shams University, 4 (part II), 345364.

Ghobashy, A.F.A. \& El-Komi, M.M. (1981a) Fouling in Lake Timsah. Hydrobiological Bulletin, 14 (3), $169-178$.

Ghobashy, A.F.A. \& El-Komi, M.M. (1981b) Fouling in the southern region of the Suez Canal. Hydrobiological Bulletin, 14 (3), 179-185.

Ghobashy, A.F.A., El-Komi, M.M. \& Ramadan, S.E. (1980) Fouling in the Suez Canal. In: Aritio, L. (Ed.). Proceedings of the 5th International Congress on Marine Corrosion and Fouling: Marine Biology (Barcelona 19-23 May 1980). Madrid (Editorial Garsi), Barcelona (Graficas Orbe, S.L.), pp. 75-92.

Ghobashy, A.F.A. \& Ghobashy, A.F.M. (2005) Marine fouling studies in Egypt. A. Serpulids. Egyptian Journal of Aquatic Research, 31 (2), 89-102.

Ghobashy, A.F.A. \& Hamada, S.F. (1984) The fouling organisms in the Damietta Harbour (Egypt). Proceedings of the $6^{\text {th }}$ International Congress on Marine Corrosion and Fouling, Athens, 5-8 September, 1984, 53-63.

Ghobashy, A.F.A. \& Selim, S.A. (1976a) Growth of the tube worm Hydroides norvegica (Gunnerus) in the eastern harbour of Alexandria. Bulletin of the Institute of Oceanography and Fisheries, Cairo (Alexandria), Egypt, 6, $303-313$.

Ghobashy, A.F.A. \& Selim, S.A. (1976b) Settlement behaviour of the tube worm Hydroides norvegica Gunnerus in the eastern harbour of Alexandria. Bulletin of the Institute of Oceanography and Fisheries, Cairo (Alexandria), Egypt, 6, 287-295.

Ghobashy, A.F.A., Shalaby, I.M.I. \& Shalla, S.H. (1986) Serpuloids (Tube worms) of Lake Timsah. In: Zoological Society of the Arab Republic of Egypt (Ed.). Proceedings of the Zoological Society of the Arab Republic of Egypt, 12, 319-338.

Ghobashy, A.F.A., Shalaby, I.M.I. \& Shalla, S.H. (1990) Lake Timsah as a barrier for the serpuloid (Tube Worms) migration along the Suez Canal. Egyptian Journal of Applied Science, 5, 677-686.

Giard, A. (1876) Note sur l'embryogénie de la Salmacina dysteri Huxley. Note sur le développement de la Salmacina dysteri Huxley. Comptes rendues de la Académie des Sciences, Paris, 82, 233-235, 285-288.

Gibbs, P.E. (1971) The Polychaete fauna of the Solomon Islands. Bulletin of the British Museum (Natural History) Zoology, 21 (5), 101-211.

Godeaux, J. (1988) Thaliacés récoltés en mer d'Arabie, dans le golfe Persique et dans le golfe d'Aden par N.O. Commandant Robert Giraud. Bullétin de la Académie Royale des Sciences d'Outre-Mer (ARSOM), 34 (2), 301-324.

Golani, D. (1990) Environmentally-induced meristic changes in Lessepsian fish migrants, a comparison of source and colonizing populations. Bullétin de l'Institut Océanographique, Monaco, nouvelle série, 7, 143-152.

Golani, D. (1994) Niche separation between colonizing and indigenous goatfish (Mullidae) along the Mediterranean coast of Israel. Journal of Fish Biology, 45, 503-513.

Golani, D. (1998a) Distribution of Lessepsian migrant fish in the Mediterranean. Italian Journal of Zoology, 65, 95-99.

Golani, D. (1998b) Impact of Red Sea fish migrants through the Suez Canal on the aquatic environment of the eastern Mediterranean. Bulletin of the Yale School of Forestry and Environmental Studies, 103, 375-387.

Golani, D. (1999) The Gulf of Suez Ichthyofauna-Assemblage Pool for Lessepsian Migration into the Mediterranean. Israel Journal of Zoology, 45, 79-90.

Golani, D. (2000) First record of the bluespotted cornetfish from the Mediterranean Sea. Journal of Fish Biology, 56, $1545-1547$.

Golani, D., Appelbaum-Golani, B. \& Gon, O. (2008) Apogon smithies (Kotthaus, 1970) (Teleostei: Apogonidae), a Red Sea cardinalfish colonizing the Mediterranean Sea. Journal of Fish Biology, 72, 1534-1538.

Golani, D., Azzurro, E., Corsini-Foka, M., Falautani, M., Andaloro, F. \& Bernardi, G. (2007) Genetic bottle-necks and successful biological invasions: The case of a recent Lessepsian migrant. Biology Letters, 3, 541-545.

Golani, D. \& Ben-Tuvia, A. (1989) Characterization of Lessepsian (Suez Canal) fish migrants. In: Spanier, E., Steinberger, Y. \& Luria, M. (Eds), Environmental Quality and Ecosystem Stability, Vol. IV-B. Israel Society for Ecology 
\& Environmental Quality Sciences (ISEEQS) Publication, Jerusalem, 235-243.

Golani, D. \& Ben-Tuvia, A. (1995) Lessepsian Migration and the Mediterranean fisheries of Israel. In: Armantrout, N.B. (Ed.). Conditions of the World's Aquatic Habitats. Proceedings of the World Fisheries Congress, Theme I, 279-288; New Delhi (Oxford \& IBH Publishing Company).

Golani, D. \& Ritte, U. (1999) Genetic relationship in goatfishes (Mullidae: Perciformes) of the Red Sea and the Mediterranean, with remarks on Suez Canal migrants. Scientia Marina, 63, 129-135.

Gollasch, S. (1996) Untersuchungen des Arteintrages durch den internationalen Schiffsverkehr unter besonderer Berücksichtigung nichtheimischer Arten. Dissertation, Universität Hamburg. Verlag Dr. Kovac, Hamburg, 314 pp.

Gollasch, S., Lenz, J., Dammer, M. \& Andres, H.-G. (2000) Survival of tropical ballast water organisms during a cruise from the Indian Ocean to the North Sea. Journal of Plankton Research, 22 (5), 923-937.

Gopalakrishnan, S., Thilagam, H. \& Raja, P.V. (2007) Toxicity of heavy metals on embryogenesis and larvae of the marine sedentary polychaete Hydroides elegans. Archives of Environmental Contamination and Toxicology 52, 171178.

Goren, M. (1979) Succession of benthic community on artificial substratum at Elat, Red Sea. Journal of Experimental Marine Biology and Ecology, 38, 19-40.

Goren, M. (1980) Development of benthic community on artificial substratum at Ashdod, eastern Mediterranean. Oceanologica Acta, 3 (3), 275-283.

Gorgy, S. (1966) Les pêcheries et le milieu marin dans le secteur méditerranéen de la République Arabe Unie. Revue des Travaux de l' Institut des pêches maritimes, 30 (1), 5-91.

Grassle, J.P. \& Grassle, J.F. (1976) Sibling species in the marine pollution indicator Capitella (Polychaeta). Science, 192 , 567-569.

Gravier, C. (1905 [1906?]) Sur deux types nouveaux de Serpuliens, Pomatoceropsis nov. gen. coutierei nov. sp. Bonhourella nov. gen. insignis nov. sp. Bulletin de la Musée nationale d'Histoire naturelle, Paris, 11, 445-451.

Gravier, C. (1906a) Contribution à l'étude des Annélides Polychètes de la Mer Rouge. Mémoires et Nouvelles Archives du Muséum d'Histoire Naturelle de Paris, (4) 8, 123-236.

Gravier, C. (1906b) Sur les Annélides Polychètes de la Mer Rouge (Serpulides). Bulletin du Muséum d'Histoire Naturelle, Paris, 12, 110-115.

Gravier, C. (1908) Contribution a l'étude des Annélides Polychètes de la Mer Rouge (suite). Mémoires et Nouvelles Archives du Muséum d'Histoire Naturelle de Paris, 4 (10), 67-168.

Grube, A.E. (1862) Mittheilungen über die Serpulen, mit besonderer Berücksichtigung ihrer Deckel. Jahresbericht und Abhhandlungen der Schlesischen Gesellschaft in Breslau, 39, 53-69.

Grube, A.E. (1868) Beschreibungen einiger von Georg Ritter von Frauenfeld gesammelter Anneliden und Gephyreen des Rothen Meeres. Verhandlungen der zoologischen und botanischen Gesellschaft in Wien, 18, 629-650.

Grube, A.E. (1870) Beschreibungen neuer oder weniger bekannter von Hrn. Ehrenberg gesammelter Anneliden des Rothen Meeres. Monatsberichte der Königliche Preussische Akademie der Wissenschaften zu Berlin 1869, 484-521.

Grube, A.E. (1878) Neue Anneliden aus Japan. Jahres-Bericht der Schlesischen Gesellschaft für vaterländische Cultur, $55,104-106$.

Gunnerus, J. (1768) Om nogle Norske Coraller. Skrifter det Kongeliger Norske Videnskabers Selskab Trondhjem, 4, 3873.

Gunter, G. (1957) Temperature. In: Hedgpeth, J. (Ed.). Geological Society of America Memoir, 67. Geological Society of America, New York, pp. 159-184.

Hadfield, M.G. (1998) The D.P. Wilson lecture. Research on settlement and metamorphosis of marine invertebrate larvae: Past, present and future. Biofouling, 12 (1-3), 9-29.

Hadfield, M.G., Carpizo-Ituarte, E.J., Carmen, K. del \& Nedved, B.T. (2001) Metamorphic competence, a major adaptive convergence in marine invertebrate larvae. American Zoologist, 41 (5) 1123-1131.

Halim, Y. (1960) Observations on the Nile bloom of phytoplankton in the Mediterranean. Journal du Conseil, 26 (1), $57-$ 67.

Hartman, O. (1954) Marine Annelids from the northern Marshall Islands. Geological Survey Professional Paper, 260-Q: 619-644.

Hartman, O. (1974) Polychaetous annelids of the Indian Ocean including an account of species collected by members of the International Indian Ocean expeditions, 1963-1964 and a catalogue and bibliography of the species from India. I. Journal of the Marine Biological Association of India, 16 (1), 191-252.

Hartmann-Schröder, G. (1980) Die Polychaeten der tropischen Nordwestküste Australiens (zwischen Port Samson im Norden und Exmouth im Süden). Mitteilungen aus dem Hamburgischen Zoologischen Museum und Institut, 77, 41110.

Harzhauser, M., Kroh, A., Mandic, O., Piller, W.E., Göhlick, U., Reuter, M. \& Berning, B. (2007) Biogeographic responses to geodynamics: A key study all around the Oligo-Miocene Tethyan Seaway. Zoologischer Anzeiger, 246, 241256.

Hassan, M. (1998 [1997]) Modification of carbonate substrata by bioerosion and bioaccretion on coral reefs of the Red Sea. Thesis, Kiel Universität. Shaker Verlag, Aachen, 126 pp.

Hassan, M. \& Bonhomme, F. (2005) No reduction in neutral variability of mitochondrial and nuclear genes for a Lessepsian migrant, Upeneus moluccensis. Journal of Fish Biology, 66, 865-870. 
Hassan, M., Harmelin-Vivien, M. \& Bonhomme, F. (2003) Lessepsian invasion without bottleneck: Example of two rabbitfish species (Siganus rivulatus and Siganus luridus). Journal of Experimental Marine Biology and Ecology, 291, 219-232.

Haswell, W.A. (1883) On some new Australian tubicolous annelids. Proceedings of the Linnean Society of New South Wales, 7, 633-638.

Haswell, W.A., (1885 [1884]) The marine annelids of the order Serpulea. Some observations on their anatomy, with the characteristics of the Australian species. Proceedings of the Linnean Society of New South Wales, 3, 649-675.

Heck, K.L., Jr. (1979) Some determinants of the composition and abundance of motile macroinvertebrate species in tropical and temperate turtlegrass (Thalassia testudinum) meadows. Journal of Biogeography, 6, 183-200.

Heimdal, B.R., Taasen, J.P \& Elbrächter, M. (1977) Phytoplankton of the Great Bitter Lake in the Suez Canal. Sarsia, 63, 75-83.

Heppell, D. (1963) Serpula Linnaeus, 1758, Annelida (Polychaeta): Proposed designation of a type-species under the plenary powers and relevant proposals. Z.N.(S.) 1606. Bulletin of Zoological Nomenclature, 20 (6), 443-446.

Hoenselaar, H.J. \& Dekker, H. (1998) Molluscs of Great Bitter Lake, Suez Canal. Basteria, 62, $197-214$.

Holthuis, L.B. \& Gottlieb, E. (1958) An annotated list of the Decapod Crustacea of the Mediterranean coast of Israel, with an appendix listing the Decapoda of the Eastern Mediterranean. Bulletin of the Research Council of Israel, 7B (1-2), 1-126.

Hove, H.A. ten (1970a) Additional notes on the polychaetes of the Iranian Gulf (Annelida, Polychaeta Serpulidae). Steenstrupia, 1 (7), 55-60.

Hove, H.A. ten (1970b) Serpulinae (Polychaeta) from the Caribbean, I. The genus Spirobranchus. Studies on the Fauna of Curaçao and Other Caribbean Islands, 32, 1-57.

Hove, H.A. ten (1973) Serpulinae (Polychaeta) from the Caribbean. II. The genus Sclerostyla. Studies on the Fauna of Curaçao and Other Caribbean Islands, 43, 1-21.

Hove, H.A. ten (1974) Notes on Hydroides elegans (Haswell, 1883) and Mercierella enigmatica Fauvel, 1923, alien serpulid polychaetes introduced into the Netherlands. Bulletin of the Zoological Museum, Amsterdam, 4, 45-51.

Hove, H.A. ten (1975) Serpulinae (Polychaeta) from the Caribbean: III. The genus Pseudovermilia (including species from other regions). Studies on the Fauna of Curaçao and Other Caribbean Islands, 47, 46-101.

Hove, H.A. ten (1984) Towards a phylogeny in serpulids (Annelida; Polychaeta). In: Hutchings, P.A. (Ed.). Proceedings of the First International Polychaete Conference, Sydney, 1983. Linnean Society of New South Wales, pp. 181-196.

Hove, H.A. ten (1990) A description of Hydroides bulbosus sp. nov. (Polychaeta: Serpulidae) from the Iranian Gulf with a terminology for Hydroides opercula. Beaufortia, 41 (16), 115-120.

Hove, H.A. ten (1994) 6.6. Serpulidae (Annelida, Polychaeta) from the Seychelles and Amirante Islands. In: Land, J. van der (Ed.). Oceanic Reefs of the Seychelles. Cruise Reports of the Netherlands Indian Ocean Program, 2. National Natural History Museum, Leiden, pp. 107-116.

Hove, H.A. ten \& Ben-Eliahu, M.N. (2005) On the identity of Hydroides “priscus”, taxonomic confusion due to ontogeny in some Hydroides species (Annelida: Polychaeta: Serpulidae). Senckenbergiana Biologica, 85 (2), $127-145$.

Hove, H.A. ten, Ben-Eliahu, M.N. \& Fiege, D. (2006). Serpulidae of the Gulf of Aqaba, the Gulf of Suez, and the Red Sea: Comparative species richness. Workshop on the high biodiversity of the Gulf of Aqaba: Origins, dimension and protection, 16-20 October 2006, Jerusalem and 22-23 October 2006, Eilat. Book of Abstracts. p. 29.

Hove, H.A. ten \& Hurk, P. van den (1993) A review of recent and fossil serpulid "reefs"; actuopalaeontology and the "Upper Malm" serpulid limestones in NW Germany. Geologie en Mijnbouw, 72, 23-67.

Hove, H.A. ten \& Jansen-Jacobs, M.J. (1984) A revision of the genus Crucigera (Polychaeta, Serpulidae); a proposed methodical approach to serpulids, with special reference to variation in Serpula and Hydroides. In: Hutchings, P.A. (Ed.). Proceedings of the First International Polychaete Conference, Sydney, 1983, The Linnean Society of New South Wales, Sydney, pp. 143-180.

Hove, H.A. ten \& Kupriyanova, E.K. (2009) Taxonomy of Serpulidae (Annelida, Polychaeta): The state of affairs. Zootaxa, 2036, 1-126.

Hove, H.A. ten \& Pantus, F.J.A. (1985) Distinguishing the genera Apomatus Philippi, 1844 and Protula Risso, 1826 (Polychaeta: Serpulidae). A further plea for a methodical approach to serpulid taxonomy. Zoologische Mededeelingen (Leiden), 59, 1-25.

Hove, H.A. ten \& Weerdenburg, J.C.A. (1978) A generic revision of the brackish-water serpulid Ficopomatus Southern 1921 (Polychaeta, Serpulinae), including Mercierella Fauvel 1923, Sphaeropomatus Treadwell 1934, Mercierellopsis Rioja 1945 and Neopomatus Pillai 1960. Biological Bulletin, 154, 96-120.

Hsü, K.J. (1972) When the Mediterranean dried up. Scientific American, 227 (6), 26-36.

Hsü, K.J., Montadert, L., Bernoulli, D., Cita, M.B., Erickson, A., Garrison, R.E., Kidd, R.B., Mélières, F., Müller, C., \& Wright, R. (1978) History of the Mediterranean salinity crisis. In: Hsü, K.J., Montadert, L. et al. (Eds), Initial Report of the Deep Sea Drilling Project, National Science Foundation, Washington, D.C., 42 (1), 1053-1078.

Huxley, T.A. (1855) On a hermaphrodite and fissiparous species of tubicolar annelid. Edinburgh New Philosophical Journal, new series, 1 (1), 113-129.

Hydrographic Office (1967) Admiralty Pilot Book, 1979 edition. Nautical Publication no. 64. Red Sea and Gulf of Aden Pilot comprising the Suez Canal, the Gulfs of Suez and Aqaba, the Red Sea, the Gulf of Aden, the South-eastern coast of Arabia from Ras Baghashwa to Ras Al Hadd, the coast of Africa from Ras Asir to Ras Hafun, Socotra and 
its adjacent islands. Hydrographer of the Navy, Publications, $11^{\text {th }}$ edition, London, $599 \mathrm{pp}$.

Ilan, M., Ben-Eliahu, M.N. \& Galil, B.S. (1994) Three deep-water sponges from the eastern Mediterranean and their associated fauna. Ophelia, 39, 45-54.

Imajima, M. (1976) Serpulid polychaetes from Tanega-shima, Southwest Japan. Memoirs of the National Science Museum, Tokyo, 9, 123-143.

Imajima, M. (1977) Serpulidae, Annelida (Polychaeta) collected around Chichi-jima (Ogasawara Islands). Memoirs of the National Science Museum, Tokyo, 10, 89-111.

Imajima, M. (1978) Serpulidae, Annelida, Polychaeta) collected from around Nii-jima and O-shima, Izu Islands. Memoirs of the National Science Museum, Tokyo, 11, 49-72.

Imajima, M. (1979) Serpulidae, Annelida, Polychaeta) collected from around Cape Shionomisaki, Kii Peninsula. Memoirs of the National Science Museum, Tokyo, 13, 159-183.

Imajima, M. (1982) Serpulinae (polychaetous annelids) from the Palau and Yap Islands, Micronesia. Proceedings of the Japanese Society of Systematic Zoology, 23, 37-55.

Imajima, M. \& Hove, H.A. ten (1984) Serpulinae (Annelida, Polychaeta) from the Truk Islands, Ponape and Majuro Atoll, with some other new Indo-West-Pacific records. Proceedings of the Japanese Society of Systematic Zoology, 27, 35-66.

Imajima, M. \& Hove, H.A. ten (1986) Serpulinae (Annelida, Polychaeta) from Nauru, the Gilbert Islands (Kiribati) and the Solomon Islands. Proceedings of the Japanese Society of Systematic Zoology, 32, 1-16.

Ishaq, S. \& Mustaquim, J. (1996) Polychaetous annelids (order Sabellida) from the Karachi coast, Pakistan. Pakistan Journal of Marine Sciences, 5 (2), 161-197.

Johnson, H. P. (1901) The Polychaeta of the Puget Sound Region. Proceedings of the Boston Society of Natural History, 24(18), 381-437.

Jones, M.L. (1962). On some polychaetous annelids from Jamaica, the West Indies. Bulletin of the American Museum of Natural History, 124 (5), 169-212.

Kambouroglou, V. \& Nicolaidou, A. (2006) A new alien species in Hellenic waters: Pseudonereis anomala (Polychaeta, Nereididae) invades harbors in the Eastern Mediterranean. Aquatic Invasions, 1 (2), 97-98.

Kevrekidis, K., Galil, B.S. \& Kevrekidis, T. (1998) Three Lessepsian migrant penaeids (Decapoda) in Rodos Island (Greece). Crustaceana, 71, 474-478.

Kitsos, M.-S., Christodoulou, M. Arvanitidis, C., Mavidis, M., Kirmitzoglou, I. \& Koukouras, A. (2005) Composition of the organismic assemblage associated with Caretta caretta. Journal of the Marine Biological Association, United Kingdom, 85, 257-261.

Knight-Jones, E.W., Knight-Jones, P. \& Nelson-Smith, A. (1995) Chapter 6. Annelids (Phylum Annelida). In: Hayward, P.J. \& Ryland, J.S. (Eds), The marine fauna of the British Isles and North-West Europe. 1. Introduction and Protozoans to Arthropods. Clarendon Press, Oxford, pp. 165-277.

Knight-Jones, P., Knight-Jones, E.W. \& Ergen, Z. (1991) Sabelliform polychaetes, mostly from Turkey’s Aegean Coast. Journal of Natural History, 25, 837-858.

Koçak, F. (2007) A new alien bryozoan Celleporaria brunnea (Hincks, 1884) in the Aegean Sea (eastern Mediterranean. Scientia Marina, 71 (1), 191-195.

Koçak, F., Ergen, Z. \& Çinar, M.E. (1999) Fouling organisms and their developments in a polluted and an unpolluted marina in the Aegean Sea (Turkey). Ophelia, 50, 1-20.

Krauss, W. (1958) Eine Bemerkung zur Abnahme des Salzgehaltes im Suezkanal. Deutsche hydrographische Zeitschrift, 11 (3), 109-112.

Kupriyanova, E.K. (1999) The taxonomic status of Serpula cf. columbiana Johnson, 1901 from the American and Asian coast of the North Pacific Ocean (Polychaeta: Serpulidae). Ophelia, 50, 21-34.

Kupriyanova, E.K., \& Jirkov, I.A. (1997) Serpulidae (Annelida Polychaeta) of the Arctic Ocean. Sarsia 82, $203-236$.

Kupriyanova, E.K., Nishi, E., Hove, H.A. ten \& Rzhavsky, A.V. (2001) A review of life-history patterns in serpulimorph polychaetes: Ecological and evolutionary perspectives. Oceanography and Marine Biology: An Annual Review, 39, $1-100$.

Kupriyanova, E.K. \& Rzhavsky, A.V. (1993) Serpula and Crucigera (Annelida, Polychaeta) of the Russian Far Eastern Seas. Ophelia, 38, 47-54.

Lamarck, J.B. de (1818) Histoire Naturelle des animaux sans vertèbres, présentant ... Part 5. Deterville and Verdiere, Paris, 612 pp. [Annélides, 274-374]

Langerhans, P. (1880) Die Wurmfauna von Madeira. III. Zeitschrift für Wissenschaftliche Zoologie, Leipzig, 34, 87-143.

Laubier, L. (1966) Sur quelques Annélides Polychètes de la région de Beyrouth. American University of Beirut Miscellaneous Papers, 5, 9-22.

Lavee, D. \& Ritte, U. (1994) 3.5 Genetic variability and success in colonization in two intertidal mussels. In: Beaumont, A.R. (Ed.). Genetics and Evolution of Aquatic Organisms. Chapman \& Hall, London, Glasgow, New York, Tokyo, Melbourne, Madras, pp. 168-176.

Lavie, B. \& Nevo, E. (1986) Genetic diversity of marine gastropods; contrasting strategies of Cerithium rupestre and $C$. scabridum in the Mediterranean Sea. Marine Ecology Progress Series, 28, 99-103.

Lewis, J.A., Watson, C. \& Hove, H.A. ten (2006) Establishment of the Caribbean serpulid tubeworm Hydroides sanctaecrucis Krøyer [in] Mörch, 1863, in northern Australia. Biological Invasions 8, 4, 665-671. 
Link, H., Nishi, E., Tanaka, K., Bastida-Zavala, R., Kupriyanova, E.K., \& Yamakita, T. (2009) Hydroides dianthus (Polychaeta: Serpulidae), an alien species introduced into Tokyo Bay, Japan. Marine Biodiversity Records, 2, 1-5, Cambridge University Press (doi:10.1017 / S1755267209000931).

Linnaeus, C. von (1758) Systema Naturae, 10th edition, Vol. 1. L. Salvius, Holmiae, 823 pp.

Linnaeus, C. von (1767) Systema Naturae, $12^{\text {th }}$ edition. Vol. 1, Part 3. L. Salvius, Holmiae, pp. 533-1327.

LoBianco, S. (1892) Gli Anellidi tubicoli trovati nel Golfo di Napoli. Atti della Reale Accademia di Scienze Fisiche e Matematiche, (2) 5, 11, 1-97.

Lotan, A., Fine, M. \& Ben-Hillel, R. (1994) Synchronization of the life cycle and dispersal pattern of the tropical invader scyphomedusan Rhopilema nomadica is temperature dependent. Marine Ecology Progress Series, 109, 59-65.

Luksch, J. (1901) Expedition S. M. Schiff "Pola” in das Rothe Meer. XVIII. Physikalische Untersuchungen. Denkschriften der Mathematisch-Naturwissenschaftliche Klasse, Wien, 69, 337-398.

Marenzeller, E. von (1885 [1884]) Südjapanische Anneliden. II. Ampharetea, Terebellacea, Sabellacea, Serpulacea. Denkschriften der Königliche Akademie der Wissenschaften, Wien, 49 (2), 197-224.

Marenzeller, E. von (1893) Polychaeten des Grundes, gesammelt 1890, 1891 und 1892. Denkschriften der Mathematisch-Naturwissenschaftliche Classe der Kaiserlichen Akademie der Wissenschaften, Wien, 60, 25-48.

Mayr, E. (1942) Systematics and origin of species. Columbia University Press, New York, 334 pp.

Mayr, E. (1963) Animal Species and Evolution. Belknap Press, Harvard University Cambridge, Mass., 797 pp.

McIntosh, W.C. (1885) Report on the Annelida Polychaeta collected by H.M.S. "Challenger" during the years $1873-$ 1876. Challenger Reports, 12 (Zoology), 554 pp.

Mesnil, F. \& Fauvel, P. (1939) Polychètes sédentaires de l'Expédition du "Siboga". Maldanidae, Cirratulidae, Capitellidae, Sabellidae et Serpulidae. Siboga Expeditie, 24 (2) 1-42.

Mienis, H.K. (2002) Is the Lessepsian migrant Cellana rota replacing native limpets along the Mediterranean coast of Israel? The Conchologists' Newsletter, 163, 275-276.

Mienis, H.K. (2003) Native marine molluscs replaced by Lessepsian migrants. Tentacle, 11, 15-16.

Mienis, H.K. (2004) New data concerning the presence of Lessepsian and other Indo-West-Pacific migrants among the molluscs in the Mediterranean Sea with emphasis on the situation in Israel. In: Öztürk, B. \& Salman, A. (Eds), Proceedings of the $1^{\text {st }}$ National Malacology Congress, 1-3 September 2004, Izmir. Turkish Journal of Aquatic Life, 2 (2), 117-131.

Mienis, H.K., Galili, E. \& Rapoport, J. (1993) The spiny oyster, Spondylus spinosus, a well-established Indo-WestPacific bivalve in the eastern Mediterranean off Israel, Mollusca, Bivalvia, Spondylidae. Zoology of the Middle East, 9, 83-91.

Minchin, D. \& Gollasch, S. (2003) Fouling and ship's hulls: How changing circumstances and spawning events may result in the spread of exotic species. Biofouling, 19, 111-122.

Miura, T. \& Kajihara, T. (1984) An ecological study of the life histories of two Japanese serpulid worms, Hydroides ezoensis and Pomatoleios kraussii. In: Hutchings, P.A. (Ed.). Proceedings of the First International Polychaete Conference, Sydney, Australia, July 1983. The Linnaean Society of New South Wales, Sydney, pp. 338-354.

Mohammad, M.-B.M. (1971) Intertidal polychaetes from Kuwait, Arabian Gulf, with descriptions of three new species. Journal of Zoology, London, 163, 285-303.

Mohammad, M.-B.M. (1975) Competitive relationship between Balanus amphitrite amphitrite and Pomatoleios kraussii with special reference to their larval settlement. Hydrobiologia, 46, 1-15.

Mohammad, M.-B.M. (1976) Relationship between biofouling and growth of the pearl oyster Pinctada fucata in Kuwait, Arabian Gulf. Hydrobiologia, 51 (2), 129-138.

Mohammad, M.-B.M. (1981) Malformations in some polychaete annelids from Kuwait, Arabian Gulf. Hydrobiologia, 78, 129-131.

Mona, M.H. (1992) Gametogenic cycle of the tube worm Hydroides dirampha (Polychaeta, Serpulidae) from Lake Timsah (Suez Canal, Egypt). Delta Journal of Science, 16 (1), 244-261.

Monod, T. (1976). Expedition "Rumphius" II (1975). Crustacés parasites, commensaux, etc. I. Introduction. Bulletin de la Musée nationale d'Histoire naturelle, Paris, Série 3, 391 (Zoologie 273), 833-843.

Monro, C.C.A. (1937) Polychaeta. The John Murray Expedition Scientific Reports, 4 (8), 243-321.

Montagu, G. (1803) Testacea Brittanica, or, Natural history of British Shells, marine, land- and fresh-water, including the most minute: Systematically arranged and embellished with figures. Part II, J.S. Hollis, London, pp. $293-606$.

Moore, J.P. (1923) The polychaetous annelids dredged by the U.S.S. "Albatross" off the coast of southern California in 1904. Spionidae to Sabellariidae. Proceedings of the Academy of Natural Sciences of Philadelphia, 75, 179-259.

Moran, P.J. (1984) Variability in the opercular structures of the serpulid polychaete Hydroides elegans (Haswell). Proceedings of the Linnean Society of New South Wales, 107 (4), 487-492.

Mörch, O.A.L. (1863) Revisio critica Serpulidarum. Et bidrag til røromenes naturhistorie. Naturhistorisk Tidsskrift Henrik Krфyer, Kobenhavn (Ser. 3), 1, 347-470.

Morcos, S.A. (1960) Die Verteilung des Salzgehaltes im Suez-Kanal. Kieler Meeresforschungen, 16 (2), $133-154$.

Morcos, S.A. (1967) The chemical composition of the water from the Suez Canal Region. Part I: The major anions. Kieler Meeresforschungen, 23, 80-90.

Morcos, S.A. (1970) Physical and chemical oceanography of the Red Sea. In: Barnes, H. (Ed.) Oceanography and Marine Biology Annual Review, 8, 73-202. 
Morcos, S.A. \& Messieh, S.N. (1973) The circulation and salinity distribution in the southern part of the Suez Canal. Limnology and Oceanography, 18 (1), 121-130.

Moritz, B., (1998-2003) Maritime topics on stamps: The Great Bitter Lake Locals. Available from: http://www.shipsonstamps.org/Topics/html/gbla.htm/ (November 2010).

Natterer, K. (1898) Expedition S.M. Schiff "Pola" in das Rothe Meer, nördliche Hälfte (October 1895-Mai 1896). Chemische Untersuchungen. Denkschriften der Mathematisch-Naturwissenschaftliche Klasse, Wien, 65, 445-572.

Nishi, E. \& Nishihira, M. (1997) Multi-clonal pseudo-colony formation in the calcareous tube worm Salmacina dysteri (Huxley) (Serpulidae, Polychaeta). Natural History Research, 4 (2), 93-100.

Nogueira, J.M.M. de, \& Hove, H.A. ten (2000) On a new species of Salmacina Claparède, 1870 (Polychaeta: Serpulidae) from São Paulo State, Brazil. Beaufortia, 50, 151-161.

Nogueira, J.M.M. de, \& Abbud, A. (2009) Three new serpulids (Polychaeta: Serpulidae) from the Brazilian Exclusive Economic Zone. Zoosymposia, 2, 201-227.

Oren, O.H. (1952) Some hydrographical features observed off the coast of Israel. Bulletin de l'Institut Océanographique, Monaco, 1017, 1-9.

Oren, O.H. (1962) A note on the hydrography of the Gulf of Eylath (Aqaba). Sea Fisheries Research Station Bulletin, 30 , 3-14.

Oren, O.H. (1964) Hydrography of Dahlak Archipelago (Red Sea). Israel South Red Sea Expedition, 1962, Reports, 1, 322, Sea Fisheries Research Station, 35, 3-22.

Oren, O.H. (1969) Oceanographic and biological influence of the Suez Canal, the Nile and the Aswan Dam on the Levant basin. Reports on Progress in Oceanography, 5, 161-167.

Oren, O.H. (1970) The Suez Canal and the Aswan High Dam-their effect on the Mediterranean. Underwater Science and Technology Journal. Dec., 1970, 2, 222-229.

Pallas, P.S. (1766) Miscellanea Zoologica. Petrum van Cleef. Hagae Comitum (The Hague), 224 pp.

Parab, P.P. \& Gaikwad, U.D. (1989) Occurrence and ecology of Serpula indica sp. nov. (Serpulidae-Polychaeta) from Ratnagiri coast. Journal of Ecobiology, 1, 223-232.

Perthuisot, J.-P., Guelorget, O., Ibrahim, A., Jusserand, C., Margerel, J.-P. \& Maurin, A. (1900) L'organisation biogéologique de lac Temsah (Ismaïlia, Égypte). Revue d'Hydrobiologie Tropicale, 23 (1), 77-90.

Philippi, A. (1844) Einige Bemerkungen über die Gattung Serpula, nebst Aufzählung der von mir im Mittelmeer mit dem Thier beobachteten Arten. Archiv für Naturgeschichte, 10, 186-198 (translated in Annals and Magazine of Natural History, London, 1 (14), 153-162).

Pillai, T.G. (1960) Some marine and brackish-water Serpulid Polychaeta from Ceylon, including new genera and species. Ceylon Journal of Science (Biological Science), 3, 1, 1-40.

Pillai, T.G. (1965) Annelida Polychaeta from the Philippines and Indonesia. Ceylon Journal of Science (Biological Science), 5 (2) 110-177.

Pillai, T.G. (1971) Studies on a collection of marine and brackish-water polychaete annelids of the family Serpulidae from Ceylon. Ceylon Journal of Science (Biological Science), 9, 2, 88-130.

Pillai, T.G. (2009) Descriptions of new serpulid polychaetes from the Kimberleys of Australia and discussion of Australian and Indo-West Pacific species of Spirobranchus and superficially similar taxa. Records of the Australian Museum, 61, 93-199.

Pillai, T.G. \& Hove, H.A. ten (1994) On recent species of Spiraserpula Regenhardt, 1961, a serpulid polychaete genus hitherto known only from Cretaceous and Tertiary fossils. Bulletin of the British Museum (Natural History), Zoology, London, 60, 39-104.

Pixell, H.L.M. (1913) Polychaeta of the Indian Ocean, together with some species from the Cape Verde Islands. Transactions of the Linnean Society of London (Zoology), 16, 69-92; London. (Vol. 5, The Reports of the Percy Sladen Trust Expedition to the Indian Ocean in 1905).

Por, F.D. (1969) The Canuellidae (Copepoda: Harpacticoida) in the waters around the Sinai Peninsula and the "problem" of the "Lessepsian" migration of this family. Israel Journal of Zoology, 18, 169-178.

Por, F.D. (1972) Hydrobiological notes on the high-salinity waters of the Sinai Peninsula. Marine Biology, 14, 111-119.

Por, F.D. (1978) Lessepsian Migration. The influx of Red Sea biota into the Mediterranean by way of the Suez Canal. Springer Verlag, Berlin [Ecological Studies, 23], 225 pp.

Por, F.D. (1989a) Lessepsian migration: A historical appraisal. In: Spanier, E., Steinberger, Y. \& Luria, M. (Eds), Environmental Quality and Ecosystem Stability. Vol. IV-B: Israel Society for Ecology \& Environmental Quality Sciences (ISEEQS) Publication, Jerusalem, pp. 195-203.

Por, F.D. (1989b) The Legacy of Tethys. An Aquatic Biogeography of the Levant. Kluwer Academic Publishers. Dordrecht, The Netherlands, $214 \mathrm{pp}$.

Por, F.D. (1990) Lessepsian migration. An appraisal and new data. In: Godeaux, J. (Ed.); A propos des migrations lessepsiennes. Bulletin de l'Institut Océanographique, Monaco, numéro spécial, 7, 1-11.

Por, F.D. (1997) Monitoring and studying Lessepsian migration. Working paper. In: Papaconstantinou, C. (Ed.) Workshop on Mediterranean Marine Biodiversity, Nicosia, Cyprus, May 1997, CIESM Workshop Series, 1. Monaco, pp. 34-39.

Por, F.D. \& Dimentman, Ch. (1985) Chapter 25. Continuity of Messinian biota in the Mediterranean Basin. In: Stanley, D.J. \& Wezel, F.-C. (Eds), Geological Evolution of the Mediterranean Basin. Springer-Verlag, New York, Heidel- 
berg, Tokyo, 571 pp. (pp. 545-557).

Por, F.D. \& Dimentman, Ch. (2006) Mare Nostrum: Neogene and anthropic natural history of the Mediterranean with emphasis on the Levant. Pensoft, Sofia-Moscow, 349 pp.

Por, F.D. \& Dor, I. (1975). Ecology of the metahaline pool of Di Zahav, Gulf of Elat, with notes on the Siphonocladacea and the typology of near-shore marine pools. Marine Biology, 29 (1) 37-44.

Por, F.D. \& Ferber, I. (1972) The Hebrew University-Smithsonian University collections from the Suez Canal (19671972). Israel Journal of Zoology, 21, 149-166.

Por, F.D. \& Ferber, I. (1977) Circular letter-Additional Collections from the Suez Canal, sent to specialists associated with the Hebrew University-Smithsonian Institution Joint Program, "Biota of the Red Sea and the Eastern Mediterranean", $1 \mathrm{p}$.

Por, F.D., Steinitz, H., Ferber, I. \& Aron, W. (1972) The biota of the Red Sea and the Eastern Mediterranean (19671972). A survey of the marine life of Israel and surroundings. Israel Journal of Zoology, 21, 459-523.

Potts, F.A (1928) Zoological Results of the Cambridge Expedition to the Suez Canal. Report on the annelids (sedentary polychaetes). Transactions of the Zoological Society of London, 22 (5) 693-705.

Quatrefages, A. de (1866). Histoire naturelle des Annelés marins et d'eau douce. Annélides et Géphyriens. 2 volumes and atlas: Vol. 1: 1-588, vol. 2 (1): 1-336; vol. 2 (2): 337-794. Librairie Encyclopédique de Rôret, Paris.

RAFIMAR International Multimodal Transport. Available from: http://rafimar.com/suez/suez_canal.html/ (accessed 2009).

Ramadan, S.E., Kheirallah, A.M. \& Abdel-Salam, K.M. (2006) Marine fouling community in the Eastern harbour of Alexandria, Egypt compared with four decades of previous studies. Mediterranean Marine Science, 7 (2), 19-29.

Read, G.B., \& Gordon, D.P. (1991) Adventive occurrence of the fouling serpulid Ficopomatus enigmaticus (Polychaeta) in New Zealand. New Zealand Journal Marine and Freshwater Research, 25, 269-273.

Reish, D.J. (1968) The polychaetous annelids of the Marshall Islands. Pacific Science, 22, 2, 208-231.

Rioja, E. (1917) Datos para el conocimiento de la fauna de Anélidos Poliquetos del Cantábrico. Trabajos del Museo Nacional de ciencias naturales de Madrid (Zoologia), 29, 1-111.

Rioja, E. (1923) Estudio systemático de las especies Ibéricas del suborden Sabelliformia. Trabajos del Museo Nacional de Ciencias Naturales de Madrid (Zoológica), 48, 1-144.

Rioja, E. (1931) Estudio de los poliquetos de la Península Ibérica. Memorias de la Academia de Ciencias Exactas, Fisicas y Naturales de Madrid 2. Serie Ciencias Naturales, 2, 1-472.

Risso, A. (1826) Histoire Naturelle des principales productions de l'Europe Meridionale et particulièrement de celles des environs de Nice et des Alpes Maritimes. IV, Mollusques, Annélides. Paris, VII + 439 pp., 12 pls. [Annélides, pp. 397-432].

Ritte, U. \& Pashtan, A. (1982) Extreme levels of genetic variability in two Red Sea Cerithium species (Gastropoda: Cerithidae). Evolution, 36, 403-407.

Rosenfeldt, P. (1989) Die Polychaeta der Rotmeer-Expeditionen MESEDA I (19770 mit FS "Sonne" und MESEDA II (1979) mit FS "Valdivia". Senckenbergiana Biologica, 69 (1/3), 213-242.

Saad, M.A.H. (1974) Calcareous deposits of the brackish-water lakes in Egypt. Rapport et procès-verbaux des réunions, Commission internationale pour l'Exploration scientifique de la Mer Méditerranée, 22 (6), 53.

Safriel, U.N. \& Ritte, U. (1980) Criteria for the identification of potential colonizers. Biological Journal of the Linnean Society, London, 13, 287-297.

Safriel, U.N. \& Ritte, U. (1983) Universal correlates of colonizing ability. In: Swingland, I. R. \& Greenwood, P. J. (Eds), The Ecology of Animal Movement. Clarendon Press, Oxford, pp. 215-223.

Safriel, U.N. \& Ritte, U. (1985) Suez Canal migration and Mediterranean colonization-their relative importance in Lessepsian migration. Commission internationale pour l'Exploration scientifique de la Mer Méditerranée, 29 (5), $159-262$.

Safriel, U.N. \& Ritte, U. (1986) Population Biology of Suez Canal migration-which way, what kind of species and why. In: Karlin, S. \& Nevo, E. (Eds), Evolutionary Processes and Theory. Academic Press, Inc., New York, San Francisco and London, pp. 561-582.

Safriel, U.N., Gilboa, A. \& Felsenburg, T. (1980) Distribution of rocky intertidal mussels in the Red Sea Coasts of Sinai, the Suez Canal and the Mediterranean coast of Israel, with special reference to recent colonizers. Journal of Biogeography, 7, 39-62.

Saint-Joseph, A. de (1894) Les annélides polychètes des Côtes de Dinard. Pt. 3. Annales des Sciences naturelles (Zoologie et Paléontologie, series 7), 17, 1-395.

Savigny, J.C. (1820 [1822]) Système des Annélides, principalement de celles des côtes de l'Égypte et de la Syrie, offrant les caractères tant distinctifs que naturels des ordres, familles et genres, avec la description des espèces. Déscription de l'Égypte, Histoire Naturelle. l'Imprimerie Royale, Paris I (3), 128 pp.

Scacchi, A. (1836) Catalogus conchyliorum regni Neapolitani quae usque adhuc reperit A. Scacchi. Neapoli, $18 \mathrm{pp}$.

Schander, C. \& Halanych, K.M. (2003) DNA, PCR and formalinized animal tissue-a short review and protocols. Organisms, Diversity and Evolution, 3, 195-205.

Scheltema, R.S., Williams, I.P., Shaw, M.A. \& Loudon, C. (1981) Gregarious settlement by the larvae of Hydroides dianthus (Polychaeta: Serpulidae). Marine Ecology Progress Series, 5, 69-74.

Schmarda, L.K. (1861) Neue wirbellose Thiere beobachtet und gesammelt auf einer Reise um die Erde 1853 bis 1857. I. 
Turbellarien, Rotatorien und Anneliden (2). Verlag von Wilhelm Englemann, Leipzig, 164 pp.

Selim, S.A. (1996a) New record of polychaete annelids from Alexandria waters, Egypt. Journal of the Egyptian German Society of Zoology, 21 (D), 75-87.

Selim, S.A. (1996b) Notes on the distribution of polychaetes along Alexandria coast, Egypt. Bulletin of the High Institute of Public Health, 26 (2), 341-350.

Selim, S.A. (1997a) Assessment of polychaete fauna in the eastern harbour of Alexandria, Egypt. Bulletin of the High Institute of Public Health, 27 (1), 131-146.

Selim, S.A. (1997b) Description and remarks on Suez Canal serpulids (Polychaeta). Journal of the Egyptian German Society of Zoology, 22 (D), 87-110.

Selim, S.A. (2009) Polychaete fauna of the north part of the Suez Canal (Pourt-Said-Toussoum). Egyptian Journal of Aquatic Research, 35 (1), 69-88.

Selim, S.A., Abd-Elnaby, F., Gab-Alla, A.A.-F.A. \& Ghobashy, A. (2005) Gametogenesis and spawning of Spirobranchus tetraceros (Polychaeta, Serpulidae) in Abu Kir Bay, Egypt. Mediterranean Marine Science, 6 (1), 89-97.

Seurat, L.G. (1934) Formations littorales et estuaires de la Syrte Mineure (Golfe de Gabès). Bulletin Station Océanographique de Salammbô, 32, 1-65.

Shakman, E.A. \& Kinzelbach, R. (2008) Non-native fish species of the Lybian coast. Middle Eastern Biodiversity Congress, Aqaba, 20-23 October 2008, p. 164.

Shalla, S.H.A., Ghobashy, A.F.A. \& Hartnoll, R.G. (1995) Studies on the barnacle Balanus amphitrite Darwin, 1854, Cirripedia) from Lake Timsah in the Suez Canal. Crustaceana, 68 (4), 503-517.

Shalla, S.H.A. \& Holt, T.J. (1999) The Lessepsian migrant Pomatoleios kraussii (Annelida Polychaeta)—Recent formation of dense aggregations in Lake Timsah and the Bitter Lakes (Suez Canal, Egypt). Egyptian Journal of Biology, 1, $133-137$.

Shefer, S., Abelson, A., Mokady, O. \& Geffen, E. (2004) Red to Mediterranean Sea bioinvasion: Natural drift through the Suez Canal, or anthropogenic transport. Molecular Ecology, 13, 2333-2343.

Siokou-Frangou, I., Sarantakos, K. \& Christou, E. D. (2006) First record of the scyphomedusa Rhopilema nomadica Galil, 1990 (Cnidaria: Scyphozoa: Rhizostomeae) in Greece. Aquatic Invasions 1, 3, 194-195.

Smith, R.S. (1985) Photoreceptors of Serpulid Polychaetes. Doctoral dissertation, James Cook University, Townsville, Queensland, Australia, 3 vols, 539 pp.

Soliman, G.F., Morcos, S.A. \& Helali, N.A. (1988) The exchange of water through the Mediterranean and the Red Sea through the Suez Canal. Bulletin of the Institute of Oceanography and Fisheries of the Arab Republic of Egypt, 14 (1), 205-223.

Spanier, E. \& Galil, B.S. (1991) Lessepsian Migration: A continuous biogeographical process. Endeavour, New Series, 15 (3), 102-106.

Spanier, E., Tom, M., Pisanty, S. \& Almog-Shtayer, G. (1989) Comparison between Lessepsian migrants and local species in the fish community of shallow shelf of northern Israel. In: Spanier, E., Steinberger, Y. \& Luria M. (Eds), Environmental Quality and Ecosystem Stability, Vol. IV-B. Israel Society for Ecology \& Environmental Quality Sciences (ISEEQS) Publication, Jerusalem, pp. 177-186.

Stagl, V., Sattmann, H. \& Dworschak, P.C. (1996) The material of the "Pola" Red Sea expeditions (1895-1898) in the collections of the Natural History Museum in Vienna. In: Uiblein, F., Ott, J. \& Stachowitsch, M. (Eds), Deep-sea and extreme shallow-water habitats: Affinities and adaptations. Biosystematics and Ecology Series, 11, $29-41$.

Steinitz, H. (1968) Remarks on the Suez Canal as pathway and as habitat. Rapport et procès-verbaux des réunions, Commission internationale pour l'Exploration scientifique de la Mer Méditerranée, 19 (2), 139-141.

Steinitz, W. (1929) Die Wanderung indopazifischer Arten ins Mittelmeer seit Beginn der Quartärperiode. Internationale Revue der gesamten Hydrobiologie, 22 (1-2), 1-90.

Strathmann, M.F. (1987) Reproduction and development of marine invertebrates of the northern Pacific coast. Data and methods for the study of eggs, embryos, and larvae. University of Washington Press, Seattle \& London, xii +670 pp.

Straughan, D. (1967a) A small collection of Serpulidae (Annelida: Polychaeta) from Darwin, Northern Territory, Australia. Australian Zoologist, 14 (2), 222-225.

Straughan, D. (1967b) Marine Serpulidae (Annelida: Polychaeta) of Eastern Queensland and New South Wales. Australian Journal of Zoology, 15, 201-261.

Straughan, D. (1967c) Some Serpulidae (Annelida: Polychaeta) from Heron Island, Queensland. University of Queensland Papers, Heron Island Research Station Series, 1, 27-45.

Straughan, D. (1969) Intertidal zone-formation in Pomatoleios kraussii (Annelida: Polychaeta). Biological Bulletin, 136 (3), 469-482.

Sturany, R. (1899) Lamellibranchiaten des Rothen Meeres. Expeditionen S.M. Schiff "Pola" in das Rothe Meer (1895 / 96 und 1897 / 98). Zoologische Ergebnisse Wien, 14, 1-41.

Tebble, N. (1959) On a collection of polychaetes from the Mediterranean coast of Israel. Bulletin of the Research Council of Israel, B8 (1), 9-30.

Thorson, G. (1950) Reproductive and larval ecology of marine bottom invertebrates. Biological Reviews, 25, 1-45.

Thorson, G. (1971) Animal migrations through the Suez Canal in the past, recent years and in the future (A preliminary Report). Vie et Milieu, Supplément, 22, 841-846.

Treadwell, A.L. (1906) Polychaetous annelids of the Hawaiian Islands collected by the steamer "Albatross" in 1902. Bul- 
letin of the United States Fish Commission (1903), 23 (3), 1145-1181.

Treadwell, A.L. (1929) New species of polychaetous annelids in the collection of the American Museum of Natural History from Porto Rico, Florida, Lower California and British Somaliland. American Museum Novitates, 393, 1-13.

Uchida, H. (1978) Serpulid tube worms (Polychaeta, Sedentaria) from Japan with the systematic review of the group. Bulletin of the Marine Park Research Station, 2, 1-98.

Unabia, C.R.C. \& Hadfield, M.G. (1999) Role of bacteria in larval settlement and metamorphosis of the polychaete Hydroides elegans. Marine Biology 133, 1, 55-64.

Vadiya, V. \& Shenuda, S. (1985) Role of the Suez Canal and flow from the Nile River in changing the salinity and faune of the Mediterranean Sea. Voprosy Ikhtiologii 1985 (1), 155-156 (translated by Scripta Technica, Inc., 1985, 16, 134-135).

Verrill, A.E. (1873) Results of the recent dredging expeditions on the coast of New England. No. 3. American Journal of Sciences and the Arts, 3 (6), 620-621.

Vine, P.J. (1986) Red Sea Invertebrates. Immel Publishing, London, $224 \mathrm{pp}$.

Vine, P.J. \& Bailey-Brock, J.H. (1984) Taxonomy and ecology of coral reef tube worms (Serpulidae, Spirorbidae) in the Sudanese Red Sea. Zoological Journal of the Linnean Society, 80, 135-156.

Wehe, T. \& Fiege, D. (2002) Annotated checklist of the polychaete species of the seas surrounding the Arabian Peninsula: Red Sea, Gulf of Aden, Arabian Sea, Gulf of Oman, Arabian Gulf. Fauna of Arabia, 19, 7-238.

Weinberg, S. (1996) Découvrir de la Mer Rouge et l'Océan Indien. Nathan, Paris, 415 pp.

Wesenberg-Lund, E. (1949) Polychaetes of the Iranian Gulf. Danish Scientific Investigations in Iran, 4, $247-400$.

Willey, A. (1905) Report on the Polychaeta collected by Professor Herdman, at Ceylon, in 1902. In: Herdman, W.A. (Ed.). Report to the government of Ceylon on the pearl oyster fisheries of the Gulf of Manaar. London, Royal Society, 4, Supplementary Reports, 30, 243-342.

Wu, B.-L., Sun, R.P. \& Chen, M. (1979) Two new species of the Polychaeta from the South China Sea. Oceanic Selections, 2 (2), 89-94.

Wüst, G. (1934) Salzgehalt und Wasser bewegung im Suezkanal. Naturwissenschaften, 22, 446-450.

Zenetos, A., Çinar, M.E., Pancucci-Papadopoulou, M.A., Harmelin, J.G., Furnari, G., Andaloro, F., Bellou, N., Streftaris, N. \& Zibrowius, H. (2005) Annotated list of marine alien species in the Mediterranean with records of the worst invasive species. Mediterranean Marine Science, 6 (2), 63-118.

Zibrowius, H. (1968) Étude morphologique, systématique et écologique, des Serpulidae (Annélida Polychaeta) de la région de Marseille. Recueil des Travaux de la Station Marine d'Endoume, Bulletin, 43 (59), 81-252.

Zibrowius, H. (1971) Les espèces Méditerrannéennes du genre Hydroides (Polychaeta Serpulidae). Remarques sur le prétendu polymorphisme de Hydroides uncinata. Téthys, 2, 691-746.

Zibrowius, H. (1972) Hydroides norvegica Gunnerus, Hydroides azorica n. sp. et Hydroides capensis n. sp. (Polychaeta Serpulidae), espèces vicariantes dans l'Atlantique. Bulletin du Muséum d'Histoire Naturelle, Paris, Série 3, 33 (39), 433-446.

Zibrowius, H. (1973a) Remarques sur trois espèces de Serpulidae acclimatées en Méditerrannée Hydroides dianthus (Verrill, 1873), Hydroides dirampha Mörch, 1863, et Hydroides elegans (Haswell, 1883) Rapport et procès-verbaux des réunions, Commission internationale pour l'Exploration scientifique de la Mer Méditerranée, 21 (9), 683-686.

Zibrowius, H. (1973b) Serpulidae (Annelida Polychaeta) des côtes ouest de l'Afrique et des Archipels Voisins. Annales du Musée Royal de l'Afrique Centrale, Tervuren, Belgique, Série 8, Sciences zoologiques, 207, 1-93.

Zibrowius, H. (1979a). Quelques récoltes de Serpulidae (Annélida Polychaeta) sur les côtes nord de Tunisie. Bulletin de l'Office national de Pêche de Tunisie, 2, 211-222.

Zibrowius, H. (1979b) Serpulidae (Annélida Polychaeta) de l'Océan Indien arrivés sur les côques de bateaux à Toulon (France, Méditerranée). Rapport et procès-verbaux des réunions, Commission internationale pour l'Exploration scientifique de la Mer Méditerranée, 25-26 (4), 133-134.

Zibrowius, H. (1983) Extension de l'aire de répartition favorisée par l'homme chez les Invertébrés marins. Oceanis, 9 (4), 337-353.

Zibrowius, H. (1991) Ongoing modification of the Mediterranean marine fauna and flora by the establishment of exotic species. Mesogée, 51, 83-107.

Zibrowius, H. (1994) Introduced invertebrates: Examples of success and nuisance in the European Atlantic and in the Mediterranean. In: Boudouresque, C.F., Briand, F. \& Nolan, C. (Eds), Introduced species in European coastal waters. Ecosystems Research Report 8, European Commission 15309, 44-49; Luxemburg.

Zibrowius, H. (2002) Assessing scale and impact of ship-transported alien fauna in the Mediterranean? In: Briand, F. (Ed.). Alien marine organisms introduced by ships-Istanbul, 6-9 November, 2002, CIESM Workshop Monographs, 20, 63-68, Monaco (CIESM).

Zibrowius, H. \& Bitar, G. (1981) Serpulidae (Annélida Polychaeta) indo-west-pacifiques établis dans la région de Beyrouth, Liban. Rapport et procès-verbaux des réunions, Commission internationale pour l'Exploration scientifique de la Mer Méditerranée, 27, 159-160.

Zibrowius, H. \& Bitar, G. (2003) Invertebrés marines exotiques sur la côte du Liban. Lebanese Science Journal, 4 (1), 67-74. 


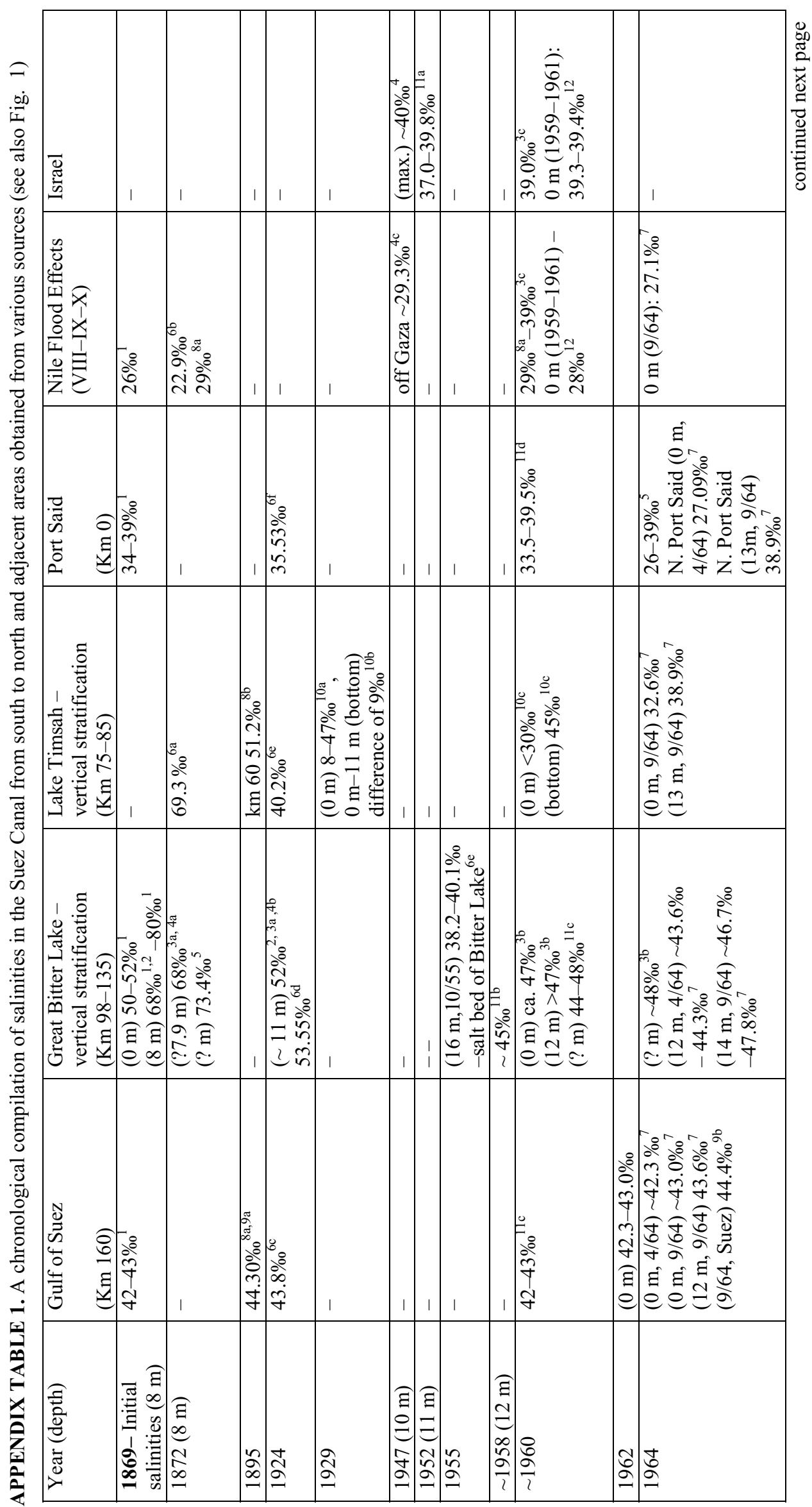




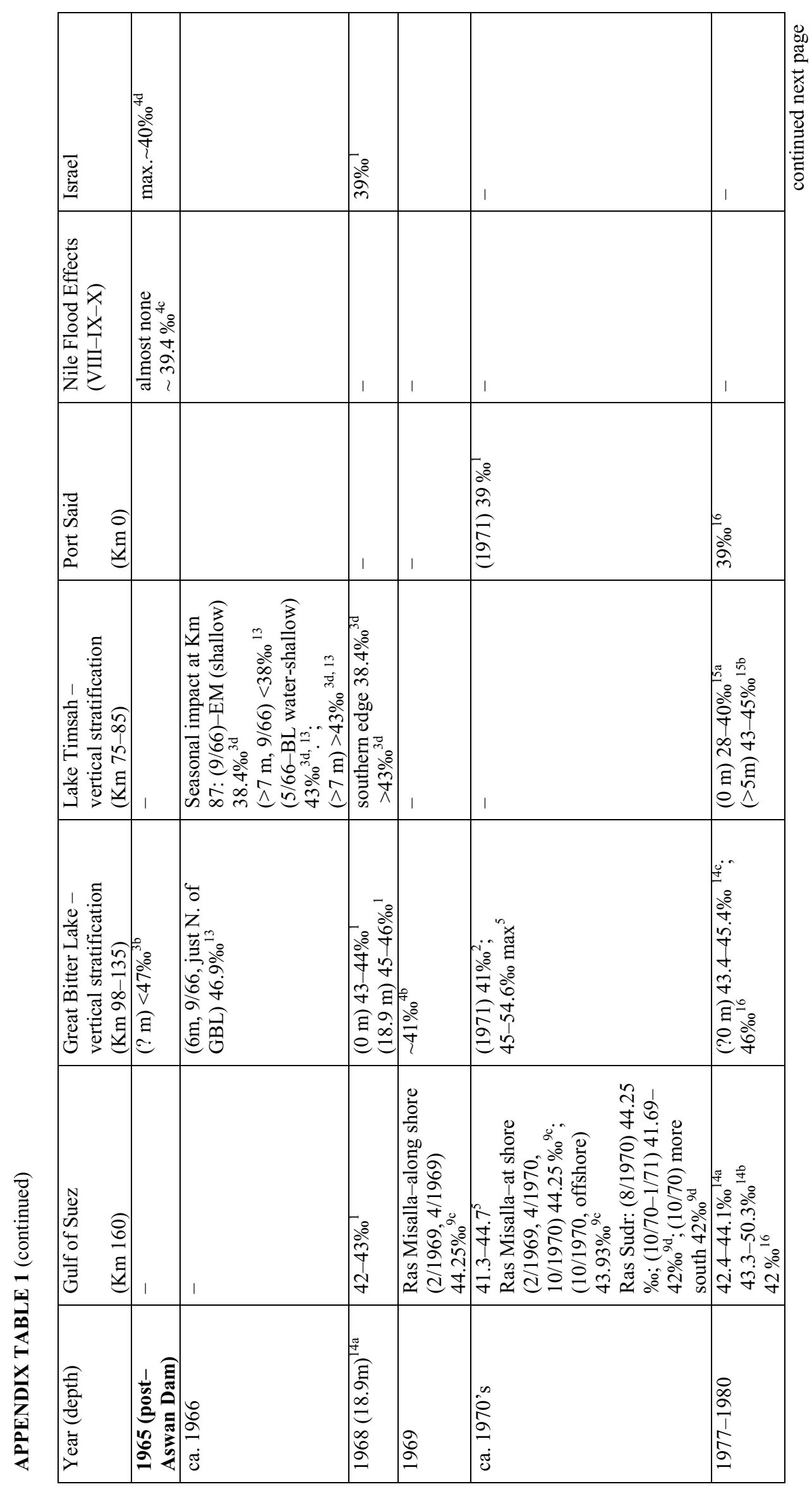




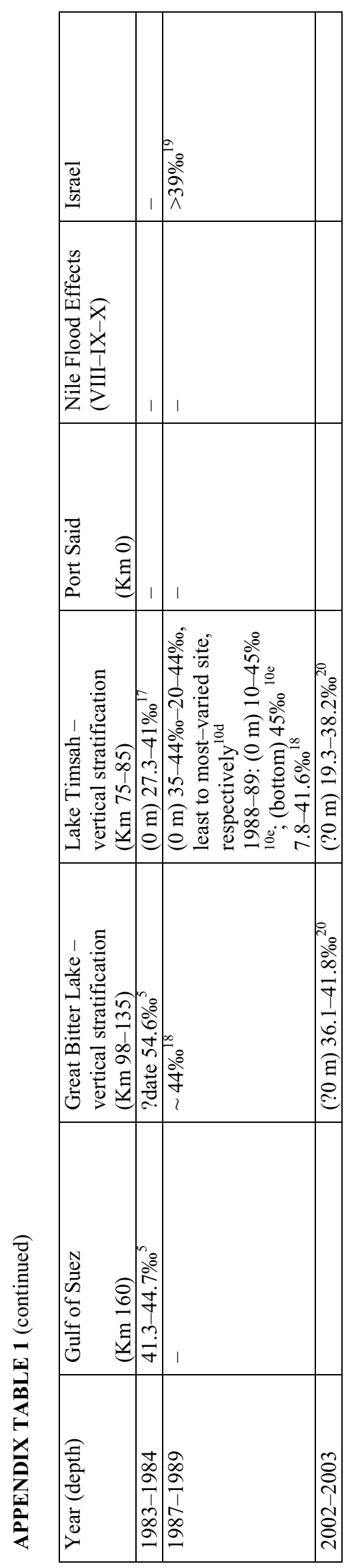

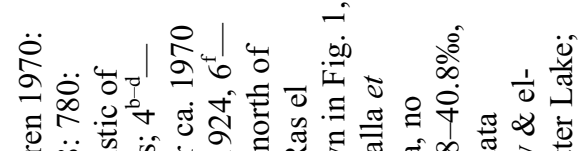

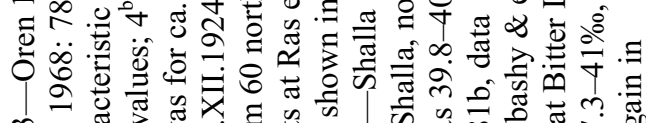
m

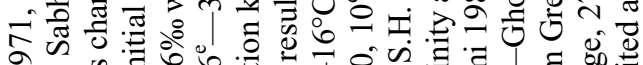

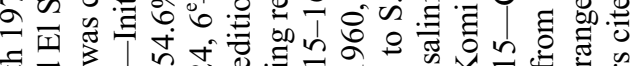

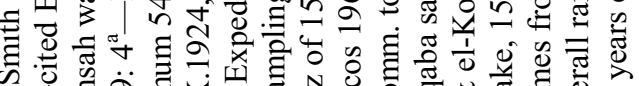
केणीं

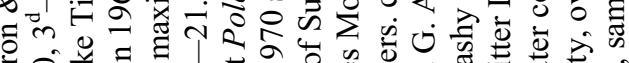

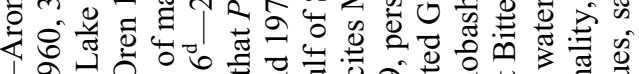
入े

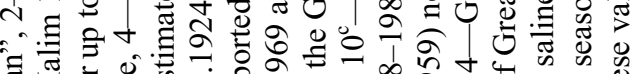

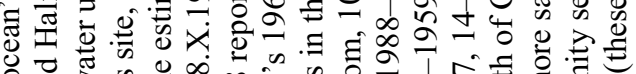

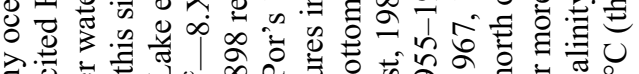

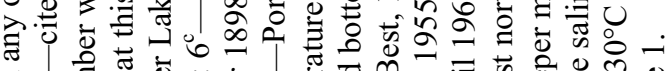

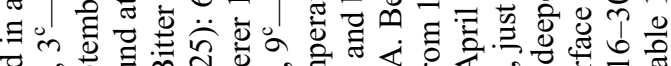

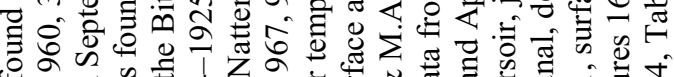

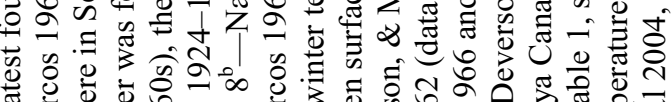

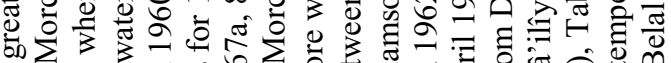

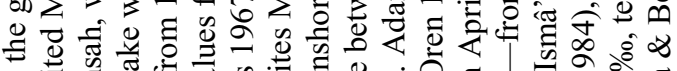
o

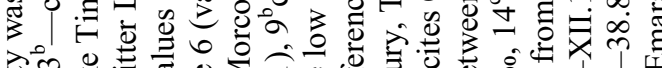

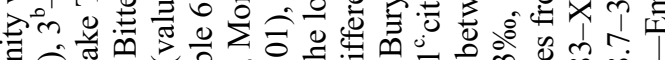

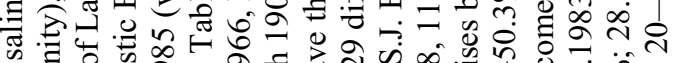
N 出

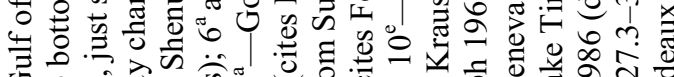

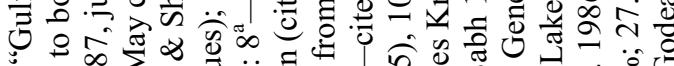

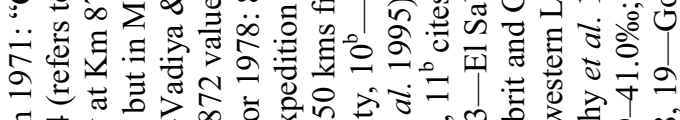

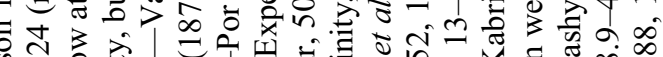

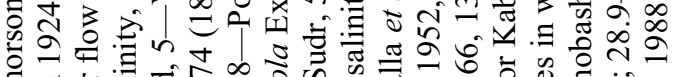

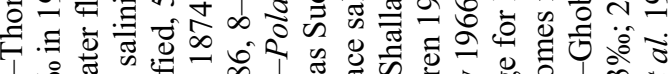

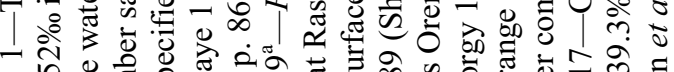

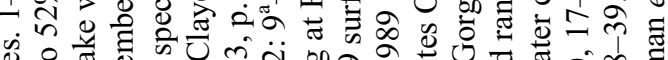

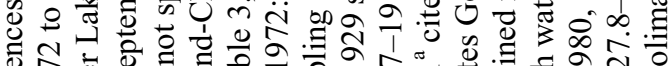

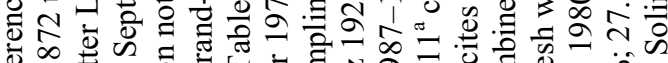

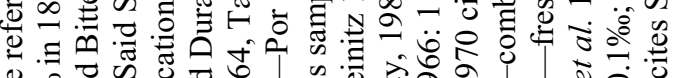
\%

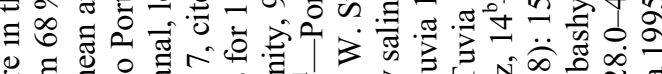

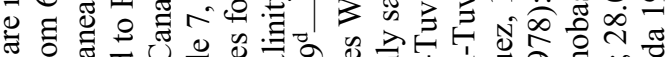

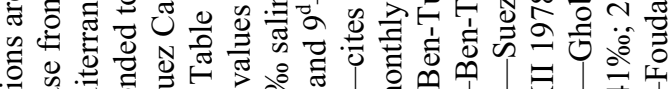

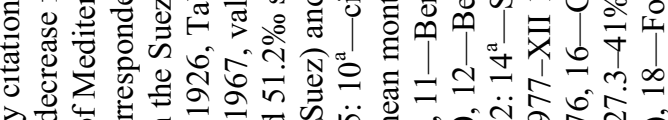

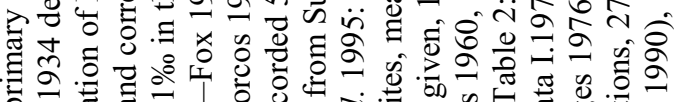

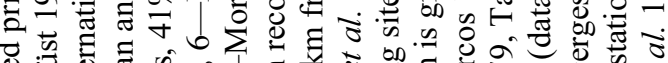

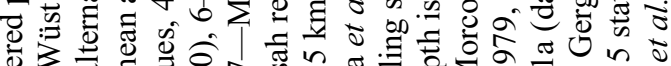

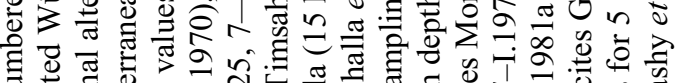

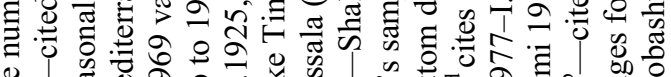

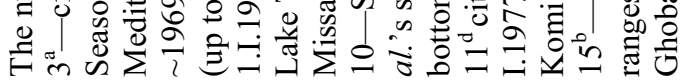


Appendix Table 2. Sources of the "new" sample material—a list of samples and subsamples studied for the present paper (149 samples or subsamples) ${ }^{1}$

A. PREVIOUSLY UNDESCRIBED CAMBRIDGE EXPEDITION, 1924 SERPULIDS (6.X.-29.XII.1924). 6 samples (see Fox 1926 for details of the sampling venues).

Lake Timsah - Km 78

- Isma'iliya, 26.XI.1924, on Malvufundus normalis (previously Malleus anatinus ${ }^{1}$, BM(NH) 1928.3.30.179: Hydroides elegans 1 spec.; H. "priscus" juvenile stage 1 spec.

- T9, shallow, dredge, 6.XII.1924, on Pinctada radiata* (previously Pinctada vulgaris ${ }^{1}$ ), BM(NH) 1928.3.30.83: Hydroides elegans $1 \mathrm{spec}$.

Toussoum - Km 87

- 29.XI.1924, on Crenatula picta (previously C. mytiloides ${ }^{1}$ ), BM(NH) 1928.3.30.343: Hydroides diramphus 1 spec.

- 6.X.-29.XII.1924, on Chama gryphoides, BM(NH) 1928.3.30.344-351: Hydroides elegans 1 spec.

Presumably Port Taufiq

- From "Barge 568" (Potts, 1928: 700, 705 referred to barges only at Port Taufiq; date of collection unknown [J. Pickering, pers. comm.]); on Crenatula picta (previously C. mytiloides ${ }^{1}$ ), $\mathrm{BM}(\mathrm{NH})$ 1928.3.30.190: Hydroides diramphus 1 spec.; H. elegans 1 spec. (juvenile).

- Specific location within the Suez Canal unknown (location details, written by NBE directly on the slide, dissolved in the glycero-formalin mounting medium): Hydroides heterocerus juvenile "form no. 1", 1 spec. (Fig. 9).

B. THE C. BEETS' GREAT BITTER LAKE, 1950 MOLLUSC COLLECTION AT THE NATIONAL MUSEUM OF NATURAL HISTORY NATURALIS, LEIDEN. Dried tubeworms from molluscs from 31 stations at the Great Bitter Lake collected in the summer of 1950 (Beets 1953, fig. 1).

- Stn 1, 1-2.7 m: Fusinus polygonoides [1 spec. (RMNH 18555)]: Taphonomic residues of Hydroides elegans 2 specs: 1 operculum (Fig. 7H [RMNH 18533]); 1 posterior of body RMNH 18546. Cerithium scabridum* [20 specs]: 1-2 abraded tubes, Hydroides sp. (too thick-walled and coarse to belong to H. elegans).

- Stn 4, 0.2-0.75 m: Fusinus polygonoides [1 spec.]: Taphonomic residues of Hydroides elegans 10 specs: Whole dried worms, 5 specs (Fig. 7A), RMNH 18530, 18531, 18548; opercular residues, 4 specs, RMNH 18528 (Fig. 7I), 18532, 18534 and 18547 (Fig. 7D); fascicle of collar chaetae (Fig. 7C) also several empty tubes; also, inquiline syllid polychaetes, 2 specs, RMNH 18536 and 18540. Chicoreus erythraeus: Fragment from operculum; small round smooth tube, Hydroides residues around the mouth. Gafrarium pectinatum* [8 specs]: Each bivalve with 2-3 Hydroides elegans tubes.

- Stn 5, 9 m: Fusinus polygonoides [1 spec.]: Tube with 2 longitudinal ridges, Hydroides ?elegans 1 spec.; thick-walled tube $1 \mathrm{spec}$. Trochus erythreus* [1 spec.]: Hydroides ?elegans 1 spec.

- Stn 6, 5-5.5 m: Cerithium scabridum* [5 specs]: Hydroides elegans 5 specs: 1 small specimen on each gastropod. Trochus erythreus* [5 specs]: H. elegans 5 specs. Perrinia stellata [as Turcica stellata ${ }^{1}, 1$ spec.]: H. elegans 1 spec.

- Stn 7, 0.5-1.5 m: Dosinia erythraea [1 spec.]: Tube with 2 or 3 longitudinal ridges, Hydroides sp. 1 spec.

- Stn 8, 10.4 m: Gastrochaena cymbium* [1 spec.]: 3 different serpulid taxa, Hydroides tubes, large; p.p. Hydroides elegans, 1 a larger tube with 3 longitudinal ridges, probably Hydroides (H. diramphus or H. homoceros); Salmacina sp. tubes.

- Stn 9, 10.6 m: Gastrochaena cymbium* [1 spec.]: Much abraded Salmacina sp. residues; Hydroides tube with three longitudinal ridges, ?H. diramphus $1 \mathrm{spec}$.; $H$. ?elegans-?too rugose $1 \mathrm{spec}$.

- Stn 10, 10.4 m: Brachidontes pharaonis* [1 spec.]: Hydroides elegans 1 spec.; 1 H. ?diramphus 1 spec; Salmacina sp. residues. Loripes fischerianus [1spec.]: H. elegans residues, 2-3 tubes.

- Stn 12, 10 m: Brachidontes pharaonis* [1 spec.]: Unremarkable abraded tube ?Hydroides elegans 1 spec.

- Stn 13, 7 m. Trochus erythreus* [1 spec.]: Hydroides elegans 1 spec. Callista florida [1 spec.]: Tube with three longitudinal ridges, $H$. ?diramphus.

- Stn 14, $8.5 \mathrm{~m}$ : Brachidontes pharaonis* [1 spec.]: Tube with 3 sharp longitudinal ridges together, presumably Hydroides homoceros 1 spec.; H. elegans 2 specs.

- Stn 15, 10.4 m: Chama asperella [1 spec.]: Taphonomic residue of Hydroides steinitzi (Fig. 14), tube and verticil, RMNH 18545; H. elegans [1 spec.]; large fragment with reticulated surface, presumably of Protula, diameter, 3.5almost $4 \mathrm{~mm}$ (Fig. 21A-C). Brachidontes pharaonis* [1 spec.]: H. elegans; ?H. homoceros; maybe $3^{\text {rd }}$ taxon with

1. Identification of molluscs revised by H.K. Mienis; for authors of mollusc taxa, see Appendix Table 3. *Denotes an Indo-Pacific mollusc taxon that has migrated and established populations in the Levant Basin of the Mediterranean, i.e., a Lessepsian migrant mollusc (H.K. Mienis, pers. comm.). 
thicker-walled tube.

- Stn 16, 9.8 m: Brachidontes pharaonis* [6 specs]: Hydroides ?elegans; Hydroides sp. Fusus polygonoides [1 spec.]: inquiline spionid polychaete 1 spec., RMNH 18543.

- Stn 19, 5-5.5 m: Brachidontes pharaonis* [1 spec.]: Hydroides elegans; Hydroides fragment with 3 longitudinal ridges; inquiline eunicid polychaete 1 spec., RMNH 18541. Chama asperella [1 spec.]: Tube with 2 longitudinal ridges, not entirely similar to $H$. elegans, diameter $2 \mathrm{~mm}$, rugose $1 \mathrm{spec}$; H. elegans $1 \mathrm{spec}$; tube of small Protula 1 spec. Gafrarium pectinatum* [1 spec.]: H. elegans; 2 fragments of tube of $2 \mathrm{~mm}$ diameter; group of tubes coarser than H. elegans. Gregariella ehrenbergi [1 spec.]: Hydroides elegans; either H. diramphus or Serpula hartmanae.

- Stn 21, 1.5-3 m: Fusinus polygonoides [1 spec.]: Taphonomic residues of Hydroides elegans (2 specs, verticils: RMNH 18538 and 18549 [Fig. 7G]; assorted inquiline polychaetes 5 specs RMNH 18544; inquiline insect larvae 4 specs, RMNH $185371 \mathrm{spec}$. and 185393 specs Pinctada radiata* [1 spec.]: Rounded tube Hydroides with 3 acute longitudinal ridges closely spaced on the upper surface, presumed H. homoceros; and H. elegans.

- Stn 24, $5.8 \mathrm{~m}$ : Trochus erythreus* [1 spec.]: Hydroides elegans.

- Stn 26, 10.8 m: Brachidontes pharaonis* [1 spec.]: 2-3 Hydroides spp.; inquiline eunicid polychaete, RMNH 18542. Chama asperella [1 spec.]: 1 enormous thick-walled tube of Protula; few fragments of Hydroides spp. Loripes fischerianus [1 spec.]: Hydroides elegans.

- Stn 28, $11.2 \mathrm{~m}$ : Brachidontes pharaonis* [1 spec.]: Abraded fragment of Hydroides elegans.

- Stn 29, 11 m: Brachidontes pharaonis* [1 spec.]: Hydroides elegans.

- Stn 30, 6.9 m: Brachidontes pharaonis* [1 spec.]: Single 3-ridged tube, Hydroides ?homoceros.

- Stn 31, 1.4-1.8 m: Brachidontes pharaonis* [1 spec.]: Hydroides elegans; spirorbids, few specs.

- Stn 33, 3.8 m: Brachidontes pharaonis* [4 specs]: Residues of a Hydroides ?elegans tube; residues of minute? Josephella tubes, in the furrows; Hydroides tube with 3 longitudinal ridges; Salmacina sp. tubes. Callista florida [ 15 specs]: Many presumed H. elegans residues. Malvufundus regulus* [1 spec.]: Residues of H. elegans.

- Stn 34, 6.2 m: Brachidontes pharaonis* [2 specs]: Hydroides elegans 3 specs; Malvufundus regulus* [1 spec.]: Tubes rather abraded, presumed $H$. elegans 3 specs; fragment of minute same or different taxon, possibly Josephella.

- Stn 35, 5.6 m: Brachidontes pharaonis* [1 spec.]: Small Hydroides tubes abraded.

- Stn 39, 10.8 m: Brachidontes pharaonis* [1 spec.]: Large much abraded, presumed Hydroides or Serpula sp. Cerastoderma glaucum [as Cardium edule, $1 \mathrm{spec}$.]: Rugose tube with three longitudinal ridges as in H. diramphus. Several rugose tubes with three longitudinal ridges; one tube with 2 longitudinal ridges possibly Hydroides and possible Serpula spp. Malvufundus regulus* [1 spec.]: H. ?diramphus, spirorbids.

- Stn 42, 2.5 m: Chicoreus erythraeus [as Murex anguliferus, $1 \mathrm{spec}$.$] : Hydroides elegans and abraded tubes. Brachidon-$ tes pharaonis* [1 spec.]: ?Salmacina sp.; Hydroides sp.

- Stn 43, 4.3 m: Brachidontes pharaonis* [1 spec.]: Hydroides elegans; coarser tubes 2 specs.

- Stn 45, 2.65 m: Brachidontes pharaonis* [1 spec.]: Hydroides elegans. Gafrarium pectinatum* [1 spec.]: Serpulid tube, semicircular, without longitudinal ridges $1 \mathrm{spec}$.

- Stn 46, 3.8 m: B. Brachidontes pharaonis* [1 spec.]: Hydroides elegans. Fusinus polygonoides: Hydroides elegans.

- Stn 47, 4.2 m: B. Brachidontes pharaonis* [1 spec.]: Hydroides elegans.

- Stn B3, ? m, on beach. Murex forskoehli* [1 spec.]: Hydroides elegans 1 spec.; ?Josephella, branching tube, diameter $0.18 \mathrm{~mm} 1 \mathrm{spec}$; Salmacina sp. tube $1 \mathrm{spec}$.

C. SERPULIDS FROM HEBREW UNIVERSITY - SMITHSONIAN EXPEDITIONS, 1967-1973 (7 expeditions, 29 samples, compiled from north to south, sample code, SLC): 20-21.VI.1967 and 10.XII.1967. Participants: The late H. Steinitz, leader: A. Amir, Y. Bin-Nun, A. Lourie, D. Masry (Darom) (Por \& Ferber 1972: 149). 11.VII.1968 and 13-14.I.1969. Participants: F.D. Por, leader: G. Eitan, Y. Lipkin, G. Raz and G. Sakhnin (Por \& Ferber 1972: 149). 89.III.1973. Participants: U.N. Safriel, leader: The late S. Ashkenazi, Y. Ayal, M.N. Ben-Eliahu, T. Felsenberg, S. Hayat, M. Horowitz, the late D. Lavee (Ben-Eliahu 1991a, sample code SBE). 8.III.1973 and 26.XII.1973. Participants: Y. Eytam and associates (Eytam 1974, Ben-Eliahu 1991a, sample code SLC, YE).

Port Fouad (swamps)

- SLC 45, on Mollusca (Lamellibranchia sample 87, Pectinidae), 11.VIII.1968: H. elegans 1 spec.; Vermiliopsis infundibulum / glandigera 1 spec.

el Qantara - Km 46

- SLC 6, 3-4 m: 21.VI.1967, mud and stones, on Malvufundus regulus*: Hydroides elegans 1 spec. (juvenile); Spirobranchus tetraceros 1 spec.; on algae, SLC 6 / Phyt 1590: H. elegans 196 specs.

- SLC 20, 0.2 m, canal walls, 10.XII.1967: Hydroides elegans 5 specs.

- SLC 31, 0.5-1.0 m, canal walls, 10.XII.1967: Hydroides elegans 9 specs (3 of them juvenile); Spirobranchus tetraceros $1 \mathrm{spec}$.

- SLC 32, 0.5-0.1 m, canal walls, 10.XII.1967: Hydroides elegans 1 spec. 
- SLC 38, 0.2-0.4 m, canal walls, 10.XII.1967: Hydroides elegans 1 spec.

Lake Timsah, $\mathrm{Km} 78$, opposite Isma'iliya - Km 78

- SLC 4, 0.2-0.5 m, 20.VI.1967, Hydroides elegans 2 specs (both juvenile).

- SBE 5, 0.4 m, 9.III.1973, shore rock: Hydroides elegans 2 specs.

- SBE 7, 9.III.1973, shore dark grey mud with rocks, pebbles, 0.3-0.4 m, rock, ca. $0.4 \mathrm{~m}$ with serpulids: Ficopomatus enigmaticus 2 specs; Hydroides diramphus $30 \mathrm{specs;} H$. elegans $1 \mathrm{spec}$; Spirobranchus tetraceros $1 \mathrm{spec}$.

- SBE 8, 0.4 m, 9.III.1973, encrustation on muddy tin can: Hydroides dirampha 44 specs; Hydroides elegans 39 specs; Hydroides steinitzi 3 specs; Spirobranchus tetraceros 3 specs.

Great Bitter Lake, east of Deversoir - Km 97

- SLC 50 (Porifera 11c), 13.I.1969, sponge cast ashore after storm: Hydroides elegans 18 specs (3 of them juveniles); $H$. homoceros $1 \mathrm{spec}$; Spirobranchus tetraceros $1 \mathrm{spec}$.

- SLC 52, 13.I.1969: Hydroides elegans 1 spec. (juvenile); on Digenea (Phyt 1599): H. homoceros 1 spec.

- SLC 55 (Porifera 14), 13.I.1969: Hydroides elegans 2 specs (juvenile).

- SLC 60, 0.5 m, 13.I.1969: Hydroides elegans 6 specs.

- SLC 61, 13.I.1969, algae cast ashore after storm: Hydroides elegans 6 specs (5 of them juvenile); Spirobranchus tetraceros 1 spec.

- SLC 64, 13.I.1969, on beachrock: Hydroides elegans 4 specs.

- SLC 67, 13.1.1969, on beachrock: Hydroides diramphus 1 spec.; H. elegans 1 spec. (juvenile).

- SLC 71, sublittoral, scuba, 13.I.1969, on Digenea: Hydroides diramphus 1 spec.; Vermiliopsis infundibulum / glandigera 1 spec.; on Laurencia: H. elegans 2 specs; Spirobranchus tetraceros 1 spec.; on Cystoseira myrica: H. elegans 1 spec.; on Sargassum: H. elegans 1 spec.

- SLC 72, 13.1.1969, Hydroides heterocerus 1 spec. (measurements recorded as no. 53 BA).

- SLC 74 (Porifera 20bc), shallow, 13.1.69: Hydroides elegans 2 specs (1 of them juvenile); Hydroides heterocerus 1 spec. (designated as juvenile form no. 1).

- SLC 76 (Porifera 21a), shallow, 13.1.69, sponge covered by filamentous alga: Hydroides elegans 1 spec.

Great Bitter Lake - Km 98

- SLC 3, 0.5-0.8 m, 20.VI.1967: On algae: Hydroides diramphus 2 specs; H. elegans 6 specs.

- SLC 117, YE St. 4, 10 m, grab, 26.XII.1973, legit Y. Eytam; scrapings of the Mollusca, Fulvia fragilis [7 specs]; Pinctada radiata* [1 valve]; Murex forskoehli* [1 spec.]; Chicoreus erythraeus [1 spec.] and Fusinus verrucosus [1 spec.]. Many serpulids in sample generally small, with opercula not fully chitinised: Hydroides diramphus 3 specs; H. elegans 175 specs (109 of them juveniles [spot-checked, some may belong to other Hydroides taxa]); H. heterocerus 1 spec. (designated as juvenile form no. 2); H. homoceros 31 specs; H. steinitzi 1 spec.; H. "priscus" 2 specs, opercula with sharp pointed radii, bayonet chaetae with sharp teeth (on Pinctada radiata*).

- SLC 123, YE, St. 10, shallow, 26.XII.1973, legit Y. Eytam; Bivalvia, Mytilidae, sponges, sandstone: Hydroides elegans 2 specs (juveniles); Hydroides heterocerus 1 spec.; Spirobranchus tetraceros 3 specs.

Little Bitter Lake opp. Kabrit - Km 120.

- SLC 77, 0.5 m, 14.I.1969: Hydroides elegans 1 spec.

- SLC 85, 14.I.1969, on sandstone rock: Hydroides elegans 4 specs (1 of them juvenile); H. steinitzi 3 type specimens.

- SBE 1, rocky promontory, eastern shore, < 0.5 m, 8.III.1973, under rocks: Ficopomatus enigmaticus 1 spec.; Hydroides elegans 1 spec., Hydroides sp. 1 spec. (juvenile); Protula cf. palliata 4 specs, all damaged, on Brachidontes pharaonis.

- SLC 89, 8.III.1973, Hydroides sp. 1 spec. (a juvenile).

Tis'ah - Km 145.

- SLC 2, 20.VI.1967, from pier wall, 2-3 m, on Laurencia: Hydroides elegans 1 spec.

D. GREAT BITTER LAKE “YELLOW FLEET” SHIP-BIOFOULING SAMPLED BY H. BRATTSTRÖM \& J.P. TAASEN, 13-20.I.1975, 81 subsamples, including the three subsamples taken at the Bremerhaven dry dock on 18.VI.1975 (D'). The subsample codes were assigned by Brattström \& Taasen, while the samples were designated B\&T.

Polychaeta subsamples (19)

MS “Killara”-sunny side

- Pol 14, 15.I.1975: Hydroides elegans 1 spec.; H. heterocerus 1 spec.; Spirobranchus tetraceros 2 specs.

- Pol 17, 13-20.I.1975: Hydroides elegans 1 spec.; Protula cf. palliata 1 spec., HUJ-Poly 1564, Spirobranchus tetraceros 1 spec.

- Pol 22, 14.I.1975: Hydroides heterocerus 1 spec.; H. steinitzi 2 specs; Spirobranchus tetraceros 2 specs.

- Pol 25, 16.I.1975: Spirobranchus tetraceros 1 spec.

- Pol 34, 15.I.1975: Hydroides elegans 1 spec.; H. heterocerus 1 spec., somewhat deviant.

- Pol 36, 15.I.1975: Hydroides elegans 1 spec.; H. heterocerus 1 spec.; H. steinitzi 3 specs; Spirobranchus tetraceros 1 
spec.

- Pol 43, 13.I.1975: Salmacina sp. 1 spec.

MS "Killara", no details

- Pol 32, 17.I.1975: Salmacina sp. 1 spec.

- Pol 35, 17.I.1975: Spirobranchus tetraceros 1 spec.

- Pol 41, 18.I.1975: Hydroides heterocerus 1 spec.; Salmacina sp. 1 spec.; Spirobranchus tetraceros 1 spec.

MS "Nordwind"

- Pol 18, 20.I.1975: Spirobranchus tetraceros 21 specs.

- Pol 27, 20.I.1975: Protula cf. palliata 1 spec.

- Pol 37, 20.I.1975: Hydroides heterocerus 4 specs.

- Pol 44, anchor chain, 14.I.1975: Spirobranchus tetraceros 2 specs.

Undesignated ships' hulls

- Pol 21, 13-20.I.1975: Hydroides heterocerus $1+$ +? specs; Spirobranchus tetraceros $1 \mathrm{spec}$.

- Pol 24, 16-20.I.1975: Hydroides heterocerus 1 spec.; Protula cf. palliata 1 spec.; Spirobranchus tetraceros 6 specs.

- Pol 31, 16.I.1975: Hydroides heterocerus 5 specs.

- Pol 26, 13-17.1975: Spirobranchus tetraceros $1 \mathrm{spec}$

- Pol ?, 13-21.I.1975: Hydroides elegans 1 spec.; H. heterocerus 17 specs; H. steinitzi 1 spec., BM(NH) ZB.1985.209; Spirobranchus tetraceros 1 spec.

Scraped from Brachyura, 2 subsamples

- [Dec 3], 13.I.1975: Hydroides elegans sp. 1 spec.; Salmacina sp. 1 spec.

- [Decapoda] 15 crabs (treated as one sample), 13\&15.I.1975: Hydroides elegans 1 spec.; Salmacina sp. 15 specs.

Scraped from Bryozoa, 5 subsamples

- MS “Killara”-sunny side, Bry 1, 13-20.I.1975: Salmacina sp. 1 spec.; Spirobranchus tetraceros 1 spec.

- MS “Killara”-shady side, Bry 2, 13.I.1975: Hydroides elegans 5 (2 of them juvenile); Josephella marenzelleri 8 specs, Salmacina sp. 3 specs.

- Hulls, Bry 5, 17.I.1975: Hydroides elegans 1 spec.; H. heterocerus 28 specs, one with several abnormal spines; $H$. steinitzi 2 specs; Josephella marenzelleri 1 spec.; Salmacina sp. few, Spirobranchus tetraceros 7 specs.

- Hulls, Bry 9, 13.I.1975: Hydroides elegans 1 spec. (juvenile); Salmacina sp. 1 spec.

- MS “Münsterland”, Pol 29, 20.I.1975, on Bryozoa with large empty tubes of Spirobranchus tetraceros, Hydroides and Salmacina sp. 1 spec.: H. elegans 1 spec. (juvenile); H. steinitzi 4 specs; Spirobranchus tetraceros 2 specs.

Scraped from Cirripedia, 2 subsamples

- MS “Killara”-shady side, Cirr 5, 13.I.1975: Hydroides diramphus 1 spec.; Josephella marenzelleri few; Salmacina sp. few.

- Hulls, Cirr 4, 13 \& 18.I.1975: Hydroides heterocerus 1 spec.; Josephella marenzelleri 1 spec.; Salmacina sp. 2 specs; Serpula hartmanae 1 spec.; Spirobranchus tetraceros 1 spec.

Scraped from Spongia, 12 subsamples

- MS “Killara"-sunny side, Spo 5, 13.I.1975: Spirobranchus tetraceros 1 spec.

- MS “Killara”-sunny side, Spo 8, 16.I.1975: Hydroides steinitzi 1 spec.; Spirobranchus tetraceros 3 specs.

- MS “Killara”, "Marit”, "Essayon”, Spo 12, 20.I.1975: Hydroides diramphus 1 spec.; H. elegans 2 specs (juveniles); H. steinitzi 2 specs; Josephella marenzelleri 31 specs; Salmacina sp. few; Spirobranchus tetraceros 4 specs.

- MS “Killara”-sunny side, Spo 13, 20.I.1975: Hydroides homoceros $1 \mathrm{spec}$.; Spirobranchus tetraceros 1 spec.

- MS “Killara”-sunny side, Spo 14, 20.I.1975: Salmacina sp. 3 specs.

- MS “Killara”-sunny side, Spo 16, 15.I.1975: Hydroides heterocerus 1 spec.

- Hulls, Spo 17, 16.I.1975: Josephella marenzelleri 2 specs.

- MS “Killara”, Spo 24, 16\&18.I.1975: Hydroides homoceros 1 spec.

- MS “Killara”-sunny side, Spo 25, 15.I.1975: Hydroides ?elegans 1 spec.; H. heterocerus $10+$ ? 1 specs; H. steinitzi 1 spec.; Serpula hartmanae $1 \mathrm{spec}$; Spirobranchus tetraceros $1 \mathrm{spec}$.

- Hulls, Spo 27, 13.I.1975: Salmacina sp. 1 spec.; Spirobranchus tetraceros 2 specs.

- MS “Killara”, Spo 31, 15.I.1975: Hydroides elegans 1 spec.; H. ?heterocerus 1 spec.

- MS “Killara”-sunny side, Spo 32, 13.I.1975: Salmacina sp. aggregate; Spirobranchus tetraceros 1 spec.

- MS “Killara”, Spo 33, 13.I.1975: empty tubes of Hydroides, not H. elegans, with 2 strong longitudinal ridges. Scraped from Tunicata, 11 subsamples.

- MS “Killara"-sunny side, Tun 12, 13\&15.I.1975: Josephella marenzelleri 2 specs.

- MS “Killara"-sunny side, Tun 17, 13.I.1975: Hydroides sp. 1 spec. (juvenile); Spirobranchus tetraceros 1 spec.

- MS “Killara”-shady side, Tun 3, 16.I.1975: Josephella marenzelleri 1 spec.; Spirobranchus tetraceros 1 spec.

- MS "Killara”-mostly shady, Tun 8, 17.I.1975: Hydroides heterocerus 6 specs; H. homoceros 1 spec.; Josephella marenzelleri 2 specs; Spirobranchus tetraceros 7 specs.

- MS “Killara", Tun 6, 13.I.1975: Hydroides elegans 1 spec. (juvenile); Salmacina sp. 1 spec.

- MS “Killara”, Tun 13, 14-15.I.1975: Hydroides elegans 1 spec.; H. steinitzi 1 spec. 
- MS "Killara", Tun 15, 16.I.1975: Spirobranchus tetraceros 3 specs.

- MS "Nordwind", Tun 1, 20.I.1975: Hydroides elegans 1 spec. (juvenile with 2 primary opercula); H. heterocerus 1 spec.; H. steinitzi 1 spec.; Hydroides sp. 1 spec. (juvenile); Salmacina sp. 6 specs; Spirobranchus tetraceros 1 spec.

- Hulls, Tun 5, 13-20.I.1975: Hydroides elegans 1 spec.; Spirobranchus tetraceros 1 spec.

- Hulls, Tun 7, 13-20.I.1975: Hydroides elegans 1 spec. (juvenile); H. heterocerus 1 spec.; Spirobranchus tetraceros 1 spec.

- Hulls, Tun 14, 17-20.I.1975: Hydroides steinitzi 1 spec.; Spirobranchus tetraceros 1 spec. Scraped from Bivalvia, 25 subsamples (Serpulids from 19 subsamples sorted by Brattström \& Taasen respectively as "Polychaeta" (6); sponges (5); tunicates (5) Hulls (no data) (3) were in fact removed from bivalves found within these samples, and thus are listed under "Bivalvia" with their original labels).

- MS "Killara"-sunny side, Pol 33, 13.I.1975, Brachidontes pharaonis*: Salmacina sp. aggregate.

- MS “Killara"-sunny side, Pol 38, 17.I.1975, on Pinctada radiata*: Salmacina sp. 2 specs; Spirobranchus tetraceros 5 specs.

- MS “Killara"-sunny side, Pol 39, 14.I.1975, on Brachidontes pharaonis*: Salmacina sp. 1 spec.; Spirobranchus tetraceros 1 spec.

- MS “Killara"-shady side, Pol 20, 13 \& 16.I.1975, on Brachidontes pharaonis*: Salmacina sp. aggregate.

- MS “Killara"-both sides - Pol 30, 16-17.I.1975, on Spondylus spinosus: Josephella marenzelleri 1 spec.; Salmacina sp. 2 specs.

- Hulls, Pol 40, 13.I.1975, on Brachidontes pharaonis*: Salmacina sp. 1 spec.

- MS "Killara"-shady side, Spo 2, on Spondylus spinosus: Hydroides homoceros 1 spec.; on Brachidontes pharaonis*: Salmacina sp. 4 specs.

- MS "Killara", Spo 3, 20.I.1975, on Mytilidae: Hydroides without operculum = ?H. heterocerus 1 spec.; Salmacina sp. aggregate.

- MS "Killara"-mainly sunny side, Spo 11, 17.I.1975, on Brachidontes pharaonis*: Hydroides elegans 1 spec.; Spirobranchus tetraceros $1 \mathrm{spec}$.

- MS “Killara"-shady side, Spo 19, 13.I.1975, Ascidia, Bryozoa, large Cirripedia, Brachidontes pharaonis*: Salmacina ca. 10 specs.

- Hulls, Spo 28, 13.I.1975, mytilid: Hydroides elegans aggregate, with single worm, 1 spec.

- Hulls, Tun 4, 18.I.1975, on Spondylus spinosus: Hydroides elegans 2 specs (juvenile); H. heterocerus 1 spec.; Josephella marenzelleri ca. 15; Salmacina sp. 1 spec.; Spirobranchus tetraceros 4 specs.

- MS “Killara"-probably sunny side, Tun 10, 16.I.1975, lots of molluscs, tubes mostly on Spondylus spinosus: Hydroides steinitzi 2 specs; Josephella marenzelleri, ca. 30 specs, Spirobranchus tetraceros 1 spec.

- MS "Killara"-sunny side, Tun 17, 13.I.1975, subsample on Brachidontes pharaonis*: Salmacina sp. aggregate.

- MS "Killara", Tun 11, 15.I.1975, on mytilid: Salmacina sp., 3 specs; Serpula hartmanae 1 spec.; Spirobranchus tetraceros 6 specs.

- MS "Killara"-shady side, Tun 3 subsample, 16.I.1975, on Brachidontes pharaonis*: Josephella marenzelleri 1 spec.; Salmacina sp., few.

- MS “Killara"-shady side, Biv 9, 16.I.1975, mollusc: Spondylus spinosus, tunicate, Bryozoa: Hydroides elegans 2 specs (1 juvenile); H. heterocerus 1 spec.; H. steinitzi 1 spec.; Hydroides sp. (juvenile) 1 spec.; Josephella marenzelleri 1 spec.; Spirobranchus tetraceros 1 spec.

- MS "Killara", Biv 11, 14.I.1975, lots of molluscs-tubes mostly on Brachidontes pharaonis* (largest Brachidontes 3.5 $\mathrm{cm})$ : Hydroides diramphus 1 spec.; H. elegans 2 specs; H. heterocerus $1 \mathrm{spec}$.; H. steinitzi $1 \mathrm{spec}$.; Hydroides sp. 2 specs (juvenile); Josephella marenzelleri 3 specs; Salmacina sp. few; Serpula hartmanae 1 spec.; Spirobranchus tetraceros 1 spec.

- MS “Killara”, Biv 12, 15.I.1975: Hydroides heterocerus, 1 spec.; Hydroides cf. heterocerus 1 spec., Hydroides heterocerus 1 spec. (juvenile form \#1); Salmacina 5 specs; Spirobranchus tetraceros 4 specs.

- MS "Killara", Biv 14, 16.I.1975, lots of molluscs-tubes mostly on Spondylus spinosus* and few Brachidontes pharaonis*, tunicates, Bryozoa: Hydroides sp. 1 spec., Salmacina sp. 4 specs, Spirobranchus tetraceros 3 specs.

- Hulls, Biv 1, 13-20.I.1975: Hydroides heterocerus 1 spec.; Hydroides sp., fragments; Josephella marenzelleri 2 specs, Salmacina sp., few; Spirobranchus tetraceros 1 spec.

- Hulls, Biv 6, 15.I.1975, on Spondylus spinosus and Brachidontes pharaonis*: Hydroides elegans 2 specs (1 of them juvenile); Josephella marenzelleri 1 spec., Salmacina sp., few.

- Hulls, no data, I.1975, on mytilids: Hydroides heterocerus 1 spec.; Salmacina sp. 3 specs.

- Hulls, no data, 13-20.I.1975, on Brachidontes pharaonis*: Hydroides heterocerus 1 spec.; Josephella marenzelleri 2 specs; Salmacina sp. 1 spec.; Spirobranchus tetraceros 3 specs (HUJ-Poly-1405).

- Hulls, no data, 18.I.1975, jar of Modiolus barbatus: Spirobranchus tetraceros 3 specs (HUJ-Poly-1406).

D'. SAMPLED AT THE BREMERHAVEN HAPAG-LLOYD AG DRY DOCK: MS “MÜNSTERLAND”, 18.VI.1975, legit J.P. Taasen, $7 \mathrm{~m}$ depth in the dry dock. Three samples. 
- Sample labelled “mix", Spondylus spinosus with empty shell; Brachidontes pharaonis* [7 specs apparently alive when sampled; 1 spec. empty]; many (various) empty tubes overrun by sponges (presumably happened in Great Bitter Lake): Hydroides diramphus $1 \mathrm{spec}$, body decaying but connected to operculum; H. heterocerus 5 specs; H. homoceros 1 spec.; Spirobranchus tetraceros 1 spec.; one fresh-water amphipod removed from debris (D. Bellan-Santini, pers. comm.).

- Sample, Mol 3?, on Spondylus spinosus: Hydroides heterocerus-some fragments one fairly small, partly chitinised, decayed, 5 specs; Spirobranchus tetraceros-fairly large, decayed $1 \mathrm{spec}$., various empty tubes.

- Sample, Poly ?, Hydroides heterocerus 1 spec.

E. RECONSTRUCTED SAMPLES FROM LAKE TIMSAH (sent to H.A. ten Hove for determination). Two samples.

- ca. 1984, legit S.H. Shalla, Hydroides diramphus 8 specs; Hydroides elegans, 17 specs and juveniles (not enumerated); mass of tubes; Pomatoleios kraussii 5 specs; Spirobranchus tetraceros 6 specs.

- Lake Timsah, El Tawan Beach: 30³3'11" N, 32¹7'51" E, 1-2.5 m, 10 / 19-11.1988, on rubber fenders and iron frames; legit, det. S.B. Shazly 1991; det. H.A. ten Hove 1992: Hydroides diramphus 3 specs; H. elegans 4 specs; H. heterocerus 1 spec.; Spirobranchus tetraceros 2 specs.

Appendix Table 3. Plant and mollusc taxa from which serpulids were removed ${ }^{\mathbf{1 , 2}}$

Plants

Caulerpa sp. / spp., Cystoseira myrica, Digenea simplex, Laurencia papillosa, Sargassum sp.

Molluscs

GASTROPODA: Aporrhais pespelecani (Linnaeus), Cerithium scabridum Philippi*1, Chicoreus erythraeus (P. Fischer) [including Chicoreus virgineus auct.; Murex anguliferus auct.] ${ }^{1}$, Diodora ruppellii (Sowerby)*¹, Fusinus polygonoides (Lamarck) ${ }^{1}$, Fusinus verrucosus (Gmelin)*, Hexaplex trunculus (Linnaeus), Murex forskoehlii Röding*1, Perrinia stellata (A. Adams) [incl. Turcica stellata A. Adams] ${ }^{1}$, Potamides conicus (de Blainville) ${ }^{1}$, Stramonita haemastoma (Linnaeus), Thais lacera (Born), Tonna galea (Linnaeus), Trochus erithreus Brocchi*1

BIVALVIA: Brachidontes pharaonis (P. Fischer)*¹, Callista florida (Lamarck) ${ }^{1}$; Cerastoderma glaucum (Poiret) [incl. Cardium edule auct.]**2; Chama asperella Lamarck $^{1}$, Chama gryphoides Linnaeus**, Crenatula picta (Gmelin) [incl. Crenatula mytiloides Lamarck], Dosinia erythraea Römer ${ }^{1}$, Fulvia fragilis (Forsskål in Niebuhr)*, Gafrarium pectinatum (Linnaeus)*1 ${ }^{*}$ Gastrochaena cymbium Spengler*1 ${ }^{1}$, Gregariella ehrenbergi (Issel) ${ }^{1}$, Loripes fischerianus (Issel) ${ }^{1}$, Malvufundus normalis (Lamarck) [incl. Malleus anatinus (Gmelin)], Malvufundus regulus (Forsskål) ${ }^{1}$, Mimachlamys varia (Linnaeus), Ostrea edulis (Linnaeus), *Pinctada radiata (Leach) [incl. Pinctada vulgaris Schumacher]*1, Spondylus spinosus (Schreibers)*

${ }^{1}$ Denotes a mollusc collected by C. Beets in the Great Bitter Lake in 1950, determined by Hoenselaar \& Dekker (1998).

${ }^{2}$ For those taxa which have been synonymised by H.K. Mienis (pers. comm.), the synonym appearing in Hoenselaar \& Dekker, 1998 is given in brackets.

*Denotes an Indo-Pacific mollusc taxon that has migrated and established populations in the Levant of the Mediterranean, i.e., a Lessepsian migrant mollusc (H.K. Mienis, pers. comm.)

**Denotes a Mediterranean mollusc that migrated into the Suez Canal (Por 1978, H.K. Mienis, pers. comm.). 
Appendix Table 4. Some unobtainable Egyptian theses and dissertations

Abd-Elnaby, F.A. (2005) Systematic and environmental studies on polychaetes from Alexandria marine waters. Ph.D. dissertation, Suez Canal University, $330 \mathrm{pp}$.

Barbary, M.S. (1992) Surveillance and ecological studies on the polychaetes in Lake Timsah (Suez Canal, Egypt). Ph.D. dissertation, Zagazig University, $249 \mathrm{pp}$.

Belal, A.H. (2001) Ecological studies on the polychaetes in the Suez Bay. Ph.D. dissertation. Faculty of Science, Zagazig University, $295 \mathrm{pp}$.

El-Komi, M.M. (2002) Ecological studies on the marine fouling in the southern region of the Suez Canal M.Sc. thesis. Mansoura University, $151 \mathrm{pp}$.

Hamada, S. (1980) Studies on the marine fouling in Damietta waters. M.Sc. thesis, Mansoura University, $131 \mathrm{pp}$.

Megally, A.H. (1970) Ecological study on the marine fouling organisms in the Eastern Harbour of Alexandria. M.Sc. thesis, Faculty of Science, Alexandria University, $240 \mathrm{pp}$.

Mostafa, M.Sh.B. (1992) Surveillance and ecological studies on the polychaetes in Lake Timsah (Suez Canal, Egypt). Ph.D. dissertation, Zagazig University, 249 pp.

Ramadan, Sh.E. (1986) Ecological and systematic studies on the marine fouling of the northern part of the Suez Canal. $\mathrm{Ph}$.D. dissertation, Faculty of Science, Mansoura University, $428 \mathrm{pp}$.

Selim, S.A. (1978) Systematic and distributional studies of Polychaeta in the Eastern Harbour, Alexandria. M.Sc. thesis, Faculty of Science, Alexandria University, 402 pp.

Shalla, S.H.A. (1985) Studies on the serpuloids (Polychaeta) in Lake Timsah. M.Sc. thesis, Suez Canal University, 179 pp. 


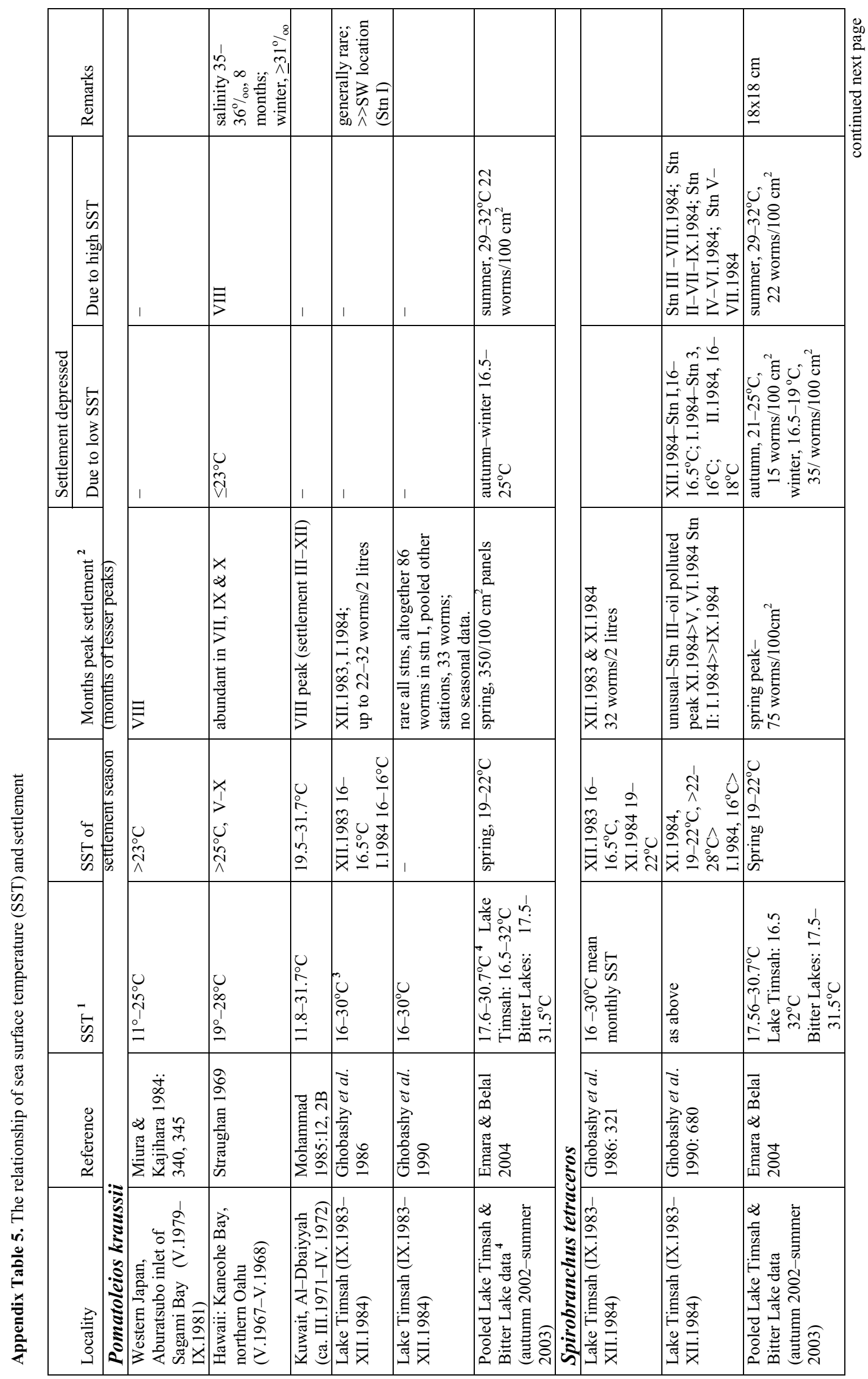




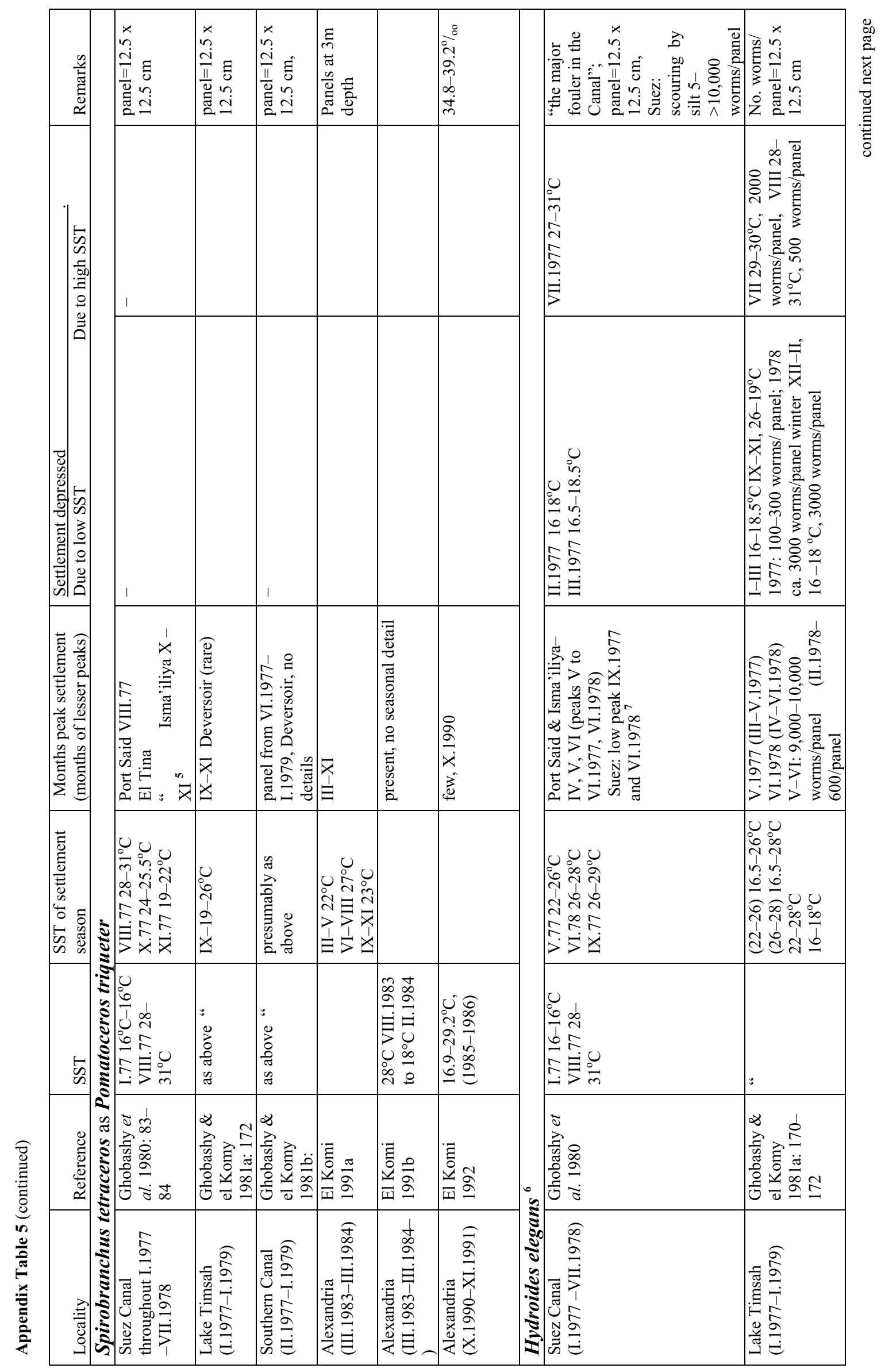




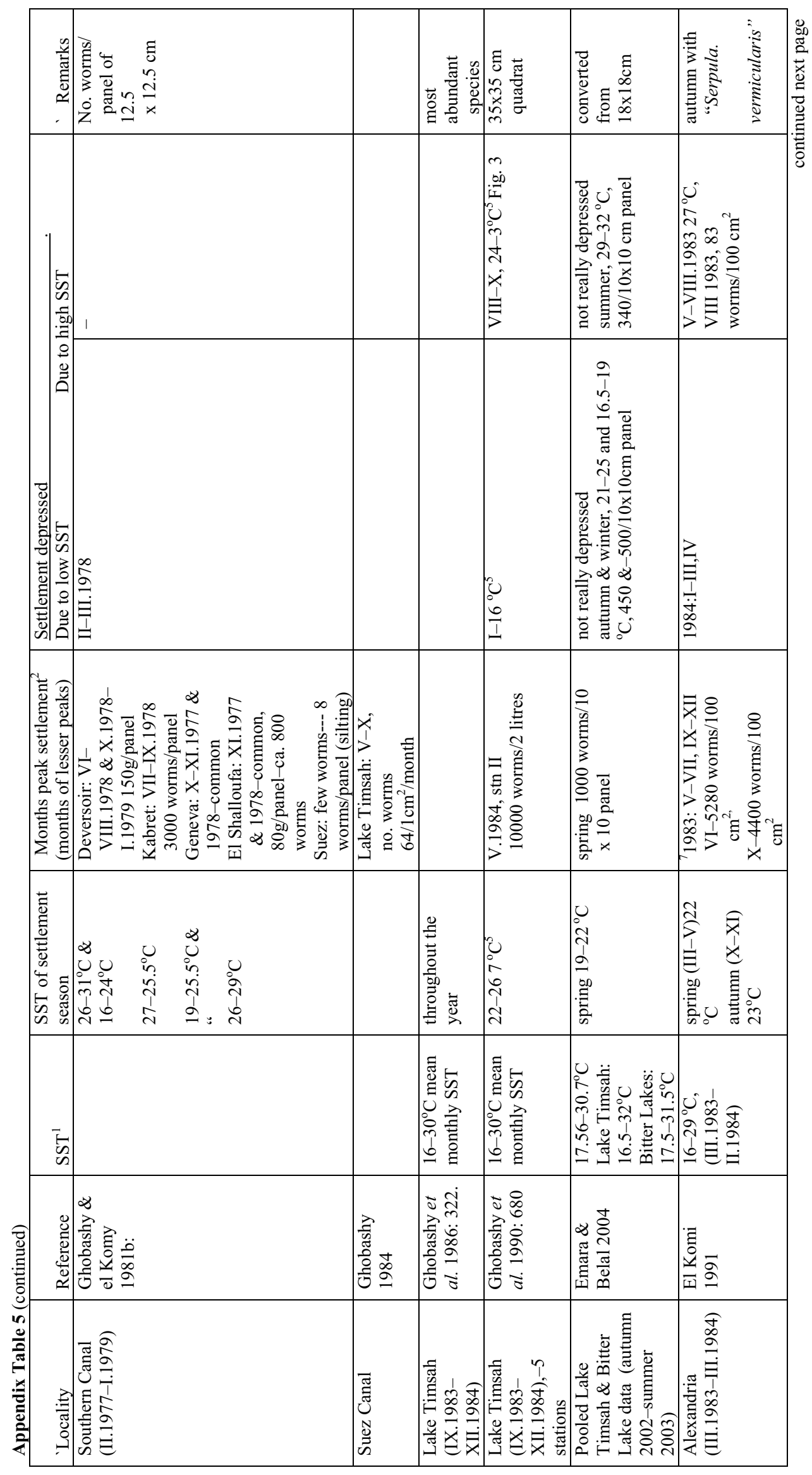




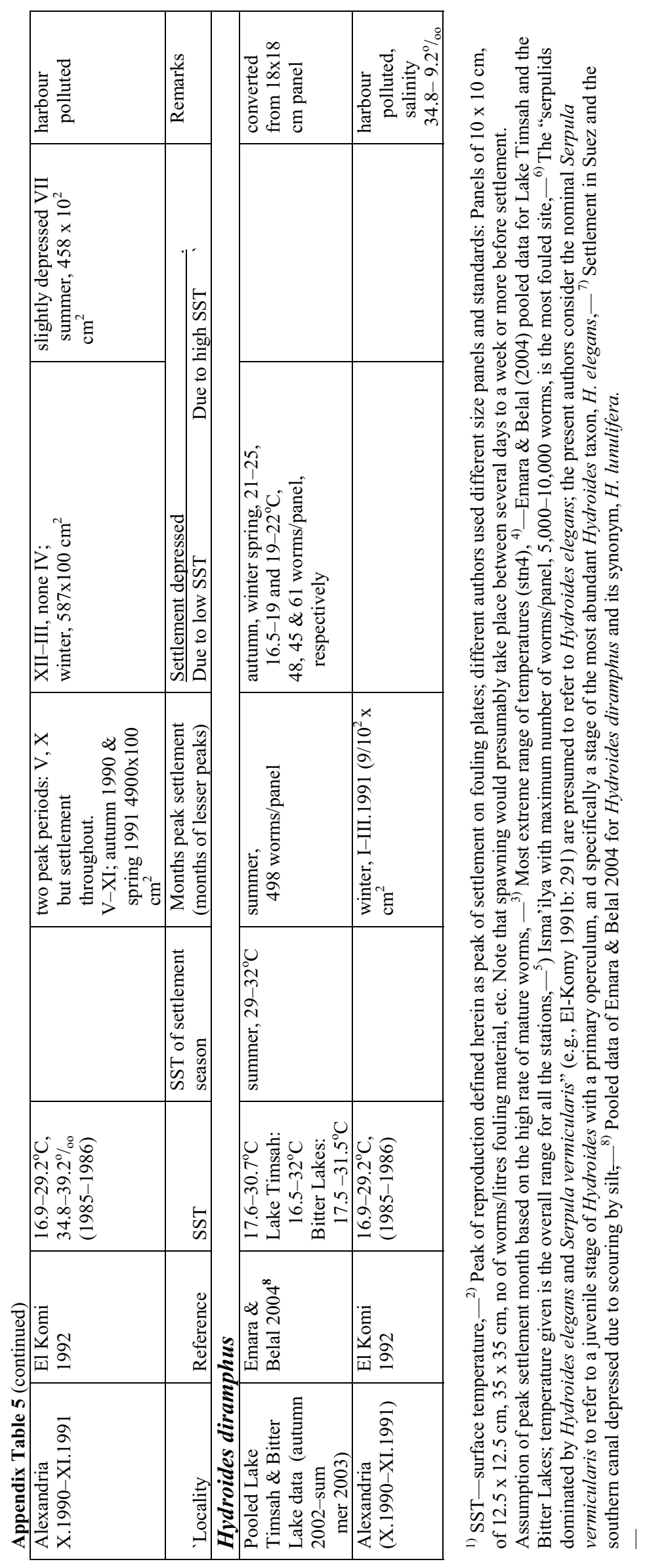

